\title{
ITINERARIES OF MODERN ETHIOPIAN INSTRUMENTAL MUSIC
}

\section{BY LUCIEN JOHNSON}

\author{
A thesis \\ submitted to the Victoria University of Wellington \\ in fulfilment of the requirements for the degree of \\ Doctor of Musical Arts in Composition
}

Victoria University of Wellington 


\section{ACKNOWLEDGMENTS}

Many thanks go to my supervisors: Dugal McKinnon for his thorough guidance and long hours of reading, Kimberly Cannady for setting me on the right path and John Psathas for his imaginative and luminous responses.

Thanks to Mulatu Astatke for doing me the honour of allowing me to play with him and for sharing his stories with me.

Thanks to Francis Falceto for bringing Ethiopiques to the world and for his insights and help with materials.

Thanks to the musicians who partook in the recordings, Justin Clarke, Nick Van Dijk, Toby Laing, Barrett Hocking, Will Ricketts, and most of all Jeffrey Grice for his stellar work in spending so much time perfecting my piano pieces and having the courage to present them in an important event in both our lives. It was something I will never forget!

I would like to express my gratitude to my mother Cecilia for providing a home that was filled with art and music. Thanks also to my sister Miranda and companion Lucy-Margaux who gave me excellent advice when I needed it and who now know a lot more about the music of Ethiopia than they ever considered possible. 


\section{Abstract}

This dissertation explores the way in which Ethiopian musicians of the 1960s and 70s adapted forms such as jazz, soul and Latin music to create a new hybrid instrumental music style variously referred to as Ethio-Jazz or EthioGroove. It will then go on to investigate the impact that this music has had, in turn, on musicians in various locations around the world since its reissuing on CD in the late 1990s. The central focus is to investigate and articulate the role of individuals' musical agency in this narrative, and to ask how, within the context of Ethiopian instrumental music and its offshoots, individual musicians and composers have engaged with, responded to and integrated music from elsewhere into their own musical languages. In particular, it looks at how musicians and composers have approached their own notion of creative individuality when their musical genealogy can be traced via affinities rather than geographic and ethnic inheritances. In adopting various influences these musicians, from both the original generation of Ethiopian musicians in the 60s and 70s who adapted soul, jazz and other American forms, and those from around the world who have in turn been influenced by this style of hybrid Ethiopian music, have had to unlock various technical musical problems, as well as navigate at times treacherous ethical waters and answer to allegations of cultural betrayal and/or appropriation. This dissertation identifies these problematic musical and ethical areas and, in the context of this criticism, it examines various viewpoints on how cultural interaction and exchange take place. The final chapter of this dissertation contextualizes my own creative portfolio, which accompanies this written work. It offers a personal response to the questions that have arisen from my affinity for Ethiopian music and from choosing an approach to composition closely informed by this affinity. 


\section{CONTENTS}

INTRODUCTION

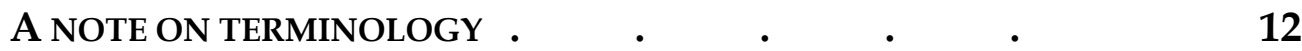

A HISTORICAL OVERVIEW OF MODERN SECULAR MUSIC IN ETHIOPIA 13

CHARACTERISTICS AND THEORY OF MODERN ETHIOPIAN MUSIC $\quad 15$

SCALES (KINIT) IN ETHIOPIAN MUSIC $\quad . \quad$. $\quad . \quad 16$

CHAPTER ONE: THREE ITINERARIES IN ETHIOPIAN

MUSIC

The Afrofuturism of Mulatu AstatKe $\quad$. $\quad$. 22

GETACHEW MEKURYA AND SHELLELA SAXOPHONE 47

EMAHOY TSEGUE-MARYAM GUEBROU'S DIVINE CONNECTIONS 59

CHAPTER TWO: INSPIRATION OR APPROPRIATION 78

THE 'GOLDEN AGE' AND THE DERG REVOLUTION . . . $\quad 81$

\begin{tabular}{llllllll} 
ETHIOPIQUES &. &. &. &. &. & & \\
\hline
\end{tabular}

$\begin{array}{llllllll}\text { COVERS } & . & . & . & . & . & . & 90\end{array}$

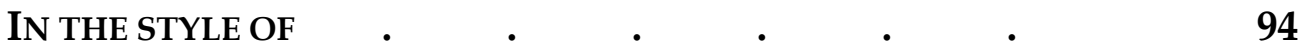

$\begin{array}{llllllll}\text { SAMPLING } & . & . & . & . & . & . & 100\end{array}$

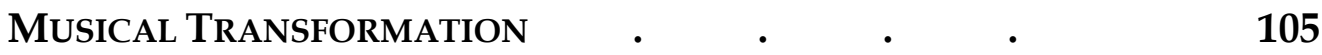

Chapter Three: A Personal Journey With ETHIOPIAN

MUSIC

BEGINNINGS .

Mulatu Astatke at the Wellington Jazz Festival

AdDis AbAba June/July 2016

TONE SCIENCE

125

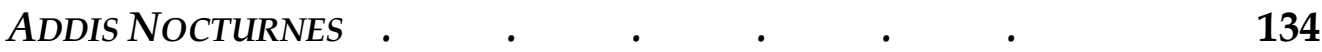

AXUM

CONCLUSION

APPENDICES $\quad$ - . $\quad$ - .

BIBLIOGRAPHY $\quad$ • $\quad$ • 


\section{INTRODUCTION}

A young Ethiopian man with dreams of becoming an astronaut is sent to Britain for his education. Discovering his true calling in music, he ends up inventing a new musical genre: Ethio-Jazz. An Ethiopian woman, despairing of the chance to undertake a similar voyage, instead resolves to become a nun. In the seclusion of a countryside convent she composes piano music in a unique style that brings together Western classical traditions and the music of her homeland. Another young man comes to Addis Ababa from the countryside to join his father selling honey. However, to the shame of his family, he joins a concert band and goes on to create new possibilities for the way the saxophone is played. A French experimental music producer hears this new music from Ethiopia some 20 years later and decides to make his life's work bringing it to the world. An American cult film director employs this unique sonic universe as the soundtrack and emotional landscape for one of his most successful and critically acclaimed features, winning the Grand Prix at Cannes. Jamaican and American hip-hop superstars sample this music, using it as the backdrop for their hit single. A punk band from Holland hears the aging Ethiopian saxophone player and brings him to Europe to record his songs in a new way. A British electronic music ensemble collaborates with a septuagenarian Ethiopian musician, he who once wanted to be an astronaut, making one of the key modern albums in Afrofuturism. "Everyone knows that Ethiopian jazz is the only kind of jazz worth listening to", remarks a blasé Italian socialite in Paolo Sorrentino's film The Great Beauty (2013) as if it had always been this way. The itineraries of modern Ethiopian music have been as curious, unexpected and sinuous as the distinctive melodies that characterize it.

This dissertation explores the way in which Ethiopian musicians of the 1960s and 70s adapted forms such as jazz, soul and Latin music to create a new hybrid instrumental music style variously referred to as Ethio-Jazz or Ethio- 
Groove. It will then go on to investigate the impact that this music has had, in turn, on musicians in various locations around the world since its reissuing on CD in the late 1990s. The central focus is to investigate and articulate the role of individuals' musical agency in this narrative, and to ask how, within the context of Ethiopian instrumental music and its offshoots, individual musicians and composers have engaged with, responded to and integrated music from elsewhere into their own musical languages. In particular, it looks at how musicians and composers have approached their own notion of creative individuality when their musical genealogy can be traced via affinities rather than geographic and ethnic inheritances. In adopting various influences these musicians, from both the original generation of Ethiopian musicians in the 60s and 70s who adapted soul, jazz and other American forms, and those from around the world who have in turn been influenced by this style of hybrid Ethiopian music, have had to unlock various technical musical problems, as well as navigate at times treacherous ethical waters and answer to allegations of cultural betrayal and/or appropriation. This dissertation identifies these problematic musical and ethical areas and in the context of this criticism it examines various viewpoints on how cultural interaction and exchange take place. The final chapter of this dissertation contextualizes my own creative portfolio, which accompanies this written work. It offers a personal response to the questions that have arisen from my affinity for Ethiopian music and from choosing an approach to composition closely informed by this affinity.

In the title of this thesis, Itineraries of Modern Ethiopian Instrumental Music, I consciously avoid terms common in sociology, anthropology or ethnomusicology such as "flows" or "routes". These terms seem to imply predetermination, or a sense of historical inevitability in musical outcomes. In this study, I use the term "itineraries" to point out the importance of agency in the stories of the musicians involved in creating their own histories. The circumstances leading to the creation and development of Ethio-Groove are, 
in a vague sense, products of a globalized world. Yet when brought into focus, and considering individuals like King Menelik II and his acquisition of the first brass instruments to give to Ethiopian musicians, Mulatu Astatke and his rites of passage in the UK and the USA, and modern day musicians such as Mesele Asmamaw or Woima Collective and their musical research, the role of individual agency and affinity seem to be distinct and unique and worthy of attention in terms of individual contributions to broader global processes and movements.

From what has been regarded by many commentators as a "golden age" of Ethiopian music and culture during the final years of the reign of Emperor Haile Selassie (1960-1974), I have chosen in Chapter One to concentrate on the works of three complementary but very distinct performer/composers. Taken together, the work of these three is representative of key aspects of Ethiopian instrumental music in the 1960s and 70s. They came to international prominence after the reissue of their music on the Ethiopiques series of reissued CDs in the late 1990s and early 2000s. The first, Mulatu Astatke is a celebrated composer/arranger and multi-instrumentalist who pioneered Ethio-Jazz but whose work, as I argue, should equally be placed in the Afrofuturist continuum alongside other luminaries from the black musical diaspora ${ }^{1}$ such as Sun Ra, Miles Davis, Parliament-Funkadelic and Lee "Scratch" Perry. The second, Getachew Mekurya, was a saxophonist whose reinterpretations of Ethiopian classics within the context of dance bands and soul grooves reinvigorated the secular Ethiopian musical tradition while also extending the possibilities of his instrument by devising an unprecedented ornamental style derived from traditional melismatic Ethiopian vocalizing. Finally, Emahoy Tsegue-Maryam Guebrou, a pianist and composer whose studies of nineteenth century European classical piano music led her to create

\footnotetext{
${ }^{1}$ An aesthetic and cultural interrelationship across Black cultures in Africa, the Americas and Europe was proposed and identified by Paul Gilroy (1993). The idea of Afrofuturism was recognized and developed theoretically by Dery (1994), Tate (1992), Eshun (1998) and Goodman (2010).
} 
an oeuvre which resides in a nebulous space between two worlds and whose origins are almost impossible to locate.

Throughout Chapter One I use a combination of historical research; analysis of scholarly work developing themes such as hybridity and mutation; musical transcription, and analysis. With these last, specifically musical approaches, I hope to bring something new to this area of research, namely the possibilities that some of the themes I have talked about (hybridity, mutation, syncretism) can be identified in specific musical examples. The purpose of this chapter is to contextualize the work of these three musicians through comparison with transnational cultural theories such as the Black Atlantic and Afrofuturism. Until now their work has been grouped together under a banner of modern Ethiopian music rather than being seen in conversation with musical trends in the United States and Europe. The research involved in this chapter also serves a purpose for my creative work: the transcriptions form the basis for my own theoretical understanding of modern music from Ethiopia and, as such, are the backdrop for my compositions, discussed in chapter three.

In Chapter Two I explore the phenomenon of the resurgence of this music around the world, led by both Ethiopian musicians and non-Ethiopian musicians and agents, over the last two decades. Contextualizing the decline of the 1960s and early 70s generation of Ethiopian music due to political upheaval, I explore the way Western agents - in the form of label executives, promoters, musicians and audiences - have contributed to the revitalization of this genre, and the ethical and cross-cultural issues this has raised. I examine the notion of musical influence via musical affinities rather than geographic and ethnic inheritances, analyzing different ways in which nonEthiopian musicians have adopted and adapted music from Ethiopia, and categorizing this in four different ways. I first discuss a literal reinterpretation of Ethiopian material, when non-Ethiopian bands have covered Ethiopian pieces, investigating the various motivations and outcomes of such attempts. I 
then examine groups such as Budos Band, Antibalas and Woima Collective that have created original music that share characteristics with vintage Ethiopian "golden age" music (and other African styles, most notably Afrobeat). It is here that I discuss the ethical tensions that have surfaced through these endeavours, commented on by scholars and African music specialists such as Danny Mekonnen and Michael Veal. I then turn to the sampling of Mulatu Astatke's "Yegelle Tezeta" in hip-hop and electronic dance music, specifically focusing on Nas and Damian Marley's use of the piece in their song "As We Enter". This example is contextualized within a broader discussion of sampling culture and its justification within Black musical practices, as opposed to some notorious instances of appropriation in pop music such as Deep Forest's "Sweet Lullaby". These practices are then contrasted with sampling as used in the movement known as Ethiopiyawi, a contemporary electronic dance music movement emanating from Ethiopia.

The final mode of critique and analysis involves what I call musical transformation: where composers and musicians have immersed themselves in the music of another culture but the influence they have taken is either not clear at a surface level, or is juxtaposed with many other sources to create an entirely different sonic universe. Looking at the historical precedents of this within Western art music beginning with the gamelan influence in Debussy's Pagodes, I then develop this idea comparatively, taking as examples Steve Reich's experiences with Ghanaian music in his piece Drumming and Olivier Messaien's involvement with Indian music in his piece Oiseaux Exotiques. I look at criticisms that such practices have faced, such as that of exoticism, and the responses to these claims of the composers.

By investigating these various tensions within the area of what can be viewed as cultural exchange or appropriation, I cannot hope to solve the problem of how best to approach such artistic endeavours. Each one of these categories leaves artists vulnerable to criticism. Within each category also, there appear 
to be examples of work that have negotiated this ethical terrain with varying degrees of success or failure. My aim in confronting these issues, however, is to develop a better understanding of them, so that I can try to avoid pitfalls and so that I can attempt to progress my creative practice in an ethical manner.

In the final chapter, using some of the concepts developed in earlier chapters, I evaluate the creative portfolio submitted as part of the dissertation. This creative work comprises of three different projects, each one of which refers back in some way to the music of the three Ethiopian musicians that are the focus of chapter one.

My Tone Science suite, developed in my home studio using electronics (vintage synthesizers and drum machines) to create a unique sonic signature, draw inspiration from the Afrofuturist aesthetic that permeates the work of Mulatu Astatke. Rather than a literal mimicking of his style, Tone Science concentrates on developing this aesthetic through the adoption of musical principles and selective musical devices. Thus, experimental, science fiction electronics are juxtaposed with mechanical rhythm-machine African dance beats and free jazz horn riffs. The use of vintage synthesizers and drum machines in a futuristic manner creates a conflicting temporal atmosphere.

Addis Nocturnes is a selection of piano pieces that combine Ethiopian and European elements, aiming to make unexpected connections between different musical cultures. Rather than extrapolating from early romantic composers, as did Emahoy Tsegue Maryam Guebrou, I have drawn from French impressionist composers such as Ravel, Debussy and Satie. These pieces are based on the pentatonic scales (kiñit) found in Ethiopian music, which have resonances with scales used in pieces such as Satie's Gnossiennes, Debussy's Pagodes or Ravel's Ma Mere l'Oye. These works show their composers to be amongst the first Western composers to act upon their 
affinities for non-Western music. At the same time, their feel for harmonic colour and sonic blurring through the use of pedal, register and arpeggiated passages can in a way be seen as a precursor to some of the instrumental effects used in Mulatu Astatke's music, such as the swirling electronics and heavily pedaled vibraphone.

Finally my piece Axum for orchestra is an experiment in adapting my research to the context of the symphony orchestra. Using the Ethiopian modes as a restrictive initiating point of tonal organization, it is an entirely intuitive piece that aims to expand upon the musical language developed in Tone Science and Addis Nocturnes, but using the possibilities of instrumental colour within the orchestra to attempt to forge a new sound. This piece is the first movement of a larger work and points toward the direction I wish to take upon the completion of this doctoral project.

This dissertation is a critically and historically informed exegesis of how I have researched and put the concepts derived from this research to work in particular musical experiments. In doing so, it is important to recognize that real asymmetries of privilege and power cannot be undone and should not be ignored. As I will argue, consciousness of privilege and subsequent selfexamination is critical to undertaking the type of cultural exchange that I am attempting. Yet I also contend that artistic creation requires the freedom of imagination that can potentially lead the artist and audience into such sensitive areas, in culturally and musically productive and progressive ways. Above all, this thesis champions the importance of fostering debate - through words and music - in coming to a deeper understanding of the value of both artistic freedom and cultural traditions. 


\section{A Note on Terminology}

The focus of this study is on a style of hybrid music originating in Ethiopia during the 1960s and early 1970s, a historical period of great cultural productivity. This music is, broadly speaking, a synthesis of Ethiopian secular music with Western popular music styles, most notably African-American soul music, but also carrying traces of jazz, Afro-Cuban music and rock'n'roll. It has often been called Ethio-Jazz, however this is something of a misnomer. "Ethio-Jazz", when used correctly, refers specifically to the music of Mulatu Astatke and its offshoots, which involves jazz forms and improvisations. In this study I use this term only when talking about Astatke's music or other musicians and bands that follow closely in his footsteps.

Ethiopian scholar and musician Danny Mekonnen has offered the term "Ethio-Groove" to cover the wider genre of Ethiopian hybrid music, which encompasses all of the vocal and instrumental music from this period, as well as the contemporary bands around the world that have performed this repertoire, or music closely inspired by it. I employ this term when needing to talk about the wider field of hybrid genres emanating from Ethiopia.

Francis Falceto has coined the term "Ethio-Sonic", to describe the phenomenon of ferenj (foreign) musicians playing Ethiopian styled music. For this reason, I use this term when needing to talk specifically about these artists and groups. The term is also useful as it implies a looser interpretation of contemporary music in some way inspired by Ethiopian sounds.

Emahoy Tsegue-Maryam Guebrou's piano music, which is itself a hybrid of European romantic period music and traditional Ethiopian elements, does not neatly fall into any of these categories. It stands alone as a unique musical language and for this reason is not discussed in terms of any of the Ethio hybrids outlined above. 


\section{A Historical Overview of Modern Secular Music in Ethiopia}

The history of modern Ethiopian secular music leading up to the period in question has been very well researched and documented elsewhere (see Teffera 2008, 2013; Falceto 2001, 2002; Kebede 1971, 1976). For readers new to Ethiopian music the following section provides a brief orientational summary of the tradition leading up to the work of the three musicians who are the subject of this research, Mulatu Astatke, Getachew Mekurya and Emahoy Tsegue-Maryam Guebrou.

By the post-World War II period, concert bands, brass bands and small orchestras were a fixture of Ethiopia's cultural life. This unlikely tradition had begun when, upon defeating the invading Italian army at Adwa in 1896, King Menelik II was offered a set of brass instruments by the Russian Tsar Nicholas II. Rather than being an offshoot of colonial rule, the success of brass music in Ethiopia "was not forcibly implemented in the country but it was rather based on approval and control by the state" (Teffera 2013, 357). From the time of Haile Selassie, as regent and later Emperor, musicians and conductors from Europe were being employed to train and direct state-sanctioned brass and military bands, beginning with the Swiss conductor Albert Nicod. A trip to Jerusalem led to the young regent meeting, and bringing back with him to Ethiopia, the Arba Lijoch, or 40 orphans from Armenia, who, along with their band leader Kevork Nalbandian, were employed by the state to become the first marching band in the country (Teffera 2013, 360). Numerous foreign bandleaders have been credited with playing important roles in the development of contemporary Ethiopian music during the 1940s and 50s, however two in particular stand out: Nerses Nalbandian (nephew of Kevork), in charge at various times of the Addis Ababa Municipality Band and the Police Band, as well as helping to found the Yared School of Music, and Franz Zelwecker, originally from Austria, who took over the Imperial Bodyguard 
Orchestra in 1951 before moving to take direction of the Haile Selassie I Theatre in 1955. These conductors were amongst the first to promulgate adapting traditional music and songs to the new instrumentation, as this article in an Ethiopian newspaper attests to:

Much credit should be given to Franz Zelwecker who after leaving Vienna where he was a conductor and composer, trained the sixteen Ethiopian musicians who participated in the concert. They have, through hard work in this short time, mastered the technique of playing serious orchestral music, and did remarkably well last Tuesday night at the Municipal Hall. The highlights of the evening were the 'Ethiopian Rhapsody', 'The Girls of Baden' and 'Merry Widow'. In the first, the complete Ethiopian atmosphere was maintained throughout its rendition. Taking the national melodies, the composer transposed them into harmony and adapted them to a symphonic composition. The audience was the judge and showed its appreciation by sustained applause (Ethiopian Herald, 9 January 1954. From Tafla 1994, 212).

The 1960s was a period of social revolution around the world and this was, to some extent, also true in Ethiopia. After a failed coup attempt in 1960, the increasing student and peasant restlessness led Emperor Haile Selassie to offer what were effectively bribes to the people, as an exercise of distraction and diversion. He created numerous public works such as the airport, luxury hotels and other buildings, and with Addis Ababa becoming the center of the Organisation of African Unity in 1963, the capital was imbued with a new sense of cosmopolitanism. The nightlife scene took off with a plethora of popular nightclubs opening up. A radio station, Kagnew Station, broadcasting from the American military base in Asmara is credited with keeping Ethiopian audiences and musicians alike up to date on all the latest musical offerings from the United States (Teffera 2013, 358). New bands, removed from the machinations of the state, were created and stars were born: singers renowned in Ethiopia such as Mahmoud Ahmed, Tlahoun Gessesse, Bzunesh Beqele and Alemayehu Eshete. Behind the scenes, musical arrangers such as Girma Beyene and Mulatu Astatke made arrangements for 
recordings on new record labels such as Amha Records and Phillips Ethiopia, while Getachew Mekurya's nationalistic saxophone instrumentals and towering presence became a feature of several leading bands in the scene.

After a coup by the Derg party in 1974, which deposed the Emperor Haile Selassie, a military Stalinist dictatorship took hold of Ethiopia that effectively lasted until 1991. During this period of terror and oppression, musical and cultural activities were suppressed and many musicians emigrated or suffered worse fates. There are very few recordings of the three musicians involved in this study from this time, even if they continued to be engaged in musical activities. This period is examined fully in Chapter Two, along with the ensuing comeback of Ethiopian music and its global proliferation since the fall of the Derg. This final period after 1991 is characterized by the release of the Ethiopiques album series of predominantly reissued 1960s and 70s music which began in the mid-1990s and the activities of leading Ethiopian musicians who began touring and recording once more.

\section{Characteristics and Theory of Modern Ethiopian Music}

Although traditional instruments such as the krar, a five or six stringed lyrelike instrument, and masenqo, a single stringed bowed lute, have made a comeback in recent years, during the 1960s and 70s the popular bands made songs developed directly out of the brass band scene and used largely Western instrumentation. The influence of secular Ethiopian music was still keenly felt though, and Ethio-Groove is much more than simply soul music being sung in Amharic. Ornamentation and melodic embellishment is a feature of vocal styles in Ethiopia and this began to be translated to instruments by Getachew Mekurya who developed his saxophone style out of shellela, the war cries and inspirational chants of warrior leaders. His pieces, 
and those of many other artists too, employed call and response structures liberally, a feature of traditional Ethiopian forms. Rhythmically, the beats were largely derived from soul music and other popular forms and yet $3 / 4$ time signatures are surprisingly frequent - a reference to the Ethiopian rhythm known as chik chikka. Most striking though are the distinctive pentatonic modes, called kiñit, which form the building blocks of all Ethiopian secular music. These are quite unlike European scales, and also from Arabic ones or those to be found in other areas of Africa. Their origins are thought to be ancient, some say they were even created by Saint Yared, a semimythological religious figure and the creator of Ethiopia's religious musical tradition who is thought to have lived in the sixth century.

\section{Scales (kiñit) in Ethiopian Music}

In Ezra Abate's study of kiñit, he divides the multitudinous and hugely diverse tribal groupings found in Ethiopia into three main groupings for the purpose of musical analysis (Abate 2009, 1213).

The Eastern area includes the regions of Harari, Dire Dawa, and Somali. With its history of contact and trade with the Arab world, it uses adaptations of the maqam scales, which are seven-note microtonal scales repeated at the octave most frequently associated with Arabic music. However the pentatonic scales associated with Northern and Central areas can also be found in Eastern Ethiopian music. Southern and Western music, from areas such as Gambella Kullo and Dorze, employ a variety of scale systems, from two-tone to diatonic seven note scales. The Northern and Central areas, in Amhara, Tigry, Oromo and Gurage, are home to the pentatonic scales that are utilized in the songs of the azmari, the traditional itinerant balladeers of Ethiopia, as well as much of Ethiopian popular music, including that of Mulatu Astatke and Getachew Merkurya. These modes have traditionally been divided into four main 
categories (see Kebede 1971, Powne 1968, Abate 2009, Zenebe 1987): tizita, batti, ambassel and anchihoye

The tizita and batti scales have both major and minor variations. The list of common pentatonic kiñit and their variations is redacted from the research of Abate $(2009,1218-1221)$ below.

\section{Tizita}

This scale is named after a popular Amharic song. There are major and minor variations of which the major is equivalent to the major pentatonic in Western musical terminology.

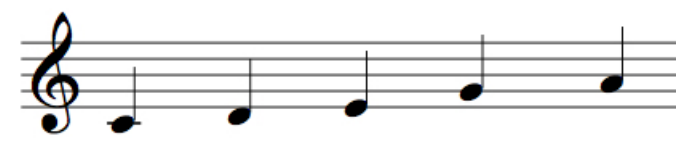

Figure 1: tizita major scale.

The tizita minor is characterized by the flattened sixth, and is the most common scale heard in the music of Mulatu Astatke and much other popular Ethiopian music.

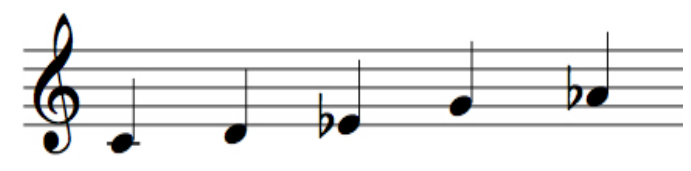

Figure 2: tizita minor scale.

\section{Batti}

Batti scales are associated with the geographical region Batti, as well as a popular song of the same name which uses this mode. It has several variations, of which the batti minor with a flattened fifth is frequently heard in 
Ethio-Jazz, while Getachew Mekurya often employs the batti major with a raised fifth.

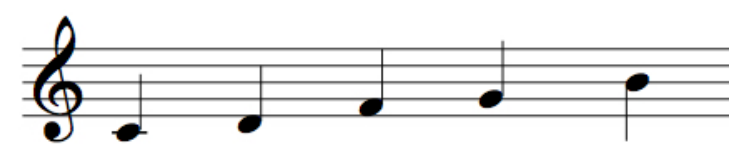

Figure 3: batti major scale.

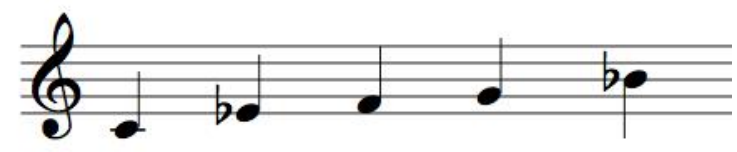

Figure 4: batti minor scale.

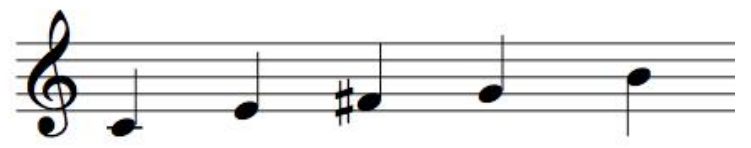

Figure 5: batti lydian scale.

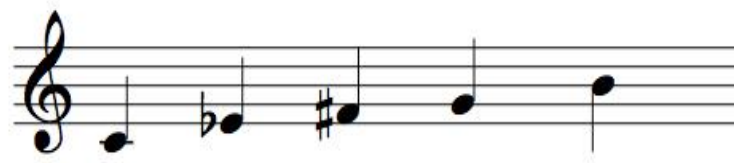

Figure 6: batti minor with a flattened fifth.

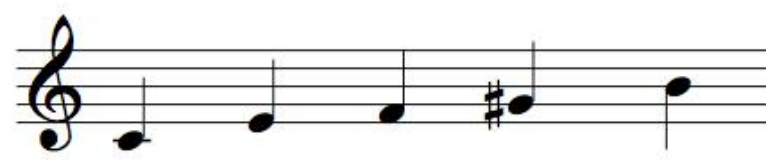

Figure 7: batti major with a raised fifth. 


\section{Ambassel}

Ambassel is also named after a popular song and is commonly used in the regions of Ambassel and Wollo. It is similar to tizita minor, starting off the fifth degree of the scale. A less common variation is printed below.

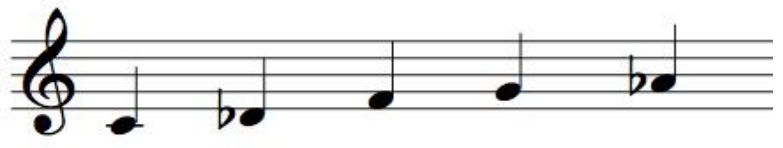

Figure 8: ambassel scale.

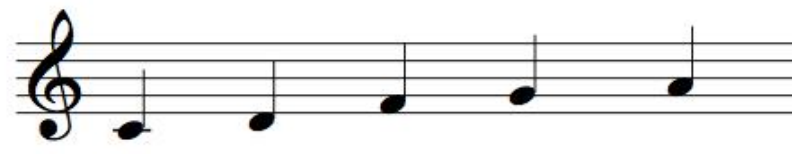

Figure 9: ambassel variant scale.

\section{Anchihoye}

This scale is named after the popular song "Anchihoye Lene".

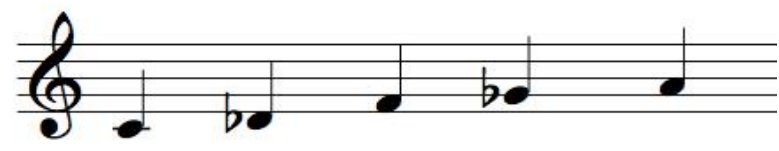

Figure 10: anchihoye scale.

These scales and their corresponding names are backed up by Michael Powne's research (Powne 1968, 47-50), which lists the four basic modes as being systems of tuning for the krar. Powne, who was the first to identify the kiñit in a scholarly manner, also claims that in performances whilst the krar may be playing one scale, the washint, a bamboo flute with four note holes, is tuned to a batti minor (minor pentatonic) thus creating a juxtaposition implying a system of polytonality and chromaticism. ${ }^{2}$

2 I have not come across examples of this phenomenon in my research. 
However it is important to note that not all commentators on Ethiopian music have endorsed the kiñit system of analysis. A recent paper by Weisser and Falceto argues that the notion of kiñit is a recent contrivance, used as an educational tool rather than being a historical constant in Ethiopian music scholarship and practice (Weisser and Falceto, 2012). They argue that it is not a term used by practitioners of traditional secular Amharic music (aside from "a chorus of urbanized Azmaris" (299) and point to the fact that the names for the modes are taken from popular songs of the 1930s and 40s, as well as the lack of any mention of them in research prior to Powne (1968) as proof of their lack of authenticity. Drawing on the thorough research of Kimberlin (1976) in particular, this scholarship argues that the scales have been adapted to fit Western notation and are approximations of the huge variations in tunings that different traditional musicians use, and are dangerous because of the way they standardize traditional music in relation to external models.

Amhara music is not (and probably never was) based on tempered intervals...This current study contributes to indicate that the introduction of the "four-scale theory" is indeed part of a very specific moment in time in the music's history of Ethiopia. This introduction arose most probably in the late 1950s-early 1960s and was linked to the practical necessities of teaching Ethiopian music to many musicians. It was then the pick of music development in Ethiopia, with numerous institutional bands like Municipality Orchestra, HSI Theatre Orchestra, Imperial Bodyguard Band, Police Orchestra, Army Band etc. On another hand, what would become Yared Music School by 1966-67 had been in a constant developing process since the Liberation and to create a rational teaching method if not a curriculum was then a priority...It induces a loss of complexity (meaning an impoverishment) due to standardization, simplification and reduction to a mere fragment of the real musical Amhara non-liturgical universe (Weisser and Falceto 2012, 314-315).

I have chosen to refer to kiñit in my analysis of modern Ethiopian instrumental music for two main reasons. Firstly, since the music has been made largely on Western instruments and using equal temperament, 
therefore the microtonal nuances of traditional Ethiopian music, secular or religious, do not tend to apply. If this study concerned itself exclusively with traditional music then a focus on the kiñit might well be less pertinent, and it is the analysis or instruction of traditional, secular music with the kiñit to which Weisser and Falceto appear to be objecting. Secondly, since some of the musicians who are the subject of this research, notably Mulatu Astatke, have used the notion of the kiñit to talk about their own music (see Astatke, 2007), I believe it is relevant to talk about their music using the codes that the musicians themselves use. 


\section{CHAPTER ONE}

\section{THREE ITINERARIES IN ETHIOPIAN MUSIC}

\section{The Afrofuturism of Mulatu Astatke}

Ethio-Jazz is a term which has at times been used to encompass all of the music of 1960s Ethiopian popular music, but when used correctly is a genre that for some decades was devised and practiced by only one man: Mulatu Astatke. Astatke is the self-proclaimed creator of the form (Astatke 2009; Adams 2014), a viewpoint backed up by other luminaries of Ethiopian music such as saxophonist Getachew Mekurya (Mekurya 2012) and French record producer and Ethiopian music specialist Francis Falceto (quoted in Eyre 2005). The hybrid nature of the music, implicit in its name, is not difficult to delineate as the various musical strands from which it was assembled are transparent; a structural and improvisational language borrowed from jazz; rhythms which reflect Astatke's and his band members' affinities for both Afro-Cuban music and the American soul-funk bands that percolated through the local radio waves; and of course, most distinctively, the tonal universe built from adaptations of traditional Ethiopian pentatonic scales.

Astatke's music is also a living metaphor for the cultural theory of the "Black Atlantic" of Paul Gilroy (1993). Rather than seeing the African diaspora as a block of people defined only by the forced alienation from their homeland, Gilroy defines the Black Atlantic by "the fractal patterns of cultural and political exchange and transformation" (Gilroy 1993, 15) among black populations on all sides of the Atlantic. Where Gilroy's work tends to concentrate on Americas and Europe however, this research firmly places 
Africa, and Ethiopia specifically, as being every bit involved in this cultural dialogue as any other location. Traditionally the Black Atlantic concept has fixated on black cultures affected by the Atlantic slave trade. As Ethiopia was largely uninvolved in this process, and indeed, was also relatively unaffected by direct colonization (not to mention its geographic distance from the Atlantic Ocean), it has, to some extent, been omitted from this discussion. However, I would contend that Ethiopia is strongly present in the conversation as a symbolic force. Ethiopia has been seen as a symbol of African independence, heralded the Rastafarian movement. By others, such as Sun $\mathrm{Ra}$, it is revered for its history as an example of a mighty African empire, an inspiration for his compositions such as "Ancient Aethiopia" (from Jazz in Silhouette, 1959). Reciprocally, Ethiopian popular culture has taken in influences from the United States, the Caribbean and elsewhere, as is demonstrated in Astatke's music. Gilroy's musical examples tend to focus on black American forms such as jazz and hip-hop, to the neglect of an often overlooked African relationship with modernity and what he terms the "double-consciousness" of being both black and living within Western power structures. Astatke's music, largely unknown outside of Ethiopia at the time of Gilroy's writing, encapsulates the idea of "forging compound cultures from disparate sources" (15) within an African cultural diaspora of and beyond the Black Atlantic, and thus lends weight to his theories of commonalities and a perpetually evolving black identity which transgresses the nation state.

A strong case can be made to define Astatke's music more specifically as an example of Afrofuturism, a movement that has been identified somewhat retrospectively by cultural theorists such as Mark Dery (1994), Mark Sinker (1992) and Greg Tate (1993), and subsequently developed by Kodwo Eshun (1998) and Steve Goodman (2010), amongst others. Afrofuturism is a philosophy and a cultural aesthetic that is revisionist in its approach to black history and combines science-fiction, magic realism and a re-imagining of African traditions and civilizations in its projections of the future. Musically 
and conceptually it harks back to the work and philosophical musings of Sun $\mathrm{Ra}$ in its combination of futuristic science fiction with non-Western cosmologies, notably the semi-mythological readings of the great Nile civilizations of ancient history. It draws links between the science fiction novels of Octavia Butler, the comic strips of Milestone Media and the paintings of Jean-Michel Basquiat (Dery 1994, 182). Musically speaking Afrofuturism is not a genre. Instead it is a set of aesthetic criteria and thematics that crop up in various styles of music from across the Black Atlantic, whether that be in jazz, funk, hip-hop or electronic dance music. Some of the essential elements in Afrofuturist music include science fiction and space-age metaphors in both the use of electronic instrumentation and lyrical content; an embrace of the machine, manifesting in an accentuation on synthesizers and drum machines; an emphasis on sonic effects and postproduction to create other worldly landscapes; a codification of both the music itself and the language with which to talk about the music, in order to define it as cultural property exclusive to those who are its creators.

The link between Astatke's music and Afrofuturism have not previously been discussed, but I would argue that given the sonic and timbral tendencies, which place him in the heart of the early jazz fusion experiments of Miles Davis, Herbie Hancock and others, and his use of the Ethiopian scales which themselves sound not dissimilar to much of Sun Ra's work, Astatke's music is an excellent example of early Afrofuturist experimentation.

Kodwo Eshun wrote in 1998:

The last 2 decades of jazz constitute a collective machine for forgetting the years ' $68-75$, the Era when its leading players engineered jazz into an Afrodelic Space Program, an Alien World Electronics...The Jazz Fission Age, that starts with George Russell's '68 Electronic Sonata for Souls Loved by Nature and ends with Macero's and Miles' Dark Magus in '75 (Eshun 1998, 001). 
Astatke's most significant albums from this era, Mulatu of Ethiopia (1972) and Yekatit Ethio Jazz (1974), reflect a similar interest in electronic instrumentation, and a desire to transport references to Africa's traditions into a futuristic, psychedelic sonic landscape.

Once again however, the musical icons of Afrofuturism have largely been black Americans - Sun Ra, George Clinton, Warp 9, or Jonzun Crew - or occasionally Afro-Caribbean artists such as dub producers Lee "Scratch" Perry and King Tubby. That similar experiments were being developed in the bars and improvised recording studios of Addis Ababa rather than the obvious cultural powerhouse incubators such as New York only reinforce Eshun's (and Gilroy's) concept of a common black avant-garde aesthetic.

The following sub-section traces Astatke's development and analyzes his music in order to discover how and why he was able to invent this music now known worldwide as Ethio-Jazz. By dissecting some of the elements inherent in his music, I aim to shed light on how this music was formed. In doing so I hope to offer some illumination into the process by which the cultural dialogue between the African diaspora has manifested itself, to provide some material data to the theories of scholars such as Paul Gilroy and Kodwo Eshun.

\section{Astatke's Background}

If Astatke's music seems to encapsulate the metaphor of the Black Atlantic, that is in no small part due to the fact that the physical itinerary he has followed through his career has been one of education, collaboration and creation between the African diaspora in the United Kingdom, the United States, the Caribbean and his homeland, Ethiopia. Born in 1943 in Jimma, 
West Ethiopia, he was sent to boarding school in Wales while still in his early teens. He credits his schooling in Wales as being integral to his journey into music and of self-discovery (see Astatke 2007).

Astatke went to university in London and earned a degree in music at Trinity College. During his time there he became acquainted with leading British jazz musicians such as Ronnie Scott and Tubby Hayes, Latin music aficionado Edmundo Ros, as well as being inspired by the strong West African music scene there. Although Astatke hoped to integrate his own heritage into the music in the same way, he lacked the collaborators with whom he could investigate a possible amalgamation of traditional Ethiopian and contemporary jazz sounds. He also spent time at Berklee College of Music in Boston, 1961, becoming the first African student to enroll there, and he specialized in vibraphone and percussion.

Astatke displayed an early interest in Cuban music, and his first records, AfroLatin Soul, vols. $1 \mathcal{E} 2$ (1966) were recorded in New York with a Puerto Rican/New York rhythm section including Rudy Houston on piano and trumpet, Felix Torres and John Perez on congas and bongos, Robert Cuadrado on bass and Tony Pearson on timbales. Astatke was later to travel to Cuba and noted how similar the drumming patterns were to West African music, while also detecting a link between the piano montunos of Cuban music with East African music.

The language was only Spanish but the rhythms, the movements, everything was what I'd seen in West Africa. If you had a drummer coming from West Africa, the Cubans could just count one-two-three-four, they could just play straight. These are the rhythms and the music I've heard there; same with the dancers...Probably what the difference is, what we call the montunos, that is the repetitive sounds in Latin music, which differs from African. Maybe, if you go Eastern Africa, to Swahili music, there are some similarities (quoted in Astatke 2007). 
The pieces on Afro-Latin Soul are largely Cuban inspired mambos and chachas. There is little, either in the melodic or the rhythmic content to distinguish the music from a typical Caribbean lounge group. Despite the fact that the album was being marketed as a piece of exotica, with the original record sleeve proclaiming the "Ethiopian Quintet" as “Wild! Pulsating! By African new sound sensation" (Ethiopiques: vol. 4), the music itself shows few traces of the Ethiopian modernism for which Astatke is renowned.

It was not until Astatke's return to Addis Ababa in the late 1960s that he began working in earnest on the idea of a synthesis between the jazz and Latin music he had been studying and performing in London and the United States, and traditional Ethiopian music. Initially, Astatke's new music was controversial and he ran into several problems. He had difficulties getting the music recorded and was at times rejected by audiences, for example when he attempted to introduce a traditional Ethiopian instrument, the bagana, a 10 stringed lyre-like instrument used to accompany prayer and meditation, to a jazz setting:

There was a very famous playwright in Ethiopia and this very well known priest who killed himself for what he believed. So this playwright wrote a play about this priest. By using the bagana I wrote some nice jazz arrangements for the piano and other instruments backing this instrument. So we had a concert and I heard people telling me to get off the stage. I'll remember that always. It was a big struggle, I wouldn't stop, I just kept on doing my Ethio-jazz, I was fighting more for the baganas, just fighting everybody (quoted in Astatke 2007).

Whether the issue was that the bagana is an instrument associated with religious ceremonies or whether it was the fusion of Ethiopian instruments in itself with Western forms is unclear. However this passage gives an indication as to some of the obstacles Astatke faced in introducing his concepts of modernism into Ethiopia at the time. 
Astatke also had troubles finding appropriate musicians to work with:

I had to train musicians. As far as instruments were concerned, it's very difficult, because the taxes on those instruments meant a lot of musicians couldn't afford to buy them. That's a really difficult problem for musicians in Africa. It's so hard to buy instruments (Astatke 2007).

However Astatke quickly became sought-after as an arranger for singers and bands of popular Ethiopian music. Astatke's knowledge of harmonies and rhythms, which was no doubt greatly informed by his studies and experience abroad, led him to becoming, alongside Girma Beyene, one of the most prolific arrangers of the period.

Astatke's return to the Ethiopian music scene at the end of the 1960s coincided with the birth of a record label created by a young entrepreneur and record shop owner named Amha Eshete. Eshete created his label, Amha Records in 1969, in spite of a 1948 imperial edict that banned the distribution of Ethiopian popular music (Harris 2016). The label lasted only five years, up until the Derg communist revolution, but Astatke became a house arranger. The label released an album of Astatke's compositions and instrumental arrangements entitled Ethiopian Modern Instrumental Hits (1972) which was followed by Yekatit Ethio Jazz (1974). The material was later re-released by French label Buda Musique as Ethiopiques, Vol 4: Ethio-Jazz \& musique instrumentale 1969-1974. Although the music is now some of the most familiar of the Ethiopian repertoire (at least to Western audiences) it had perhaps not the same impact at the time, even within Ethiopia (see Francis Falceto's remarks in Eyre 2005).

Since his return to his homeland, Mulatu Astatke's music has been characterized by the unique combination of Ethiopian modes and scales (kiñit) used in both melodies and ostinato bass lines, soul, jazz and Afro-Cuban 
rhythms, and a jazz sensibility and approach to form, structure and improvisation.

\section{Musical Mutation in Mulatu Astatke's Compositional Style}

The music of Astatke, Mekurya and Guebrou, and those influenced by them appears to exist as a hybrid of sources from Ethiopia, music genres from the Black Atlantic, and a number of European lineages. As a concept, however, hybridity poses some problems as it can mask some of the significant, ongoing processes of musical transformation and combination.

In the words of ethnomusicologist Martin Stokes, "All music is, of its very nature, hybrid" (Stokes 2004). It may seem redundant then to use the term at all, but as the ethnomusicologist R.Anderson Sutton points out, "it can be useful if we ascribe to it a measure of intentionality and/or perceptibility" (Sutton 2010, 180). Stokes' qualification of the term, which is particularly relevant to modern Ethiopian music, claims that: "If anything is authentic now, it is hybrid genres, organically connected to the social life and cultural aspirations of particular localities. If anything can be truly described as inauthentic, in this view, it is state-promoted efforts to install authentic national traditions." For Paul Gilroy, the problem with the term hybridity lies in the way it fixes in time what is essentially an active process. He describes it as a "rather unsatisfactory way of naming the processes of cultural mutation and restless (dis)continuity that exceed racial discourse and avoid capture by its agents" (Gilroy 1993, 2).

In the music of Astatke, however, there seems to be an intentional and perceptible hybridity of the Ethiopian traditional tonal universe with jazz forms and Latin and funk rhythms and the following analysis of his 
compositions intends to uncover the methods he used to reach this outcome. Rather than defining this process as simply one resulting in hybridity however, I will prefer to demonstrate how this has come about through a process of what Gilroy calls "cultural mutation", in what I am here caling "musical mutation". In this sense, specific elements of one musical genre are taken and transformed or combined with another form, in order to produce something new. Mutation implies that this transformation is an ongoing process as opposed to hybridity, which tends to suggest that there is a fixed result of a process of a combination of elements.

Through the dissection of the following transcriptions I will highlight the mutative elements within the structure of the music itself, or find examples of direct juxtaposition. Gilroy also reflects, "Where African American forms have been borrowed and set to work in new locations they have often been deliberately reconstructed in novel patterns that do not respect their originators' proprietary claims or the boundaries of discreet nation states and the supposedly natural political communities they express or simply contain" (Gilroy 1993, 98). At times Ethio-Groove, and Mulatu Astatke's music in particular, harbours conflicting tendencies which, on the one hand, demonstrates a direct acknowledgement and attachment to traditions and, on the other, a willingness to disregard conventions in the name of modernity.

Steve Goodman (2010) uses another biological metaphor to depict the movement of genres and specific musical elements around the world. According to Goodman's dialectic worldview, musical viruses or "earworms" are used by Western imperial powers, in the form of advertising, propaganda or media manipulation. "Contemporary capitalism is accompanied by the colonization of the audio sphere by an epidemic of "earworms," or audio viruses. The concept of the virus as applied to cybernetic culture, from computer infections to the dynamics of "hype," has become generally prevalent, yet particularly under thought in relation to sound" (129). 
However the same techniques can also be employed by "the colonized of the empire [who] strike back through rhythm and sound, Afrofuturist sonic process is deployed into the networked, diasporic force field" (1). He explains further, "The contagious vibrations, sonic processes, and market tactics of strains of popular music within the African diaspora both extend the concept of an audio virology and offer a tactical outline of an affective mobilization as opposed to the modulation of preemptive capital. A virology of the Black Atlantic runs on the notion that diaspora has an epidemiological etymology" (155).

Terms such as mutation and audio virology are useful metaphors when surveying the itineraries of this particular branch of Black Atlantic music and the rhizomorphic ${ }^{3}$ nature in which it has developed and spread around the world. Astatke's music, along with other Ethiopian popular music of the period, can be seen as the mid-point in this particular journey, where various genres and traditions collided and crystallized, before this new form disseminated some decades later through underground culture throughout the rest of the world into popular consciousness, where it has now morphed again into various new musical syntheses.

By placing my research within the framework of Afrofuturism, the Black Atlantic and musical mutation, I hope to offer some data as to how such mutations or audio virology occurs in a material sense. At times I refer to hybridity in a general sense, but do so with reference to Sutton's definition, aiming to uncover an "intentionality and perceptibility" in the process. In this analysis I rely on my own transcriptions for the lead sheets of the compositions of Astatke's work, along with transcriptions of improvised solos. There is the possibility of minor human error within these transcriptions, but the overall tendency - the combinations of jazz, Latin

\footnotetext{
${ }^{3}$ A term employed by Gilroy (1993) and others to describe the cultural mutations and concurrent evolution of cultural forms in the Black Atlantic.
} 
music and funk with the Ethiopian elements, the kiñit and a melismatic melodic approach - should remain evident.

\section{Sabye}

"Sabye" is a traditional Ethiopian song that depicts a young woman's relationship with an unfaithful suitor. ${ }^{4}$ The following analysis examines three very different versions of this song, in order to illustrate how Mulatu Astatke transformed traditional materials into Ethio-Jazz hybrid forms. It demonstrates the idea of cultural mutation as described by Gilroy, with a traditional song going through two separate modernizing stages to the point where it is virtually unrecognizable from its original state.

The first version is performed by Asnaqetch Werqu, a celebrated musician and actress who sang and played the krar. The transcription (appendix 1 ) is of the vocal part as well as the krar part, and brings to light several aspects of traditional Ethiopian musical performance. The first significant factor is that the piece is largely non-metrical, although when the voice enters it does become more rhythmical, hinting at a 7/8 time signature. The krar is tuned to a five note scale, G, B C\#, D and F\# (corresponding to a batti lydian scale) although the notes are not tuned exactly to Western temperament with the B and $G$ in particular being a little flatter than their corresponding Western tones. Like most Ethiopian traditional music, the vocal style is strikingly melismatic, and the virtuosic krar playing is also highly ornamental. The krar introduces the piece before the vocal melody enters, at which point the krar reinforces the vocal line as well as playing a tag at the end of each phrase. Sabye consists of a series of phrases in a repeated melodic line which itself consists of two parts: a rising melody followed by an answering line. In Werqu's version, the melody is repeated 14 times before a coda section.

\footnotetext{
4 Translation provided by Yilma Tafere Tasew.
} 
Werqu's krar playing is exceptionally rapid, but the nature of the instrument means that it is also staccato sounding, which contrasts with the sliding, melismatic vocals. The dynamics are largely uniform throughout the piece.

The second version of "Sabye" is sung by Belnayesh Wubante and Assagedetch Asfaw. This rare 7" record was made in 1974 and released by Phillips, the arranger being Mulatu Astatke himself. Although recorded after Astatke's version with his own band, one can view this as being in between a traditional rendering of the song and an Ethio-Jazz styled adaptation.

In this treatment of "Sabye" (see transcription, appendix 2), the two female vocalists sing in unison accompanied by piano, bass and drums. Opening the rendition is one of Astatke's characteristic rhythmic tags. The singers' vocal melody is highly ornamental and microtonal, and an analysis within the bounds of the kiñit may be meaningless. However, the accompanying instruments play with the batti minor with a raised fifth mode, F\#, A, C, C\#, F natural. ${ }^{5}$ The bass is playing an ostinato pattern which, at 4 bars long fits oddly with the vocal melody which is 5 bars long, however this type of displacement was not unusual in modern Ethiopian music (see chapter 2, Musicawi Silt). This piece is strongly rhythmic, in a 3/4 time signature often favoured by modern Ethiopian musicians. The main melodic phrase, which is repeated only four times in this version before the coda at bar 23, follows a similar contour to the version by Werqu, but the actual note choice and ornamentation are quite different. Again, the dynamics are largely uniform, although Wubante and Asfaw's strongly projected vocals are striking.

Finally, in Mulatu Astatke's Ethio-Jazz version (transcription appendix 3), the instrumentation is now entirely devoid of traditional Ethiopian components, with a horn section (trumpet and tenor saxophone) replacing the vocal

\footnotetext{
${ }^{5}$ It could also be argued that this scale is Anchihoye as the two scales are essentially the same but starting on different degrees.
} 
melody, whilst accompanied by Wurlitzer electric piano, electric guitar, electric bass and drums. The piece uses the batti minor with a raised fourth, but where in the other versions the melodies were performed in unison, now they have contemporary harmonies, alternating between thirds, fourths and tritones, as well as interweaving counter melodies in the bridge. While some aspects of the piece have been simplified or standardized - notably the melodic line which contains far less ornamentation and no use of microtones, and the rhythmic formal aspect with the melodic phrase now being consistently four bars long in 3/4 time - others, such as the harmonic language and the textural universe are further developed and contemporized. Astatke also introduces jazz-styled improvisations into modern Ethiopian music. After the theme is iterated, the saxophone player Tesfa-Maryam Kidane embarks on a fluid solo reminiscent of Getachew Mekurya. This solo too reveals a melding of Ethiopian and modernist, Western inspirations. On the one hand there is the jazz impulse, the spontaneous exchange between soloist and band, and on the other, the invocation of a traditional Ethiopian sonic landscape, through a rubato, ornamental approach. In Astatke's music it is within the improvisations rather than the compositions that the virtuosic, melismatic style of the azmari is invoked.

\section{Yekermo Sew}

The example of "Sabye" demonstrates how Astatke was able to adapt traditional Ethiopian materials to his new music, combining it with jazz inflections and a new textural landscape that mirrored the experiments of jazz fission maverick artists such as Miles Davis and George Russell in the United States. However, Astatke was also partial to adapting jazz material to his Ethiopian sound, alongside converting Ethiopian songs into jazz. "Yekermo Sew" (transcription appendix 4) is one of Astatke's better known compositions, which bears a striking resemblance to Horace Silver's classic 
hard bop composition "Song for My Father" (1965). A comparison of these two pieces would suggest that drawing attention to Silver's influence on Astatke is more than just speculation.

Firstly there is a strong correlation between the sinuous contours of both of the initial melodies ("Song for my Father" has been transposed to G minor for the sake of comparison from its usual key of F minor).

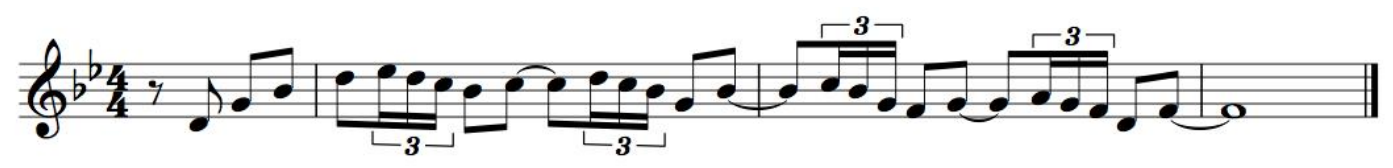

Figure 11: "Song for My Father" melody.

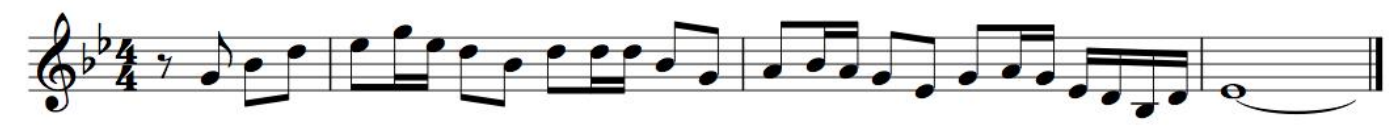

Figure 12: “Yekermo Sew" melody.

Instead of Silver's use of the Aeolian minor in his composition, Astatke uses the tizita minor pentatonic (although the tenor saxophone sometimes plays a parallel harmony that obliges a departure from this mode). The effect of this difference in mode immediately transforms the musical language into a distinctively Ethiopian tonal universe.

The bossa nova bass line is another point of similarity in the compositions:

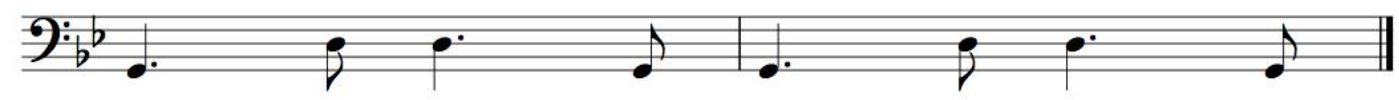

Figure 13: "Song for My Father" bass line. 


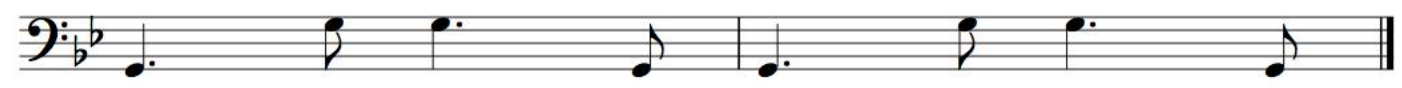

Figure 14: "Yekermo Sew” bass line.

Both compositions' tonal centers drop at the bridge. In "Yekermo Sew" the bridge drops a major third, from a G minor to an Eb dominant tonal center. In "Song for My Father" it drops only a tone, from F minor to Eb dominant. The effect however is similar.

This example demonstrates clearly how musical mutation can work in terms of metamorphosizing musical materials. By using an Ethiopian scale instead of its Western counterpart, as well as contemporizing the instrumentation (using electric instruments such as electric guitar and Wurlitzer electronic piano) to create his own sonic signature, Astatke transformed a jazz standard into a distinctively Ethio-Jazz composition.

\section{Yekatit}

Although most of Astatke's compositions and arrangements may not betray their influences as clearly as "Sabye" and "Yekermo Sew", the tendency of combining the Ethiopian tonal landscape in the form of kiñt with the rhythmic and harmonic language of jazz, funk and Afro-Cuban music remains evident throughout his work. The composition "Yekatit" (transcription appendix 5) again utilizes the batti minor with a raised fourth, which appears in "Sabye". The 6/4 tag which begins and ends the piece is a distinctive Astatke device which appears in many of his compositions and arrangements (see above "Sabye" and "Yekermo Sew"). The rhythmic feel of "Yekatit" is a type of Latin funk which prominently features congas, cowbells, 
and other Latin percussion instruments that Astatke had introduced from his studies abroad:

The vibes are not known well in Africa, even though it's found in West Africa. It has different techniques and different names, but it's a traditional instrument, which is very similar to a marimba. Vibraphone is the development of those instruments. It's very strange to Ethiopia, also the Hammond organ and conga drums. We had drums, but conga drums are a different shape. These were introduced when I went back home with these instruments and changed the arrangements" (quoted in Astatke 2007).

However, as French record producer Francis Falceto, who reissued a great number of classic Ethiopian records on his Ethiopiques series, pointed out: "Mulatu introduced the vibraphone to Ethiopia, and after 30 years remains its sole practitioner. Conga and bongos, which he also particularly favours, haven't fared much better either" (Ethiopiques, Vol.4, liner notes, 17).

The harmonies between the trumpet and saxophone in the melody relate to the batti minor with the raised fifth scale, meaning that the interval separating the two parts is a combination of fourths, thirds and tritones. It differs slightly from Yekermo Sew which uses a parallel harmony in the lower part played by the saxophone in fourths exclusively. By using so many fourths in his harmonies (rather than thirds or sixths) Astatke showed his awareness of the contemporary jazz voicings of the time, notably the harmonic devices of artists such as John Coltrane and McCoy Tyner.

\section{Pieces in the key of Tizita Minor}

Astatke's most frequently employed scale is the tizita minor scale, which features in compositions such as "Yekermo Sew", "Kasalefkut Hulu", "Yegelle Tezeta", and "I Faram”. "Kasalefkut Hulu” (transcription appendix 
6) is one of Astake's most hard hitting funk feels, with bass ostinato and driving rhythmic guitar providing the backdrop for some emotive tenor saxophone playing. Like most of Astatke's music, the piece uses only one scale and tonal center throughout, in this case F tizita minor. The bridge section (bars 29-48) stays in the same scale and tonal center, with just the bass part changing to a pedal from the ostinato to differentiate the sections. The constancy of the music is accentuated by the fact that the rhythm section (particularly drums, bass and guitar) rarely deviate from their parts, even during solos. This repetition evokes a certain trance-like feeling. The solo instruments (often the saxophone or organ), whose melismatic approach have been aptly described as "swirling" (Mekonnen 2010) and the sonic landscape of the semi-electronic instrumentation (Wurlitzer, electric guitar) also contribute to this psychedelic-trance elicitation. Although the recording is cut short only minutes into the saxophone solo, one can imagine the rubato, arrhythmic phrases invocative of the vocal styles of the azmari swelling to a climax on top of a rhythm section if the piece were to be performed live.

"Yegelle Tezeta" (transcription appendix 7), perhaps Astatke's best known composition, is a song which has been sampled and remixed many times over in recent years by musicians and music producers (discussed at length in Chapter 2). The rhythmic pattern provided by the drums, electric bass and guitar (also included in the score) again is virtually constant and unchanging throughout the entire piece with even very few drum fills. The soloists (organ and saxophone) tend to toy with this constancy, playing rubato type phrases or purposefully stretching their phrases behind the beat. The horn melody is played in harmonies on a G tizita minor scale, with the lower saxophone part being more prominent than the trumpet in the recording. As the rhythm section is such an important aspect of this piece (the full melody only appears after more than two minutes of the recording, by which time it is nearly over) I have included the basic drum, guitar and bass rhythms as well. 


\section{Spiritual jazz}

Astatke's music has some links to the form known as "Spiritual Jazz", a form that developed out of John Coltrane's mid 1960s work and was subsequently concretized by musicians such as Alice Coltrane and Pharoah Sanders. Like Astatke's Ethio-Jazz, spiritual jazz often used single modalities and psychedelic instrumentation to invoke a trance-like state. Whereas both Alice and John Coltranes' music used explicit religious or spiritual references, Astatke's music is largely secular. One exception is the track "Dewel" (a reference to the hand bells used in Ethiopian Coptic church ceremonies) which has aesthetic similarities to spiritual jazz forms, namely a rubato shimmering introduction followed by a medium tempo $3 / 4$ vamp.

Alice Coltrane lived in Addis Ababa at one point, and collaborated with Astatke:

Alice came over to Ethiopia as she was involved with a trance, meditation movement, and they opened an office in Ethiopia. So I knew her, it was so great. I introduced her to Ethiopian musicians and we played together and she recorded at radio stations in Ethiopia. It was a privilege. (Astatke 2014)

Whether Coltrane's and Astatke's music rubbed off on each other is purely speculative, but "Dewel" does appear to acknowledge the spiritual free jazz prevalent in much American jazz of the 1960s. Another composition in a similar vein is "Tezetaye Antchi Lidj" (transcription appendix 8) whose principal theme, in the key of F tizita major.

\section{Years of Wilderness}

In those times [the golden era of the 1960s and early 1970s] things were really happening in music ... if we had had a 
chance to stay together ... we could really have done something. But ... I took my life back to Ethiopia, I had a commitment. I came back here and contributed. [After 1974] it was a totally different atmosphere. It was hard to develop something ... it sometimes held me back (Cleret \& Holland 2005, 94).

Like most Ethiopian musicians there is a telling absence of releases in the discography of Mulatu Astatke during the years of the Derg military rule, which began in 1974 and continued until 1987, with the Communist ruler Mengitsu Haile Mariam finally deposed and exiled in 1991. The curfew imposed by the dictatorship also meant that concert opportunities were limited. Astatke is quoted as commenting on his musical life during the Derg period:

You had to be really careful of what type of music you were playing. Because most of this American stuff was called imperialist music and we were told what we could play and what we couldn't. The curfew meant that all the clubs had to close by 10:30 but then the small joints closed the doors and carried on with maybe one singer and a drummer and everyone drinking and talking. But I didn't do much recording (Thomas 2006, 48).

However, in a more recent interview, Astatke appeared to slightly contradict his earlier statements on the relative musical situations under the Haile Selassie empire and the proceeding Derg rule:

For me it was no problem. I was actually doing what I am doing now. I was travelling and I was playing, and I was also a board member of the International Jazz Federation. But there was some restriction. For me, nothing very much. It was only that the musical atmosphere was different than what it is now. Now we are freer, you can do what you want to do, sing what you want to sing, play what you want to play, travel and go out. Now we are free, there were some restrictions at that time (Troughton 2013). 
Astatke was able to maintain his status as one of Ethiopia's preeminent musicians, composers and arrangers during the Derg period. A highlight of his career during this era was his role as musical director in a show called "People-to-People" promoting Ethiopian culture around the world.

During these years, Astatke focused his endeavours on musicological research into various aspects of Ethiopian music. This included investigating the liturgical music of the Ethiopian Coptic church, and the music of the Derashe people of Southern Ethiopia that, in contrast to the five note kin $\square$ it systems of Northern and Central Ethiopia, employs instruments that play twelve note scales (Zegeye 2009, 27-28). He taught for four years at the Addis Ababa University Cultural Centre from 1987 to 1992 (Zegeye 2009, 29) and his dedication to community works was to culminate in the year 2000 with his creation of the Mulatu Astatke African Jazz Village in Addis Ababa. The activities of this cultural center included music education, performance and radio transmission (Zegeye 2009, 29).

\section{Ethiopiques and the growing global appetite for Ethio-} Jazz

Material from Mulatu Astatke's two classic albums Mulatu of Ethiopia (Worthy Records, 1972) and Yekatit Ethio Jazz (Amha Records, 1974) was re-released in 1998 as Ethiopiques Vol 4: Ethio Jazz \& Musique Instrumentale (Buda Musique, 1998). The impact of this project, the initiative of French record producer Francis Falceto was that Astatke's music was brought into a global popular consciousness. The implications for Astatke's music career were vast, particularly after music from the album was featured heavily in the Jim Jarmusch film Broken Flowers (2005). He was to perform in Ethiopia and the United States with American group The Either/Orchestra and in the last ten years has been performing regularly in the US, Europe, Asia and Oceania 
with his own ensembles. He has been able to record again, and his recent albums demonstrate a will to delve deeper into the possibilities of hybrid combinations between jazz, Latin rhythms and Ethiopian music.

Mulatu Steps Ahead (Strut Records, 2010) and Sketches of Ethiopia (Jazz Village, 2013) can be seen as complementary records, using many similar personnel and forging a similar path. Unlike his earlier albums, these recordings utilize a combination of traditional Ethiopian and Western instruments, as well as being inspired by tribal Ethiopian areas whose tonal systems extend beyond the kiñit. Steps Ahead opens with two traditional Ethiopian instruments, the washint performed by Henry Cook, and the masenqo, performed by Endalkachew Akunya, before the entry of a rubato theme in tizita minor with brass, vibraphone and percussion in the spiritual jazz style. Astatke has stated that "Mulatu Steps Ahead is more acoustic, more how I wanted to hear Ethio Jazz originally...the whole idea of Ethio jazz will be to play with developed Ethiopian instruments" (quoted in Troughton 2013), and in this sense the album is indeed a major advance for this particular ambition. Astatke delves into his own past as well, re-inventing the mambo track "I Faram Gami I Faram", originally recorded as a Latin jazz piece on Mulatu of Ethiopia (Worthy Records, 1972), this time with the Ethiopian vocals of Gashaw. Sketches of Ethiopia also employs the washint and masenqo, along with the krar as well as various Ethiopian vocalists. "Assosa Derache" evokes the music of the Derache people whose music was the subject of Astatke's previous musicological research, while he also writes an arrangement of a piece originating from the Gumuz tribes ("Gumuz") who live in Western Ethiopia.

On Mulatu's Mood and Motherland, from Steps Ahead, the Senegalese kora player Kadialy Kouyate is featured, which adds another element into the synthesis. Abebe Zegeye states, "what distinguishes Mulatu's music is its syncretic nature and its capacity to constantly rejuvenate itself by way of accepting musical 'contamination' from other cultures as the decisive 
condition of possibility of popular culture" (Zegeye 2009, 35). Astatke's ability to draw on so many different musical styles from around the African diaspora is an example of the description of Paul Gilroy's Black Atlantic "forging compound cultures from disparate sources" $(1993,15)$.

For Astatke, the use of hybridity was a conscious decision but one not without its own pitfalls.

Ethio-jazz is based on a mix of Ethiopian musical scales with European scales. Creating this kind of fusion music is not as easy as it sounds, because you have to be careful not to end up with a mishmash of styles and influences. It's important to respect the different cultures you are trying to incorporate and I think that was part of the reason why I was so successful. I managed to integrate the mood of traditional Ethiopian music in Western jazz (quoted in Astatke 2009).

At the same time, it could be said that taking hybridity to such an extent, mixing the traditional with the modern and futuristic, boldly throwing together European instruments with both East and West African ones, along with African American forms and Caribbean rhythms, shows a will to deconstruct history and to subvert expectations in order to create a new vision. It is this will, alongside the sonic landscape that he has created, that places his music at the heart of Afrofuturism: "The mayday signal of Black Atlantic Futurism is unrecognizability, as either Black or music. Sonic futurism doesn't locate you in tradition; instead it dislocates you from origins" (Eshun 1998, -001).

\section{Mulatu Astatke and the Heliocentrics: Inspiration Information}

A large part of the popularity of Astatke's music released on Ethiopiques Vol 4 is the sonic signature created through the instrumentation of these records. 
Distorted guitar combines with Wurlitzer electronic piano and Latin percussion to give the music a hard funk edge, while vibraphone and horns shimmer and float above the machine-like rhythms. In other words, Astatke's music encapsulates what Eshun describes as the "Afrodelic Space Program, an Alien World Electronics" (Eshun 1998, 001). Although Astatke appears to have distanced himself somewhat from this approach on the more acoustic sounding Mulatu Steps Ahead and Sketches of Ethiopia, his collaboration with London based space-funk ensemble The Heliocentrics extends upon these textures to create, at certain moments at least, some of Astatke's most futuristic and invigorating music. Astatke's music benefits greatly from the introduction of synthesizer, performed by Oliver Parfitt, the theremin played by Tom Hodges and the production of Jake Ferguson and Malcolm Catto.

"Cha Cha" (transcription appendix 9) is a relatively straightforward piece consisting of an Afro-Cuban bass line using a minor pentatonic, although the horn melody superimposes a batti minor with a raised fourth. The lead sheet only tells half the story however, as the real highlight is the swirling moog synthesizer which combines with the wah-wah pedaled guitar and vibraphone to create an electronic bed of noise which floats between the background and foreground of the sonic landscape.

Another highlight on the album is "Chik Chikka" (transcription appendix 10), which uses the traditional Ethiopian 3/4 rhythm of the same name, along with a rare sighting of the anchihoye scale. This is one of Astatke's more complex compositions in the sense that there are a number of crucial interlocking parts, from the slowly evolving horn melody to the doubled guitar and bass riff to the percussion parts. It demonstrates how a traditional Ethiopian rhythm can be adapted and mutated to suit a modern percussion section featuring drum kit and Latin percussion. The melody is longer and more complex than many of Astatke's previous compositions. Perhaps this is indicative of a desire to reintroduce some of the rhythmic and ornamental 
complexities of Ethiopian traditional music into his writing. In the recording, piano and bass clarinet solos are complemented by guitar riffs and horn backings, which, in the absence of a more electronic instrumentation, creates a similarly shimmering effect.

The rediscovery in the West of Mulatu Astatke's music has demonstrated that the cultural reciprocations taking place between the African diaspora were not limited to musicians in the United States and Europe. Astatke's music makes great use of subtle transformations of existing materials, or what Paul Gilroy would call "cultural mutation". This has been shown to be particularly striking in his arrangements of the traditional piece "Sabye", in which he took a traditional Ethiopian ballad and through a process of simplification of some elements (melody, ornamentation, rhythm) and elaboration of others (harmony, texture, form, instrumental improvisation) he was able to transform it into a unique form of contemporary jazz. Equally striking is his composition "Yekermo Sew", in which he took a jazz, Horace Silver's "Song for My Father" standard and gave it an Ethiopian treatment through the imposition of an Ethiopian scale. Astatke's transformative music continues to mutate in other ways through to his present day materials. This occurs hybrid instrumentations, or in adapting Ethiopian rhythmic elements to jazz ("Chik Chikka") or in further exploring the possibilities of Afrofuturist electronic textures (Inspiration Information).

Some of the most sophisticated and enduring music that can be categorized as Afrofuturism, was created by Mulatu Astatke, an Ethiopian man working in Addis Ababa in the late 1960s and early 1970s. Astatke's music may be only one small step away from the Afrodelic space music of Miles Davis, George Russell or Sun Ra, yet it is also entirely unique due to the influence of Astatke's own itinerary; from Ethiopia to London to New York and the Caribbean and back again. Astatke's approach to tradition and conventions throwing together instruments from different parts of Africa, Europe and the 
Caribbean and superimposing scales and rhythms from different cultures shows a willingness to break with those traditions as much as build upon them. These experiments were not always met with acceptance, as shown by his experience of being heckled by audiences when initially introducing an Ethiopian instrument, the bagana, into Ethio-Jazz. However, in juggling these apparently contradictory tendencies - respect and research of tradition on the one hand and the impulse to juxtapose disparate elements in the name of modernity on the other - he has managed to design his own version of Ethiopian instrumental music. In doing so, Astatke has designed a unique vision of the music of an African future. 


\section{Getachew Mekurya and Shellela Saxophone}

When French record producer Francis Falceto, the man responsible for the Ethiopiques series of reissued albums of Ethiopia's music scene from the 1950s through to the 1970s, first heard the saxophonist Getachew Mekurya, he thought he had discovered an avant-garde instrumentalist, someone akin to, or influenced by the American free jazz saxophonist Albert Ayler (see Eyre 2015). In terms of the intensity of their vibrato and power of their tone production, the comparison is apt: both players have a penchant for uninhibited blowing at a fortissimo dynamic. However, where Ayler's music was a deconstruction of the tradition from which he came, an apocalyptic rendering of African American spirituals, Mekurya's music is rooted in, and pays homage to his local traditions. Rather than being an avant-gardist, his music, and indeed his own personal musical itinerary, draws largely on Ethiopian musical history, adapting this to modern Western instrumentations, in particular his chosen instrument, the tenor saxophone.

The following section of this chapter examines the music of Mekurya, from his early recordings, which demonstrate his twin influences of traditional Ethiopian vocalizing via the war chants of warrior generals in a style named shellela, and the brass bands and concert bands that Mekurya performed in for much of his life. It continues right through to his latter day collaborations with Dutch punk group The Ex. In comparison with Mulatu Astatke, there is very little in the way of interviews or textual sources on Mekurya's work and life. With Mekurya's passing in 2016 this now seems unlikely to change unless some new documents come to light. This section draws heavily on the liner notes of Mekurya's albums for its biographical information, notably Francis Falceto's text for the reissue of Mekurya's first album Negus of Ethiopian Sax (1970, reissued as Ethiopiques Vol. 14), as well as Mekurya's own notes for his 2006 and 2012 albums with the Ex, Moa Anbesssa and Y'Anbessaw Tezeta, and one revealing newspaper interview he participated in for the Ethiopian 
Reporter (Tigabu 2012). This section compiles the information on Mekurya in one place and contains musical transcription and analysis of Mekurya's work, which has not previously been attempted.

Born in 1935 in the countryside of Yefat in the Shoa region of central Ethiopia, Mekurya moved with his father, a honey merchant, to Addis Ababa while still a baby (Mekurya 2006). He started playing the washint at a very young age and began performing in the Addis Ababa Municipality Orchestra in 1948 at the age of just 13, initially on clarinet then on saxophone. According to Mekurya, his decision to pursue music met initial resistance from his family, a statement that gives insight into the status of musicians within Ethiopian society at the time:

My relatives, including my uncle, felt that I was spoiling the good name of the family by becoming an Azmari, a despised caste of musicians. They distanced themselves from me. It was only when I was given a prize by the Emperor Haile Selassie that they revised their earlier attitude (Mekurya 2006).

In the Municipality Orchestra, Mekurya studied Western music and notation, and learnt “300 to 400 Western standards” (Mekurya 2012, liner notes).

The early hybrid experiments of bandleaders Nerses Nalbandian and Franz Zelwecker were to set the precedence for the likes of Mulatu Astatke and Getachew Mekurya to develop a distinctive and authentic synthesis of Ethiopian and Western music. For Mekurya though, their influence was more direct. He performed in several of the orchestras directed by Nalbandian and Zelwecker; after the Municipality Orchestra he joined the orchestra at the Haile Selassie I Theatre in 1955 under Zelwecker where he also performed acting roles such as Hannibal, Othello and Julius Caesar (Mekurya 2006) before moving on to the Police Band in 1963. Mekurya became the most respected saxophonist of his generation, and even Astatke was to 
acknowledge his predominance as an influential leader in the scene in developing new pathways for Ethiopian music (Tigabu 2012).

Although Mekurya learnt Western notation and repertoire under Zelwecker and Nalbandian, his real interest lay in the onerous and unprecedented task of converting Ethiopian music to the saxophone. "Traditional music you could mainly hear at weddings, the epiphany, Christmas and many other holidays. I started playing those songs and later added the war-songs...I listened to a lot of traditional music in the Hager Fekir [a popular theatre in Addis Ababa], to different Azmaris and from many other sources" (Mekurya 2012). Mekurya's task was not only difficult from a technical, instrumental viewpoint, but also for the scorn he received from other musicians: “To transcribe Ethiopian music on paper is very difficult. I don't think there is any. Some musicians in bands like the Imperial Bodyguard Band (Kibur Zebegna), who only played European standards from paper, despised me because we were also playing Ethiopian traditionals. You are Azmari, they said!" (Mekurya 2012).

Mekurya was to record one album for Phillips Ethiopia in 1970, Negus of Ethiopian Sax, re-released as Ethiopiques Vol 14: Negus of Ethiopian Sax in 2003 (which also includes a single from the late 1950s, "Shellela"). Mekurya's repertoire is exclusively based on adaptations of traditional Ethiopian songs. For example, "' Akale wube" [a piece from Negus of Ethiopian Sax] is also an old song with some new creativity added to it. I try to tell stories through my sax. And I always listen, improvise, and add my own element after that" (Tigabu 2012). 


\section{Shellela Saxophone}

While playing a theatrical role as a warrior killing Italian soldiers, "singing and ranting the war chants" at the Haile Selassie I Theatre, Mekurya formed the idea to transpose the war songs to the saxophone (Mekurya 2006, liner notes). These songs formed a vocal style known as shellela. This was a form of chant or declamatory song used by military leaders to rally their troops before a battle. For Mekurya, "History inspires me. Shellela was done only through voices back in the day. It was never done by instruments, so I played it with sax and tried to add my elements to it" (quoted in Tigabu 2012). This invocation of war songs resonated strongly with local audiences, according to Falceto: "Ethiopians themselves, they love this style of saxophone, not because it is free jazz, but because it reminds them of the vocal style, the war songs. The shouting style. This is nationalism. When he plays this, each and every Ethiopian can hear behind the saxophone the lyrics to the traditional war song" (quoted in Eyre 2005). Mekurya's invocation of the national warrior hero could only have been enhanced by his wearing an animal skin tunic (lemd) and lion mane headdress (gofere), as can be seen in many images of him in performance.

In the liner notes to Ethiopiques Vol 14: Negus of Ethiopian Sax two examples of shellela rituals and their texts are given, the first an account from a French book published in 1935 (Lachin and Weliachew 1935, 182-183). These examples allow us an insight into the ferocity of shellela, the intensity of which Mekurya derived his saxophone style.

Ho ye hou hou hout!

In his hand he holds a sword. There is foam on his lips. He shouts, he cries:

"Zaraf! Zaraf! Forward, forward! At Adwa, I fought. There were 50 Italians before me, 50 behind, 50 to my right, 50 to my left. I killed them all!"

Ho ye hou hou hout! 
A shiver goes through the circle.

"Ghedami, Ghedami, it was a Saturday, Zaraf, Zaraf, forward. Tomorrow I will strike down 100 Italians to the north, 100 to the south, 100 to the east, 100 to the west.

Ho ye hou hou hout!

(Lachin and Weliachew 1935, 182-183. From Mekurya 2003, liner notes).

Or this from a war veterans' celebration in the 1980s:

Courage! Courage! Our fighters have already had occasion to disembowel the white man and throw his entrails to the vultures. Never underestimate a short man. Never try to make a rock tremble (Mekurya 2003, liner notes).

Ethiopian musicologist Timkehet Teffera argues that:

The powerful song lyrics along with their agitative messages are first and foremost meant to encourage and inspire but also honour warriors. They always served to maintain selfconfidence and courage by stimulating physical aggressiveness, demonstrate manliness and the recklessness of Ethiopian warriors. Apart from stories and legends, key figures in ancient battles and their great heroic deeds are preserved and immortalized in the Shilela songs (Teffera 2009, 9).

Teffera lists the lyrics of an Amharic song "Qererto" by the singer Adugnaw Worku as typical of the bravado associated with the shellela style:

Jegna sewu qorat new aysasam lenefsu melkam gobezna nebir and nachewu derewu sewu aynekum kalkotekotwachewu A hero has not fear to die Brave warriors and a tiger are alike They don't touch anyone, unless they are provoked (Teffera $2009,10)$.

The shellela songs which Mekurya was to perform throughout his life reflect both his deep sense of national pride and his masculine and combative approach to music, as alluded to by Teffera. Unlike Mulatu Astatke it would 
appear that Mekurya was less concerned with forging new hybrid styles and his music did not seek to reflect an increasingly cosmopolitan Ethiopian world view. On the contrary, Mekurya was a deep traditionalist who would use whichever instrumental tools surrounded him - the brass and concert bands of his youth, the soul of "swinging Addis" in the 1960s and 70s, the synthesizer, one-man-band approach common during the 1980s, or the collaborations with European musicians of different stripes in the 2000s - to express his connection with the Ethiopian secular musical traditions.

\section{A Musical Analysis}

Some commentators and reviewers have made allusion to Mekurya's sound and abrasive approach. Critic Chris May (2007) for example, describes it as "Primal and shamanic...pumped up, epic, threatening and boastful, harsh and hoarse-voiced" yet few, if any, have commented on what is truly virtuosic and nuanced about Mekurya's music: his extensive and controlled use of ornamentation. In the history of saxophone playing this is rivaled perhaps only by South Indian classical saxophonist Kadri Gopalnath. Mekurya's playing is replete with grace notes, trills, mordents and fioritura which suggest that Ethiopian melismatic vocal styles are deeply ingrained in his music. Plainly speaking, the adaptation of shellela to the saxophone was not simply invoking the emotional state of the warrior, it also required the capturing of all the ornamental subtleties of these songs on a Western instrument not particularly intended for the task.

The transcription of the opening verse of "Shellela" (appendix 11) is a song recorded by Mekurya on Negus of Ethiopian Sax (1972) that is strongly representative of the essence of his saxophone style. This piece can be imagined as a war chant, simply revolving around the note A from bars 1 to 7 . At bars 7 through 11, the focal note moves down a half step to G\# before 
resolving to A halfway through 11 and staying there for the rest of the verse. As is clear from the transcription though, Mekurya creates interest through the virtuosity of his ornamentation, reflecting the melismatic vocal styles of shellela chanting. What the transcription does not capture is the fervour of Mekurya's sound, giving the music a remarkable textural intensity.

There are prominent differences between the music of Mulatu Astatke, the creator of Ethio-Jazz and that of his forerunner, Getachew Mekurya. Mekurya was to comment, "It's sometimes weird that many people, from America or England, come here and they want to discuss about the jazz. Some journalists bother me, I really know nothing about the jazz. I just play Ethiopian music...Mulatu Astatke (the smart guy!) studied jazz and studied different ethnic groups here in Ethiopia and mixed it together. He is a good arranger, but it is different" (Mekurya 2012, liner notes). Like Mulatu Astatke's music, Mekurya's music is generally built on the kiñit and is entirely modal. The transcription of "Almaz Yeharerwa" (appendix 12), for example, employs the batti minor mode exclusively. However, a notable difference is the use of ornamentation, which relates to shellela songs and other traditional Ethiopian vocal styles which Mekurya focused on adapting to the saxophone. Astatke largely rid melisma and ornamentation from his music, even from traditional arrangements (for example, "Sabye"). Where Astatke makes a feature out of instrumentation and group interplay, a legacy of the jazz tradition, Mekurya's band largely plays an accompanying role, even if they include contemporary Western instruments such as the organ, electric bass and drum kit.

"Almaz Yeharerwa" translates to "My Diamond from Harer", a city that Mekurya would travel to and admire when he was a young man (Mekurya 2006, liner notes). Again, Mekurya's controlled and extensive use of ornamentation is evident, bringing virtuosity and intrigue to what would otherwise be quite a simple piece (transcription appendix 12). 
Leading Ethiopian musicologist Ashenafi Kebede, writing in 1976, lamented the watering down of this important element of traditional Ethiopian music within the new contexts: "As a result of acculturation, the most drastic changes in zemenawi musika occur in its temporal organization. Traditionally, the temporal element of [modern Ethiopian music containing Western elements] vocal melody was based largely on textual considerations. The traditional practice - the melismatic, free rhythmed, parlando-rubato style of vocal melody - is rarely encountered today in contemporary performance approaches" (Kebede 1976, 295). Mekurya is one of the only musicians then who bucked this trend, managing to incorporate the complexities of traditional Ethiopian melody in a contemporary context, alongside the temporal aspects of the music to which Kebede refers.

Many of Mekurya's pieces follow a similar structure: a rubato introduction with the saxophone introducing the mode in an incantatory style. This is followed by the eventual introduction of a rhythm, often in the $3 / 4$ chik chikka meter, and the introduction of the main melodic theme, which is often performed in a call-and-response style. This theme is then repeated and extemporized on, rather than free flowing jazz improvisations that depart form the theme.

The transcription of the introduction and initial statement of "Yegenet Muziqa" (appendix 13) demonstrates this structure precisely. The saxophone enters using fioritura type embellishment on the anchihoye kiñit, with the organ mirroring the end of his phrases all in free rubato time. Eventually the rhythm section enters, led by a guitar riff which establishes a fast 3/4 chik chikka rhythm. After the riff is repeated eight times the saxophone comes back in with the main melody, embellished with mordents and grace notes, a simplified version of which is repeated back by the organ in a call-andresponse style (bars 27-44 of the transcription). This melody is repeated three times before a saxophone improvisation around the theme. Mekurya's intense 
vibrato and crescendos as he ascends to notes at the highest register of the tenor saxophone bring a sense of climax to the piece.

\section{During the Derg Period}

Negus of Ethiopian Sax remains Mekurya's most important recording. He continued to perform during the Derg years from 1974, at some point moving from the Police Band to a better paid residency at the Sheraton Hotel (Tigabu 2012). According to Mekurya, "during the Derg period, music was turned into an instrument for politics and it began to decline and fade" (Mekurya 2006, liner notes). Although his recording output diminished, a cassette recording of Mekurya's has recently surfaced via the website Awesome Tapes from Africa. Teffera (2013) states that during the Derg era, synthesizers and one-man bands replaced the orchestras and "golden-era" dance bands: "Where the political instability had already shaken up the economy, the new concept of music performance and music production by electronic keyboards/one-man band was very much welcomed" (Teffera 2013, 370). Although this context may help in understanding how Mekurya's 1980s cassette recording came out, it still does not really prepare the listener for the juxtaposition of his harsh shellela saxophone style with 1980s digital synthesizer and drum machine beats.

\section{Post Ethiopiques and The Ex}

Like Mulatu Astatke and many other "golden age" Ethiopian musicians, Mekurya may have faded into obscurity had it not been for the Ethiopiques series. Ethiopiques 14 brought Mekurya's sound into the ears of Western audiences as well as, perhaps even more crucially, musicians around the world. Soon Mekurya was performing around Europe and the United States 
with eager Western groups including the Either/Orchestra from the United States and one of Europe's leading avant-garde orchestras, the Instant Composer's Pool. The most enduring of these collaborations for Mekurya though was with Dutch avant-garde punk band The Ex. Falceto again draws the link between Mekurya's shellela saxophone and the European avant-garde, explaining what a comfortable fit these very different traditions turned out to be:

He really feels at home with them. He enjoys so much to blow. Who is the one who will boast the loudest? And musically, the result is incredible. They play free jazz. The Ethiopian blows war songs. Aesthetically, formally, it's very, very close (Eyre 2005).

With The Ex, Mekurya was to play over 100 concerts and release two new albums, Moa Anbessa (2006) and Y'Anbessaw Tezeta (2012). Of The Ex, Mekurya states: "They have the capacity to adapt to different groups and keep their style. I admire them because we were able to mix both new European and Ethiopian music and harmonize them...They retain the charm as well as being able to arrange it for electric string music" (Mekurya 2006, liner notes). With the Ex, Mekurya was able to find a group that played with a power and intensity to which he responded and it was perhaps this more than anything else which made it a successful collaboration. As stated previously, Mekurya did not see himself as a jazz musician and the idea of improvisation was perhaps a little foreign to him. Likewise, The Ex were from a punk rock background, rather than an improvisation background, and as such they learnt the songs and retained the structure of the pieces, where jazz musicians may have treated them more as vehicles for improvisation.

"Ethiopia Hagere" (transcription appendix 14), the opening track from Moa Anbessa is an electrifying introduction to the group's style. Distorted guitars, a heavy shuffle beat and monotonous vocals underpin the traditional Ethiopian melody. The main theme is played first by the European horn section of 
Xavier Charles (clarinet), Brodie West (alto saxophone) and Joost Buis (trombone) before being reiterated as a solo by Mekurya. A comparison of the two renditions of the melody gives insight into the nature of Mekurya's use of ornamentation and complex rhythms to add colour to melodies.

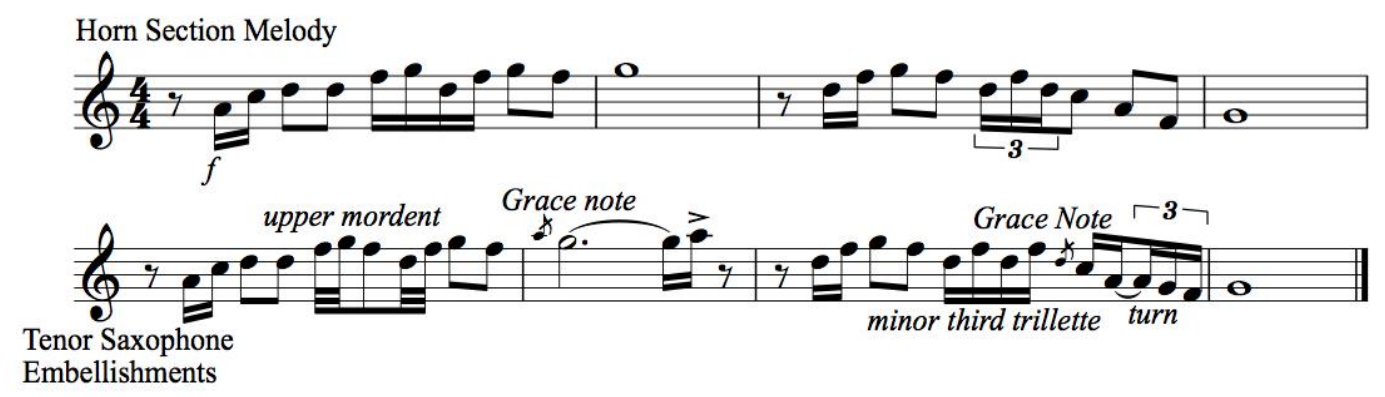

Figure 15: Ethiopia Hagere theme with and without embellishments.

Where Moa Anbessa largely revisits repertoire from Negus of Ethiopian Sax and other relatively familiar Ethiopian standards such as Girma Beyene's 1970 classic "Musicawi Silt", Mekurya's 2012 masterpiece Y'Anbessaw Tezeta branches off into less familiar territory. Listed as his final recording, it is more poignant and reflective than his previous albums, with Mekurya choosing the songs that were "the best, not necessarily the most popular on the street" (Mekurya 2012). As a final statement, Y'Anbessaw Tezeta confirms Mekurya as an unequivocally original and towering musician.

In later years Getachew Mekurya was finally able to tour abroad and present his sound to the world. Yet still he deserves wider recognition as a brilliant and unique saxophone player. Although he has been compared to various great American jazz saxophonists, such analogies can be misleading; Mekurya arrived at his style through the study of Ethiopian music and independently of the jazz language. However, it would not be wrong to include him in the highest level of the pantheon of saxophonists who have contributed to multifarious voices of this instrument. He is also a champion of Ethiopian 
music, a musician who found an authentic and undiluted way of bringing the traditional music to Western instrumentation and modern audiences. 


\section{Emahoy Tsegue-Maryam Guebrou's Divine Connections}

The instrumental music of Mulatu Astatke and Getachew Mekurya represent a hybrid of Ethiopian traditional music with various Western forms - jazz, Latin music, soul music, even perhaps as some commentators have claimed, the influence of Balkan and Middle Eastern brass music, probably via the teachings of various Armenian band leaders (Mekonnen 2010, 308). There are some notable differences in Astatke's Ethio-Jazz and Mekurya's shellela saxophone; Astatke's international education and experience led him into an improvisatory and timbral landscape, one which, in hindsight, can be compared to the Afrofuturist jazz of Sun Ra, Miles Davis and George Russell. Comparatively, Mekurya's adaptations of traditional Ethiopian vocal styles to Western instruments retained more of the melodic embellishments typical of Ethiopian music and, as a result, was arguably more strongly rooted in Ethiopian musical culture. Through the context of the performance and presentation of their music, these two musicians can be said to have worked in closely related fields, and as such are readily compared; both played for and collaborated with the dance bands and popular music ensembles of "Swinging Addis" during the 1960s and early 70s and their music reflects this cosmopolitan era of booming nightlife, recording sessions and musical innovation.

An entirely different approach to Ethiopian musical hybridity, in sound, motivation and context, is offered by the pianist and composer Emahoy Tseque-Maryam Guebrou. Born in Addis Ababa in 1923, Guebrou is the daughter of Guebrou Desta, one of Ethiopia's leading politicians and diplomats of the time and Kassaye Yelmitu, a woman with close familial ties to Emperor Haile Selassie. ${ }^{6}$ As a young girl, Guebrou was sent away to a Swiss boarding school where she began learning piano and violin before

\footnotetext{
${ }^{6}$ The biography of Guebrou is largely redacted from the liner notes to Ethiopiques 21: Emahoy Tsegue-Maryam Guebrou and from Guebrou 2013.
} 
returning to Ethiopia at age 10. With her family she was exiled during the Italian occupation due to their political prominence, but after the war she was able to continue her musical education in Egypt under Alexander Kontorowicz, the head of the music department at Cairo University at the time. Guebrou returned to Ethiopia at age 21 and was to undertake further music studies in England until stymied by local authorities who refused to give her permission. Guebrou was heartbroken and fell sick, very nearly dying. Upon recovery, she neglected music, becoming more and more interested in spiritual life and the Ethiopian Coptic Christian church, eventually leaving Addis Ababa to take up residency in a convent in Northern Ethiopia. Some time later, her health still too fragile to cope with country life, she returned to Addis Ababa to teach in an orphanage, at which point she took up music again.

Although performing in public only very rarely, Guebrou made several recordings as fundraising projects for the orphanage and other charitable causes. Guebrou recorded four LPs of solo piano (and occasionally organ) during the 1960s and early 70s, three in Germany and one in Israel. Many of the tracks from these records were re-released in 2006 as Ethiopiques 21: Emahoy Tsegue-Maryam Guebrou on Buda Musique. In 1984 Guebrou was to move permanently to the Ethiopian Monastery in Jerusalem where she still resides today. A book of her piano scores, compiled by Israeli pairing Maya Dunietz and Ilan Volkov, was published in 2013 (Guebrou 2013).

As one might expect, Guebrou's music is reflective and spiritual in intent, largely melancholy with a strong underlying sentiment of isolation. A key device in conveying the spiritual intent of her music is the sense of spaciousness and an elasticity of time and tempo. Indeed in Guebrou's original compositional sketches, rhythms and barlines were largely omitted editors Maya Dunietz and Ivan Volkov only inserted them for the sake of legibility (Guebrou 2013, 7-8). 
Some of Guebrou's pieces seem to resemble the blues, most strongly felt in the track "Homeless Wanderer", and yet she herself claims as her lineage early romantic piano composers, such as Beethoven, Chopin and Schumann (Bruce 2015). According to Dunietz "it is classical music, with a very special sense of time, space, scenery" (quoted in Sherwood 2013). Francis Falceto chooses to emphasize her Ethiopianism in describing her music: "Beyond a few neoclassical temptations gleaned from the European piano tradition, her compositions embody a profoundly Ethiopian essence - and for this reason fully deserve their place in Ethiopiques" (Guebrou 2013, liner notes). However, it would seem that Guebrou herself may dispute Falceto's claims as Nadav Haber explains: “When I asked Emahoy Tsegue-Mariam about the impact of Ethiopian music on her work as a composer, she was a little surprised. Although she had been told a few times that these influences were evident in her music, she was almost totally unaware of them. This lack of awareness is particularly interesting as it shows how an individual is influenced, even subconsciously by the environment, the surrounding language with its different tones, religious music and possibly even unconnected to music" (Guebrou 2013, 17).

All of these definitions of Guebrou's music are in some way correct. In some of her pieces, such as "The Last Tears of the Deceased", Guebrou could have been writing an elegant, restrained waltz in the early romantic era. In other pieces, this Eurocentrism is tempered by pianistic flourishes and embellishments, or short interjections of kiñit. Only occasionally do the compositions seem largely Ethiopian in heritage, and yet these are usually accompanied in the left hand by Western triadic harmonies rather than the contrapuntal and antiphonic style used by the azmari. 


\section{Identifying the influences in Guebrou's Music}

As has already been determined in my analyses of Astatke's and Mekurya's music, the key elements that have contributed to the sense of Ethiopianism within their jazz and popular music hybrids include:

1) The use of particular pentatonic scales (kiñit) derived from, if not exactly replicated from, Ethiopian traditional music.

2) Extensive use of ornamentation and melodic embellishment.

3) Favouring 3/4 time signatures, a reference to chik chikka rhythms.

4) Employing rubato introductions, or indeed entire pieces where rhythm is used in an elastic sense.

5) Frequent use of call-and-response or antiphony.

Most of the pieces composed by Guebrou on Ethiopiques 21 conform to some, if not all of these guidelines.

\section{The Homeless Wanderer}

Much of the melodic content of "The Homeless Wanderer" uses an F tizita major scale with a raised second.

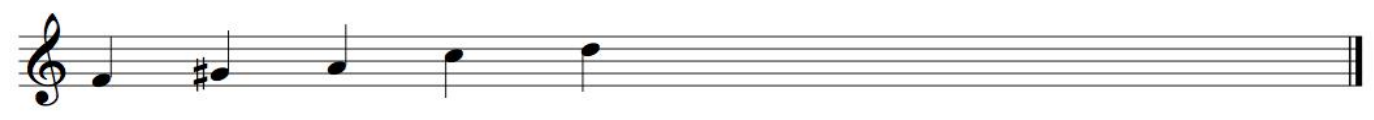

Figure 16: F tizita major with a raised second. 


\section{The Homeless Wanderer}
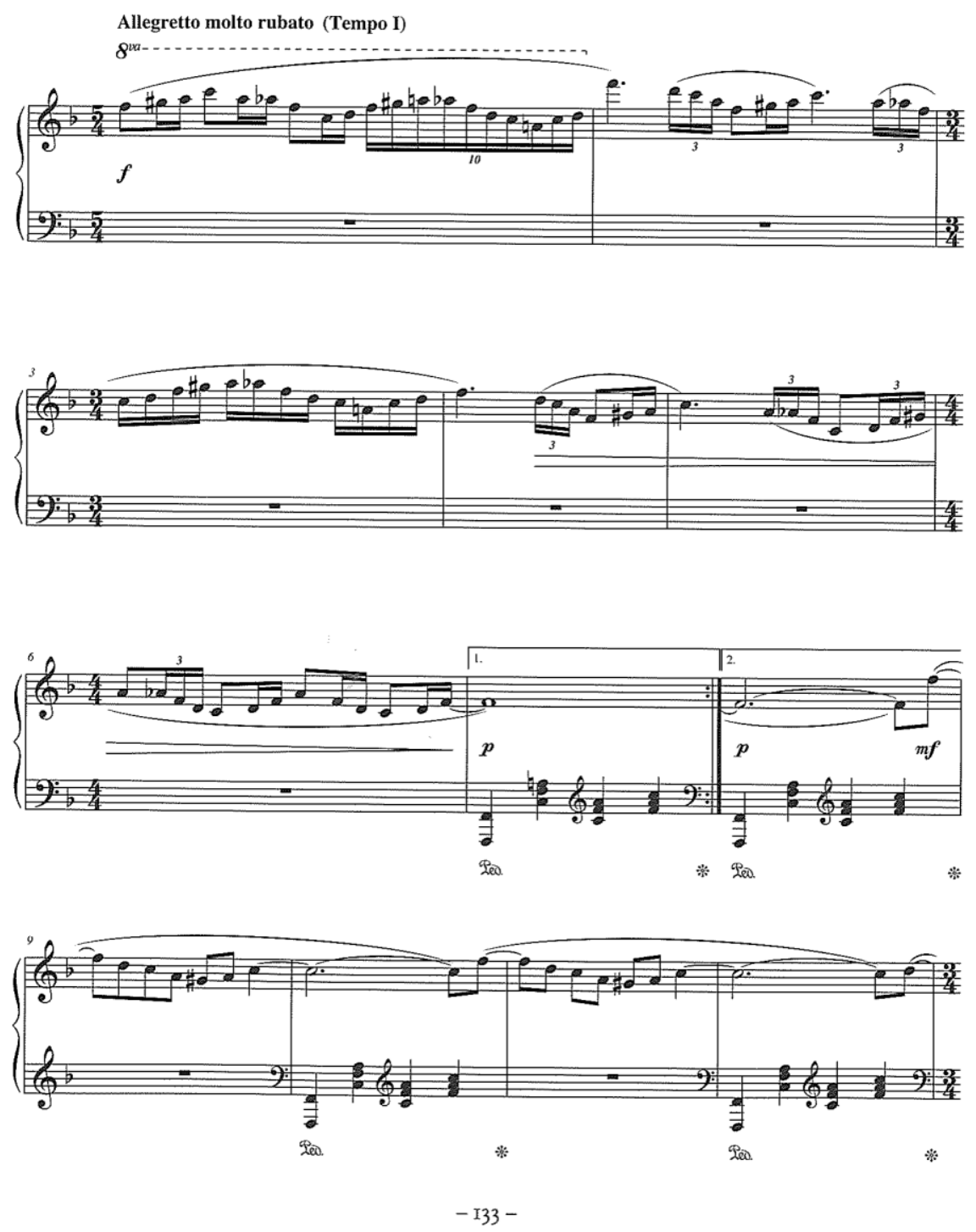

Figure 17: Initial statement of "The Homeless Wanderer" featuring the adapted tizita mode (Guebrou 2013, 133).

Although the raised second means that the scale is not strictly one of the kiñit listed in Abate's study, this is a variation on the tizita mode. 
After setting up this tonality and the ear becoming accustomed to this one scale, Guebrou slowly introduces other tones from outside the mode. The first time this occurs is at bars 65-66 where the flattened second, or G flat, is used in the melodic line.

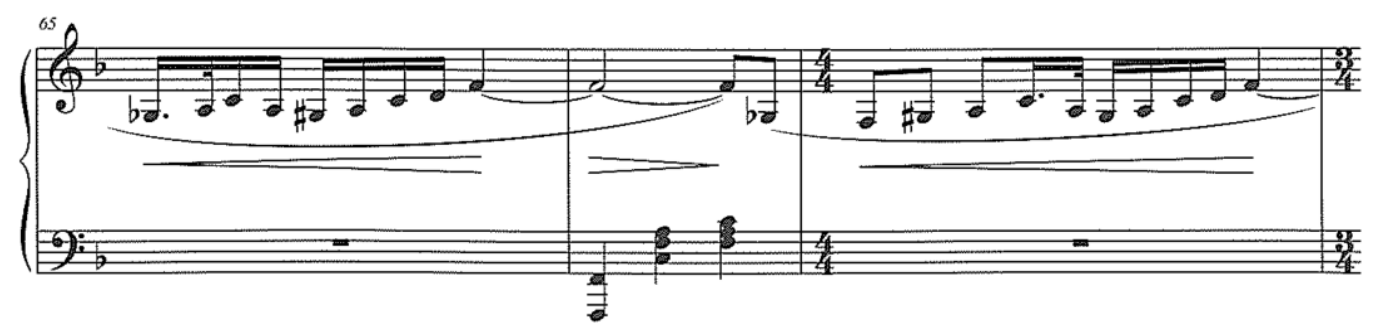

Figure 18: Flattened second, bars 65-66 (Guebrou 2013, 137).

Again this choice is interesting: where a European composer may well have used a natural second to contrast with the G\# used elsewhere in the piece, Guebrou's flattened second positions her music elsewhere, hinting at the Ethiopian anchihoye mode.

Halfway through the piece, at bar 109, the composition switches to a minor mode. Again this is pentatonic, (the F minor pentatonic, or using Ethiopian terminology, the batti minor, which alternates between a raised and flattened $7^{\text {th }}$ in this section).
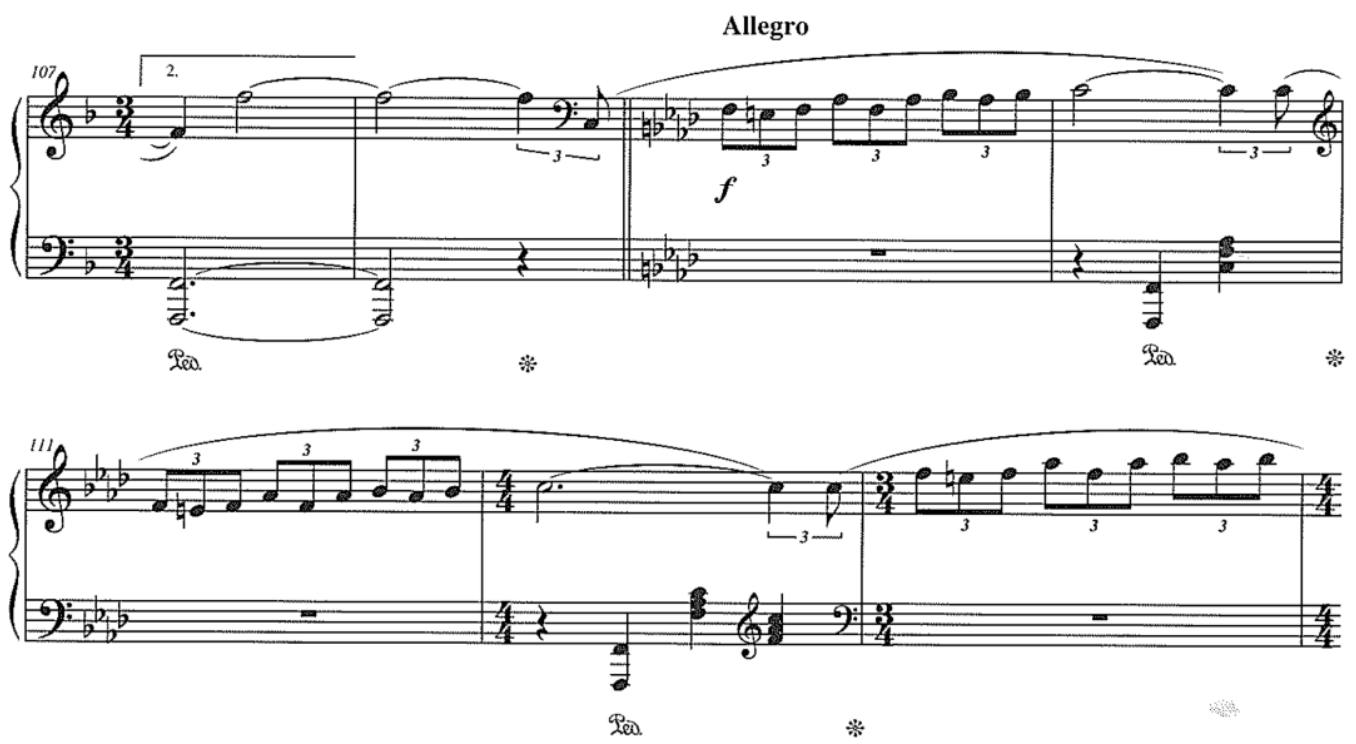
Figure 19: The modulation to the batti mode at bar 109 (Guebrou 2013, 140).

Some commentators have compared Guebrou's style to the blues and in particular list "The Homeless Wanderer" as evidence of a jazz and blues influence in her music. Reviewer Thom Jurek commented, "the opening cut also displays her incredible ability to play an extremely melodic blues piano as read through the great jazz masters of the instrument. One can hear a bit of Albert Ammons, a bit of Count Basie and Oscar Peterson, and even a trace of Art Tatum in "The Homeless Wanderer"" (Jurek 2006). Although the pentatonic scale does resemble a blues scale and the harmonic progression, which alternates between tonic and dominant only, is reminiscent of blues progressions, I argue that this piece is in fact more a meditation on traditional music of Ethiopia and the music of the azmari than a commentary on American blues. The piece is rubato, arrhythmic, with the barlines inserted in Dunietz's transcription largely present for the sake of legibility. Guebrou's right hand, replete with ornamental flourishes, represents the vocal melodies of the azmari or the melodic embellishments of the washint player. The left hand is the accompaniment which refers to both the responses of the krar in the way they are positioned in between the right hand melodies (one could recall the version of "Sabye" by Asnaqetch Werqu for an idea of the antiphonic style inherent in the music of the azmari), and to Western classical music in terms of their harmonic language (triads and seventh chords). In Guebrou's notes for the piece, she depicts it as "The homeless wanderer plays on his flute, while he worries about the wilderness around him" (Guebrou 2013, 132). There is no evidence of her style having been informed by the blues or jazz in any of her interviews or commentaries on her pieces.

This particular tizita scale (transposed to the key of $\mathrm{Bb}$ ) and the rubato call and response structure is also used in Guebrou's composition "Presentiment". An interesting sense of bitonality is created in this piece through the use of the Gb Major chord at bar 4 and again at bar 7. In this piece the melodic 
material remains the same, derived from the $\mathrm{Bb}$ adapted tizita mode. The minor third $(\mathrm{Db})$ acts as a pivot note for the non-diatonic Gb Major chord, becoming the fifth of this new chord. However the Bb Major sound is heard on top of the Gb Major chord in the ornamental flourishes at occur at the end of these two bars, a juxtaposition of two harmonies.

As in "Homeless Wanderer", "Presentiment" exhibits a combination of Ethiopian and European influences, divided literally between the two hands. The right hand plays melodic material derived from Ethiopian scales and ornamentation while the left hand plays harmonies and chord structures based on the classical musical language of the early Romantic period. 


\section{Presentiment}
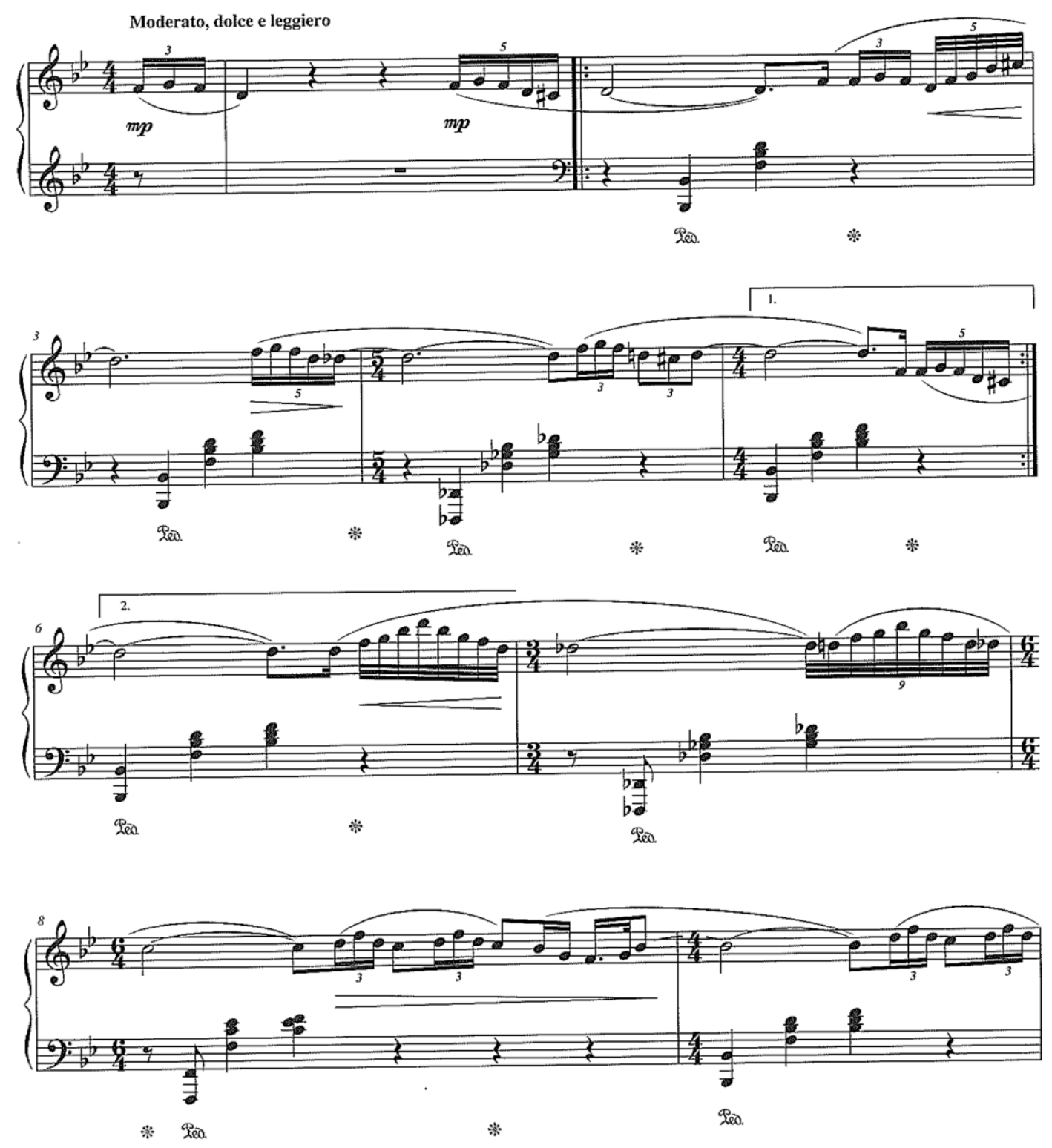

- II -

Figure 20: The tizita mode in the initial statement of "Presentiment" (Guebrou 2013, 11). 


\section{Mother's Love}

This composition employs a tizita major exclusively in the right hand melody, this time with a natural second. Indeed, the piece bears resemblance to the traditional song from which the mode is named. Where a major mode may convey happiness or contentedness for a Western audience, tizita means literally nostalgia or wistfulness in Amharic, and indeed the piece is dedicated to a relative who lost her son during the Italian war (Guebrou 2013, 20). Again, as is shown in the extract below, other elements common to Ethiopian music such as the elastic, rubato rhythmic sense and the ornamental melodies, are present in this composition. As Naber comments, the phrases "could have been directly taken from traditional krar music" (Guebrou 2013, 20).

Incidentally, "Mother's Love" is not the only Guebrou composition to use a major scale to express loss, with "Homesickness" (included in Ethiopiques Vol. 21 but not the book of piano scores) also employing the tizita major mode. 


\section{Mother's Love}
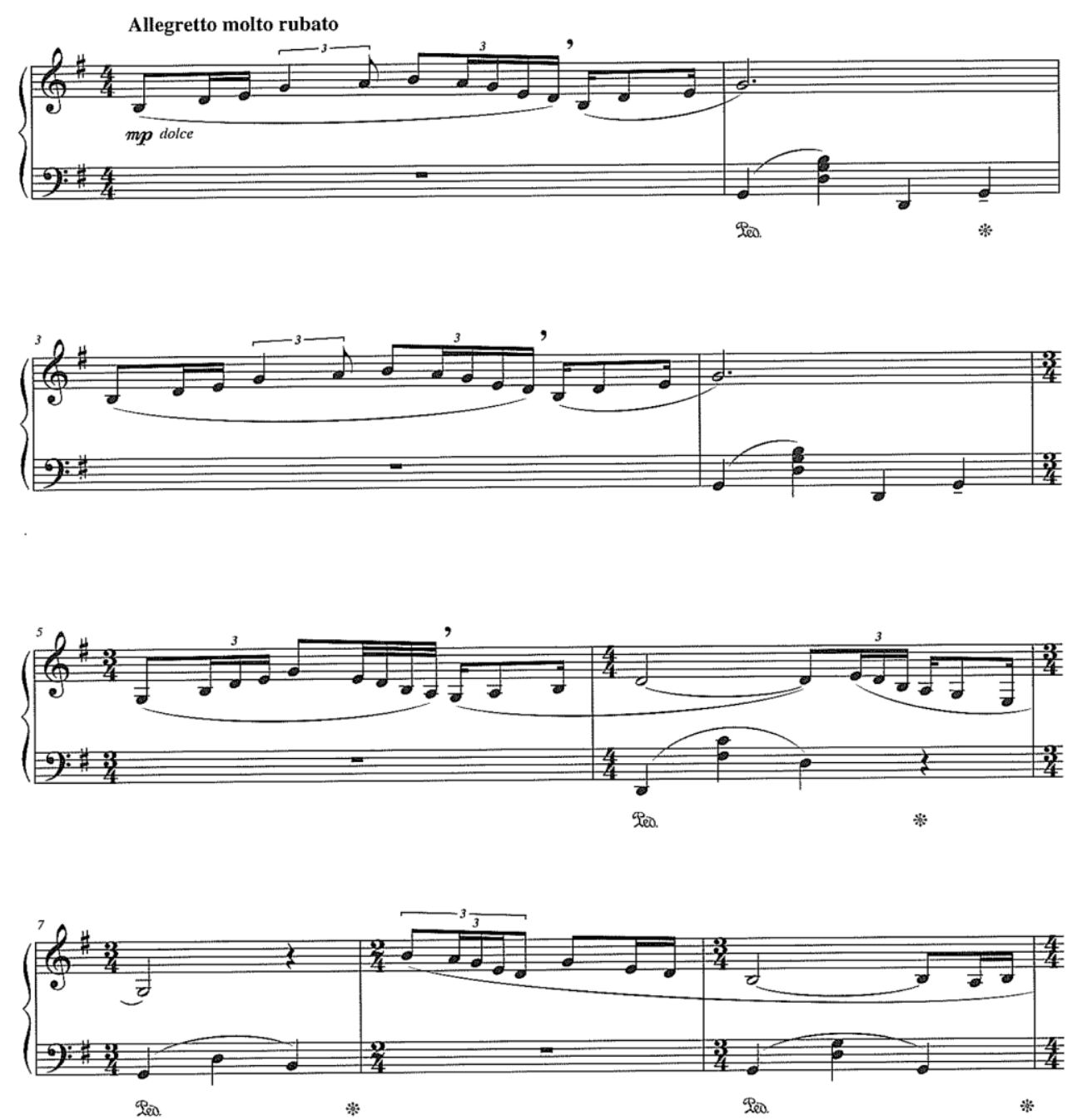

$-2 \mathrm{I}-$

Figure 21: The G tizita mode and rubato melodic phrasing in "Mother's Love" (Guebrou 2013, 21).

\section{Ballad of the Spirits}

There are examples of Guebrou's pieces that, while made distinctive by her personal piano touch and reflective tempos, are largely devoid of any 
particularly identifiable Ethiopian influence. They can more accurately be identified as relatively incomplex alternatives to the musical language of Schumann and Chopin. Pieces which fall into this category include "The Last Tears of the Deceased", "A Young Girl's Complaint" and "The Mad Man's Laughter". Occasionally however, a composition will begin in this European manner before departing curiously into a distinctively Ethiopian landscape. Such is the case with "Ballad of the Spirits" which begins in Ab Major, cycling around a simple diatonic progression (Ab - F Major - Eb7) with the occasional use of an $\mathrm{Ab}$ diminished passing chord (bars 10-11) before departing unexpectedly into a middle section based around an Ethiopian mode, the batti minor with a raised fourth (from bar 27), which it explores in a rubato manner for the rest of the piece. 


\section{Ballad of the Spirits}
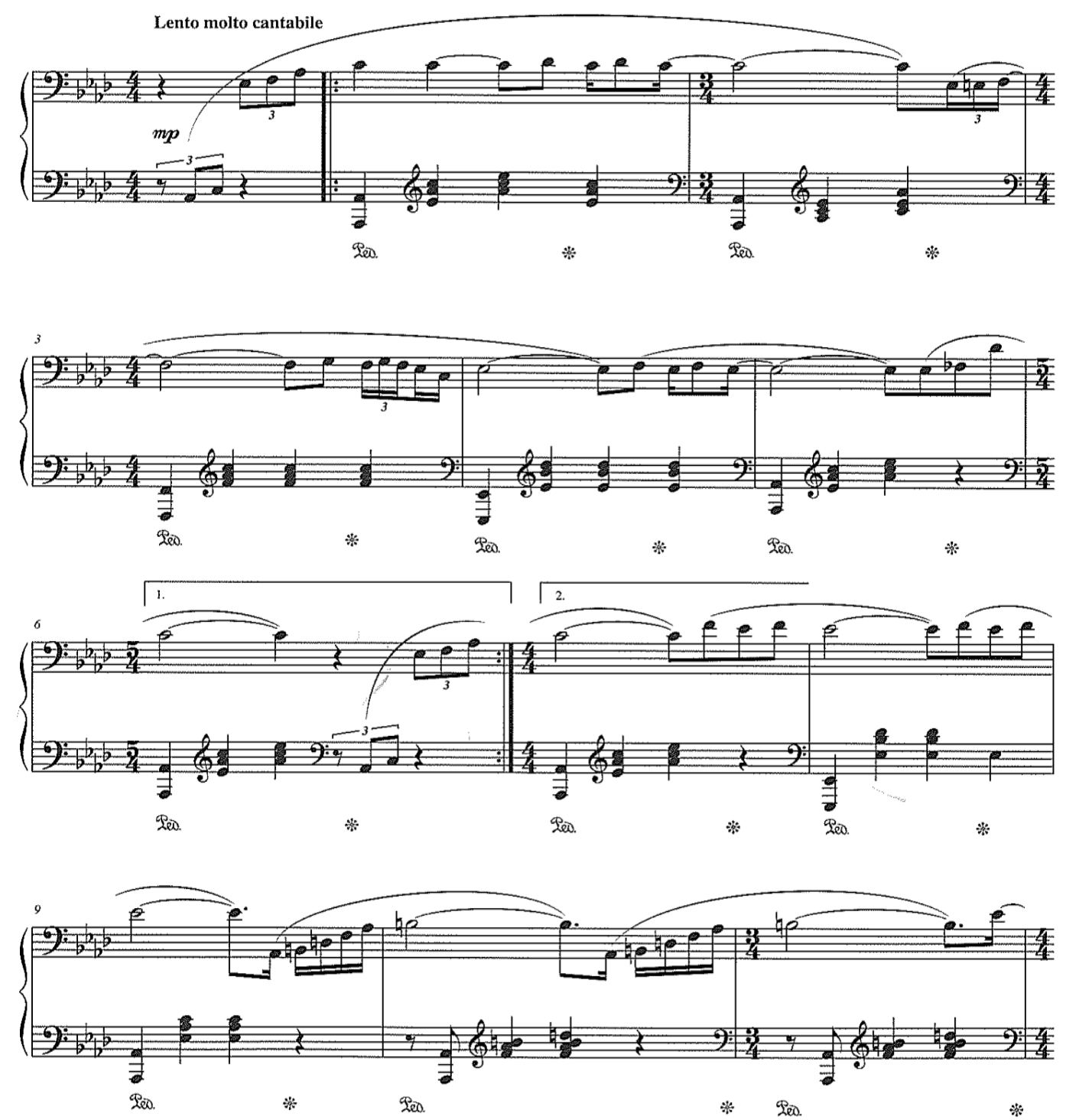

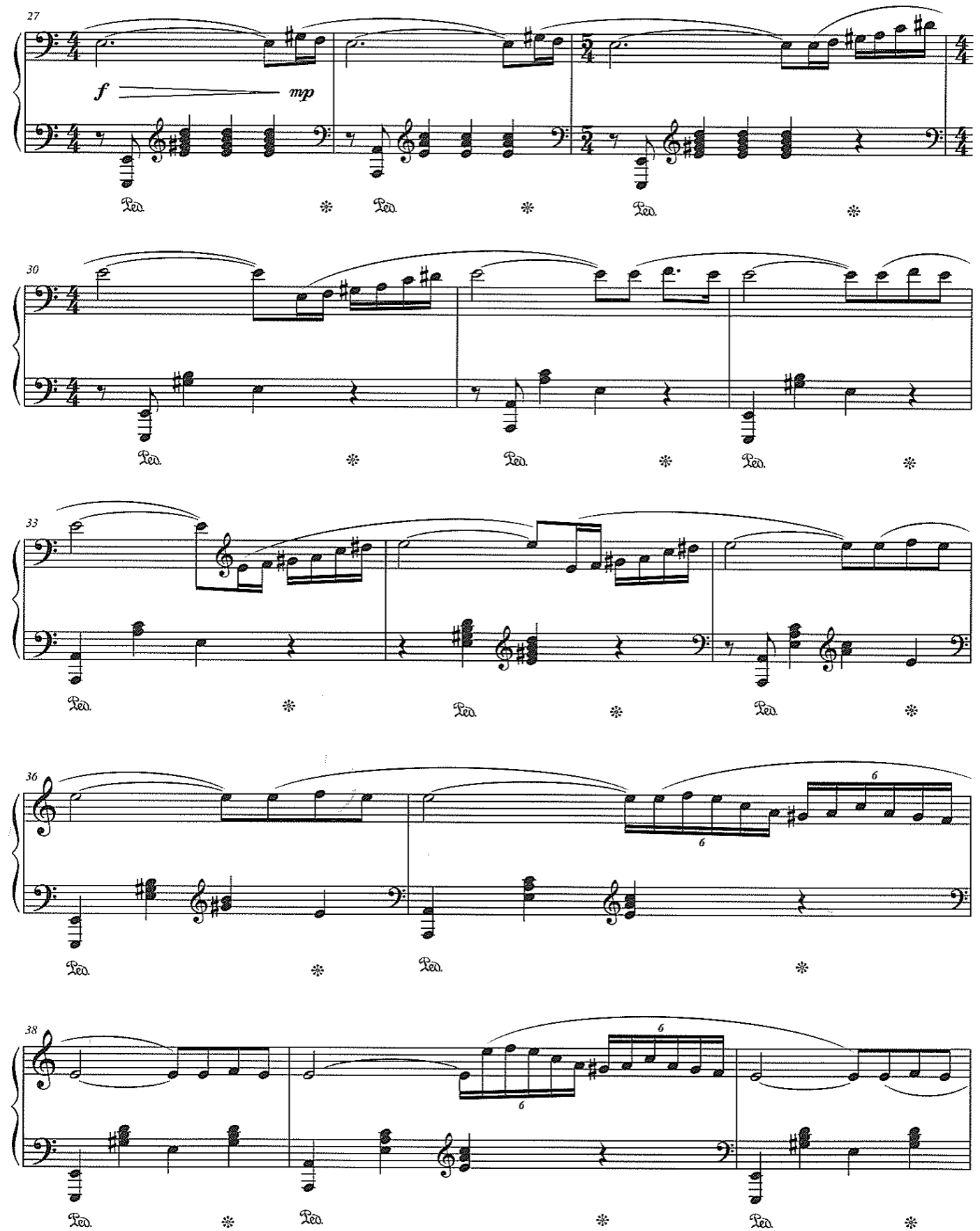

$-93-$

Figure 22: Sudden departure into the batti minor with a raised fourth and embellished melodic phrases (Guebrou 2103, 91-93). 


\section{The Garden of Gethsemane}

This piece, with its dark religious undertones ${ }^{7}$, is perhaps the most recognizably Ethiopian of all of Guebrou's compositions. Beginning in F batti minor, the piece uses call-and-response melodic phrases between the left and right hands, rather than the device of melody in the right hand and triadic accompaniment in the left seen in previous examples. With shifting time signatures and a high degree of chromaticism, it is also one of the most complex of Guebrou's pieces. The extract below shows several of these elements, the antiphony between the hands, the alternating time signatures, from $5 / 4$ to $9 / 8$ to $4 / 4$ to $5 / 8$ and so on, to the chromatic passing notes such as $\mathrm{Fb}$ (bar 49) and $\mathrm{Cb}$ (bars 50,51, 53,54) within the context of the $\mathrm{F}$ minor tonality.

${ }^{7}$ According to the Bible, the garden of Gethsemane is where Christ was betrayed by Judas. 

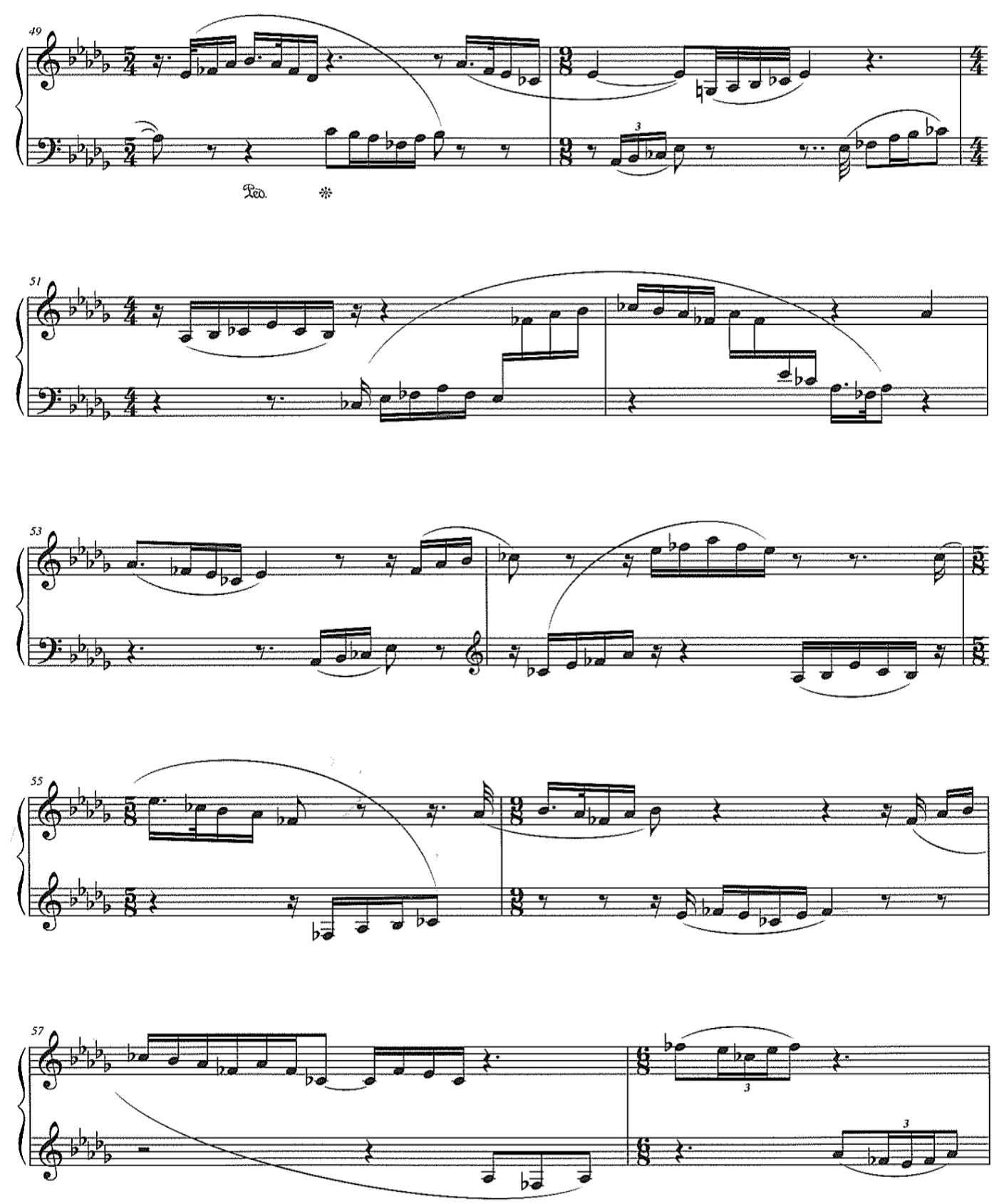

$-87-$

Figure 23: Antiphonic phrases in "The Garden of Gethsemane" (Guebrou 2013, 87).

At face value the music of Emahoy Tsegue-Maryam Guebrou may appear to have little in common with Ethio-Groove, the popular, cosmopolitan forms 
that were the soundtrack to "Swinging Addis" in the 1960s and early 1970s. However, her music actually contains many of the traditional Ethiopian elements that musicians such as Mulatu Astatke and Getachew Mekurya also used to fuse into their strands of instrumental hybridity. What is more, her compositions further expose the malleability of Ethiopian music. Its capacity to connect and combine with other genres is not restricted to AfricanAmerican soul and jazz or Latin music; this combination of traditional music with the music of early romantic music, white European composers that lived 100 years prior to Guebrou, suggests that any number of combinations was, and is, possible. To some extent her music defies analysis, as it eschews values of virtuosity or complexity, which naturally contain more theoretical material for dissemination. Instead, it contains an attractive simplicity, a quiet curiosity and a meditative power, and its true depth is difficult to illustrate in extracting and scrutinizing its parts.

The works of Mulatu Astatke, Getachew Mekurya and Emahoy TsegueMaryam Guebrou represent three very different visions of modern Ethiopian instrumental music. Where there are some elements which are, to lesser or greater degree, common and representative of an Ethiopian heritage throughout, such as the kiñit, call-and-response structures, melodic ornamentation, rubato introductions and certain rhythms (for example chik chikka), there are also differences, most evident in the choice of style and genre. Astatke's and Guebrou's music are stylistic hybrids, indicative of their international upbringings and experiences, albeit with vastly different outcomes. Astatke's cosmopolitanism led him towards the cutting edge of jazz, whereas Guebrou's more hermetic tendencies led her towards neoclassical piano composition. Mekurya, who came from a more humble background and did not have access to an international education, found a way to adapt the Ethiopian standard repertoire to Western instruments and was perhaps the first to do so while retaining all of their melodic, ornamental complexity. 
It is interesting to note that the diversity of these three musicians' styles has resulted in responses and collaborations from Western musicians from equally diverse stylistic groupings. Astatke has collaborated with musicians from both jazz and electronica genres, no doubt attracted to the Afrofuturist sonic leanings in his early music. Mekurya, despite his deep sense of traditionalism has participated in concerts and recordings by a Dutch punk band that was drawn to him because of his ferocious and combative sound and approach to performance. Guebrou was championed by a pair of Israeli avant-garde musicians working in both classical and improvised music who were attracted to the quiet curiosity of her pieces.

Where there have been numerous interpretations of these musical styles, there have also been misunderstandings as the music has travelled around the globe. Astatke's original attempts at hybridity were at times misunderstood or met with hostile opposition when in fact his music is deeply rooted in tradition. Reviewers have errantly labeled both Mekurya's and Guebrou's music as jazz when it is not. Guebrou has been surprised herself at the depiction of her compositions as containing Ethiopian influence, thinking that her pieces were of entirely European classical heritage.

Without wanting to downplay the role Ethiopian history and culture has had on the development of these three musicians, it could possibly be argued that the idea of location within their respective stories has been overemphasized, from the use of the label Ethio-Jazz through to the bundling together of such disparate artists under the Ethiopiques banner. While such exercises have done much to carve out a niche for these artists and to attract attention to this previously overlooked and undoubtedly fascinating musical location, it has tended to downplay the role that the cultural exchange has had on the music. More significantly, the music of Astatke is still not seen in context of international jazz in the 70s, alongside the likes of Miles Davis, Herbie 
Hancock or the early ECM records that were being produced in Scandinavia. Neither has Getachew Mekurya achieved renown as a saxophonist in the same breath as John Coltrane or Marcel Mule, nor will one find Emahoy Tsegue-Maryam Guebrou's name in any list of twentieth-century piano composers. By placing the music within a "World Music" category, these musicians have achieved a level of recognition, and yet it is this categorization that itself prevents the music, to a certain extent, from taking part in the global conversation that it deserves. It is perhaps this inherent tension that has led to some of the ethical problems to do with the diffusion, influence and appropriation of this music from Ethiopia over the last two decades, which will become a major theme of the following chapter. 


\section{CHAPTER TWO}

\section{INSPIRATION OR APPROPRIATION: ETHIOPIAN MUSIC GOES GLOBAL}

In the past 15 to 20 years there has been a surge of interest globally in the Ethiopian music of the 1960s and 70s. Aside from the continued performances and musical activities of the Ethiopian musicians themselves, a number of other participants have become involved in the promulgation and diffusion of this music: record labels and executives, most notably Francis Falceto and his Ethiopiques series on French label Buda Musique, and musicians and producers from around the world. Although this initially took place in the United States and Western Europe, there are now instances of musicians performing and recording Ethio-Groove from Latin America, Asia and Oceania, proving that it is a worldwide, not exclusively Western, movement. Finally, there is a considerable and burgeoning international audience for Ethio-Groove. This chapter examines some of the different ways that musicians from around the world have integrated elements derived from Ethiopian music into their own sounds. This includes sampling, playing covers, playing original music directly inspired by Ethio-Groove, and finally creating music with a less direct form of inspiration or by combining or juxtaposing various musical styles and components. It investigates some of the problematic areas and controversies that have arisen through these ventures, in part by comparing this issue with ethical debates concerning other musical styles. The size and complexity of writings on the relationship between post-colonialism and appropriation is too vast to be fully explored within the scope of this chapter, however a brief summation of these key 
concepts is offered, followed by a discussion of the issues in relation to EthioGroove. ${ }^{8}$

The practice of borrowing elements from other musical cultures by Western composers or musicians, from classical or Western art music through to contemporary popular music, has been brought into question through the development of post-colonial theory. In Edward Said's seminal 1978 text he decries the notion of orientalism as representing:

\begin{abstract}
[A] certain will or intention to understand, in some cases to control, manipulate, even to incorporate, what is a manifestly different (or alternative and novel) world. It is, above all, a discourse that is by no means in direct, corresponding relationship with political power in the raw, but rather is produced and exists in an uneven exchange with various kinds of power, shaped to a degree by the exchange with power political (as with a colonial or imperial establishment), power intellectual (as with reigning sciences like comparative linguistics or anatomy, or any of the modern policy sciences), power cultural (as with orthodoxies and canons of taste, texts, values), power moral (as with ideas about what "we" do and what "they" cannot do or understand as "we" do) (Said 1978, 20).
\end{abstract}

Viewed within this context any use of materials from the "other" by Western cultural agents such as composers can be seen as an "uneven exchange" of intellectual power. Extrapolating on this theory, by adapting instruments, melodies or rhythms, ideas or materials from an exotic other, a Western composer or musician, however well intentioned, would be perpetuating systematic cultural dominance. ${ }^{9}$ The notion of exoticism is linked to

\footnotetext{
${ }^{8} \mathrm{An}$ in depth history of writing on African music and related ethical problems can be found in Agawu (1992).

${ }^{9}$ A parallel is given by Said in his depiction of Oriental scholars: "I doubt that it is controversial, for example, to say that an Englishman in India or Egypt in the later nineteenth century took an interest in those countries that was never far from their status in his mind as British colonies. To say this may seem quite different from saying that all academic knowledge about India and Egypt is somehow tinged and impressed with, violated by, the gross political fact-and that is what I am saying in this study of Orientalism. For if it is true that no production of knowledge in the human sciences can ever ignore or disclaim its
} 
orientalism and I have used it interchangeably. Once used as a celebratory term to evoke distant cultures, the term now has negative connontations as it is thought to reinforce colonial power relations and further marginalize dominated groups. This chapter examines some of the historical examples of what can variously be seen as exoticism ${ }^{10}$ or interculturalism within Western art music and popular music in the modern era. It offers arguments for this viewpoint to be balanced within a context of hybridity and fluidity and posits that, by contrast, to neglect to engage with cultures other than one's own would be a negation of one's place in the contemporary world. By examining the specific cases and arguments surrounding this issue with regards to EthioGroove and its offshoots, this chapter discusses a range of methods, with an equally wide variety of nuance and outcomes that have occurred in recent years.

In Chapter One, Mulatu Astatke is quoted as stating, with reference to his adoption of jazz and Latin music, that "it's important to respect the different cultures you are trying to incorporate" (Astatke 2009). This present chapter attempts to come closer to a notion of exactly what it means to "respect the different cultures", if such a definition is at all possible, by examining how musicians and commentators have responded to such issues.

To look into these themes, some historical background is required to explain why the music of 1960s and 70s Ethiopia has resurfaced and what happened in the intervening period. The standard view, as put forward by Francis Falceto and other commentators, is that the 1960s and 70s were a 'golden age' of Ethiopian music before the Derg party, a militaristic Stalinist plutocracy, staged a coup and instigated a long period of repression. The Derg years,

author's involvement as a human subject in his own circumstances, then it must also be true that for a European or American studying the Orient there can be no disclaiming the main circumstances of his actuality: that he comes up against the Orient as a European or American first, as an individual second" (Said 1978, 19).

${ }^{10} \mathrm{I}$ have preferred to use the term exoticism rather than orientalism as it is less geographically specific and can be applied to any form of fetishization of ethnic groups. 
which began in 1974 and lasted effectively until 1991, involved a receding of musical practices and of the production of culture in general. While most scholars generally accept this view, there are some caveats to this historical interpretation, which are detailed within this chapter. This is then followed by a review of the events and forces that brought about the revitalization of the genre from the mid-1990s onwards. It examines some of the discourse around the tensions arising from the relationship between Ethiopian music and musicians, and various Western agents.

\section{The 'Golden Age' and the Derg Revolution}

There is no doubt that after the 1974 revolution the Ethiopian music scene was indelibly altered, but the nature of musical life before this event remains a contentious issue amongst scholars. Francis Falceto's numerous publications, including his book Abyssinie Swing: A pictorial history of modern Ethiopian music (Falceto 2001) as well as the series of reissued discs, paint a picture of a 'golden age' of Ethiopian music during the 1960s through to 1974. An aborted coup d'état in 1960 had shaken Emperor Haile Selassie. As a result he turned a blind eye to a certain degree of social liberalization in an attempt to placate the nation. The story of Amha Records, an independent record label that defied a government decree on producing music outside official channels and went on to put out many of the classic records of the period, is an indication of the possibilities of positive outcomes from political manoeuvring at the time (see Eshete, 2012). Falceto describes this 15 year period as "the most brilliant, the most productive for modern Ethiopian music" (Falceto 2001, 83) going on to describe in anecdotal detail the wild nightlife scene of Addis Ababa, before concluding: "Nothing of the golden era remains in Ethiopia in the year 2000, save for these photographic documents and a few musical recordings" (Falceto 2001, 92). The golden age theme crops 
up frequently in Falceto's writings as well as in the names of albums (Ethiopiques 1: Golden Years of Modern Music) and in interviews, contrasting heavily with his depiction of the era following the Derg military coup.

Historical and political circumstances (the dramatic Derg time) had brutally put an end to the post-World War II development of modern Ethiopian music. Almost overnight, Derg has closed and locked an incredible sequence full of explosive creativity and cultural innovation (not to mention each and every aspect of Ethiopian social life which were crushed too). After an initial hope for a good change it had briefly brought in, this criminal regime turned to become the gravedigger of Ethiopian development at large. Suspicion and paranoia became the ground for defaming, imprisoning and murdering - people as well as values. Through permanent curfew (18 years non-stop) censorship, compulsory propaganda, the modern music scene dynamism dried up (Obling, 2012).

However, the research of Ethiopian/German ethnomusicologist Timkehet Teffera suggests a more complex picture of the Derg period. Teffera portrays the early years of the revolution as one of cultural awakening and artistic liberation, with politically charged songs supporting the sweeping changes of the new regime (Teffera 2009, 3). For Teffera, it was not until 1977-78, a period known in Ethiopia as the Red Terror, that musicians and artists began to suffer under the Derg regime. When artists during these years began to raise their voices in opposition to the government they faced incarceration, torture or even execution (Teffera 2009, 5-6). Many responded to such threats by seeking refugee status abroad.

Falceto's motivations in promulgating his depiction of events in terms of a Golden Age/Dark Age dialectic are questioned by Danny Mekonnen, scholar and bandleader of United States-based Ethio-groove ensemble, Debo Band.

As great as Falceto's contributions are one cannot help but read critically his use of the term "golden age" and question his position as a white man in the west. To what extent is the label 
"golden age" a marketing strategy? How do Ethiopian musicians - past and present - understand the term? (Mekonnen 2010, 303).

In fact, the musicians involved in this study have been fairly reticent with regards to voicing their opinions on this issue in the published materials that exist, and no doubt with just reason; any political opinions or affiliations could carry negative consequences in a country that has undergone so much political upheaval in recent years. Some may have been initially optimistic at the changing situation; Mulatu Astatke's album Yekatit: Ethio Jazz refers to the month in which the Derg took over (Yekatit means February in Ge'ez) "suggesting Astatke's support for the regime" (Williams 2014). Subsequently, Astatke seems to have made slightly contradictory statements in reminiscing about the 'golden age' as quoted in Chapter One (see page 39). In one interview he talks about the Derg shutting down the music scene, in another he queries the term 'golden age' and implies that he was not personally afflicted by the military takeover. During the Derg regime Astatke was able to take on an unofficial role as musical ambassador, touring fellow socialist countries in Eastern Europe and Cuba, as well as being the musical director for the 1986 "People to People" tour which travelled in Europe and the United States in an attempt to change people's perceptions of the country which had suffered the terrible famine of the previous year. Getachew Mekurya performed with the Police Band during the Derg years but has not made mention of the political ramifications of this in the rare interviews that he has given that have been translated to English. Of the three musicians included in this study, it was perhaps Emahoy Tsegue-Maryam Guebrou who was the most affected under the new regime. Like many other prominent Ethiopian musicians, such as Girma Beyene and Hailu Mergia from the Walias Band, she was forced into exile in 1986 to escape persecution, taking up residence in Jerusalem. 
If the use of the Golden Age/Dark Age analogy is possibly a little simplistic, there is still no doubt that the music produced after 1974 was not the same as that produced before the Derg seized power, nor that the climate of fear and repression during the years from at least the Red Terror period were immense. ${ }^{11}$ The combination of factors - the depletion of top musicians through political asylum and the restrictions on concerts through an imposed curfew - led to a reduction in prominence of live music in social life. Another key factor for Falceto in what he sees as the diminishing of quality of Ethiopian music that occurred coincidentally around this time was that certain technological innovations proved detrimental to the performance of live music. Electronic synthesizers and drum machines replaced live rhythm sections in both performance and recording circumstances, which led to potentially much weaker and more static musical renditions. According to Falceto it was not the fact that new instruments were being introduced but that "it spoiled the music because the keyboard was used mostly as an imitation of acoustic instruments. With an electronic keyboard they think they can have a horn section, a string section, bass drums etc" (quoted in Eyre 2005). Thus bands became downsized, the whole world of timbre that had been built up through the 50s and 60s replaced by an artificial sound, and the role of musical arranger, integral to the 60 s and early 70 s recordings, was destroyed. At around the same time, cassettes began to replace vinyl which, while more affordable for the average listener, led to widespread piracy and consequently smaller economic returns for artists.

Two examples of these changes that occurred may be found in comparing the music of Getachew Mekurya and Hailu Mergia, pre- and post Derg eras. A cassette tape originally released in 1993 recently resurfaced on the website

\footnotetext{
11 The number of Ethiopians killed at the hands of the Derg party is estimated at around 32 000 with many tens of thousands suffering torture and persecution (Tiruneh 1997, 222-223).
} 
Awesome Tapes from Africa. ${ }^{12}$ On this recording, Mekurya is accompanied only by synthesizer/electric keyboard and drum machine, a very different textural landscape from the Negus of Ethiopian Saxophone album which featured live bands, ranging from large brass bands to small jazz/funk combos. In Negus the live drums and percussion, not to mention group interplay, are integral to the resultant sound. On the Awesome Tapes recording, the pre-programmed and stilted drum patterns give nothing for Mekurya to bounce off and yet he is able to retain his emotive sound, however subdued. Hailu Mergia was a keyboard player and accordionist who led one of Ethiopia's most popular bands in the 1960s and 70s, the Walias Band (which also featured luminaries such as Mulatu Astatke and Girma Beyene). Their release Tche Belew (recorded in 1974 and released in 1977 just before the "Red Terror" began) was a classic of Ethio-Groove, with heavy funk feels and polyrhythmic, intertwining melodic lines. Mergia's 1985 solo cassette Hailu Meriga and his Classical Instrument is altogether different; it is a one-man-band affair, with Mergia providing melodies, chords and bass lines on his Yamaha DX7 synthesizer, Rhodes piano and accordion, and again with a pre-programmed drum machine instead of live drums. These later albums are not without their charms. Indeed, restricted to this limited instrumentation, master musicians like Mekurya and Mergia are able to create fascinating curiosities, which, if not as striking as their "golden age" recordings, are no less unique. Indeed a comparison of their music across the two periods both proves and disproves Falceto's statements; the later albums lack perhaps the vitality and impact of the 1960s and 70s live band albums, yet these musicians moved into more introspective and arguably more experimental areas due to their imposed solitude. While Falceto was no doubt talking more about mainstream Ethiopian pop when he talked about the "heavy impoverishment of music production" (quoted in Obling 2012) post-revolution, these little known

\footnotetext{
12 The title is a little unclear but could translate to "Getachew Mekurya - Modern and traditional instrumentals". Sourced from http://www.awesometapes.com/getatchewmekurya/
} 
cassettes prove that some practitioners continued to innovate during some of the darkest of times.

\section{Ethiopiques}

Francis Falceto was a free jazz and experimental music concert promoter before becoming aware of the Ethiopian singer Mahmoud Ahmed in 1984. The following year he flew to Ethiopia to strike out a deal to release a compilation of Ahmed's music on a double LP named Ere Mela Mela (1986) on Belgian label Crammed Discs. After the relative success of this release, Falceto determined to release Amha Records' full catalogue, organizing for the rights to be purchased from exiled Ethiopian record producer Amha Eshete by the record label Buda Muqsique, for which Falceto was employed as a curator or editor. Unfortunately, Eshete did not have the correct documentation to allow the retrieval of the discs and the pair were obliged to wait for the fall of the Derg period to begin hunting down the lost master tapes (see Eshete 2012). These were eventually discovered in Athens after a considerable effort to find them, and the Ethiopiques project began in earnest in 1997. To date, 29 albums have been released in the series, with Falceto's work being a key factor in the revival of interest in Ethiopian music and culture.

Initially, I would have never thought I was dealing with preserving a unique musical legacy. I just wanted to present to a general and world audience one of the last great musical styles from Africa unknown outside of its national borders or outside of the Ethiopian diaspora. It's little by little that I understood I was dealing with Ethiopian heritage and its preservation, just by seeing the state of contemporary Ethiopian music, and realizing that there had been a huge musical gap between before and after the Derg (quoted in Obling 2012). 
Falceto's timing could not have been better: the Ere Mela Mela re-release coincided historically with the advent of the "World Music"13 phenomenon, whereas the Ethiopiques series just managed to anticipate the second wave of international interest in African music, one which valued vintage recordings with acoustic instruments and rejected the studio produced "new age"14 or "world beat" 15 hybrids of the late 80 s and early 90 s.

Ethiopiques became a slow-burning success, mainly releasing music from the 1950s, 60s and 70s, with whole albums dedicated to the music of Astatke, Mekurya and Guebrou respectively. These albums in particular resonated with audiences in the West, no doubt due to the fact that they were instrumental, lending the music a certain universality. Their popularity increased exponentially when Ethiopiques music featured prominently in the Jim Jarmusch film Broken Flowers (2005).

However, the Ethiopiques project has not passed without controversy. Danny Mekonnen (2010) is strongly critical of Falceto's role as Western mediator of Ethiopian music for international audiences. Linking Falceto's Crammed Disc record to other early "World Music" projects such as Paul Simon's controversial Graceland record (1986), Mekonnen laments that "Falceto's access to capital, technology and marketing resources is incommensurate with those of the Ethiopian musicians and producers with whom he works" (305). For Mekonnen, Falceto is "a privileged white man [who] brought Ethiopian music to Western audiences in the same way Simon increased Western exposure to South African music through Graceland" (306). In fact the two cases are barely comparable. As Mekonnen admits, Falceto did nothing to

\footnotetext{
13 Taylor (1997) and Feld (1994) thoroughly dissect the creation of the "World Music" category by record label executives in the 1980s in order to promote non-Western music under one banner, and analyze the ensuing problems that arose from this strategy.

14 Enigma's "Return to innocence" or Deep Forest's "Sweet Lullaby" are examples of this type of production.

${ }^{15}$ See any of Youssou N'dour's 1990s work for an example of an African artist involved in world beat.
} 
influence the music, nor did he superimpose his own name, lyrics and ego on top of an Ethiopian band in the way that Simon did with Graceland. What is more, the Graceland album was also hugely controversial because of Simon's disregard for the boycott of South African apartheid in place at that time Simon's ethical ambiguity in this regard does not have a parallel with Falceto's dealings with Ethiopian music. Falceto's response to such criticism of his position as a white mediator of Ethiopian music is noteworthy: "The simple truth is that I did it because I could not see anybody, Ethiopian or foreigner, intending to do so. I would really love to be just a purchaser of ready-made Ethiopiques, re-released by anybody else, and in a nicer way if possible. I would avoid then many headaches and complications" (Falceto 2012). ${ }^{16}$ With Falceto's efforts came considerable editorial decisions, which doubtless elevated some musicians' fortunes above others, but the exposure and subsequent success that many Ethiopian musicians had, must surely outweigh the negative aspects of the operation. Indeed, some of the artists who received less initial exposure from Ethiopiques, such as Girma Beyene and Hailu Megia, are now also beginning to tour worldwide. The immensity of the Ethiopiques project (currently at 29 albums) is a remarkable record of a nation's musical heritage, and represents an assemblage of documentation that is unparalleled in other African nations' discographies. While immediate recognition for the content must always be given to the musicians themselves followed by the original record producers such as Amha Eshete and Ali Tango (Kaifa Records), a great degree of respect must also be given to Falceto's Ethiopiques project for its collative work.

What is brought to light in these debates is that any such association between Western agents and artists from a non-Western country such as Ethiopia is a perilous operation for all involved. Record producers are treated with

\footnotetext{
16 Falceto has also had the financial integrity of the Ethiopiques project questioned, accusations he has vigorously denied (Falceto 2012). Without any material evidence presented by the accusers, this author has decided to omit the discussion from the thesis as speculation.
} 
inevitable suspicion while musicians fear losing control of their artwork and being exploited. Meanwhile there is no shortage of commentators ready to add fuel to the fire. The initial impulses of curiosity and fascination that bring about such collaborations and associations can easily turn sour when power imbalances are highly visible.

\section{Inspiration or Appropriation}

One of the unexpected outcomes of the Ethiopiques series is just how popular the music would be amongst musicians abroad, to the extent that there are bands playing Ethio-Groove, or having been inspired by it, from the USA (Either/Orchestra, Budos Band, Debo Band, Antibalas), France (Akale Wube), Switzerland (Imperial Tiger Orchestra), Germany (Karl Hector and the Malcouns, Woima Collective), Columbia (Transgressors), Brazil (Iconili), Australia (Black Jesus Experience) and New Zealand (Shogun Orchestra). This list is by no means exhaustive. Indeed, Mekonnen and Falceto are united in observing that the majority of Ethio-Jazz is being developed by ferenj (foreign) musicians, rather than Ethiopians, although there are some, such as the pianist Samuel Yirga or the saxophonist Jorga Mesfin from the current generation of Ethiopian musicians, who are exploring this tradition.

The following part of this chapter looks at a selection of representative individual pieces which can be seen as responses to Ethiopian instrumental music. It examines what has been borrowed from Ethiopian music in these new renditions, speculating on the intentions of the artists in each case, and explores any issues, ethical or philosophical that may have arisen from these creations. At times it compares them with similar cases in other musical genres that have generated public or scholarly discourse, or controversy. 


\section{Covers}

In Western cultures, playing cover renditions of pieces or songs is broadly speaking a way of identifying with a certain tradition, style or a certain musical ancestor or peer. The status of such a practice varies from genre to genre. In classical music, performers generally only play the music of other composers. In jazz, a mixture of original music and standards is a common method of displaying both innovation and connection to tradition, slightly contradictory values that nevertheless tend to coexist. In popular music, the addition of too many covers can be frowned upon, as individualism tends to trump any notions of a collective connection with the past - however it is not uncommon for artists to augment their set with one or two covers to demonstrate their musical affinities. But when playing the music of another culture, the idea of playing covers takes on another dimension of complexity to do with cultural ownership and understanding.

It would be difficult to understate the importance of tradition within the

multifarious strands of Ethiopian music. For example, the entire body of liturgical music of the Ethiopian Coptic church is said to have been created in the $6^{\text {th }}$ Century by the semi-mythical figure Saint Yared through divine inspiration, and this chant tradition has been transmitted and endured throughout the centuries (Teffera 2008, 1). Even within Mulatu Astatke's cosmopolitan and internationalist Ethio-jazz one can hear echoes of this tradition, such as in his piece "Dewel", invoking the gongs used to summon worshipers to church. In secular music as well, tradition plays a key role and it is not uncommon for musicians, such as in the case of Getachew Mekurya, to base their entire repertoire on traditional songs whilst finding their own unique voice within the confines of interpretation.

However, many ferenj (foreign) musicians around the world have opted to invest their energies in Ethiopian music because of affinity rather than an 
inherent sense of tradition. A number of groups have taken on the challenge of learning the repertoire of Ethiopian 'golden age' music. Although Mulatu Astatke's music, which is closest to jazz and more familiar Western forms, is the most frequently covered music, groups such as the Ex and Akale Wube have reinterpreted some of the classics performed by Getachew Mekurya. Perhaps the most covered piece in the repertoire comes from the Walias Band (of which Astatke was an occasional member), "Musicawi Silt" ("Modern Music Style") by prolific composer and arranger Girma Beyene. For Mekonnen, "Musicawi Silt" "serves as the locus of Ethio-Groove's fundamental stylistic and compositional model" (Mekonnen 2010, 307) as it brings together many of the elements that have made this style popular. Specifically, the piece (transcription appendix 15) uses: a simple and catchy melody based on a tizita minor scale; a polyrhythmic funk feel, which is unusual in that while some members of the band play an ostinato figure in $3 / 4$, the horn melody and guitar figure are in $4 / 4$, so that the band metrically synchronizes every 12 beats; a classic Ethio-Groove instrumentation of trumpet and tenor saxophone with an electrified rhythm section including organ and electric guitar; a swirling organ solo, invoking the melismatic and ornamental traditions of Ethiopian secular music.

For some groups, such as New York based Antibalas, pieces such as "Musicawi Silt" have been a stepping-stone towards creating original music. Other groups, such as the Either/Orchestra or Akale Wube have developed an entire repertoire out of Ethiopian classics, leading to collaborations with Ethiopian musicians. Still others look to re-imagine the classics in a new context with the Secret Chiefs 3 electronic version of "Musicawi Silt" being a prime example. However, the latter's renaming of the song Safina can only be described as a misguided attempt to claim ownership over something that was not theirs, even if the version does take the song in an overall different direction. 
While "Musicawi Silt's" relatively simple melody lends it an easy familiarity for Western groups to cover, some have also attempted more ambitious material, with varying degrees of success. Non-Ethiopian bands have sometimes come unstuck when attempting to cover more traditional Ethiopian pieces. Below is a transcription of the traditional Ethiopian song "Almaz Yeharerwa" as covered by French band Akale Wube with the melody performed by their baritone saxophonist Etienne de la Sayette, followed by the same melody performed in original form by Getachew Mekura.

Baritone Saxophone

Almaz Yeharewa

Ethiopian Trad. Performed by Akale Wube
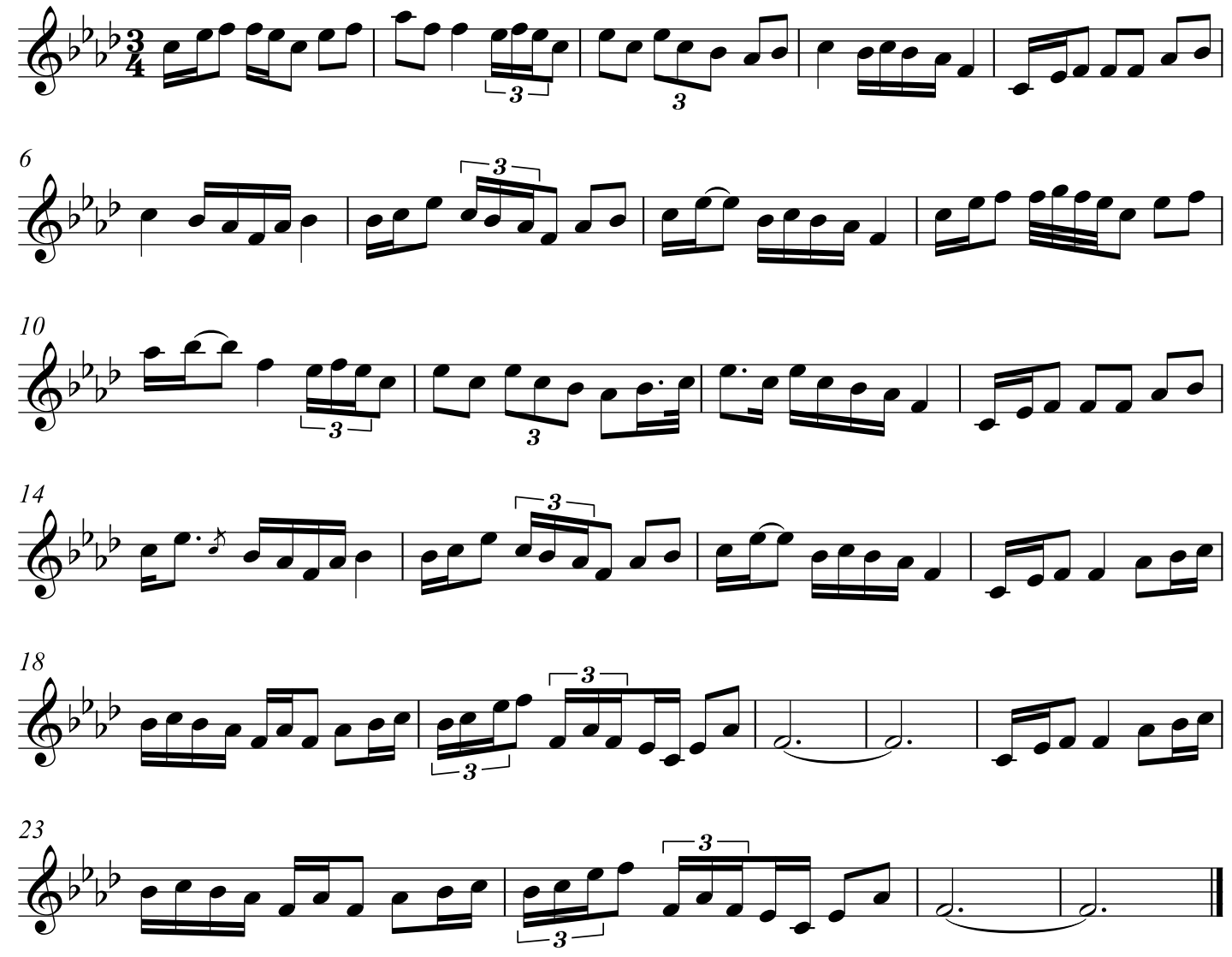

Figure 24: "Almaz Yeharerwa", as performed by Akale Wube (appendix 16). 

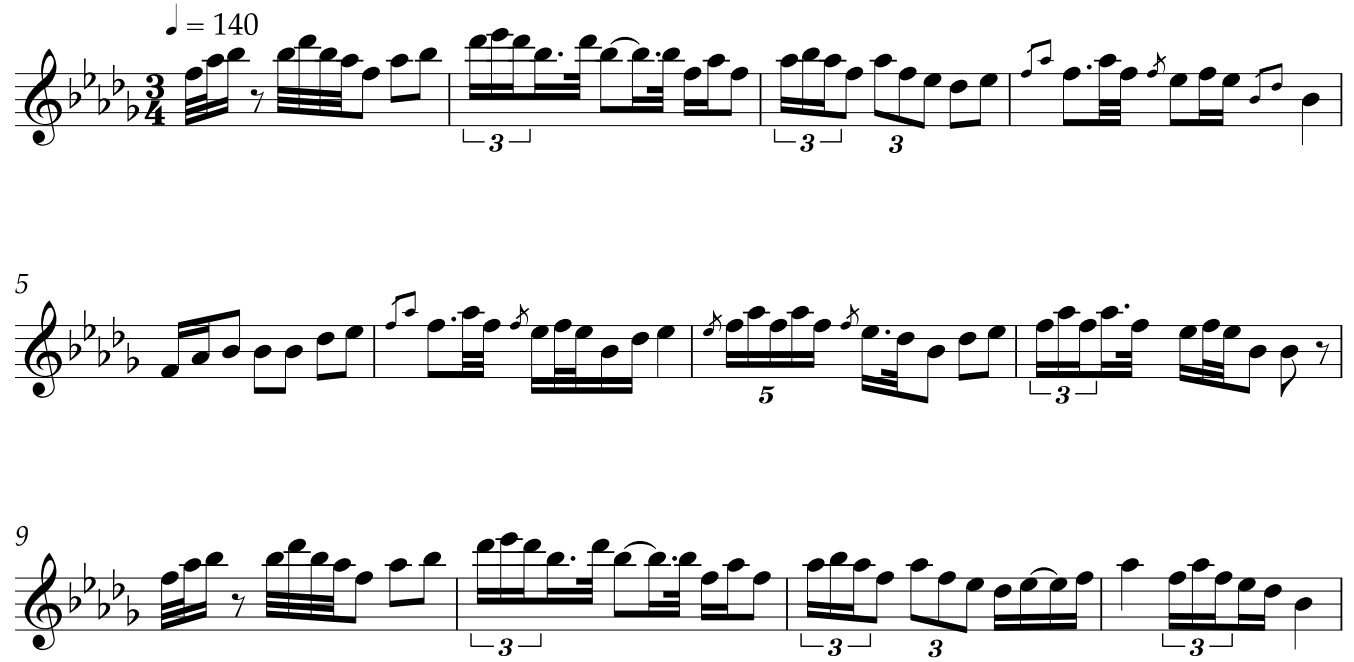

Figure 25: Beginning of Almaz Yeharerwa, as performed by Getachew Mekurya (full transcription appendix 12).

Mekurya's version, from his Negus of Ethiopian Sax album, contains a significant amount of melodic complexity through the use of ornamentation and demonstrates his intimate knowledge of the melismatic approach to melody derived from Ethiopian traditional vocalizing. By contrast, in Akale Wube's version many of the grace notes and the rhythmic variation have been omitted, along with the driving intensity of Mekurya's playing, making for a far less captivating listen.

The aims of making cover versions can be the preservation and revitalization of a tradition and, in the case of Ethiopian "golden age" music, the diffusion of this tradition to new international audiences. Akale Wube for example, have played over two hundred concerts around Europe, Asia and Africa including collaborations with Ethiopian musicians and dancers and claim themselves to be "one of the world's leading ambassadors of Ethiopian groove." 17 Covers can also be a stepping-stone, a method for musicians to learn about the materials and devices of the Ethiopian musical traditions,

17 Recovered from Akale Wube website http:/ / akalewube.com/info.html, sourced 02/03/17. 
before moving on to create their own music, as is the case with some of the bands that have covered "Musicawa Silt" such as New York based groups Antibalas and the Daktaris. However, especially where recording is concerned, it seems it has proved extremely difficult for groups to recapture the charm and nuance of the original versions, and one wonders if in most cases this goal is unattainable. When coupled with a sense of ownership, as Akale Wube's "world's leading ambassadors" statement belies, or the Secret Chiefs 3 renaming of intellectual property that was not theirs, bands move into dangerous ethical territory, which is both misrepresentative and appropriative of the culture they are intending to honour.

\section{In the Style of...}

A common phenomenon in recent years has been bands that have been inspired by Ethiopian music, specifically the Ethio-Jazz of Mulatu Astatke as well as the harder funk sound of the Walias Band, creating their own music in these styles. More often than not these groups have used the Ethiopian sound as only one element of their repertoire, also playing other African genres (usually Fela Kuti-derived Afrobeat) or funk. In rare cases though, bands have almost exclusively investigated Ethiopian music, such as German band Woima Collective's first album Tezeta (2012), a brilliant, if little known addition to the Ethio-Groove canon.

On the face of it, such projects surely add currency to the world of Ethiopian music. The amount of actual content in terms of instrumental Ethio-Groove is fairly limited: a couple of Mulatu Astatke records, one by Getachew Mekurya and one by Hailu Mergia and the Walias Band. With such a small amount of music available in this genre, it would seems logical that more musicians may want to contribute to extending this tradition. 
Inevitably though, the movement has not been without its detractors, most notably Danny Mekonnen (2010). Mekonnen takes particular aim at New York based group The Budos Band, who, like Antibalas, are part of the Daptone label that has specialized in creating vintage sounding black genres, from soul to reggae and Afrobeat.

The Budos Band's sophomore album, The Budos Band II, is one of the first Ethio-Groove albums to feature mostly original compositions. While one could argue that the entire album is an example of the Ethio-Groove phenomenon four compositions in particular most clearly exhibit an Ethiopian influence...What's left to be seen is if the Budos Band will acknowledge any of this formally. Every band has a unique narrative and for the Budos Band Ethiopian music has not been one of the "keywords" to emerge in their biographies. What is at stake in the Budos Band's omission of this disclosure? (Mekonnen, 309).

While the intention of trying to direct credit towards Ethiopia's musicians, so many of whom remain under-recognized, is commendable, Mekonnen's argument for acknowledgment seems difficult to put into practice and his singling out of Budos Band in particular appears unwarranted. Musicians or composers have never been obliged to officially list all their influences when creating original music and to attempt to do so thoroughly would border on the ridiculous. Even in the case of Budos Band, Mekonnen acknowledges Ethio-Jazz is far from the only influence that they reference in their compositions. If they were to list Mulatu Astatke and Hailu Mergia, then surely they should also doff their caps to Jimi Hendrix, James Brown, Tito Puente and any number of other musicians to have had direct or indirect impact on their sound?

This issue does, however, touch on what appears to be a recurrent problem for Ethio-Sonic (or African revivalist) bands. Namely, once the music has been created and the influences assimilated, how is the music to be presented? No doubt in all these cases the adoption of another culture's music comes from a 
sense of passion for that subject - the amount of work required to learn it would rule out any other motivation - but does that adoption then provoke some kind of crisis of identity, or ethical dilemma, for the musicians concerned?

A scan of some Ethio-Sonic groups indicates that playing on the idea of "exoticism" - with varying degrees of self-awareness and irony - shows this approach still appears to hold a fair degree of currency. Australian group The Black Jesus Experience mostly play from the Ethio-Groove songbook along with some original music, and have accompanied Mulatu Astatke on his Australasian tours. They have one member of Ethiopian origin and have been on trips to Ethiopia to perform and collaborate with musicians there. In Ethiopia they purchased traditional attire and regularly perform adorned in shirts made from shemma cloth. ${ }^{18}$ Presumably this is intended to demonstrate what the group sees as solidarity with Ethiopian culture and to show that they have a connection to the country through having been in situ. However in assuming the costume of traditional customs, The Black Jesus Experience may be treading a fine line between acknowledging and fetishizing another culture. ${ }^{19}$ That line is distinctly crossed by the cover art of their latest album Cradle of Humanity (2016), with an image by a white Australian illustrator, John Ryrie. Naked African figures, with oversized, cartoonish arms surround the musicians wildly gesticulating; their postures resemble nothing one would ever witness in traditional Ethiopian dancing. Regardless of intentions, such imagery appears to be playing upon outdated and, indeed racist, notions of Africans as primitives.

\footnotetext{
18 I was invited to perform as guest artist with Mulatu Astatke accompanied by the Black Jesus Experience at the 2016 Wellington Jazz Festival. My knowledge of their dress code and their time in Ethiopia stems from this meeting.

${ }^{19}$ See Tate (2003) for a discussion on the appropriation of black culture.
} 


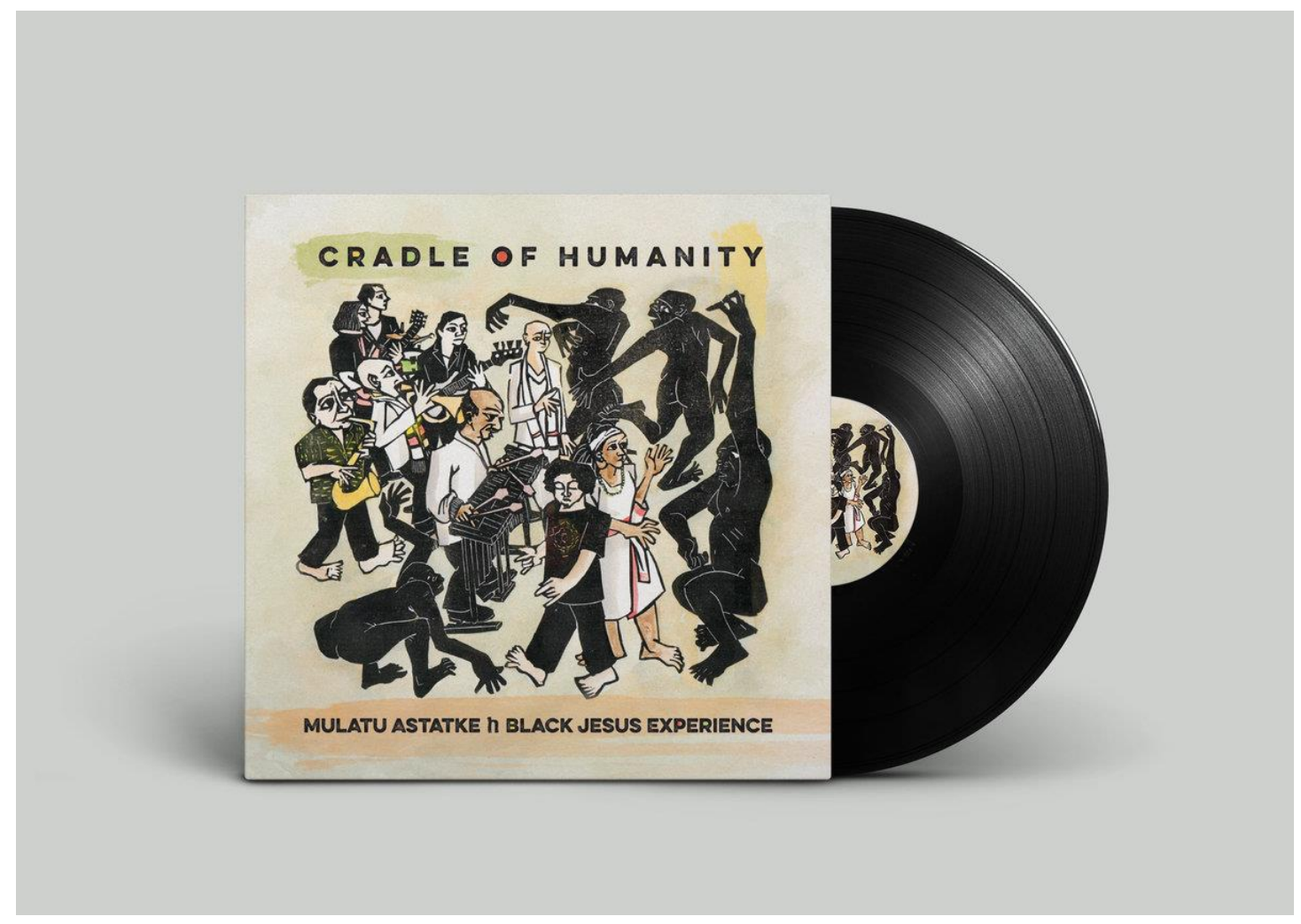

Figure 26: Cradle of Humanity (2016) album cover by the Black Jesus Experience.

New York's Antibalas (another Daptone group), perhaps the most successful of all modern day vintage African offshoot bands, consistently use photos of the band in suits and African animal masks in various locations; around a dining table or in a subway. The images consciously play on the two cultures being syncretized in the band's music; a contemporary urban, cosmopolitan society juxtaposed with a clichéd or commodified vision of African wildlife.

The postmodern consumerist kitsch of the masks is an ironic gesture, alluding to the idea of authenticity, or how we perceive it. Antibalas are notable as a band for having faithfully reproduced the sound of 1970s Africa, paying scientific attention to every detail from brass arrangements to keyboard tones to recording techniques in order to match the sonic signature of the original records. Even for experienced listeners it can be sometimes hard to tell their records apart from unknown Fela Kuti instrumental or a lost side from the Walias Band. The masks disguise the fact that they are by and large a white 
band from New York and yet they are also so inelegant as to point to that very fact. The band is ironically drawing attention as to how Africa is perceived in the West - an exotic place full of fruit and wild animals. They could also be making a joke about how white musicians playing black music are perceived - never as anything more than a cheap imitation.

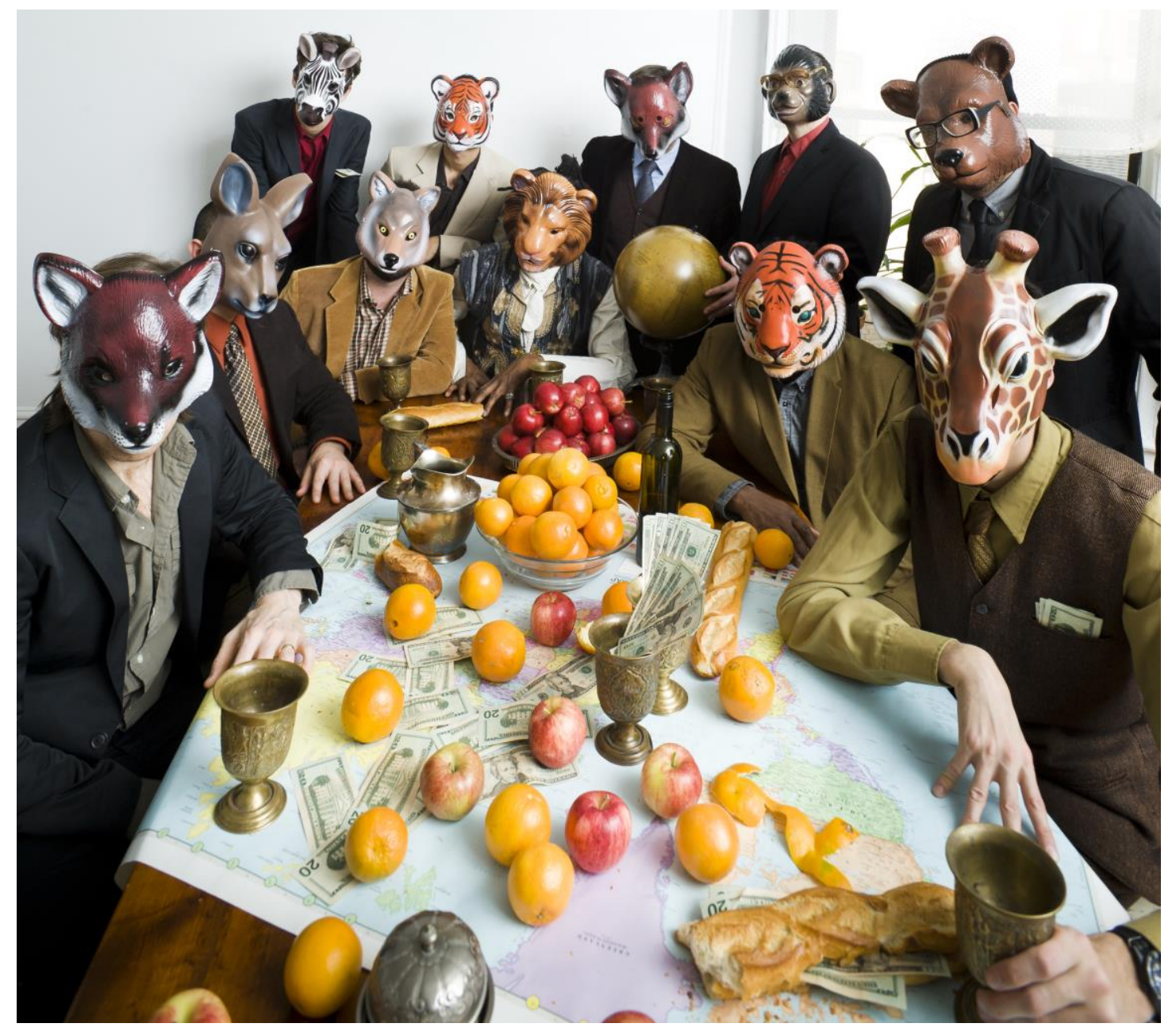

Figure 27: Publicity photo of Antibalas.

Ultimately though, The Black Jesus Experience and Antibalas are examples of the same trend - a revivalism of African music from a very distinct time period - albeit with different levels of nuance and awareness. To cleverly frame such projects in a witty manner cannot conceal the feeling that there is an inherent tension in these musicians' labours. The path they are treading has already been laid out for them by various African musicians half a 
century ago. Without a new juxtaposition of genre or elements, even when they are making original music, the music cannot truly be said to be original.

Commentators have begun to question whether the resurgence of music in the past decade or so styled after that of the 1960s and 70s is superficial and opportunistic. As Michael Veal, a musician and ethnomusicologist, states in response to Afro-funk revivalism (with particular reference to Fela Kuti's music), "the current interest of American record companies in African pop smacks of a fad, an attempt to maximize short-term saturation of a particular niche market" and he attacks the music as being "defanged of its political baggage" (Veal 2004, 30). These criticisms are plain to see in the case of Afrobeat and Fela Kuti's music. ${ }^{20}$ However, in Astatke or Mekurya's instrumental music, any political message is not as immediately striking. ${ }^{21}$ Where the politics are either ambiguous, or simply not present, should Western covers or sound-a-like bands need to pay attention to such "defanging" as Veal has put it, or to be aware of their "White man's privilege" as Mekonnen has argued? These questions have no definitive answer, but raising them contributes to a growing consciousness around the issues of appropriation, of African musical styles in particular. Any artist's attempt to take inspiration from the music of another culture would do well to pay close attention to the nuances of the music itself, as well as to its contextual meaning and political ramifications. It would also do well to find a way to present its music while considering and acknowledging its debt to that music's origins; for some such as Mekonnen this includes crediting those origins publicly. The idea of costume while on stage and in publicity photos is

\footnotetext{
${ }^{20}$ For example a New Zealand band which performed Fela Kuti's music in the 2000s, The Scribes of Ra, did so without vocals which of course removed the highly political lyrical content from the music.

${ }^{21}$ Many Ethiopian singers, most notably Teddy Afro, use their song writing to express political dissent, however these messages have not travelled as well as Fela Kuti's music in no small part due to the fact that Kuti sings in English whereas Teddy Afro's music is in Amharic.
} 
a delicate issue and any accompanying visual materials such as cover art need, in this context, to be thoroughly thought through.

German group Woima Collective's first album Tezeta (2010) is a homage to Ethio-jazz, containing all original compositions based on the different kiñit, albeit with contemporary Afro-funk rhythms and perhaps a touch of a Balkan brass influence. Woima Collective may not have had the commercial success or exposure of Antibalas or Budos Band, but their first album must rank among the most significant of Ethio-Sonic recordings, and is one of the few that could happily sit beside the likes of Mulatu Astatke, Getachew Mekurya, and the Walias Band in the wider genre of modern Ethiopian instrumental music. By not placing emphasis on exoticism in the music they created - their biography details in fairly unromanticized terms their bandleader Johannes Schleiermacher's travels and research in Africa ${ }^{22}$ - Woima appear to have made a record without pretenses as well as one with obvious musical homework behind it. Such an approach sees cultural differences and exchange as a normal part of globalized contemporary life, and one that does not have to be dressed up or promoted as anything other than what it is.

\section{Sampling}

The use of sampling in music, which originated and has thrived in hip-hop in particular, has brought the issue of plagiarism to the surface. A defense of such practices is ethically built on the idea that "this version of meaning, originality and authorship is located within a Western cultural and historical tradition which stresses creative and possessive individualism" (Pennycook 1996), and that such concerns are inapplicable, or indeed oppositional, to black music practices. In this context, sampling can be seen as an extension of

\footnotetext{
22 Information recovered from Woima Collective band website http:/ /www.woimacollective.de/.
} 
"the riff", which for Leroi Jones (1963) was the mimetic cultural attribute which formed the basis of jazz and blues music. The use of sampling in hip hop as a radical political tool rather than an appropriative one is commented on by Tillet when she argues that, "through its extensive citation of recorded songs and sounds, sampling has always posed a threat to capitalist notions of public and intellectual property" (Tillet 127, 2014). This viewpoint is developed further by Goodman: "The contagious vibrations, sonic processes, and market tactics of strains of popular music within the African diaspora both extend the concept of an audio virology and offer a tactical outline of an affective mobilization as opposed to the modulation of preemptive capital" (Goodman 2010, 155).

It is not surprising then, that some of the most strident attacks of sampling culture have taken to task examples which consist of Western commercial musical productions using samples from "World Music" sources, rather than the ubiquitous use of samples in hip hop, in which there are deeper political and cultural resonances to take into account than the appropriation of one artist's work by another. Steven Feld (2000) details the story of Sweet Lullaby, a track by Deep Forest that featured an unlicensed sample of the song of a Solomon Islands woman named Afunakwa (incorrectly presented by Deep Forest as a Pygmy rainforest sample). For Feld, the episode was a potent example of the abuse of minorities and indigenous culture by "the dream desires of technological and artistic elites [which] are jolted by market cycles of agitated wakefulness. Then, blanketed in promotion, they are once more cradled and lulled on a firm mattress of stark inequities and padded mergers, and nurtured at the corporate breast" (Feld 2000, 168).

A difficult question arises out of these examples: is it acceptable for essentially the same appropriative practices to be condemned or revered depending on who is doing it? In other words, does a sense of belonging to an oppressed minority justify individual cases of appropriation, where an instance of the 
same practice by a member of a dominant culture is denounced? Extrapolating further, why have commentators such as Mekonnen directed their criticism at bands such as Budos Band for referencing Ethiopian tonalities in their compositions, rather than questioning the far more direct and much less musically and culturally engaged exploitation of Ethiopian recordings via the sampling of it in hip-hop and electronic dance music?

In Tillet's examinations of the use of Nina Simone's voice in hip-hop, she celebrates the use of sampling, stating that "Simone becomes a sonic ideal for hip-hop artists who want to engage in aesthetic experimentation and launch a sociopolitical critique against the long history of black disenfranchisement" (120). Thus, the use of Nina Simone's voice has political significations with which artists such as Lauren Hill and Kanye West invoke an ongoing political discourse and a sense of historical black solidarity. One would be hard placed to uncover such discursive double meaning, however, in the many instances Mulatu Astatke has been sampled, the most well known of which was Nas and Damian Marley's sampling of the classic 1969 piece "Yegelle Tezeta", in their hip hop collaboration "As We Enter" (2010). "Yegelle Tezeta"'s tight groove and memorable organ riff make it ideal fodder for hip-hop producers, and in "As We Enter" the two bar sample forms the basis for the entire track over which the vocalists rap. "Yegelle Tezeta", means "my own memory", but any reference to this, or to the Ethiopian origins of the song, are forgone in Nas and Marley's lyrics which focus on a largely self-congratulatory parade of each other's credentials:

\section{Damian Marley}

You the Jamrock, the lyrical official

Send out the order, laws and the rituals

Nas

Burn candles, say prayers, paint murals

It is truth, we big news

\section{Damian Marley}


Break past the anchor, we come to conquer

Man a badman we no play Willy Wonka

Nas

I got the guns

Damian Marley

I got the ganga

It seems evident from the lyrics that these artists had no intention of acknowledging in any way the music which underpins their performance. The lyrics cannot be said to have any broader political meaning, and the rap is simply imposed on top of Astatke's track.

Determining whether or not the economic rewards of the piece reflected Mulatu Astatke's presence in the music is beyond the scope of this study. However, it is clear that in terms of artistic recognition, such practices lead to misconceptions around the true composers of the music. For example, in Pitchfork, a reputable online popular music magazine, "As We Enter" was given a glowing review:

The track is a brisk little workout, with Nas and Marley kicking unforced slick talk, bouncing the flow back and forth between each other in that old Run-D.M.C. tag-team style... The beat keeps everything moving at a quick little clip without sacrificing vintage-soul atmosphere; those horn stabs at the beginning are great. Everything about the song is warm, easy, and lived in (Breihan 2010).

It seems incredulous that the "vintage-soul atmosphere" and the "great horn stabs" are entirely the work of Mulatu Astatke and his band, yet this is not once acknowledged, let alone recognized, by the reviewer; in his eyes the genius comes exclusively from the pens and voices of Nas and Damian Marley. 
The interconnected arguments that hip hop and black music in general have a less individualistic approach to cultural ownership and that sampling is used in part to purposefully threaten Western capitalist notions of intellectual property make for compelling reasoning. But in this particular case - which is actually probably a far more common representation of hip-hop than the Nina Simone example, used by Tillet above, in which the sample is used for historical, political reasons - does nothing to support such views. "As We Enter" is an exercise in the self-aggrandisement often noted in hip-hop and, as a song which reached number 18 in the US R\&B/hip hop charts ${ }^{23}$, it is not exactly an anti-capitalist statement either.

For his part, Mulatu Astatke is fairly diplomatic about the fact that his tracks seem to be continually being reworked in this manner. "It brings young people to the music", he says, "and eventually the young people come around to check out the real thing" (Johnson 2016). It is quite possible that Astatke has realized that no amount of rallying against the use, or misuse, of his work will stop it happening and that it makes more sense to accept it and give it his blessing than to vocally denounce it.

A recent development in Ethiopian music merits mention: the birth of the Ethiopiyawi movement. In this Addis Ababa-based scene, electronic music producers such as Mikael Seifu and Endeguena Mulu have used primarily samples and original recordings of traditional Ethiopian music and instruments (such as the krar, washint and masenqo) as their source material, in a cut-up, collage manner. The production techniques, using software such as Ableton, are not dissimilar from that of contemporary producers at the forefront of the current experimental hip-hop scene in the United States such as Flying Lotus. A popular and significant underground movement in the current Addis Ababa scene, Ethiopiyawi shows that Ethiopian music continues to evolve and synthesize in all sorts of different and unexpected

${ }^{23}$ Nas and Damian Marley - As We Enter - Music Charts". Acharts.us. Retrieved 2012-01-14. 
directions. The originality of the work of Seifu and Mulu shows that even if sampling can be employed by some as an easy shortcut to making new music, in another's hands it can be a route to musical transcendence.

\section{Musical Transformation}

There are numerous cases in which composers from the Western art music tradition have taken inspiration, either philosophical or technical, from a musical culture and adapted these principals to their own musical concerns. In most of these cases, the resulting music remains firmly within a Western "classical" tradition, largely due to the fact that historically it has tended towards the transformation of musical materials to Western instruments, and thus the timbres and tunings of the original instruments become somewhat lost in translation. Although there seem to have been few, if any, examples of this process with regard to Ethiopian music, it seems pertinent to discuss some of the historical examples of Western art composers' dealings with musical cultures outside of their own. Many of such experiments have been questioned ethically on the grounds of exoticism. I have chosen call this process "musical transformation" for want of a neutral term from which to attempt to analyze the issues from a place of objectivity, as much as I can given my own background. This section looks specifically at two examples of this phenomenon: Steve Reich's adoption of Ghanaian drumming practices and Olivier Messaien's study of Indian classical music. Firstly though, it gives a summary of Western composers' use of musical materials from other cultures, how this relates to the idea of exoticism, and some previous debate surrounding this issue.

While this chapter section risks casting Western composers in one bracket in opposition to all "other" music, it is important to discuss these cases as historical precursors to the debate on musical appropriation. They are also important to discuss in terms of the transformative nature of the influences 
involved - they represent a far less literal interpretation of musical materials than the cases presented in the subsections "Covers" or "In the Style of..." and as such represent an alternative method of amalgamating influences in one's original music. This section should be read however in the context of all the other instances of musical exchange presented in the thesis. Many of these instances, for example the sampling of Astatke's music by Nas and Damian Marley, or the integration of Western romantic piano traditions in the music of Emahoy Tsegue-Maryam Guebrou, demonstrate that the issues of appropriation and cultural ownership are fluid and multi-faceted, and indeed are more nuanced and complicated than a simple narrative of the West versus the rest.

The use of exotic materials in musical composition began, in a modern sense at least, with the French impressionist composers, notably Debussy and Ravel. Debussy's "Pagodes" (1903) is often cited as an exposition of his research into Javanese gamelan music with which he had become acquainted with after hearing touring ensembles perform at the Paris world fairs of 1889 and 1900. The piece employs several elements borrowed from gamelan music, including pentatonic scales, ostinato figures in the bass and certain rhythmic characteristics. According to musicologist Richard Mueller,

Debussy interpreted Javanese music as a Western composer. He unconsciously chose those elements to which he could relate. The influence of Javanese music on this work, then, amounted to compositional emphasis placed on elements that seem, to us, to coexist in both music systems. This is illustrated most clearly by Debussy's use of the pentatonic and whole-tone scale forms (Mueller 1986, 159).

As is the case with traditional Ethiopian music, the Javanese scales, such as the slendro scale, are not tuned to Western equal temperament. Thus the pentatonic scales employed by Debussy were at best approximations of the 
tonal sound of Javanese music. ${ }^{24}$ This, and the fact that pagodas themselves are a Buddhist temple that would not have existed in Indonesia at the time, are examples of what can be seen as a reductionist approach to interculturalism and a form of exoticism.

Arguments continue to rage over the success or failure of "Pagodes", or whether or not it should be seen as masterpiece or pastiche. Some commentators have remarked upon how effective Debussy was in evoking the sound of the gamelan through his harmonic skill and clever use of timbral blurring through the use of sustain and soft pedals (see Parker 2012). For Parker, "what emerges is not a vague impression, but, rather, a remarkably successful rendition of the Eastern gamelan on the Western piano." Other scholars however have viewed "Pagodes" in a very different light, as Roy Howat's comments attest to:

Several people familiar with Indonesian music, but not technically specialized in it, have viewed Pagodes as very gamelan-like, whereas some Western specialists in Indonesian music strenuously deny the kinship. In short, the newcomer, viewing the canvass from afar, is most struck by the affinities, while the specialist, close up with a magnifying glass, is all too aware of the differences (Howat 1994, 54).

Later composers, such as Lou Harrison, were to extend upon Debussy's affinity for Javanese traditions by composing music for a combination of Western instruments and gamelan, such as his work Double Concerto for Violin and Cello with Javanese Gamelan. Harrison was a devotee of the instrument,

who did just about everything one might expect to leave no doubt of his deep commitment to the gamelan: he learnt to play; he visited Indonesia; he consorted with leading Javanese musicians in California; he composed music not only to imitate

\footnotetext{
24 It should be noted that the idea of reducing and adapting Ethiopian scales to Western instruments and tuning systems was something that was embraced initially by Ethiopian musicians themselves, unlike in this case of Debussy's Pagodes. This early hybridity in the Ethiopian situation is therefore a precedent for other musicians to follow.
} 
the gamelan but even for actual gamelan instruments, and even built them himself (with his partner William Colvig) (Sorrell 2007).

Yet like Debussy, Harrison too met with criticism for his works' use of Javanese materials and the misleading presentation of them. For Sorrell,

The problem arises mainly from Harrison's appropriation of Javanese terminology, as it carries specific expectations and suggests a more genuinely Javanese product than in fact exists. Had the solution been adopted of simply omitting the terms from the title of the gamelan part it remains open to question whether the problem would have vanished. More likely it would have left its imprint, as the gamelan part would still suggest the partial modeling on a traditional form and the attempt at pastiche accorded less significance rather than erased entirely (Sorrell 2007).

Harrison's use of just intonation in combination with Javanese gamelan tunings has also come under fire for giving a false implication that Javanese music adheres to just intonation principles. For Henry Spiller,

It misleads many listeners to attribute a quality of authenticity to Harrison's gamelan music that overstates the equity of the works' fusion of East and West. Simply put: even the parts that Western audiences hear as authentic music are more Western than they sound (Spiller 2009, 32).

But can composers be held responsible for how audiences perceive their music? The criticisms of both Debussy's and Harrison's efforts at bringing together Western and Javanese traditions (despite the fact that Harrison undertook rigorous research in the field) would appear to be similar: the music is not fully representative of authentic Javanese traditions, it imposes Western constructs on the music and gives Western audiences a false sense of authenticity of Javanese culture. But although the terminology, such as Debussy's "Pagodes" reference, may be at times misleading, it is unlikely that these composers would themselves claim to be representing any sense of 
authenticity of Javanese traditions. These commentators' claim that audiences would not be able to tell the difference or would be so easily misled gives little credit to the awareness of listeners to be able to judge for themselves the relative authenticity of a Javanese gamelan ensemble and the work of a Western composer who employed the gamelan or was inspired by it.

One could speculate that the aims of composers such as Debussy and Harrison would more accurately be described as creating a syncresis of music from different traditions. In this way they would either extend upon their own traditions by introducing new elements or create new worlds entirely. The research of other musical cultures, of both context and musical materials, could open up areas of melody, harmony, rhythm and texture that were previously unheard and unrealized.

Steve Reich's Drumming was composed after a five week long journey to study West African drumming in Ghana in 1970. Reich had developed a fascination for percussion, having been obsessed in his formative years with the jazz drummer Kenny Clarke (Reich 2016, 175). Reich was inspired to travel to Africa as "percussion is the dominant voice in African music, as opposed to the Western orchestra where strings are the dominant voice. So, the message for me was there's a tradition for repeating percussion patterns, you're not all by yourself" (Reich 2016, 175). Reich's 90-minute piece makes no attempt to recreate, either in performance context or in musical material, the experience of the traditional West African music that he had studied. Instead, Reich selectively adapted aspects of this music, and applied these approaches to his own minimalist musical vision. In this manner, Reich's music differs from the composers and groups found in previous examples relating to Ethio-Groove, such as Akale Wube, Debo Band, Budos Band and Woima Collective, whose aesthetic aims would appear to be to conserve or to build upon a tradition. 
In Ali Momeni's 2001 study of Reich's piece, he lists four principals of Ghanaian drumming that Reich was to explore in the composition of Drumming. These are: pulse as a central tenet of the music; rhythmic cells of asymmetric lengths; movable downbeats (where a pattern can be played starting on different beats of the measure); and hocket, where rhythms and melodies are constructed by several performers playing different notes and fragments in rhythmic alternation to each other. As a counterpoint to these principals, Momeni states that "listening to Steve Reich's Drumming with an ear that is thirsty for African polyrhythmics is the recipe for misunderstanding and disappointment. The sort of strict polyrhythmics that is found throughout central and West African music is not at all the point of this piece of music. There is a drastic disparity between the complexity of the rhythmic material in traditional African music and the single rhythmic cell present in Drumming" (Momeni 2001, 2).

There are other significant differences in Reich's music to the music that inspired the composition. The most striking, at least from the point of view of a musician, is the idea of feel. In African drumming there is always a stretch, and pushing and pulling of the time for dramatic effect and simply as the result of human musical interaction. Often this is most noticeable in the role and musical effect of the master drummer who is often in more of an improvised soloing position. There is no such role in Reich's music and the aim would appear to be more for a slowly evolving, almost machine-like exactitude. An original feature of Reich's music is his "phasing" technique two players are playing an identical pattern then one adjusts the tempo while the other remains constant until they are playing on different parts of the bar. This was a signature device of Reich's and he employed it in many other pieces. No such practices occur in West African drumming styles.

Reich states that, rather than being a homage to his Ghanaian experience, Drumming was the "beginning of moving back to a Western way of thinking" 
(Reich 2016, 179). He talks of this mainly in the sense of structure, with the first three parts of Drumming featuring different percussion instruments, with the fourth being the "grand finale" which brings the whole ensemble together. "At the end it was very much a realization of a particularly Western obligation to put together these ingredients that I had dealt with independently" (Reich 2016, 179).

A slightly different example of a composer being influenced by the music of another culture can be found in Olivier Messiaen's relationship to Indian music. Messiaen used principals drawn from Indian rhythmic patterns, called tālas, in many of his major works, including Quator pour la fin du temps and the Turangalîla-Symphonie. Far from making orchestral music in an Indian style, Messiaen combined and juxtaposed many different elements in his work to create a new compositional language, one which marked him as one of the most unique and important classical composers of the twentieth century.

In his work "Oiseaux Exotiques" (1955) for example, Messiaen uses rhythmic arrangement derived from both tālas, to be precise the Sarangaveda system of 120 degitalas, and the Carnatic or Southern Indian system of 35 suladitalas and Greek metrical patterns, and combines this with melodic material derived from his ornithological transcriptions. In his study of "Oiseaux Exotiques", Mirjana Simundža (1988) shows how Messiaen was the first Western composer to complete a profound study of Indian music and in particular its rhythmic theory. Messiaen never traveled to India however, a regret that he harboured: "Curiously, all my life I have wanted to go to the Indies, and I never made the trip. I contented myself with studying the deci-tālas. Perhaps it was better that way: I was acquainted with ancient India in its most profound manifestations, and by going there, I would have risked being disappointed" (Messiaen 1994, 99). Simundža emphasizes that Messiaen used his theoretical studies of Indian music to pre-structure his compositions in a rhythmic fashion, creating musical parameters within which to work. This is fairly 
removed from Indian rhythmic practice within the context of Indian music itself; as Simundža states, "when retaining basic time periods, Indian musicians do not strike all the beats of one tāla, but distinguish the subsections by sound, and fill out the time spaces with various rhythmical

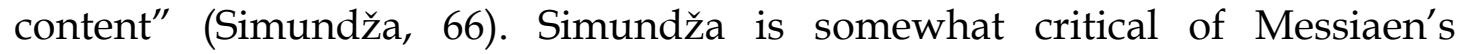
approach in taking from Indian music while removing it from its (especially religious) context and from being unaware of the spiritual meaning of the individual tālas he used: "When developing his own rhythmic and melodic modes, all he knew of Indian music came exclusively from books, and he still had not cast off the idea of Europe as the center of the universe" (Simundža, 66). For Simundža, Messiaen treats Indian music merely as material to be used according to his needs. In doing so, this aided him in creating a unique musical universe in which his own religious sensibility - a quest for infinity and eternity were the aims. It did nothing to reflect Indian music as an elevated musical art form, nor can one say that there was even a genuine hybridity in Messiaen's music. Indeed, these were never the intentions of the composer. Messiaen used Indian music because he saw in it something that the music of his culture lacked. For Messiaen, "exotic music has played a great part in my own works...because the composers of those countries we don't know; they have done studies in rhythm that we have been wrong to neglect. Finally, we live in an age of internationalism" (Messiaen 1994, 194195). The simplicity of Messiaen's final statement gets straight to the heart of the matter - no composer or musician lives in a cocoon of their own culture, and has not done since the advent of recorded music, if not before. To refuse to accept influences from elsewhere would inevitably be to reject much of one's experience of the world. At the same time, Messiaen was certain about his musical heritage and would only adapt his knowledge of "exotic music" to the musical language that he had already established.

In talking about his experience of teaching Japanese students he commented: “This double identity is a drama for composers. All the Japanese composers 
who came to my class were torn between Japanese traditions and their desire to practice Western music. I always told them: 'Remain Japanese?' [That] means using your modern knowledge, but remaining within the boundaries of Japanese traditions!" (Messiaen 1994, 102).

The lessons of Reich's and Messiaen's integration of the music of other cultures into their own language, in the context of this study, are that in doing so it is possible - and, for these composers, essential - to remain firmly in their own identity and traditions. Such pieces are not to be seen as imitations of another culture. Instead, the research involved is used as inspiration for devising new materials with which to work.

This chapter has shown how Ethiopian instrumental music became an underground global phenomenon, with producers, DJs, musicians and audiences from around the world all taking an active role in its distribution and promulgation, albeit with seemingly different amounts of research into, and solidarity with, the original form. It has shown various approaches that musicians from around the world have taken in drawing inspiration from Ethiopian music, comparing with similar examples from other genres. Through examining the amount of critical commentary that these projects have generated, this chapter has shown how any such examples of cultural exchange and transformation must expect to have their motivations and results thoroughly examined, especially in the contemporary era where cultural practices can be so widely and rapidly disseminated.

Such conversations can ultimately only be beneficial to musicians as they encourage individuals to delve deeper into their materials and at the same time, spend time examining their own individual identities. In response to Mulatu Astatke's statement that "it's important to respect the different cultures you are trying to incorporate", I would argue that true respect of different cultures is developed through research; it is also heightened by self- 
awareness of one's role as being at once within and outside cultural traditions. In this chapter I have argued that creating powerful music closely linked to the music of another culture - such as in the example of Woima Collective - is neither impossible nor inappropriate when research has been thorough and the presentation of the work has integrity. When the music has been simply adoptive and too literal, when the nuances of the music have not been fully understood or integrated, or when the presentation of the work belies a deeper misunderstanding of cultural positioning, then problems arise.

Speaking now from my personal position as a musician and composer, which will be the tone of the following chapter examining my own experience with Ethiopian music and the compositions that accompany this thesis, I believe strongly in the possibilities and inevitability of cultural exchange. With that goes the necessity of artistic freedom, but also of a responsibility to examine one's own artistic responses with every attempt at ethical objectivity. My artistic response to these questions was to push myself to create original sounding work out of my research. I tried to avoid a literal interpretation or reproduction of pre-existing music from a 'golden age' that I never experienced or was a part of. Instead, I wanted to discover what the essence of the affinity was that I felt for this music, and to use that as a point of departure into a new musical landscape. 


\section{CHAPTER 3}

\section{A Personal Journey With Ethiopian MUSIC}

It was in 2003 in a flat in East Berlin that I first heard Getachew Mekurya. A recent graduate from the jazz school in Wellington, I had left New Zealand without much of a plan and found myself in Berlin staying at the home of a fellow Wellington musician Justin Clarke. Mekurya's music was unlike anything I had heard before. Being deeply enthralled with free jazz saxophonists such as Ornette Coleman, David Murray and Dewey Redman at the time, Mekurya's abrasive approach was not in the least off-putting for me; on the contrary I found this harsh, strong sound combined with slippery ornamentation and unfamiliar scales utterly captivating. From that first listening I determined to learn more about this music, which seemed to contain so many links with both a history that I knew nothing about and the avant-garde jazz world in which I was ensconced.

The following chapter contains the background and explanation for the creative work which accompanies this thesis. It details my journey with Ethiopian music, my reflections on my experiences in being involved with this music and the musical reasoning that informs the creative decisions that $I$ have made in my portfolio work. As such, with some of the material being drawn from my work diaries, here I have allowed myself a more personal tone than in previous chapters, which I believe to be in keeping with 
discussion of the musical experiences and creative process that forms the context for this thesis.

\section{Beginnings}

In 2014 I decided to take on the challenge of a doctorate to deepen my understanding of Ethiopian music, but largely with the viewpoint of ultimately finding an original style of composition of my own. My background in this music at this point was not completely rudimentary as I had already played and composed for two bands in my hometown of Wellington, New Zealand. These were to some degree modeled on some of the European (Woima Collective, Karl Hector and the Malcouns) and American groups (Debo Band, Antibalas) which performed original music in either an afrobeat or Ethio-jazz style. The most successful of these groups was Shogun Orchestra which performed at various festivals in New Zealand and released two records on a German label named Jakarta Records. At this point I was already conscious to avoid the temptation of merely reproducing the Ethio-Jazz style and looked to integrate an eclectic range of influences in the music. ${ }^{25}$

Having also travelled, lived, performed and undertaken composition projects in many parts of the world, such as creating for a theatre project in Haiti in 2009 with voodoo drummers, accompanying a circus troop in India in 2006, and making a recording and concerts with Alan Silva, a legend of American free jazz, in France in 2007, the prospect of taking on a project of research and potential collaboration was not as daunting as it might have been if I had largely produced music only in my home country. In summary, learning from and collaborating with musicians who came from very different backgrounds

\footnotetext{
25 For example I had discovered that Japanese music contained some similar scales to Ethiopian music, and, being a fan of samurai films, one can trace the influence of the music from Kurosawa's films and other Japanese auteurs in our albums.
} 
was something with which I was fairly well acquainted within my own artistic practice.

Before I examine the creative work which accompanies this thesis, I would like to outline two other experiences I had during the period of my doctoral study that have deeply informed my musical practice.

\section{Mulatu Astatke at the Wellington Jazz Festival 2016}

In June 2016 Mulatu Astatke performed at the Wellington Jazz Festival accompanied by Australian band The Black Jesus Experience. At the initiation of festival director Shelagh Magazda, I was invited to perform as a guest artist (I had been pressing Shelagh for some years to bring Mulatu Astatke to Wellington and my interest in Ethiopian music was well known to her). Both Astatke and the Australian band were very welcoming to me and I offered them some of my previous music to demonstrate that I had a background in Ethio-Jazz. I was also able to talk to Astatke prior to his arrival on the phone, which resulted in the writing of an article in a local music blog (Johnson 2016).

It was an honour and a privilege to meet and perform with this musical giant whom I had spent so many years listening to and studying. I felt that when I played with him my hard work and understanding of some of the nuances of Ethiopian music shone through, particularly through my knowledge of Getachew Mekurya's style and the use of ornamentation. To hear Mulatu's murmurs of appreciation when listening to me play solos at both the soundcheck and during the concert was gratifying.

Astatke himself took something of a background role during the concert. More an arranger and composer than a virtuoso performer, he was happy to 
see the other musicians take the foreground in the presentation of the music. He did, however, perform one largely unaccompanied vibraphone solo, moving quickly away from Ethiopian modes into flowing, bebop type melodies. He also used very soft mallets and liberally employed the sustain pedal, creating a sonic wash of tonal colours. These were the only moments of the concerts which I felt hinted at the Afrofuturist element in his music, which I emphasized in the analysis of his early records.

The Black Jesus Experience, who accompanied Astatke throughout his Australasian tour, were a group of highly experienced professional musicians. They had learnt all of Astatke's arrangements and played them with expertise. However, there were elements of the performance, or more accurately the presentation of the performance, which I found confusing and problematic. Rather than emphasize the open, free flowing, sonic explorations and haunting, understated melodic qualities of the music, the Black Jesus Experience stressed the groove/funk elements of the music, and constantly encouraged the seated audience to get on their feet and dance. At times the rhythm section even jumped in the air, landing on a stressed beat or stop, much in the manner of $80 \mathrm{~s}$ and $90 \mathrm{~s}$ heavy metal bands. Although I would not want to suggest that Astatke's music should not be danced to or even to speculate on his intentions for the music at all, it struck me as peculiar that I could interpret this music so differently to other musicians who had also spent considerable time studying and playing the music of Mulatu Astatke.

The difference between our interpretations I also attributed to a misunderstanding of the historical context of the music. The original Astatke compositions which formed the backbone of the set list that night were recorded in the late 1960s and early 70s, and fit seamlessly into the early jazz fusion of Miles Davis, George Russell, Julian Priester and Herbie Hancock (pre-Headhunters era). The groove jazz that the Black Jesus Experience presented felt more akin to the fusion of the 1980s and 1990s, a feeling 
reinforced by the inclusion of their rapper Mr Monk, whose style was reminiscent of mid-80s hip-hoppers and, as one Australian critic put it in a review from the same tour, whose "old school rap seem[ed] incongruent with the deceptively simple Ethio-jazz blend" (Dezfouli 2016). Certainly the inclusion of a rapper at all, when the music and beats had no other obvious relationship to hip-hop felt like some kind of token gesture to nothing in particular, a misguided attempt at inclusiveness.

When music is learned from records and CDs rather than being entrenched in the culture from which it sprung, very different concepts of what the music represents can be gleaned from it. My understanding of Astatke's music was that the timbre of sound is crucial to any interpretation of it - which is why, for me, the Heliocentrics collaboration with Astatke which featured vintage synthesizers and sonic exploration was largely successful and partly why the Black Jesus Experience fell short of the mark. I felt my intuition justified a little by the fact that Astatke insisted on having a Wurlitzer electronic piano from the 1960s in his arsenal of instruments, while the Black Jesus Experience used modern day Nord keyboards which digitally reproduced piano or Rhodes keyboard sounds. I perceived this oversight of the importance of timbre as an important misinterpretation of a crucial element of Ethio-Groove. The multiplication of these misinterpretations of small details (including also the Ethiopian attire and cover art discussed in the previous chapter) led to an unsuccessful portrayal of Astatke's music. For me personally though, it remained an unforgettable learning experience. 


\section{Addis Ababa, June-July 2016}

In June 2016, immediately after my performance at the Wellington Jazz Festival, I travelled to Ethiopia, staying for two months in Addis Ababa. ${ }^{26}$ Despite having any real contacts on the ground other than an invitation from Mulatu Astatke to come down to his club, the African Jazz Village, which was situated at the Ghion Hotel in Addis Ababa, I felt that I needed to investigate the music scene firsthand.

I wanted to evaluate my reaction to my own music and musical pathway, when this music I had been studying - which up till now had existed for myself in an imagined reality of albums, old photographs and internet debate, - became material. Would I confirm any of my viewpoints and feel justified in creating the music that I had been making? Would the experience lead me further into the traditions of Ethiopian music or further away?

The first concert I attended, a Fête de la Musique celebration at the Alliance Française of Addis Ababa, featured Mesele Asmamaw and his group Qwanqwa. Asmamaw is an electric krar player 27 , and as I soon found out, one of the most respected players on the scene. His renditions of traditional Ethiopian songs felt modern. Through the use of various effects pedals on his krar, the group were able to interweave psychedelic, experimental sections into these ancient melodies, each of which were presented as coming from different regions of the country. Asmamaw, who has performed several times in Europe in recent years with The Ex as well as leading European free improvising drummer Paal Nilssen-Love, could well be seen as the Mulatu Astatke or Getachew Mekurya of his generation, and it may only take one filmmaker like Jim Jarmusch to catapult his music into international

\footnotetext{
26 Although I would have liked to have travelled throughout Ethiopia, there was political unrest and riots occurring at the time in various rural areas and travel was not recommended. ${ }^{27}$ The krar sounded something in between an electric guitar and electrified harp in this instance.
} 
consciousness in the same way that Astatke's music was through Broken Flowers (2005). The other members of the group included Dawit Seyoum on electric bass krar and Elias Wolde Mikael on a drumkit which adapted kebero (Ethiopian drums with goatskin heads) with Western drumkit elements such as hi-hats. It was a revelation to see these traditional instruments being revitalized and electrified, and played with uncompromising virtuosity. Rounding up the quartet was a violinist of American origins, Kaethe Hostetter. Conversing with Hostetter after the performance, she talked about how she spent most of her time in Ethiopia, and had been a founding member of Debo Band, one of the United States' leading Ethiopian ensembles which championed authentic Ethiopian music traditions.

Seeing the Qwanqwa concert that day, and indeed several other very strong Ethiopian groups ranging from traditional music to Ethiopian reggae, was deeply affecting. It made me realize that Ethiopian music had definitely moved on from the music I had been studying, and not at all (in my opinion) as I had been somewhat led to believe in some of Francis Falceto's depictions of the current scene (see Falceto 2014 for his rather pessimistic view of current trends) in an adverse manner. The combination of traditional instrumentation and melodies with an avant-garde sonic landscape produced through electrification and psychedelic effects was hugely appealing to me aesthetically.

A few days later I attended a concert at Mulatu Astake's club, the African Jazz Village, which is situated in the basement of the Ghion Hotel in central Addis Ababa. Playing that night was a group called Asli Ethio Jazz, led by saxophonist and keyboard player Jorga Mesfin. Mulatu was in attendance and he welcomed me warmly, talking me through the first set with information about the rhythms and which region of Ethiopia they came from. In the second set, Mulatu arranged for me to sit in with the band. Commencing the first piece of the second set, Jorga whispered the key to me 
and encouraged me just to play along. When the band started however, I immediately recognized the groove as "Almaz Yeharerwa", a traditional Ethiopian song. I had transcribed Getachew Mekurya's version of the song and so was able to play the melody in unison with the washint player, including ornamentation, as well as playing a solo a little in the style of Mekurya. The rest of the night continued in that manner and we ended with one of Mulatu's songs, "Kasalefktut Hulu”.

My contribution to the evening was warmly received by both musicians and audience alike. I was met by a certain level of astonishment from people who could not understand how I had managed to learn to play in such an identifiably Ethiopian way. The most rewarding response of the night came from Mulatu himself who was clearly very happy and invited me to coffee with him in the coming days.

The rest of my stay in Addis Ababa was spent attending concerts and generally experiencing life in the burgeoning metropolis. From traditional music and dance at venues such as Fendika to electronic dance parties at Villa Verde featuring some of the artists in the Ethiopiyawi scene, I immersed myself in the diversity of contemporary Ethiopian culture. In many respects, the experience made me feel more like an outsider to this music than before. It convinced me that, despite the obvious gains I had made by thoroughly researching and transcribing Ethiopian music, which was evident in my saxophone playing, I could never set myself up as an expert or promulgator of an authentic Ethiopian musical tradition. For one thing, it became clear that the regional and tribal origins of different rhythms and melodies was a vast area requiring years of fieldwork, and even then I find it difficult to believe that a non-Ethiopian could fully grasp all the nuances of the music. To learn Amharic would be a valuable start, but that would still leave more than 80 Ethiopian languages that I did not know. 
It is important to stress though, that the music I had been studying and was interested in was hybrid music rather than traditional. In the cases of Guebrou and Astatke at least, through their studies of classical piano literature (Guebrou) and jazz (Astatke) it may even be deemed that Western influences on their music were every bit as strong as the Ethiopian ones. For me this allowed an entry point, both aesthetically and ethically. It is music in conversation with the rest of the world and as such I believe my responses to it, by continuing in this vein of hybridity and cultural mutation, are equally valid.

My trip to Ethiopia demonstrated to me that there is no limit to the understanding of another culture, and that I was still very much at the tip of the iceberg. However, what it also confirmed for me was that I was essentially on a quest to find a unique voice in music for myself. With this in mind I resolved in my creative work to stop myself whenever I entered too far into the territory of duplication or homage. My aim was to create original music, which drew upon my research but did not copy, repeat or make a pastiche of it. I could draw on the research in a literal way - by adopting scales or devices such as ornamentation - but I also hoped to extend upon some of the theoretical side of my findings, such as Afrofuturism and how this could be reinterpreted today.

\section{The Portolio: General Observations}

The remainder of this chapter provides personal reflections and critical analysis of the creative component of this doctoral project. I broke down the creative portfolio into three separate works - in some way each of the components of the portfolio refer back to the three Ethiopian artists that I researched, although they are not intended to be homages to these musicians. 


\section{Tone Science}

A suite of six electronic pieces which invoke the concepts and sounds of Afrofuturism as discussed in the analysis of Mulatu Astatke's work. These works draw upon an eclectic range of influences from around the Black Atlantic rather than evolving specifically out of Ethiopian traditions. They seek to create a unique sonic signature through use of vintage electronic keyboards and drum machines.

\section{Addis Nocturnes}

A series of nocturnes for solo piano which take as their musical starting point the idea of viewing French impressionist piano music through the lens of Ethiopian musical traditions. These pieces attempt to create a contemporary approach to the piano nocturne through this unlikely hybridization, finding the concept of dream-trance as a common element in these two styles.

\section{Axum}

A short symphonic work which aims to build upon the language discovered in Addis Nocturnes but using a full orchestral tonal palette.

In all three of these works it is possible to discern various references to Ethiopian music through the use of modes, ornamentation, or textures. However I must stress that I did not intend these pieces to be viewed as coming from Ethiopian traditions. They are intended to be understood as contemporary music, with a range of influences, and not as evolving out of or directly building upon Ethiopian music. Of the four methods of extracting influence, as described in Chapter Two, I find myself overwhelmingly drawn 
to the fourth one above the rest: the notion of musical transformation. I feel that this approach allowed me to be the truest to myself as a composer, and the least appropriative of the tradition I have engaged with. At the same time I observed the criticism of the works of Reich and Messiaen, that the context of their musical creations were far removed from the influences upon these works, leading to accusations of exoticism. With this in mind I wanted one of the works (Tone Science) to be situated outside the realms of a concert performance; the intention of the music is that it is for dancing as well as listening. ${ }^{28}$

\section{Tone Science}

\section{The Idea}

In the half-between world, Dwell they: The Tone Scientists

In notes and tones

They speak of many things...

The Tone Scientists:

Architects of planes of discipline

Mathematically precise are they:

The Tone Scientists.

Tone Science is a suite of electronic pieces based on an instrumentation featuring vintage synthesizers and drum machines, live horns and audio effects manipulation. These pieces set out to bring together some of the various aspects of Afrofuturism: the electronics of Sun Ra, the jazz fission of Miles Davis, the spectral dub effects of Scientist and Lee Perry, the hypertrance of Fhloston Paradigm together with Mulatu Astatke's exploration of Ethiopian pentatonic scales and the rhythm machines of digital Africa.

\footnotetext{
28 Wellington-based contemporary dance company, Footnote New Zealand Dance, used some of Tone Science as music for a work within their 2016 programme, which, from my perspective, was an ideal environment for the diffusion of the work.
} 
These pieces were specifically inspired by reading More Brilliant than the Sun (1998), Kodwo Eshun's treatise on Afrofuturism, which he describes as "a webbed network of computerhythms, machine mythology and conceptechnics which routes, reroutes and criss-crosses the Black Atlantic" (Eshun 1998, -006).

A key tenet of Eshun's theory is that "the mayday signal of Black Atlantic Futurism is unrecognizability, as either Black or music. Sonic futurism doesn't locate you in tradition; instead it dislocates you from origins" (Eshun 1998, 001). This sentence was liberating for my musical practice and catalytic in finding a guiding vision for an original interpretation of the music I had been studying. It enabled me to develop and assemble a unique sonic landscape that did not need to pay homage to any specific artist or genre. In fact, in my mind, the further away I got from "authenticity" and genre replication, the better. In this way I could avoid the trap of merely making a pastiche of Ethio-Jazz albums that had already been made half a century ago. Instead the music could justifiably reside in "half-between worlds" which if anything, distinctly avoided making direct reference to the undertaking of transcriptions and sounds that informed my research of Ethiopian musicians.

Originally I conceived of this music as being performed by a band and many of the drum machine sounds in particular that I used were intended to be replaced by a real drummer. However, as the pieces evolved, the more I realized that the machine sounds were integral to the character of the music. Eshun celebrates the "machine mythology" over the human, which he characterizes within the context of Afrofuturism, a movement that shows "extreme indifference toward the human", as a "pointless and treacherous category" (Eshun 1998, -005). Thus, I decided to embrace the machine elements of the music. Indeed a common theme in science fiction writing, from Isaac Asimov to Octavia Butler, is the potential for humanity within the machine. This juxtaposition of machine and natural elements is a feature of 
Tone Science. A superficial reading of the works may recognize this simply as the combination of machine rhythms with melodic horns. However it was my intention to blur these musical elements. Thus the machine rhythms are, in many cases, based on traditional African rhythms and much attention is paid to "feel" within the interlocking parts. On the other hand, many of the brass parts and other naturalistic instruments are treated with various effects reverbs, delays, distortions etc. - in order to bring them closer to the alien and synthesized sound of the electronic elements. In this manner the theme of hybridity, which is a common thread running throughout this entire research portfolio, takes on another layer. Normally used to describe the synthesis of different cultures or genres, in this case it is also being used to depict the amalgamation of the human and the machine, in a science fictional and futuristic aesthetic.

This music is characterized by the concept of dislocation from origins, both in terms of geography and temporality. Rather than create a band sound reminiscent of Mulatu Astatke's Ethio-Jazz or the Walias Band, an idea which has been rehashed many times in recent years from the Budos Band to Woima Collective, I wished to draw from many aspects of the Afrofuturism, which included at times references to both Astatke's music along with Getachew Mekurya's saxophone style, but with an equal dose of Miles Davis' 1970s free fusion sonic inventions and Sun Ra's use of electronics. Underpinning these melodic elements were the rhythms, drawn from both East and West African traditional and modern styles. The instruments I used were nearly all vintage, most strikingly the Roland SH-2000 and Yamaha CP-10 synthesizers both dating from the early 1970s, the 1963 Selmer saxophone, the samples of 1980s drum machines and the 1970s Yamaha combo organ. The effect of these vintage instruments was to create a distinctive timbral world, which can only be described as a sort of analogue grittiness. At the same time by adding contemporary sonic effects (I mostly used effects from the software manufacturer Soundtoys) to them, my aim was to create a unique sonic 
signature, which evoked both a "retro" sound and a science-fiction, futurist aesthetic.

Nearly all the influences on this project are from music from the black diaspora and are inspired by the writings of a black theorist, Kodwo Eshun, a debt that as a white New Zealander I happily and readily acknowledge. Simply put, I consider the field of Afrofuturism one of the most exciting and refreshing areas to be working in in the present time. As Eshun states, “journalism still insists on a solid state known as 'blackness'. More Brilliant dissolves this solidarity with a corpse into a fluidarity maintained and exacerbated by soundmachines" (Eshun 1998, -003). My composition work has been an attempt not to recreate the music of another culture, but to create original and futuristic music in a context of fluidarity.

\section{The Process}

The rhythms in these pieces are all loosely based on rhythms sourced from different African traditions that I have transcribed, created electronic versions of, and then adapted to suit the needs of each individual piece.

The percussion and drum tracks for "Tone Science IV", for example, are based on rhythms found in the secular music of the Tigray region of Ethiopia (and are also commonly found in the music of Eritrea) which are used in social, cultural and political contexts and ceremonies (see Teffera 2005). These rhythms are characterized by a handclapped accent in each bar (on beat 1 and 3 or 2 and 4 depending on the song) and rhythmic accompaniment from a drum called a hebero. At a certain moment, usually around two thirds of the way through the piece as it builds to a climax in energy and emotion, the songleader shouts "derib!" meaning "make double!" from which point the group adds an upbeat handclap on the second triplet of the first and third 
beats of the bar implying a 3:2 polyrhythm. When this occurs the singing, vocalizing and dancing all greatly increase in intensity (see Teffera 2005, 135).

I followed this structure in "Tone Science IV", building the piece around a beats 2 and 4 handclap which intensifies two thirds through the piece by adding the extra "upbeat" handclap. Surrounding this I added my own bass drum, hihat and percussion patterns, which, although my own invention, emerge from an effort to achieve the loping triplet feel to be found in the music of Tigray. From this base I added various interlocking melodic parts which are based on a $\mathrm{C}$ tizita minor scale but are quite unlike the vocal melodies of Tigray music, which are more melismatic. After I had established this framework I added various solo parts and experimental sonic elements. Throughout this process I experimented with various effects on different parts - distortion, reverbs and delays and various other "tricks" - and I found that by using these modern plugins on vintage keyboards and synthesizers I was able to achieve a sense of temporal dislocation previously alluded to: the clash of gritty analogue sounds and contemporary digital effects created a sense of collision between past and future.

The other Tone Science pieces were largely constructed intuitively and do not necessarily contain such a striking confluence of theoretical threads as is evident in "Tone Science IV". However, there is a clear tendency to assemble a variety of techniques from various Afrofuturist and Black Atlantic sources in individual pieces of music. For the sake of analysis, "Tone Science I", "II" and "V" can be grouped together. All three of these pieces initiated from a drum pattern, transcribed below, derived from different sources from West African electronic music from the 1970s and 80s. In "Tone Science I" the main feature is the 3:2 polyrhythm expressed between the hihat and bass drum, with the snare providing accents. In "Tone Science II" the drum part is reminiscent of Afrobeat particularly in the snare drum pattern which mirrors the okpokolo (Nigerian woodblock) patterns in that musical genre, although 
the omission of it on the first semiquaver of beat three gives it a unique sound. In "Tone Science VI" the defining characteristic of the pattern is the bass drum anticipating beats two and three, which gives the groove an unsettled feel. These beats were then adjusted and adapted according to my own personal taste, by adding additional percussion parts and making variations in the beats. I found that by starting with the drum patterns, rather than the melody (which is how I normally compose) I had more control of the overall feeling of the piece, an outcome that I did not anticipate. The drum and percussion patterns were assembled using samples of individual drums or percussion parts from vintage drum machines.
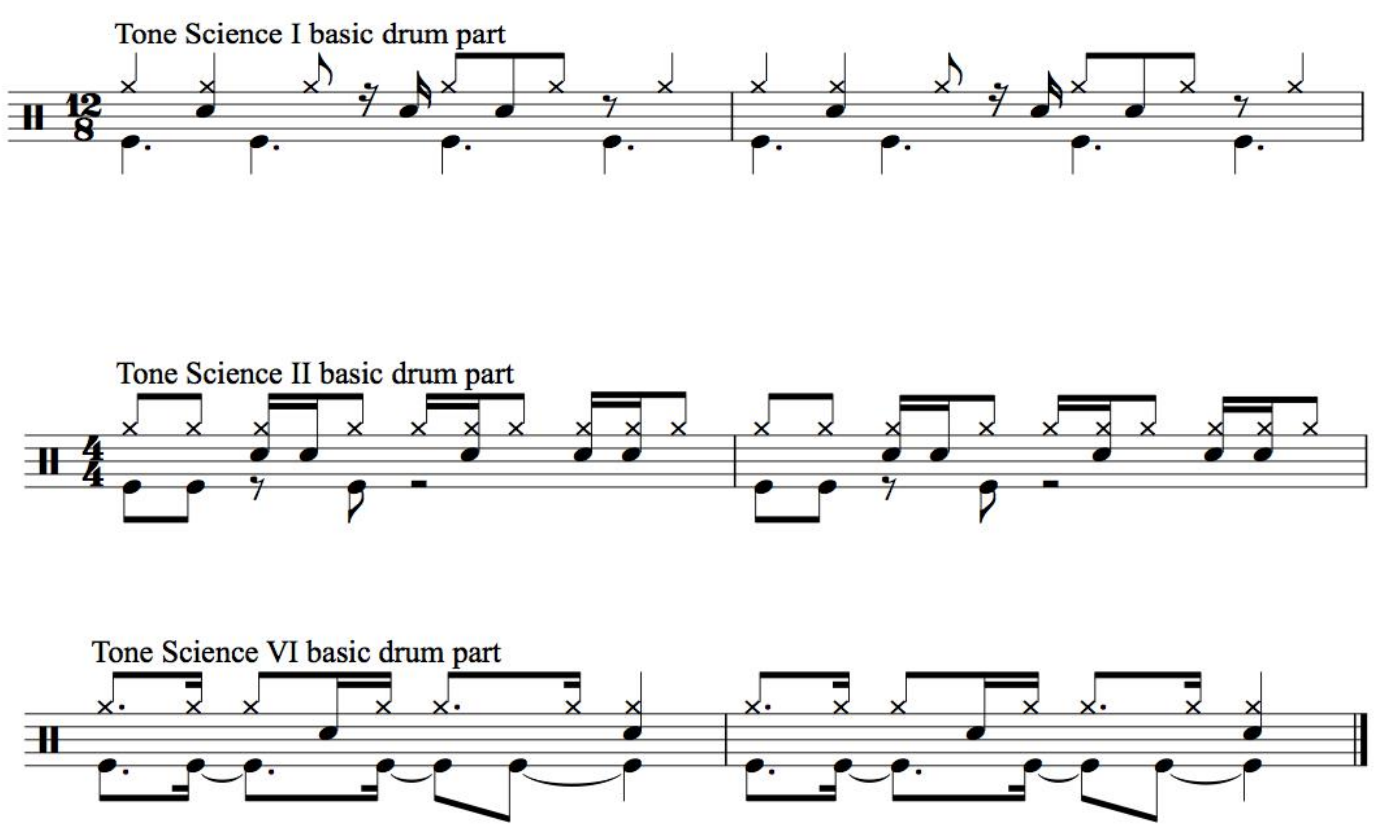

Figure 28: Tone Science drum patterns

After the drum pattern was established, I found bass lines for each of the pieces. I searched for melodic sounding ostinatos for these parts and consciously avoided lines that accentuated beat one of the bar. The effect of this was to add to the rhythmic illusion of the piece, lending the music a sense of instability. The bass lines also gave the pieces their tonalities, in "Tone 
Science I" and "II" these are minor pentatonic scales ${ }^{29}$, whereas "Tone Science $V^{\prime \prime}$ employs an Ethiopian scale, the batti minor with a raised fourth.
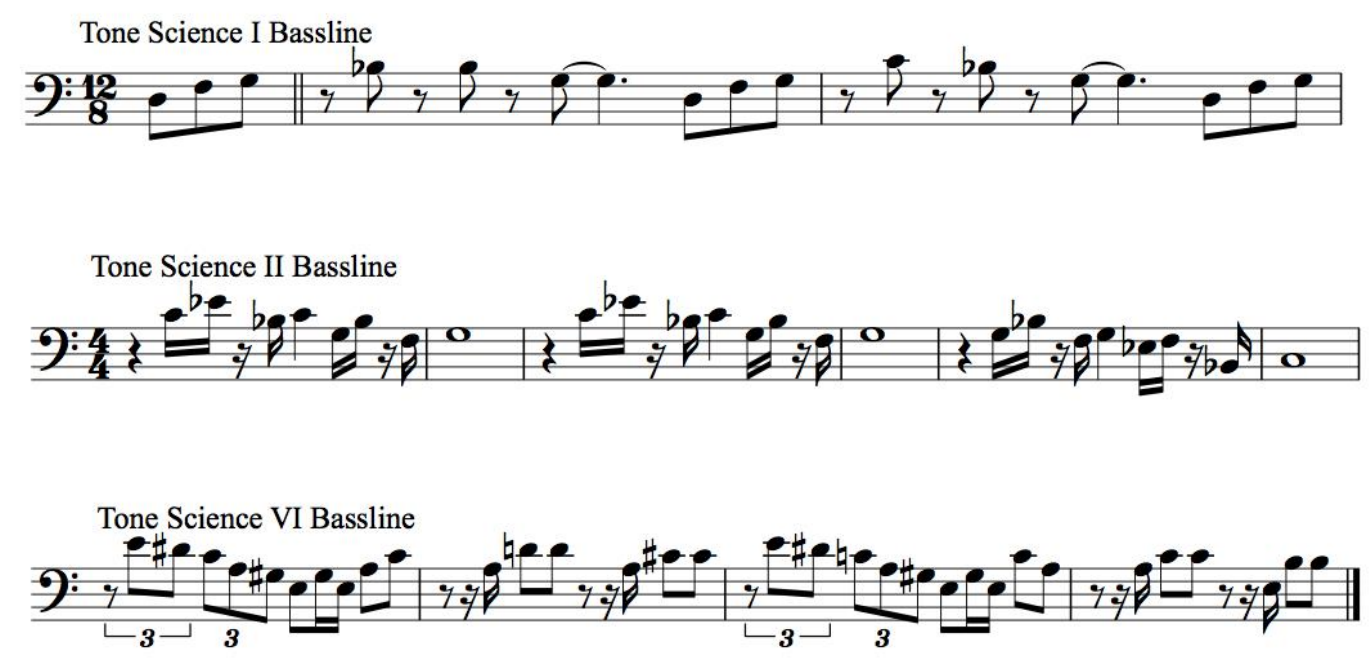

Figure 29: Tone Science bass parts

After these fundamental parts were clearly established, then other percussion, keyboard, synthesizer, guitar and brass section parts were added little by little. Sometimes these were more improvised and then edited, while at other times (especially the brass section melodies) these were composed and written out and then performed. I played all of the keyboard, saxophone and flute parts on this project. I am also indebted to the contributions of Justin Clarke who played electric guitar on "Tone Science 2" and "Tone Science 5", Patrick Bleakley who played electric bass on "Tone Science 2" and Toby Laing, Barrett Hocking and Nick Van Dijk who all contributed trumpet parts at various stages.

${ }^{29} \mathrm{I}$ am avoiding using Ethiopian scale terminology in these pieces because of the wide range of influences in these pieces. 

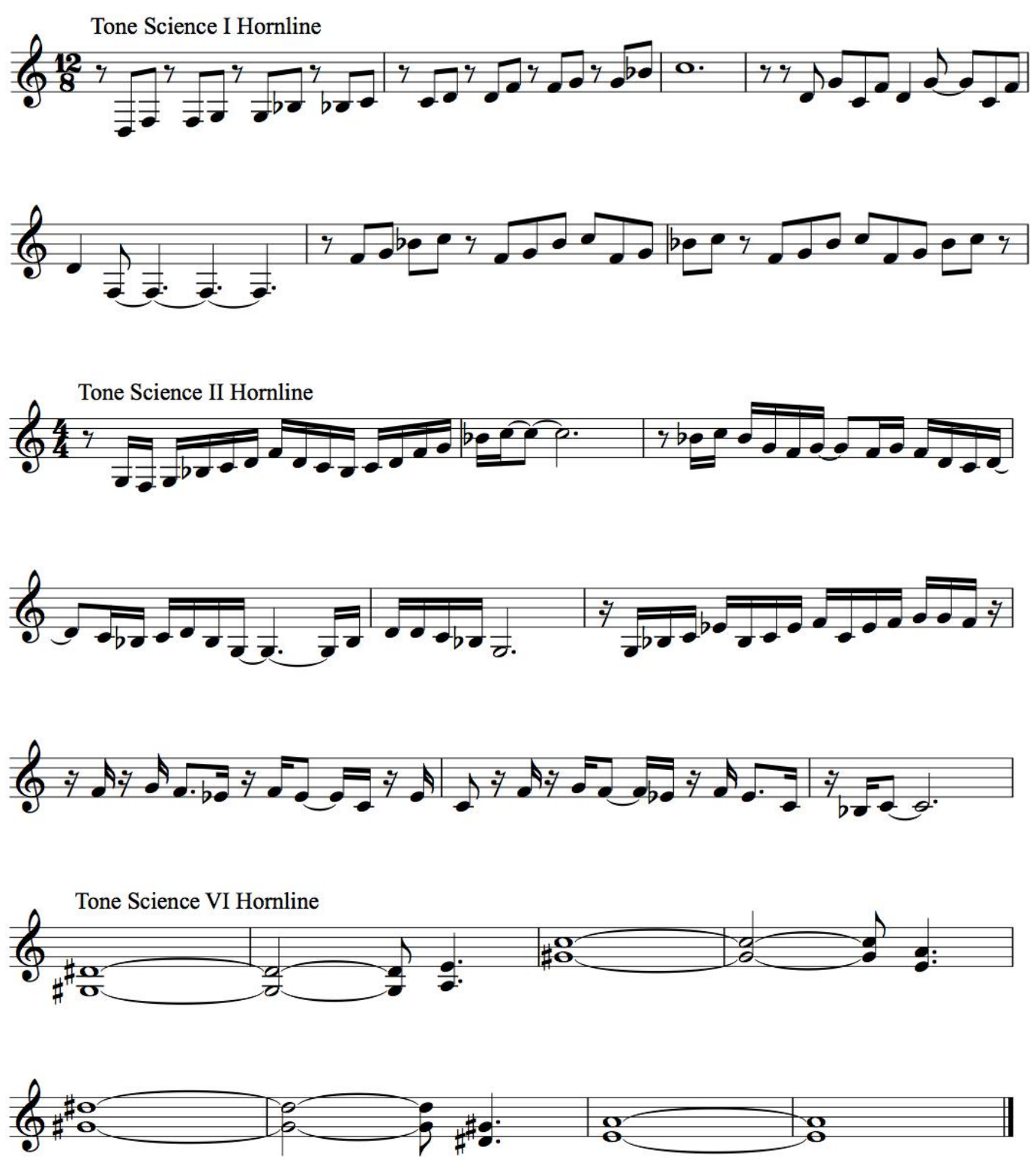

Figure 29: Tone Science horn lines

"Tone Science III" and "VI" took slightly different paths from the other pieces. Both pieces are rubato, based on drones. In "Tone Science III" the drone is implemented by long, breathy notes on the tenor saxophone, which are subsequently panned in a sliding fashion from one side of the speakers to the other. On top of this, another saxophone part plays an improvised solo on an anchihoye scale, using legato phrasing but jagged melodic contours. In "Tone Science VI" the source of the drone is a Roland SH-1000 synthesizer, the soloing instrument the trumpet and the scale a tizita minor. Both pieces 
are underpinned by the same sound of electronic bongos that have gone through various delays and other effects. They first appear in Tone Science I and the reuse of this sound lends the whole suite a sense of consistency.

A range of specific but varied influences can be heard in the music, which was an conscious effort to assemble disparate Afrofuturist styles into one coherent form. The artists referenced below can be seen as conrnerstones in Afrofuturist musical practices (particularly but not exclusively in jazz contexts) mostly for their integration of avant-garde electronics and effects into their practices. The rhythms, as previously alluded to, are based on early West African electronic music, notably artists such as William Onyeabor. Some of the brass melodies, especially that of "Tone Science II" recall Fela Kuti's brass section, particularly in tracks such as "Zombie" (1976). In “Tone Science I" there is a synthesizer sound using a random note generator which is a sonic allusion to Sun Ra, on albums such as Space is the Place (1973). Later in the piece, an alto saxophone plays some rapid melodic lines, which is reminiscent of Ornette Coleman's approach in his Primetime band of the 1980s. This is supplanted by a distorted likembe (thumb piano) invoking the sound of the Congolese group Konono No1, an orchestra of percussion and likembe instruments with a DIY approach to amplification and effects. In "Tone Science II" and "VI", the floating trumpet solos recall Miles Davis' 1970s style, on albums such as Bitches Brew (1970) or On the Corner (1972). The way the two horn lines in "Tone Science II" fade in and out was an attempt to electronically reproduce an experience I had in Haiti in 2009 while attending a rara procession (trumpets made out of PVC piping) where groups of 20 to 30 musicians would walk around a town square playing their particular song, their music becoming louder and then fading and blending in with each successive group. Mulatu Astatke's influence is felt, especially in "Tone Science IV" and "V", which employ Ethiopian scales, but also in the instrumentation and general timbre of the music. "Tone Science III" is a direct reference to the saxophone style of Getachew Mekurya (see my analysis of 
Mekurya's style in Chapter 1). Throughout the suite there is ample use of delays and other effects, a technique used extensively by dub artists such King Tubby.

The list of influences shown above demonstrates an intention to bring together a wide range of sources from around the Black Atlantic. In doing this, by paying attention to the texture of the music in using "retro" instruments, by approaching the electronic instruments to invoke a sciencefiction atmosphere and then using sonic effects liberally, I aimed to uncover an Afrofuturist sensibility in my work. Although making use of sonic references as detailed above, I hope to have created, through unexpected combinations and juxtapositions, an original and unique musical paradigm.

\section{Addis Nocturnes}

\section{The Idea}

Addis Nocturnes are a selection of eight pieces for solo piano, which were written as a result of my two month stay in Addis Ababa. These pieces exhibit various influences, or rather, make reference to various composers as a conscious artistic choice. Although an overarching influence comes from the Ethiopian composer Emahoy Tsegue-Maryam Guebrou, particularly in terms of the use of kiñit and through the reflective quality of her work, I avoided the church music and composers of the early romantic period that inform her compositions. Instead my pieces make explicit reference to early twentieth century composers whose approach may loosely be defined as impressionist, such as Ravel, Debussy and Satie (as well as touching at times on Stravinsky and Scriabin). My self-imposed provocation in this exercise was not to approach Ethiopian music as a European composer but rather to attempt to view a European piano language through the lens of Ethiopian music. How 
would this language be transformed and subverted if the fundamental building blocks (melody, harmony and rhythm) were based on Ethiopian musical theory and characteristics?

At first glance the relationship between impressionism and Ethiopian music may seem incongruous. Although my decision to approach such a synthesis was based largely on an aesthetic impulse and my strong affinities for both of these artistic movements, I also intuitively felt that there was some sense of symbiosis between these two distant styles and I looked into articulating this impression. On a technical level there are devices in common between the music of the impressionists and some of the Ethiopian music that I have analyzed. These similarities are largely timbral, but also to a lesser extent harmonic and rhythmic.

One of the many challenges for a pianist in playing Ravel's music is the pedaling, brought to the fore in his masterpiece Gaspard de la Nuit (1908). An indication of the subtleties of these challenges is outlined by Howat (2009):

At the start of Gaspard de la nuit Ravel more explicitly indicates both pedals but leaves it to the performer how long to hold either of them. Our challenge there is to let the melody breathe while keeping the texture fluid. Much of this involves the pedal's delicate slip point, something that largely defies notation where the dampers discretely touch without smothering (Howat 2009, 186).

In French piano music, pedaling became a crucial element in giving the impression of orchestral colour and creating a blurring timbral effect. Often, especially in Ravel's music, this was coupled with undulating arpeggiated passages which leant themselves to imagistic piano pieces about the elemental world, with water being a recurring theme ("Jeux d'eau" (1902), “Ondine" (1908), La Mer (1909), etc.). 
We can see similar effects being employed in Mulatu Astatke's music, in which guitar and Wurlitzer electronic piano are awash with tremolo, wah and sustain effects and synthesizers, organs and electronic effects are employed liberally. When I played with Astatke at the Wellington Jazz Festival in 2015 I was astounded by his use of pedaling with the vibraphone, creating extensive washes of sound which filled the concert hall. A similar approach can be heard in many of his pieces for example, "Dewel".

Another feature of both French impressionist piano music and Mulatu Astatke's music is harmonic ambiguity. Debussy, in conversation with his former teacher Ernest Guiraud is reported to have stated that,

There should be great freedom and flexibility in the use of major and minor thirds, thus facilitating distant modulations, and evasive effects should be produced by incomplete chords in which the third is missing or other intervals are ill-defined. By thus blurring or drowning the sense of tonality a wider sense of expression is ensured and seemingly unrelated harmonies can be approached without awkward detours (Lockspeiser 1963, 5051).

Once again the descriptive language used here is significant. Adjectives such as "distant" and "evasive" are used to create "blurring" effects and a water metaphor is employed once again by "drowning the sense of tonality" (in French, noyant le ton).

With Ethiopian music being largely modal, the use of harmonic ambiguity in order to arrive at unexpected modulations is not commonplace. Instead, Astatke uses a device which I have called "subverted tonality" whereby an implied tonality is undermined by playing a different, or "wrong" root note throughout the entire song. Such is the case in the piece "Yekatit" which, for all intents and purposes is in the key of $\mathrm{Bb}$ minor (using the batti minor with a raised fourth scale) but in which the bass part repeatedly uses an ostinato figure on the A (or major seventh). 
Finally, French composers from the turn of the twentieth century sought to break away from rhythmic conventions and the metered dance forms that dominated eighteenth and nineteenth century classical and romantic piano music. From Ravel's undulating water pieces such as "Jeux d'eau" (1902) and “Ondine" (1908) to Satie's Gnossiennes (1890) which did away with barlines altogether, a new sense of freedom was being pursued in the area of rhythm. In much traditional Ethiopian music too, as is seen in the case of Asnaqetch Werqu's "Sabye", songs are performed in a rubato, non metrical style. This practice was continued in the cascading saxophone introductions of Getachew Mekurya.

Of course these fairly common musical devices are not exclusive to impressionism or to contemporary Ethiopian music. However I would argue that in terms of intention and why these devices are used, there exists a link between them. The effect created through the use of these musical devices is that of depicting or entering into a dream-trance state. As Lockspeiser (1963) points out in his analysis of Debussy's musical relationship to dream-trance, "the fantasies to which Debussy gave a musical expression were almost Surrealist fantasies, the chaotic fantasies of dreams, such as we hear in the scene of the vaults of Pelleas (56). One of Debussy's most famous works, Prélude à l'après midi d'un faune was based on a poem by Mallarmé of the same name, which according to Lockspeiser, "is an exploration of the borderlands between the conscious and the half-conscious, the waking state and the state of reverie" (Lockspeiser 1963, 52).

In traditional Ethiopian cultures an example of the close relationship between music and the subconscious realms can be found in the $z \bar{a} r$ cult rituals, which appear in many countries around the horn of Africa, Egypt and the Middle East but which are thought to have originated in Ethiopia and have existed since at least the sixteenth century (Natvig 1987, 675). Such ceremonies 
involve singing, dancing, smoking (alternatives include the chewing of qat, a plant stimulant, or drinking coffee) and animal sacrifices in order to exorcise or appease malevolent spirits that have taken hold of someone's body. According to Natvig's understanding of a zār ceremony,

by smoking, singing and moving the body, she was deliberately working herself into a controlled ritual possession. It seems to me that all the ceremonial elements discussed above are aimed at mitigating the spirits who inflicted the illness or misfortune, in order to transform them into benevolent or at least harmful spirits. This end is achieved through ceremonial zār possession, as in the $z \bar{a} r$ cult (Natvig 1987,683).

Such ceremonies are fairly ubiquitous amongst many Ethiopian cultures and are tolerated (if not approved of) by the Coptic Christian structures that dominate the Ethiopian religious landscape (Shelemay 1994, 30).

While $z \bar{a} r$ rituals may not directly be the subject of the music explorations of Astatke, Mekurya and Guebrou it is not difficult to draw links between this culture and where their music resides aesthetically. Mekurya's music, and the ceremonial presentation of it with ritualistic costume and physical presence and movement, recall the warrior before battle, driving his troops into fervent trance states. Guebrou's music is that of a religious visionary, her piano pieces are quiet illuminations of spiritual incandescence. Astatke's compositions are future-impressionist tone poems and perhaps most strongly evoke dreamtrance states in an Afrofuturist sonic spacescape.

My ambition in writing Addis Nocturnes was to reflect this exploration of the borderlands between the waking and half waking state. To some extent this ambition draws upon the notion of the dream states of Debussy's music and the trance rituals that underlie much of Ethiopian musical expression. It differs slightly in intention however from both of these forms. In Ethiopian culture, such music is used ritually as a method of transferring the individual 
from a conscious to a sub-conscious state. In Debussy's music, as well as that of Ravel, such depictions of dreaming are literal, descriptive and follow clear narrative structures. Thus in Prélude à l'après-midi d'un faun, the 110 measures of the piece match the 110 lines of Mallarmé's poem, with narrative events such as the "incessant shapes that rise in blindness" at line 51 of the poem being matched in the music by ascending strings and clarinet. My intention with Addis Nocturnes was neither descriptive nor prescriptive; instead the pieces are meant to convey passing glimpses of this in-between state. Indeed I would be happier that this music was viewed as building on Satie's vision of "furniture music" 30 than concert music. It is also not dissimilar in idea (although not in actual sound or style) to Brian Eno's notion of ambient music as "music that allows you any listening position in relation to it. This has been widely misinterpreted as background music...creating a sense of space that alters your environment" (quoted in Grant 1982). However I would add that in both Satie's furniture music and Eno's ambient music, the aim would appear to be to change the listener's relationship to their physical environment through the use of music (subliminally or otherwise). In Addis Nocturnes this music is intended to reflect a cognitive state of drifting in and out of consciousness.

In these pieces then there were certain "rules" that, although I did not set them for myself prior to composing, became apparent the further I went. The two primary "rules" were, first, to avoid development of musical materials, thus avoiding implying narrative structures and secondly to keep the music as much as possible at a low dynamic level - too many loud passages or abrupt changes would logically disrupt the flow of the semi-conscious state. Alongside this, although the music is by no means minimalist in terms of repetitive, slowly evolving motifs, it is highly restricted. I wished to create music out of the barest of musical materials, using just the kiñit wherever

\footnotetext{
30 Satie's "furniture music" pieces comprise three sets composed in 1917, 1920 and 1923 respectively.
} 
possible. Although I composed two pieces based exclusively on one pentatonic scale ("Addis Nocturnes VI" and "VIII") the pieces contain usually not more than two or three of these scales and generally avoid chromaticism. In this way I felt I was able to create a closely delineated sonic world in these compositions.

\section{The Process}

All these pieces began as improvisations at the piano based on one of the specific kiñit. With the tizita minor and batti minor with a flattened fifth being two of the most distinctively Ethiopian amongst the scales, they feature prominently in the works, however I experimented with some of the lesser used modes. Unlike most Ethiopian music which stays largely in one mode and tonality during the entirety of a piece, I experimented with some shifting tonalities and modes, trying to find different kiñit which would complement each other. A full table of the kiñit used in each piece can be viewed below.

$\begin{array}{lll}\text { Piece } & \text { Primary kiñit } & \begin{array}{l}\text { Other kiñit used } \\ \text { I }\end{array} \\ \text { B Tizita Minor } & \text { C\# Anchihoye } 31, \text { F\# Batti Minor (b5) } \\ \text { III } & \text { F Tizita Minor } & \text { D Anchihoye } \\ \text { IV } & \text { F Tizita Minor } & \\ & \text { Ab Tizita Major } & \text { Db Tizita Minor, Gb Batti Major, Eb Batti } \\ \text { V } & \text { C Batti Major } & \text { Minor } \\ \text { VI } & \text { E Tizita Major32 } & \text { E Batti Minor (b5) } \\ \text { VII } & \text { G Batti minor (b5) } & \text { G Batti Minor } \\ \text { VIII } & \text { C Tizita Minor } & \text { A Batti Minor (b5), Eb Anchihoye, F Batti } \\ & & \text { Minor (b5), B Anchihoye }\end{array}$

\footnotetext{
31 The scale used is one of my inventions, closest to the Anchihoye scale but with a flattened third in place of a flattened second.

32 Using a flattened second, a scale used by Guebrou.
} 
These choices of kiñit were developed intuitively in each piece but often there are pitch relationships between the scales. For example in "I", the second, and fourth degree of the B tizita minor scale are the first and third degree of the C\# anchihoye scale. Indeed all three scales have two notes (F\# and $\mathrm{C \# )}$ in common, while the other three notes change.

After some time establishing a major theme in each piece I would move to the computer to continue the composition, soon finding that the pieces were beyond my limited pianistic capabilities. All through the writing process I immersed myself both in Ethiopian music and in the scores and works of the French impressionists. This came out at certain times, with "II" being distinctly Satie-esque. Another piece, in which I consciously tried to imitate some of Ravel's piano techniques, ended up being aborted; the piece was both too derivative and almost impossible to play. In some of the later pieces I felt I developed an approach that was not at all derivative, either of the Ethiopian or French influences on the music. "I", which was in fact the final piece I wrote, is closest to achieving the style of nocturne that I set out to achieve. The sense of polytonality in this piece, where different kiñit are being used simultaneously is, from my perspective, the most effective at achieving the dreamlike state, while the melodic contours are unusual and unexpected.

I workshopped the pieces in August 2016 with concert pianist Jeffrey Grice in Paris. After some minor adjustments, Jeffrey proposed to premiere the work at a concert in Paris in March 2017, in a programme that included Maurice Ravel's Le Tombeau de Couperin (1917). The concert was part of a soirée in honour of Ravel's birthday, organized by the Association des Amis de Ravel and took place in front of a capacity audience at the Cinema de Balzac. Some days later, Jeffrey recorded the pieces at the Studio de Meudon in Paris. 


\section{Axum}

\section{The Idea}

The idea of composing for orchestra was both daunting and intriguing. Initially I would have liked this work to have been a much larger component of my creative portfolio, but the logistics of convincing an orchestra to take on a project such as this proved too difficult. The audio version included here is of a MIDI orchestra rather than a live version. Therefore I see this piece as an experiment and as an indicator about a possible direction for a new type of hybrid style, rather than a concept that has been fully explored and developed.

My initial idea was to write a piece for improvised saxophone and orchestra. This proved useful as I worked on the piece, improvising a saxophone solo, which gave me some naturalistic materials to work with. Eventually though, the orchestra took over and the sound became too filled out that the saxophone became unnecessary. I was also partially influenced by logistical issues on this - I feel that I am far more likely to have an eventual orchestra performance of the piece without the soloist.

Unlike the two previous projects included in the portfolio, this piece was not created from a clear theoretical vision. It was composed intuitively, using the kiñit as an initial starting point, but really just allowing the music to take its own shape. I used the kiñit as a restricting agent, limiting myself to using only a few harmonic colours and melodic modes, which I felt was essential for me as I am not hugely experienced in composing for orchestra.

I named this piece Axum as a reference to the ancient Ethiopian city which was the center of a great trading empire from approximately $100 \mathrm{CE}$ to 900CE. I thought this was fitting because of the centrality of cultural exchange to this 
work, and the importance of translation of musical materials from one context to another.

\section{The Process}

The use of kiñit was once again useful as a restriction in putting together harmonic materials for the orchestra. The piece is based around four kiñit, the F tizita minor, B anchihoye, A tizita minor and Db anchihoye. There are echoes of an Ethiopian musical language but it could not be described as coming from an Ethiopian tradition, as most of the melodic shapes are not ornamental.

I wished to further develop, or experiment with, some of the devices I used within Addis Nocturnes and, to a lesser extent, Tone Science. This can be recognized through the idea of tone colour, in which the vibraphone plays a key role, with reverberations of Mulatu Astatke's use of the instrument, and a sense of instability in the harmony, which is constantly shifting between chords based off the kiñit previously alluded to.

In terms of orchestration, both the vibraphone and harp take prominent roles in the early section of the piece, creating an interesting tone colour. The violins take on a background role in the initial section while the cellos and double basses are in the foreground from their entrance until the introduction of the brass. After the shimmering notes of the clarinet and tremolo strings, the brass and percussion enter as a combative, almost grotesque element, juxtaposing with the delicate atmospheres prior to their entry. The use of brass in this way, hinting at militaristic traditions, is something I admire in many composers' works such as Shostakovich and selected John Adams. The coda section returns to the atmosphere of the first section, and the piece ends in a fairly open ended and ambiguous fashion. I feel that this work is the first 
movement of a larger symphonic work and it points at a creative direction I will be taking after my doctoral studies. 


\section{CONCLUSION}

This research project represents a physical and artistic journey that has taken me many years to complete, and indeed will, I envisage, underpin my creative work for many years to come. What began as a sense of affinity and curiosity became research, knowledge and understanding, but also a growing awareness of the limits of my knowledge and understanding. Nevertheless, my intention was never to make Ethiopian music but to find a way into making my own original music. I see the work that I have done not as an appropriation of a musical culture but as a translation of musical materials into a new musical landscape.

Along the way I hope to have contributed some useful material for other musicians and researchers in the field of music from Ethiopia. Many of the transcriptions I have made have not been attempted or published before. It is also the first time the assemblage of biographical information on these three Ethiopian musicians alongside critical analysis of their work, has been attempted. The research also examines in-depth the nature of hybridity and cultural mutation and the concerns surrounding the adoption of Ethiopian music by Western musicians and other agents (including myself). It has attempted to examine these issues in a balanced way, while recognizing my own position within this debate. It has shown how delicate these issues are, and how important it is for artists to not only understand the musical context of their work and that from which they are borrowing, but also to recognize the meanings that emerge in the presentation of new artworks that adopt materials from other cultures.

The issue of cultural appropriation is currently at the forefront of much academic discourse and public debate around the world. Rejecting the tendency to veer towards the polemics of this debate, which seem to happen all too frequently, this study argues for a nuanced approach, which sees 
culture as fluid and perpetually evolving, but also calls for historical injustices and power asymmetries to be respectfully acknowledged and reflected upon. The idea of hybridity to create new work is common to all cultures, as is demonstrated here by the Ethio-Jazz of Mulatu Astatke, the saxophone experiments of Getachew Mekurya and neo-classical/Ethio piano pieces of Emahoy Tsegue-Maryam Guebrou, as well as the music of Debussy, Ravel, Messaien, Reich, Budos Band, Woima Collective and any number of other artists. However, the expressive results of all of these musicians are completely individual and have the potential to be extended upon in any number of new ways. As such, the meaning of these artworks and their place within the context of cultural transaction can also only be examined individually.

My own artistic response to these issues has been to attempt to make new music that, although rooted in musical research, tries to defy the temptation of direct influence and easy categorization. My aim was to make new hybrids - in Tone Science this manifested itself as a bringing together of various strands of Afrofuturism; in Addis Nocturnes it meant finding a new piano language that drew upon both the music of Ethiopia and of French impressionism, finding within those languages the common thematic of dream/trance; Axum was a purely intuitive experiment in using my theoretical knowledge of Ethiopian modes as a restrictive element with which to construct a piece for symphony orchestra. From these creative propositions I have tried to make unique music, where the cultural and the personal, the intuitive and the theoretical, the historical and the futuristic, intersect and commune.

Finally, to return to the source itself: through many unexpected twists and turns along the route, the three Ethiopian musicians that are the subject of this research have all had a degree of deserved recognition and fame for their unique body of work, albeit in the twilight of their careers. It is equally 
exciting to see music in Ethiopia now take off on altogether new itineraries; through the electric krar experiments of Mesele Asmamaw or in the electronic productions of the Ethiopiyawi movement, for example. The 'golden age' (if ever it was that) of giants such as Mulatu Astatke, Getachew Mekurya and Emahoy Tsegue-Maryam Guebrou may now be recorded, fixed and in safekeeping on a series of Ethiopiques discs, but new music from Ethiopia is alive, expanding and traveling once more. 


\section{APPENDICES}
APPENDIX 1
Sabye

Asnaqetch Werqu

Allegro

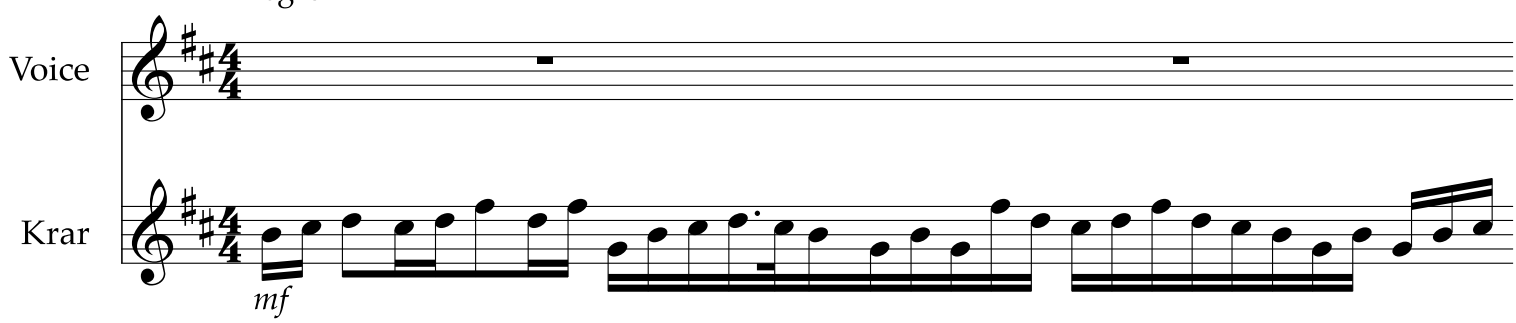

Voice

Voice $\overbrace{0}$

Voice

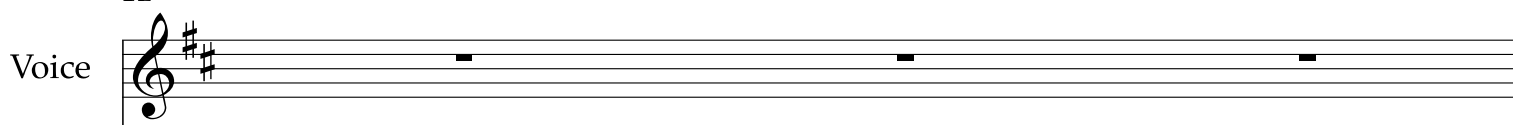

$\operatorname{Krar} \operatorname{lon}_{15}$

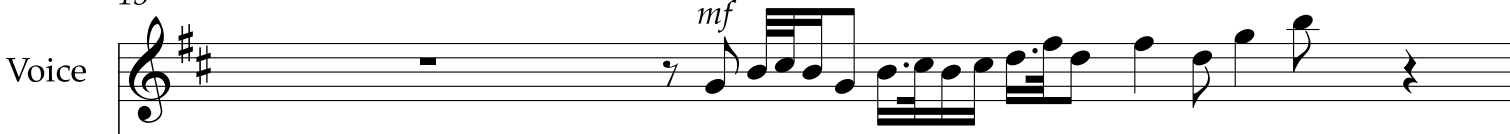

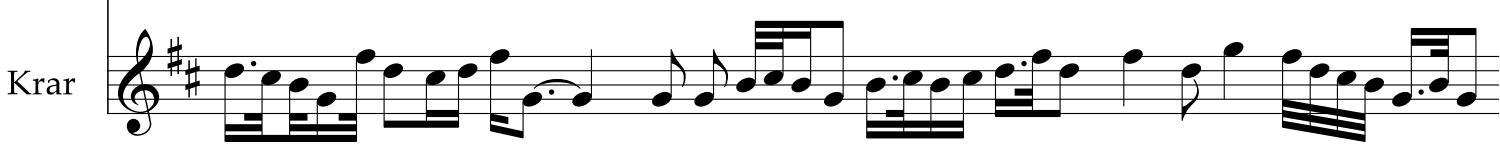


Voice $\mathrm{g}_{0}^{18}$

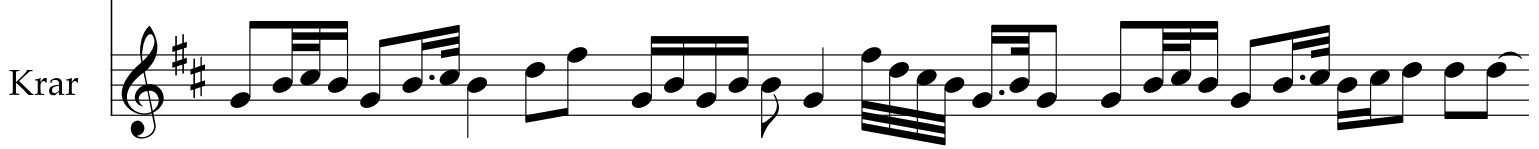
Voice $\mathrm{g}^{21}$ $\operatorname{Krar} \lg ^{0}$ Voice $\operatorname{lom}^{24}$

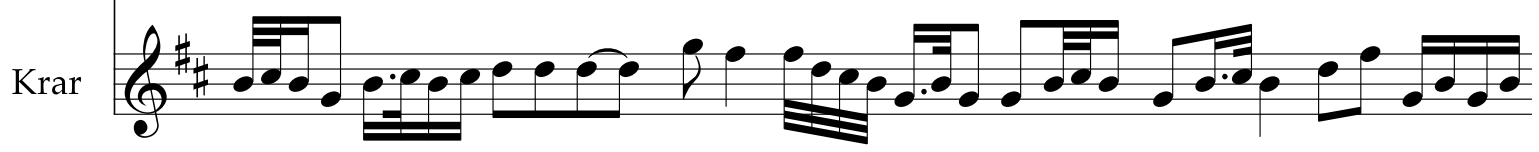
Voice

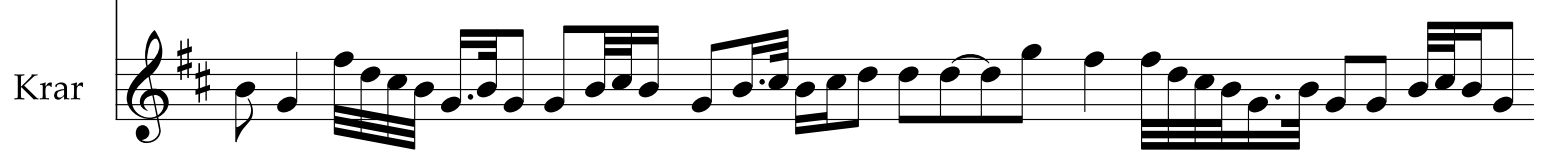
Voice

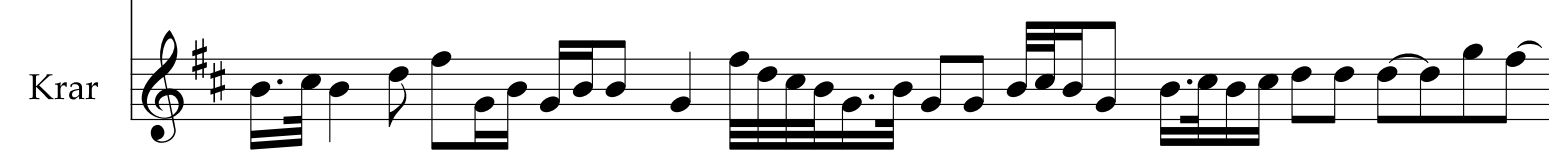
$\mathrm{O}^{33}$

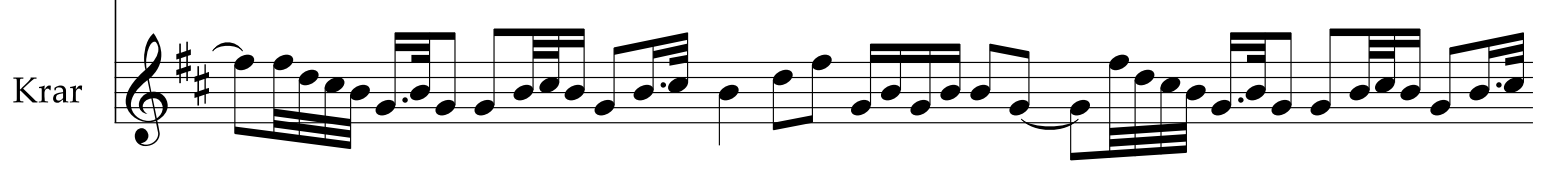


Voice $\operatorname{Krar}_{0}$ Voice $g^{39}+2$

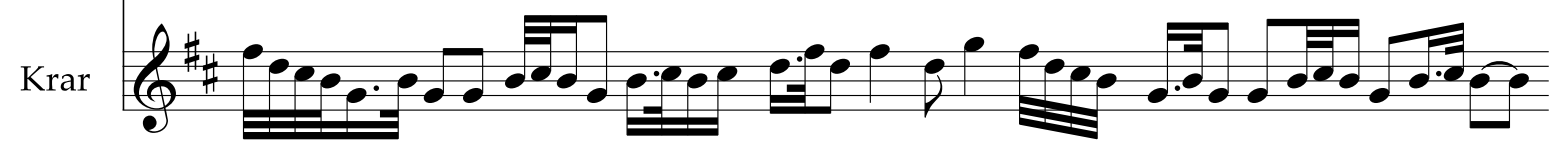
Voice

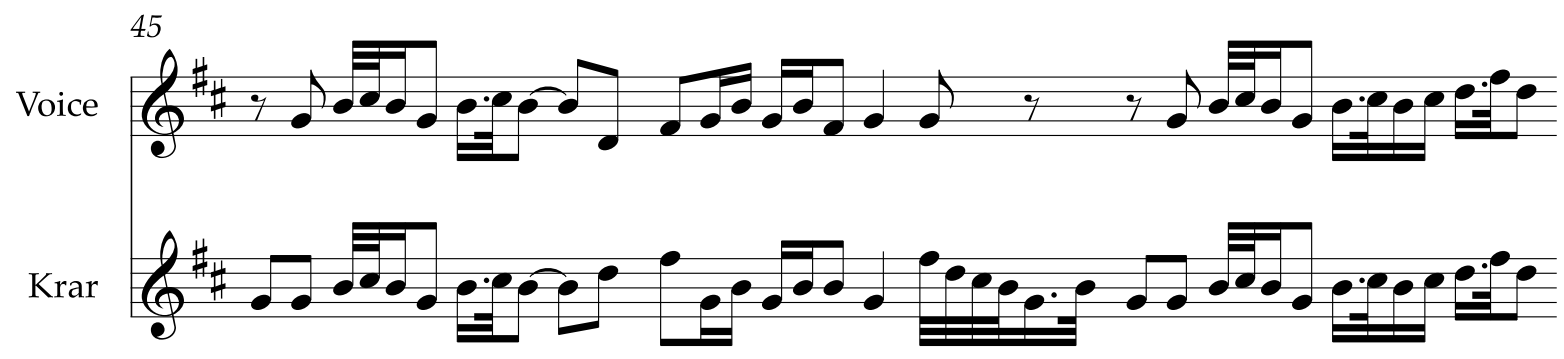

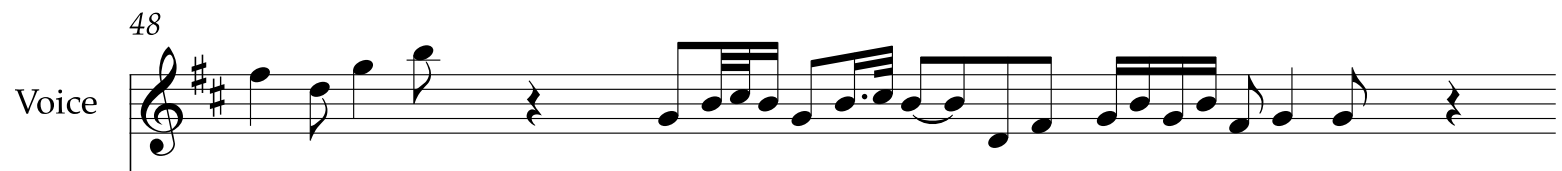

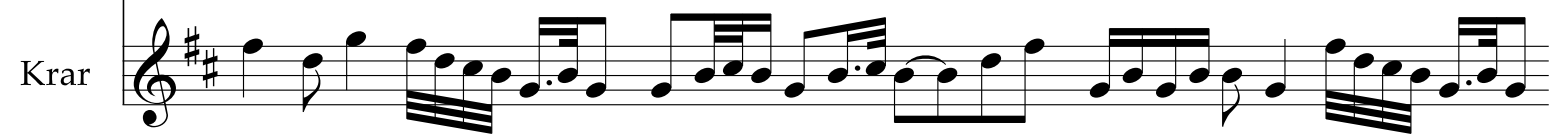
Voice $Q^{11}$ Krar

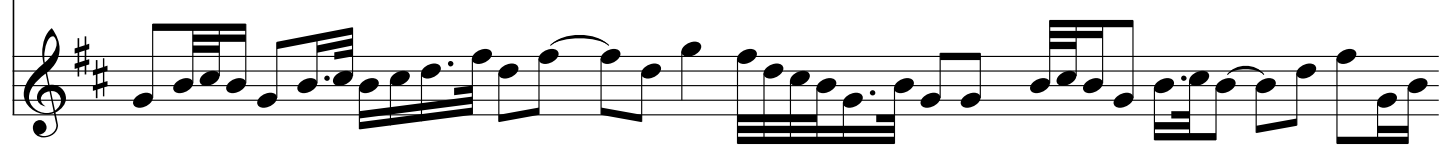


4

Voice

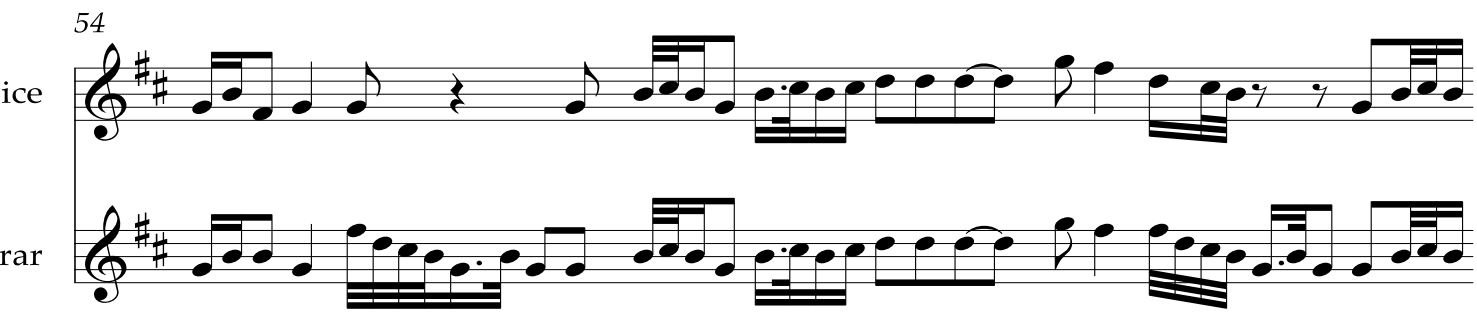

Voice

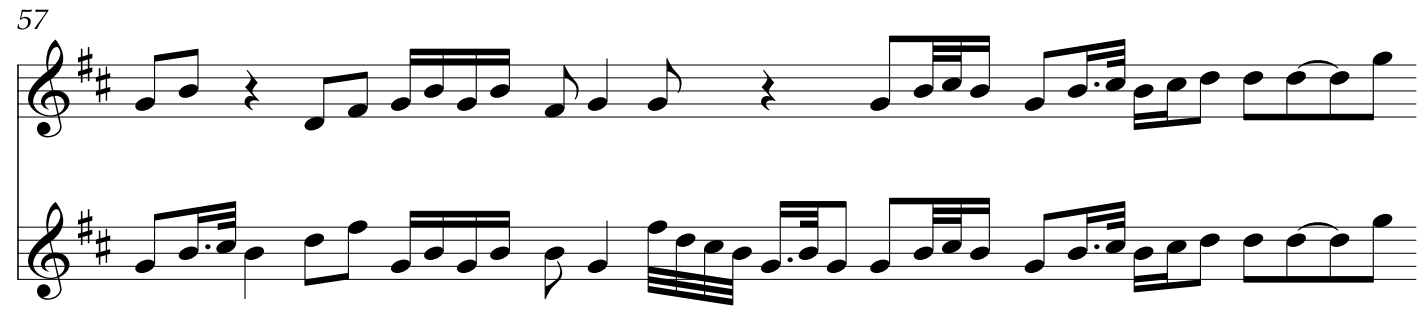

Voice

60

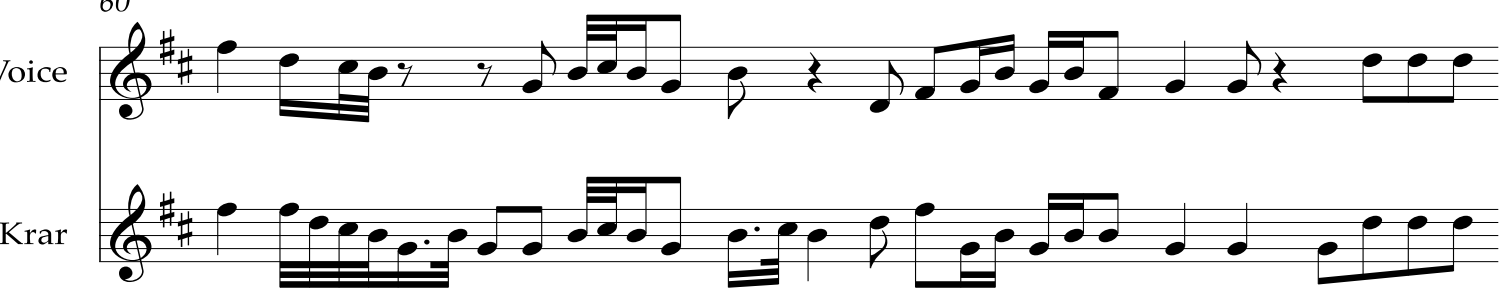

Voice

63

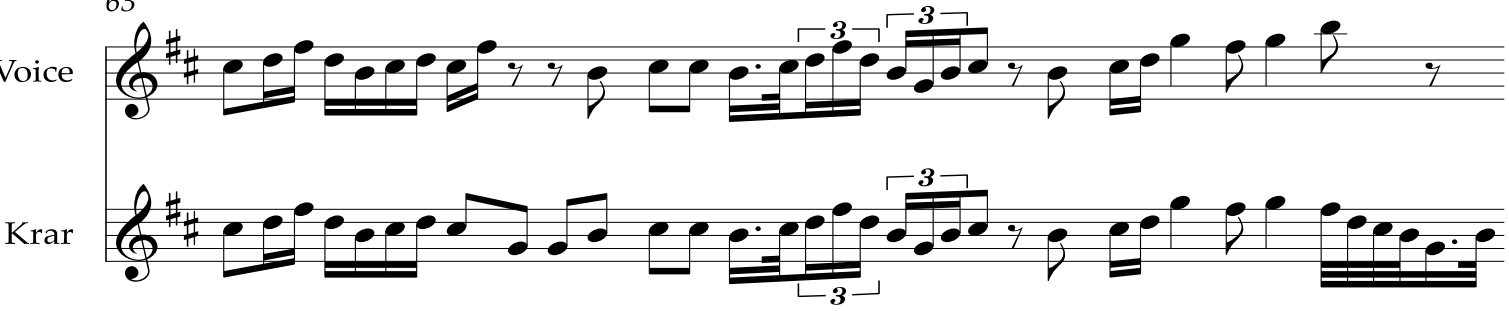

Voice

66

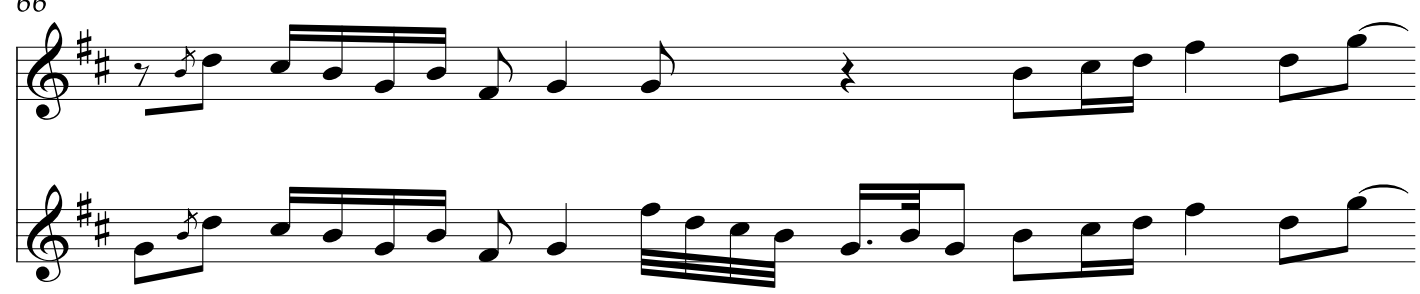

68

Voice

9

Kra

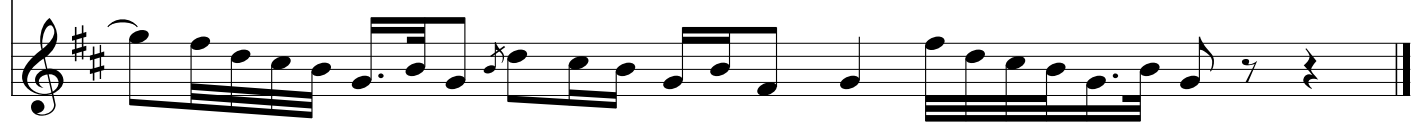

151 


\section{APPENDIX 2}

\section{Sabye}

Belnayesh Wubante and Assegedetch Asfaw
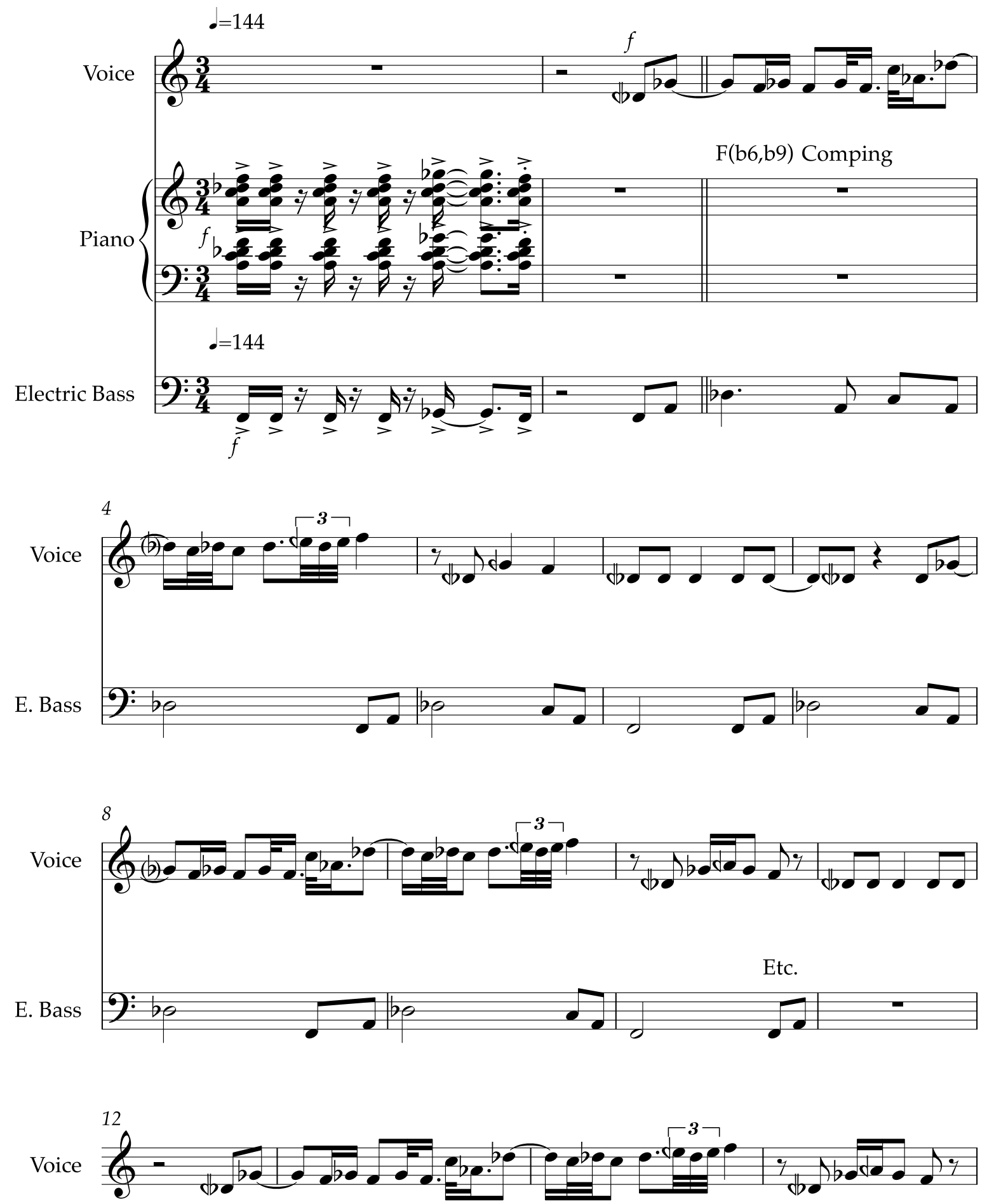


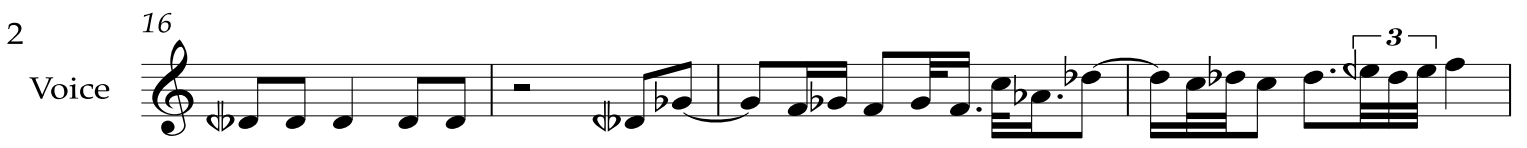
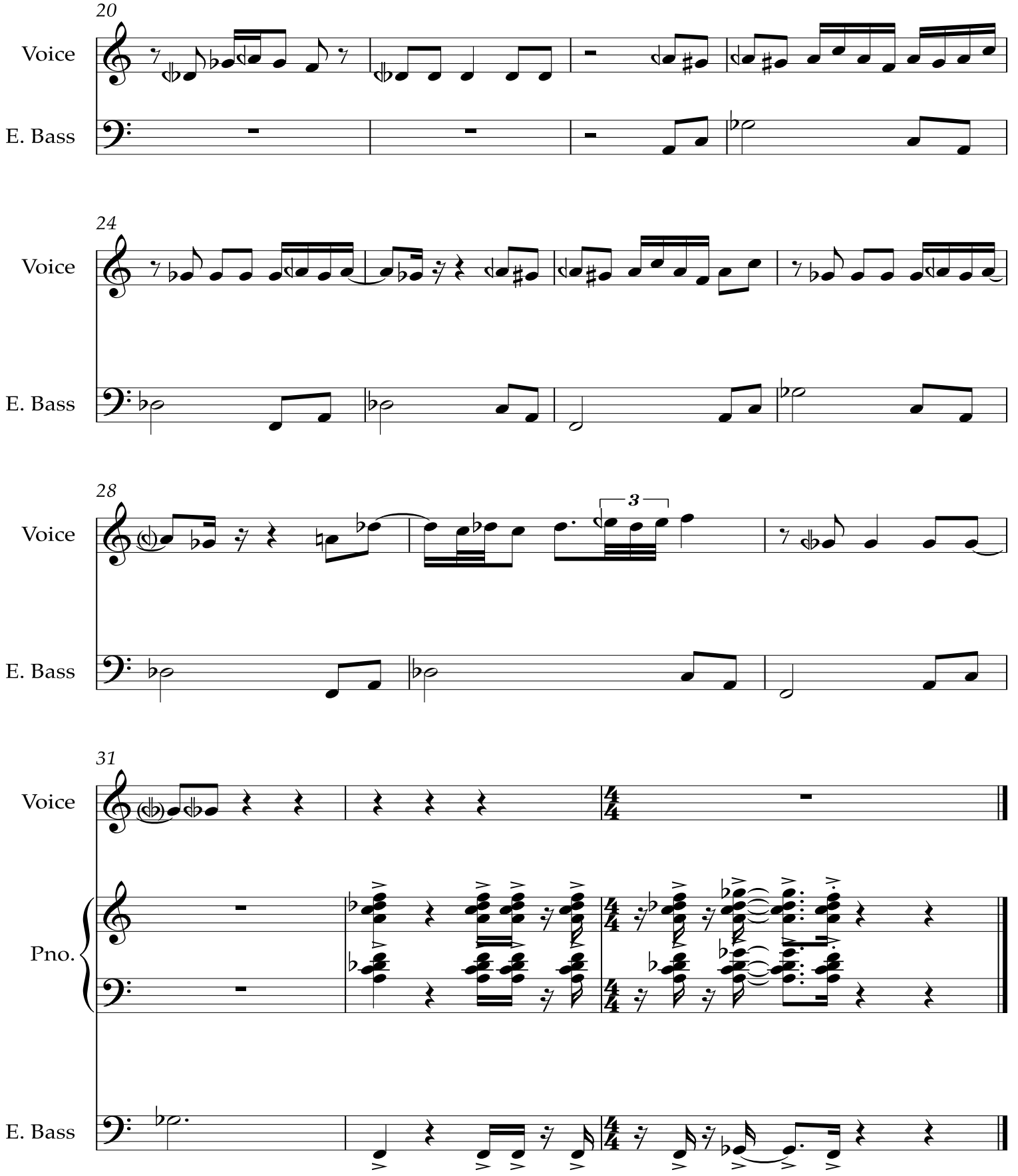
APPENDIX 3

Sabye

Mulatu Astatke

Tenor Saxophone

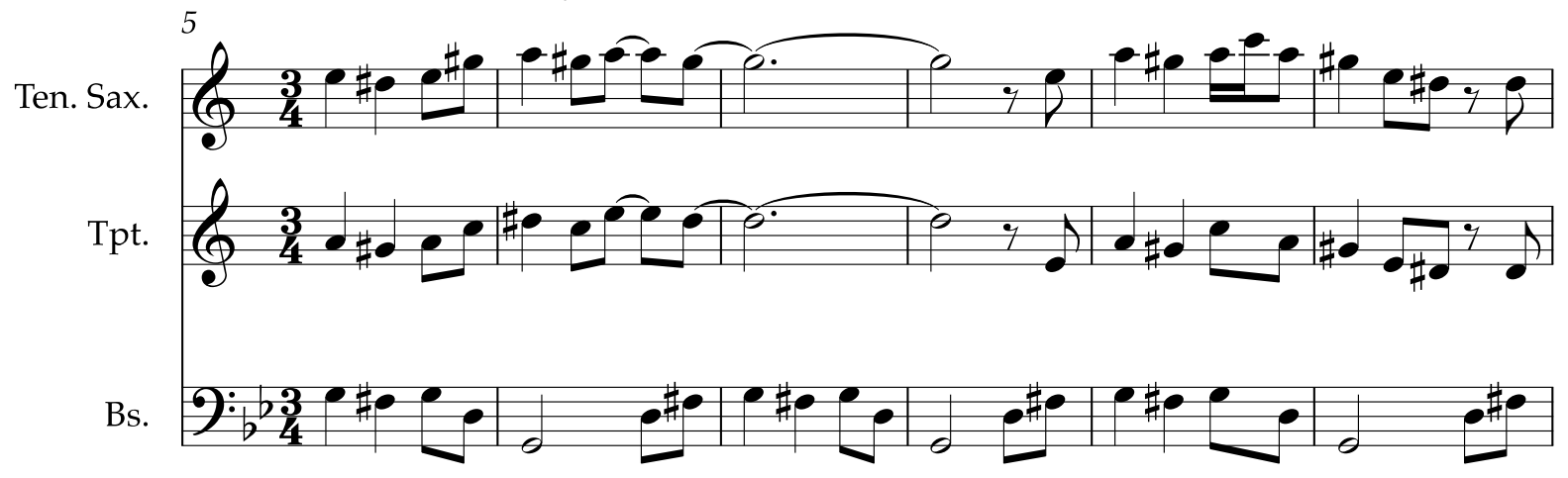

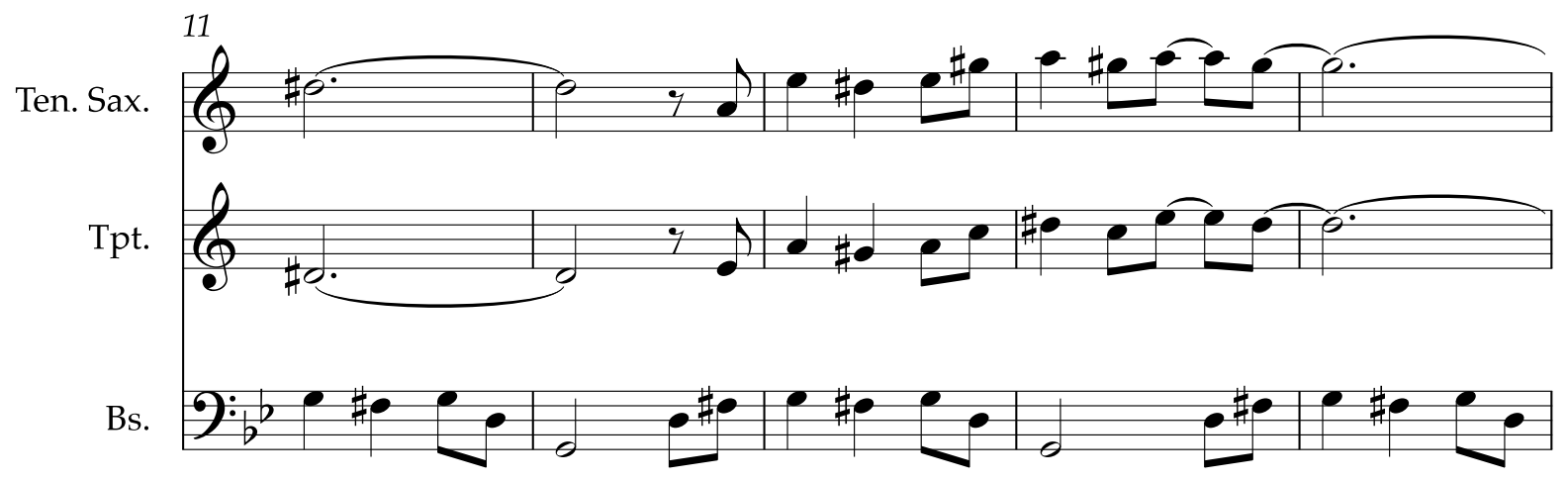

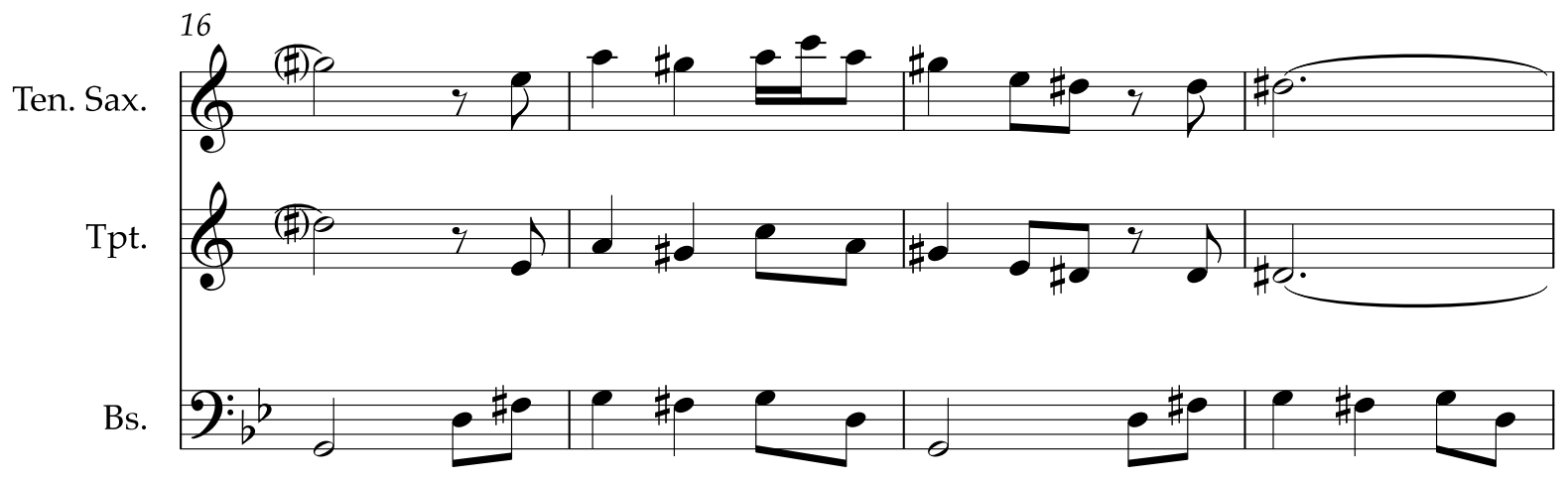


2
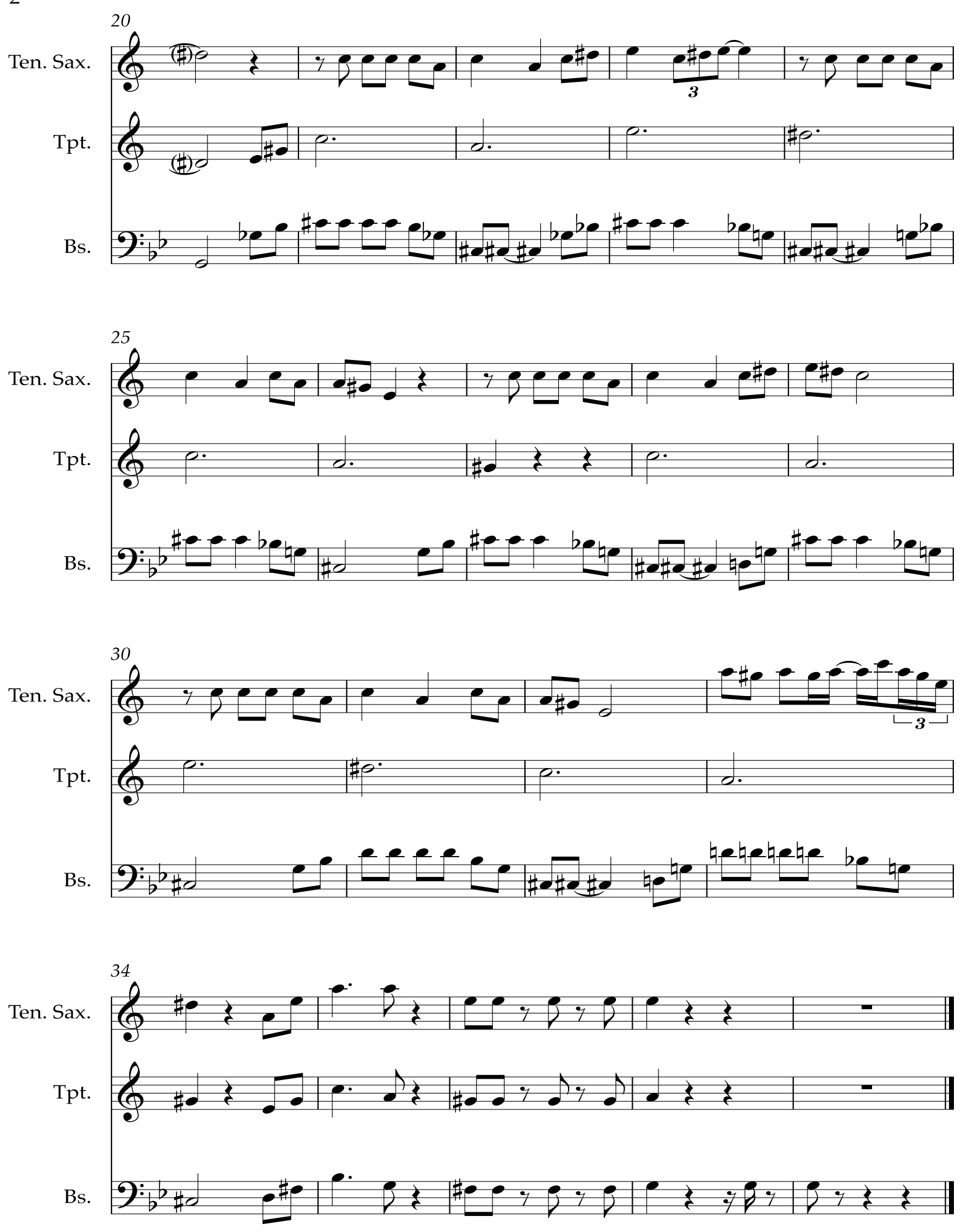

155 
APPENDIX 4

Yekermo Sew

Mulatu Astatke
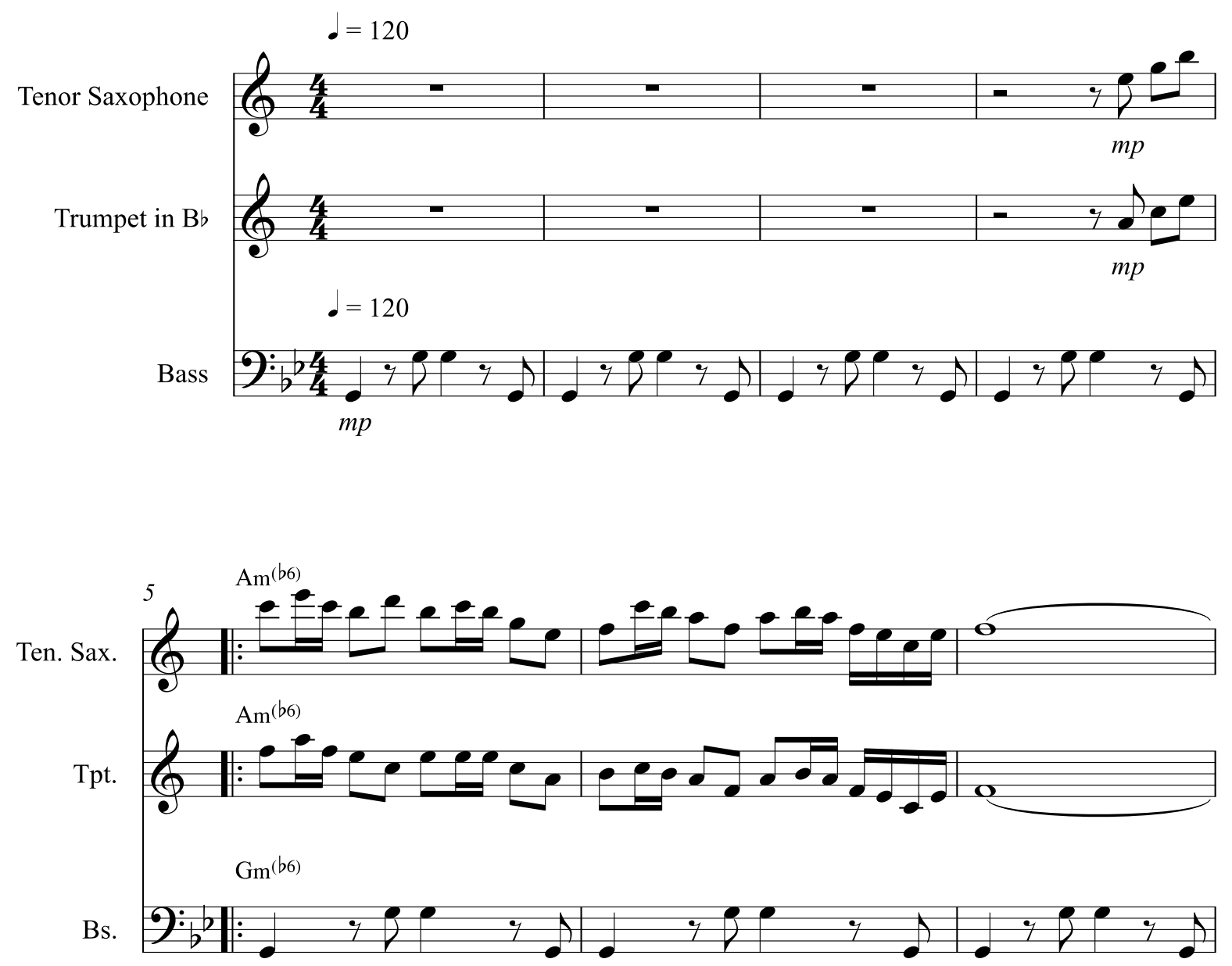

Ten. Sax

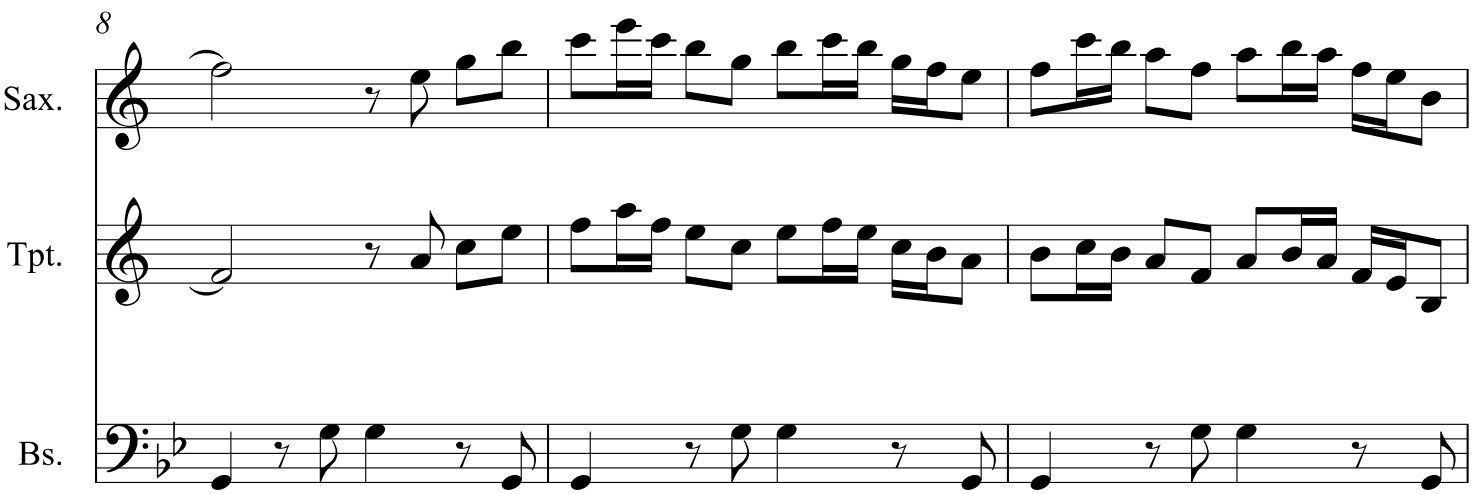

Bs.

156 
2
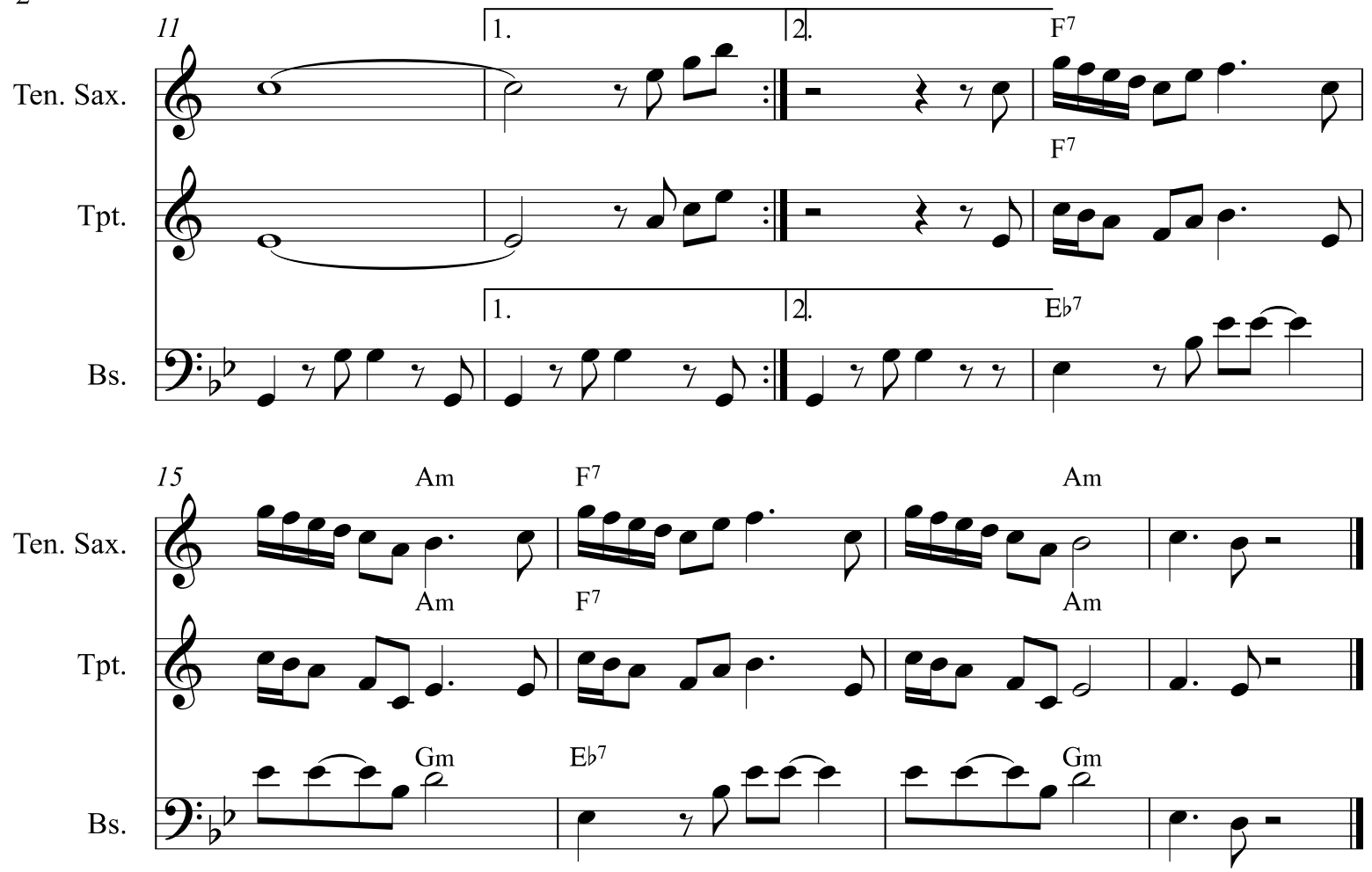


\section{APPENDIX 5}

\section{Yekatit}

Mulatu Astatke

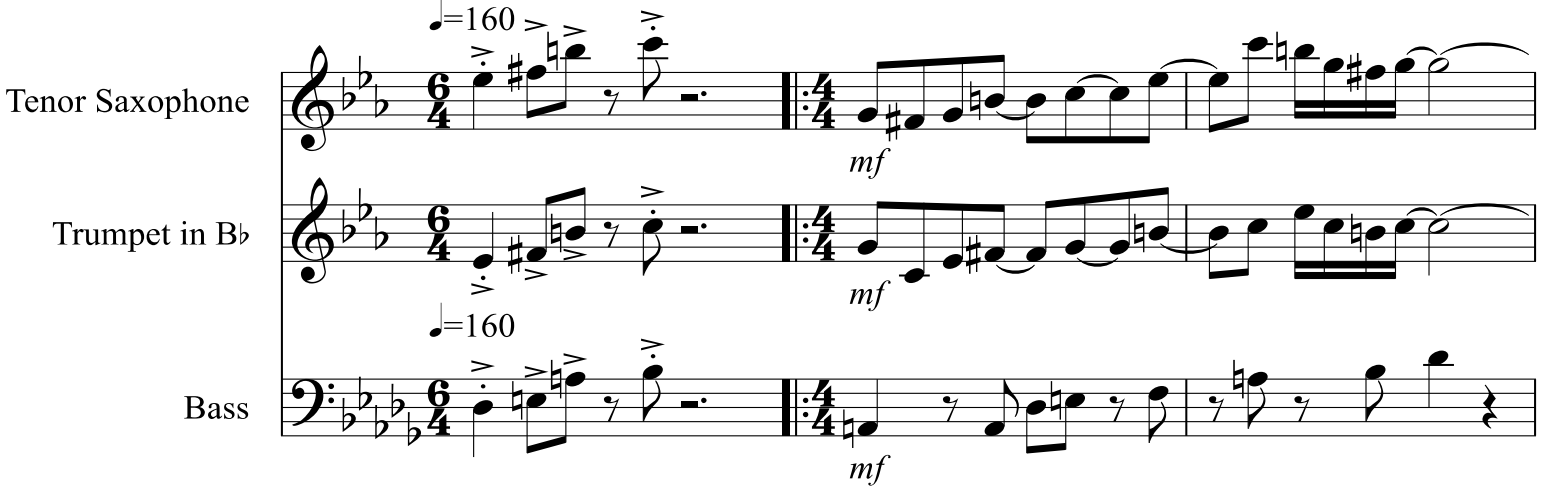

Ten. Sax.

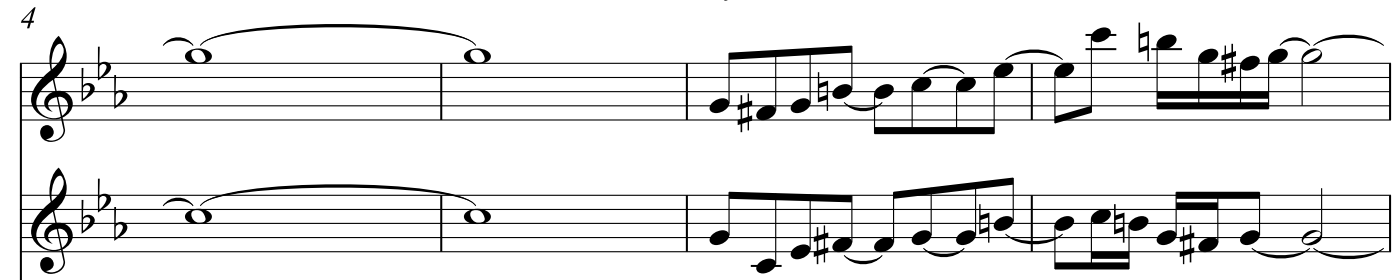

Bs.

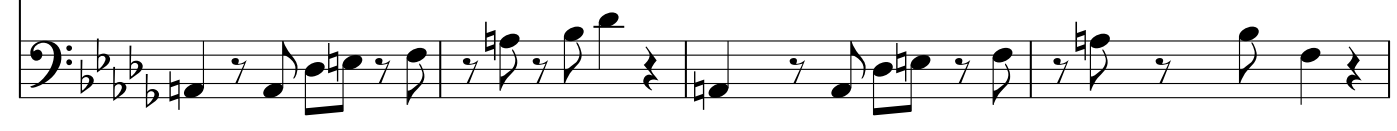

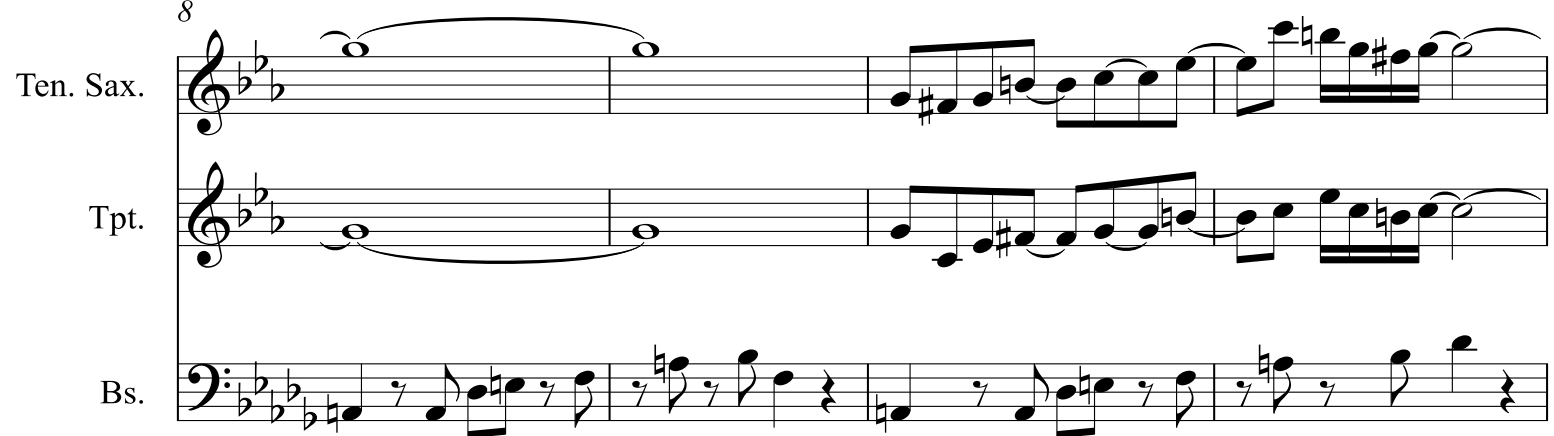

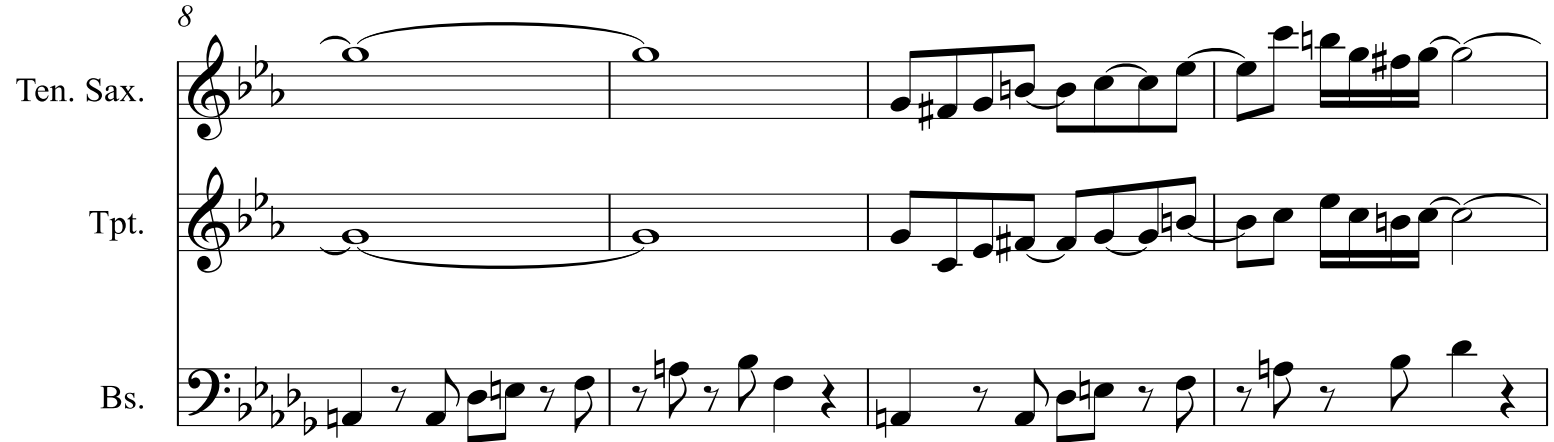

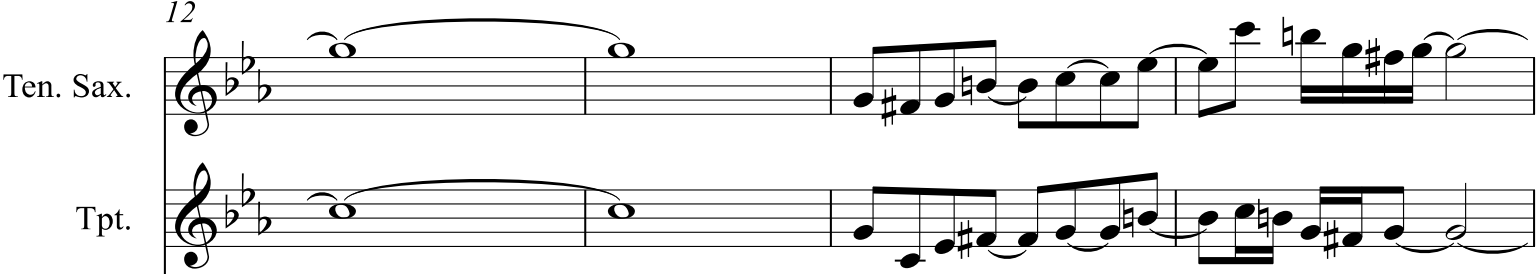

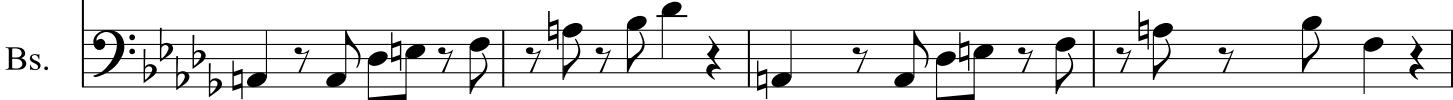


2
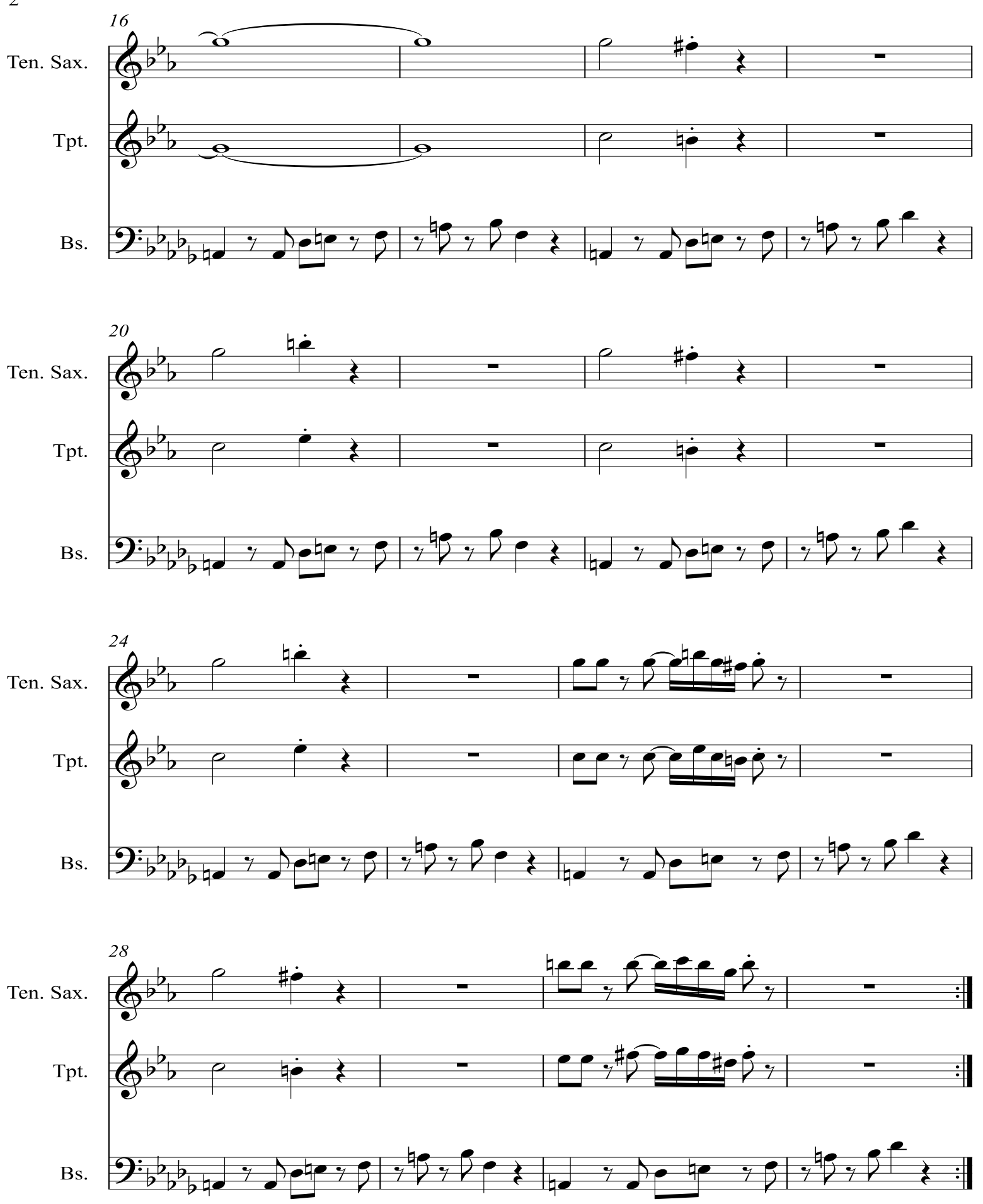

159 


\section{APPENDIX 6}

\section{Kasalefkut Hulu}

Mulatu Astatke
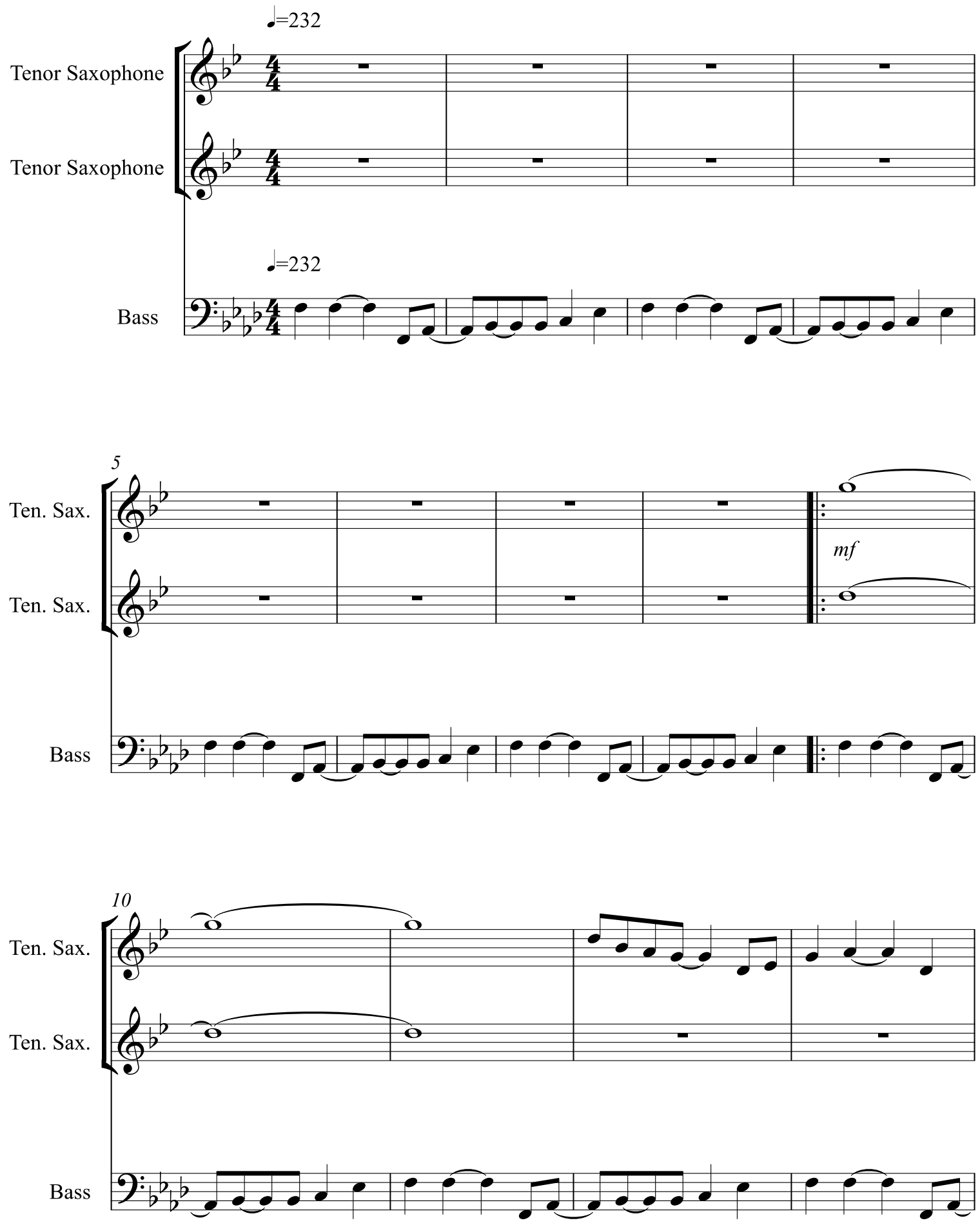
2

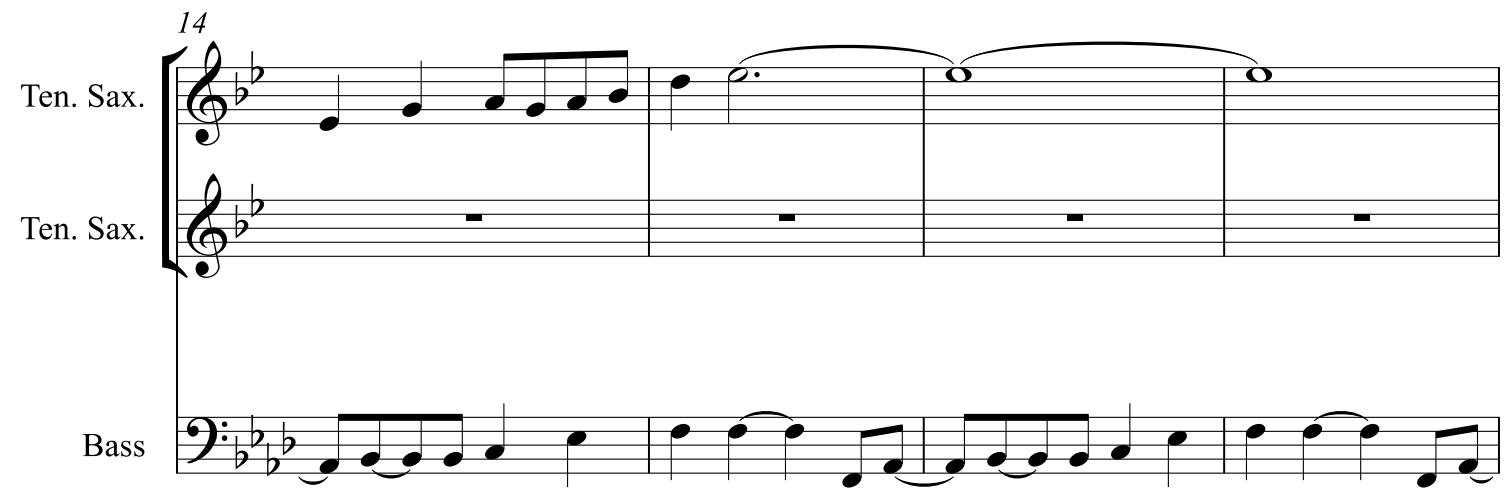

Ten. Sax. \begin{tabular}{|l|l|l|l|l|}
\hline \\
Ten. Sax.
\end{tabular}

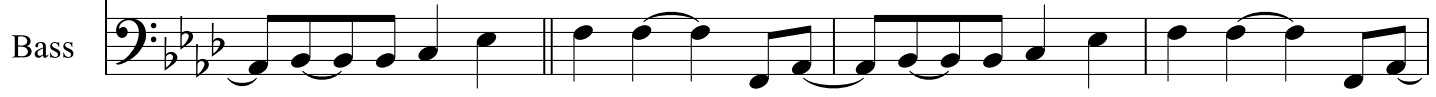
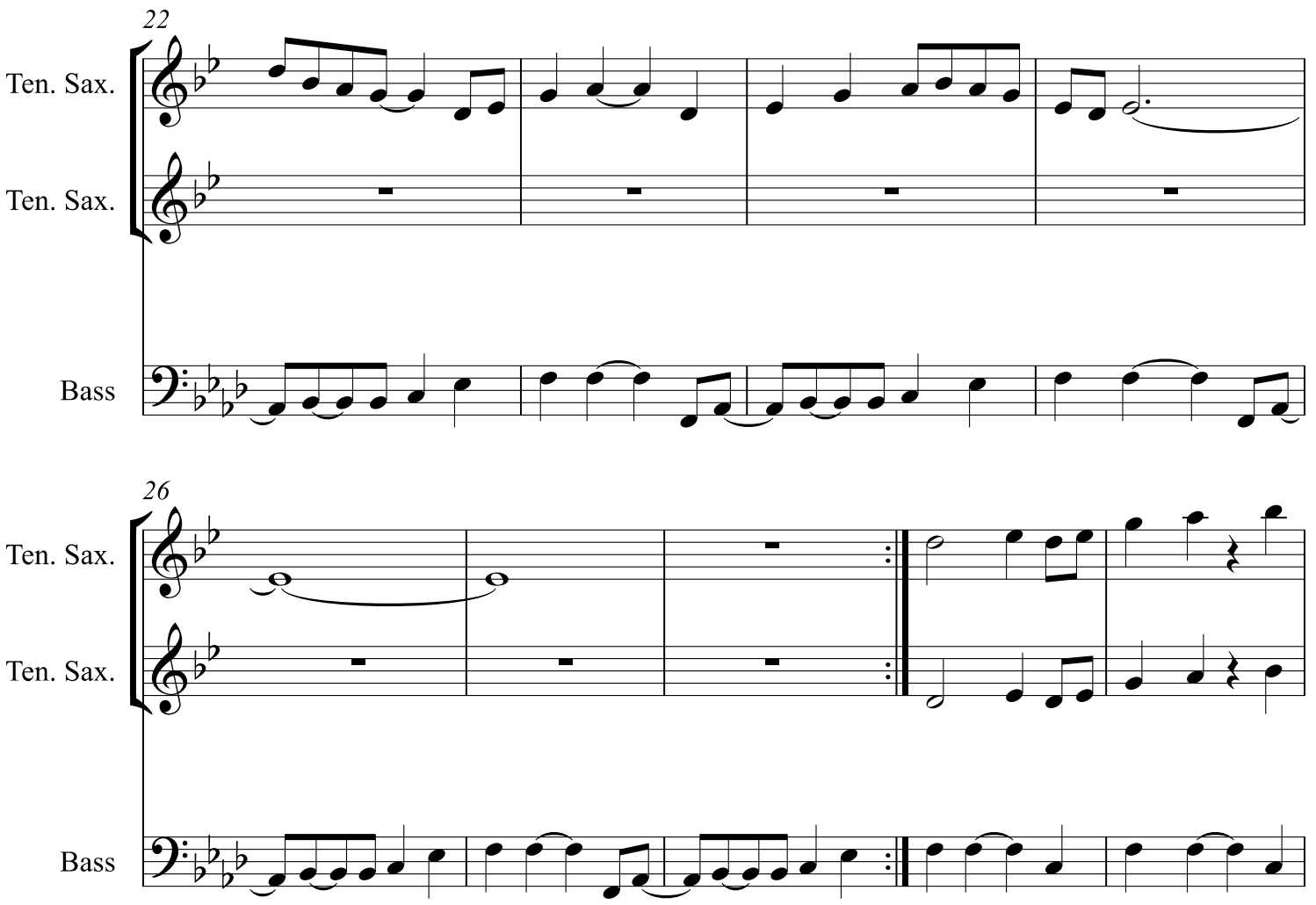

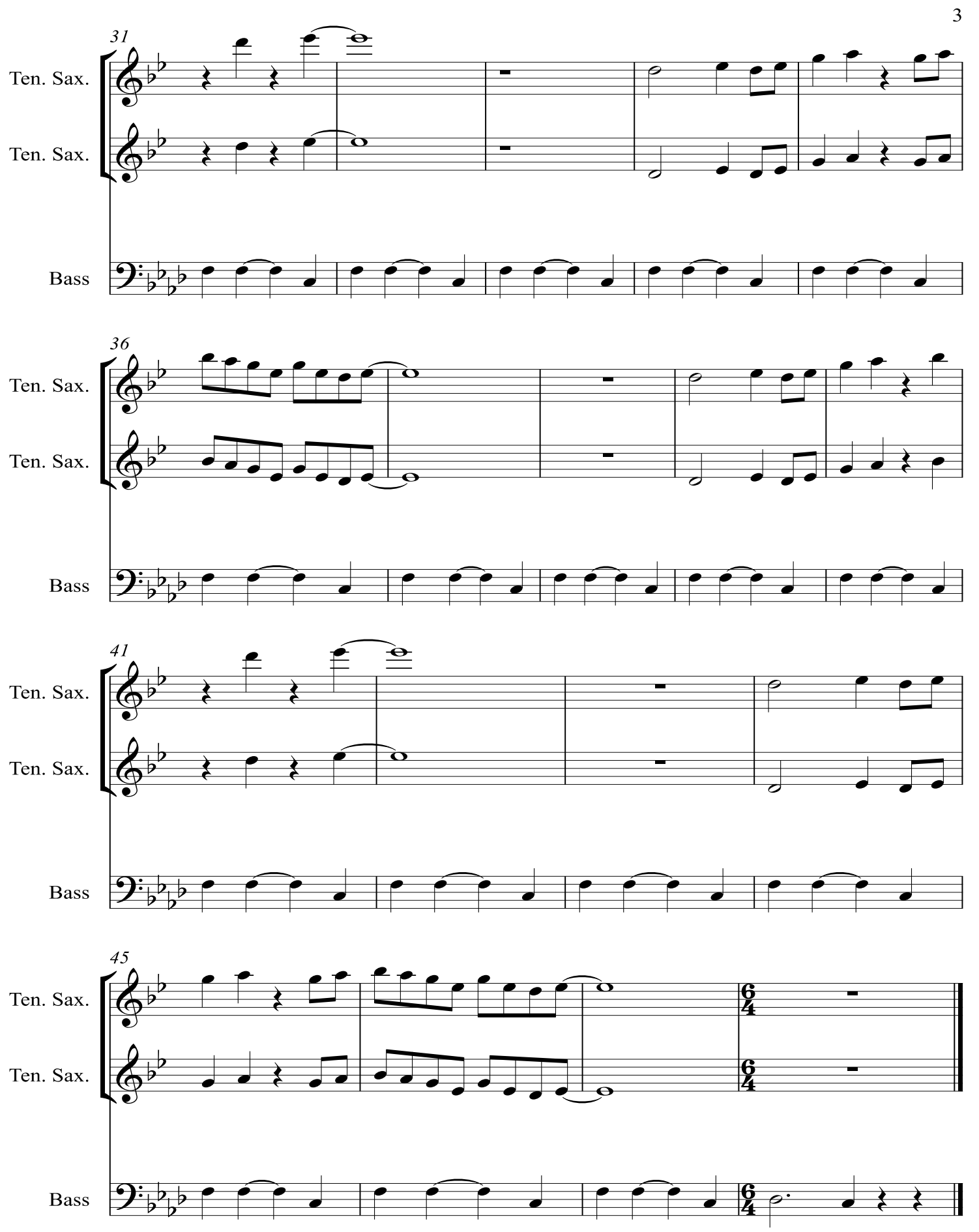

162 
APPENDIX 7

Yegelle Tezeta

Mulatu Astatke
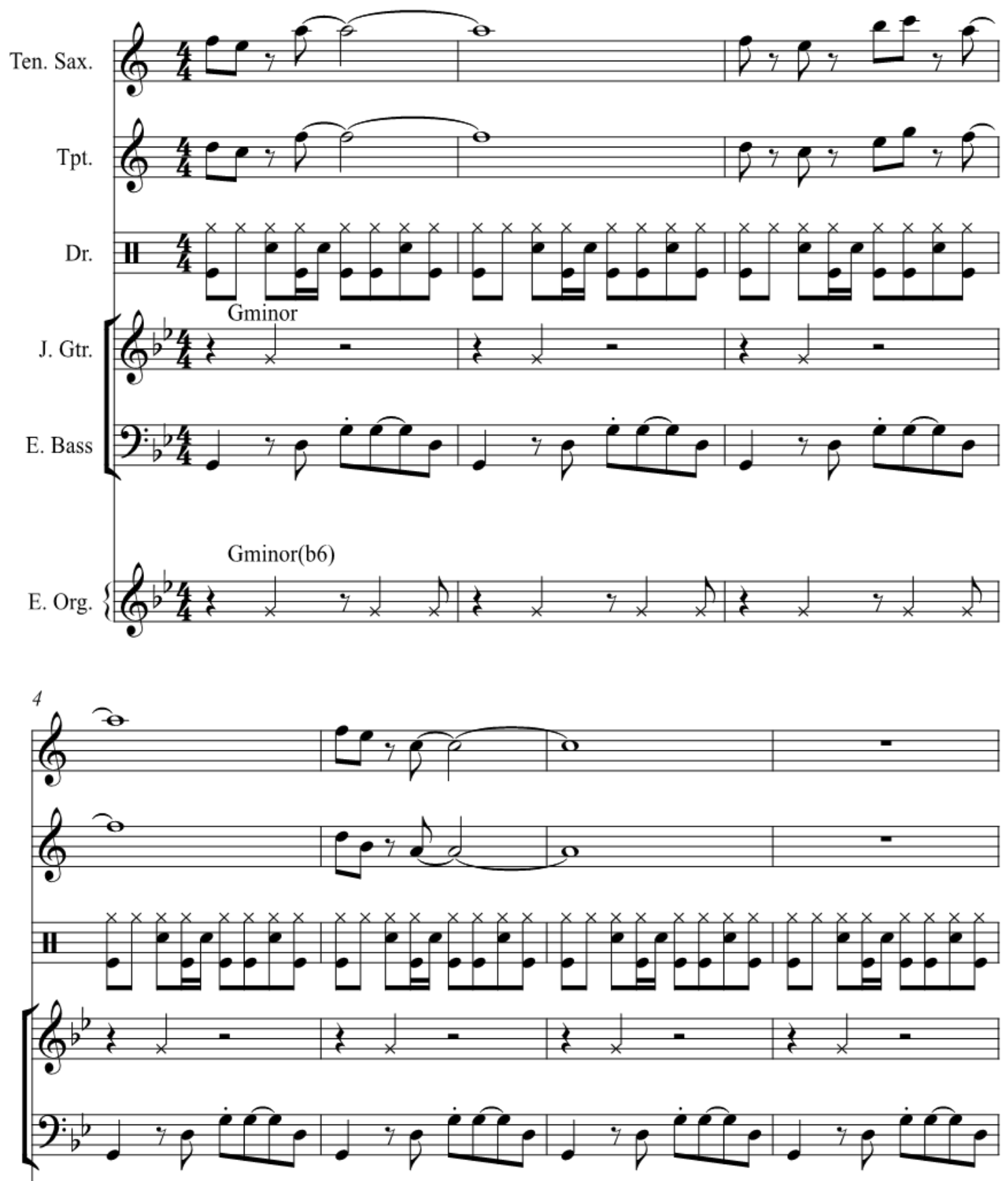

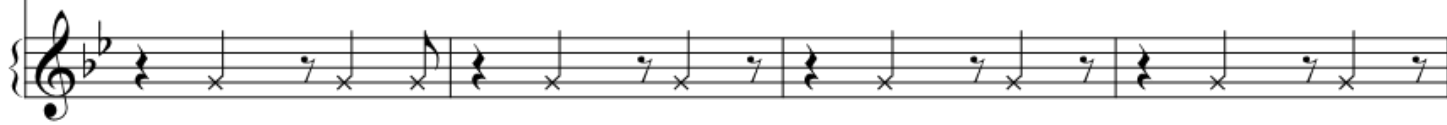




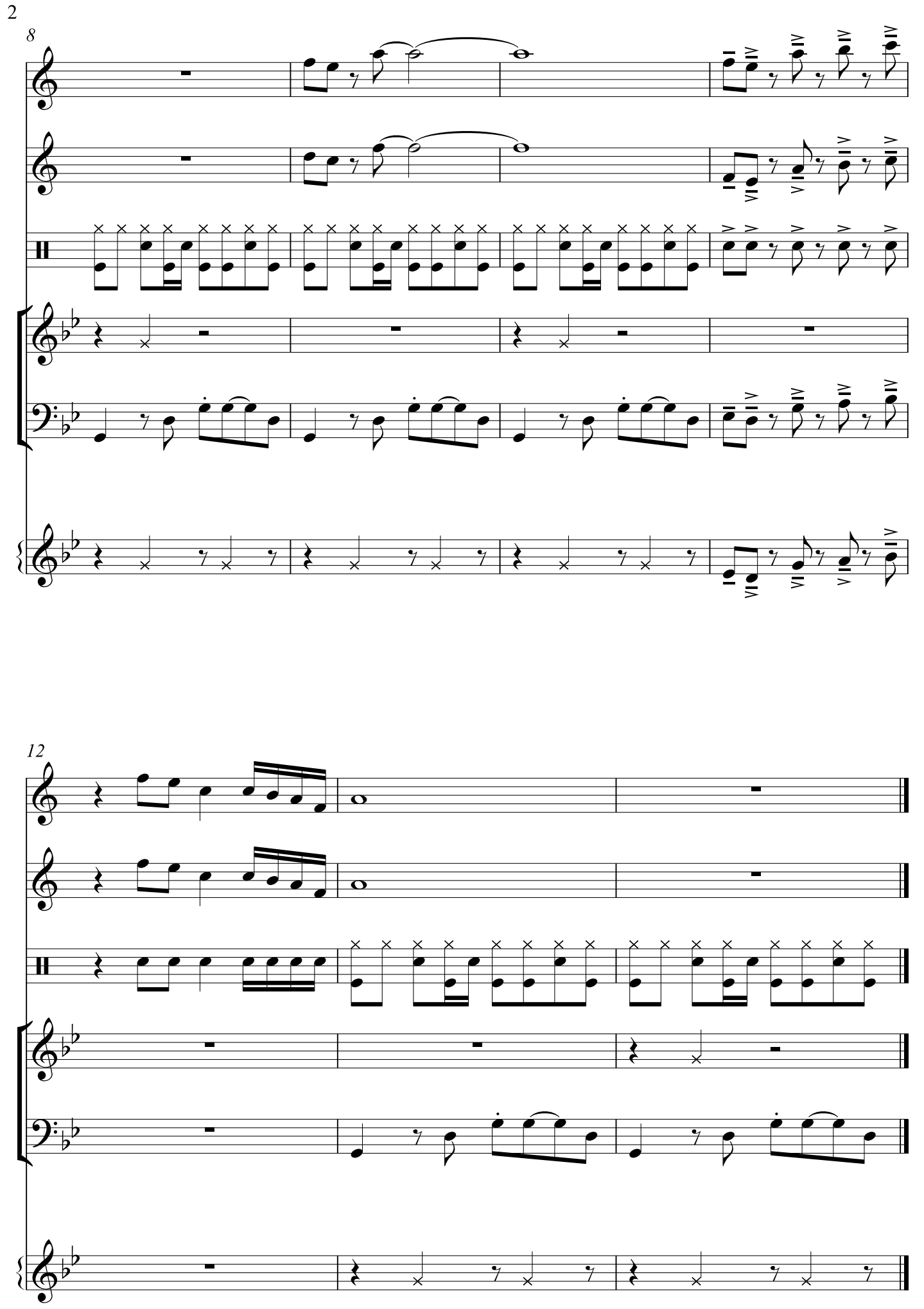


APPENDIX 8

\section{Tezetaye Antchi Lidj}

Mulatu Astatke

Tenor Saxophone

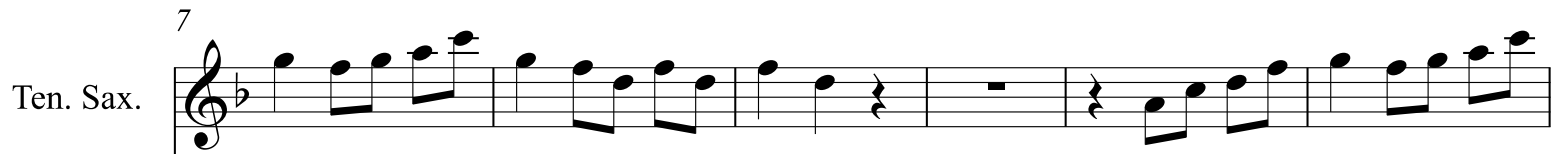
Tpt.
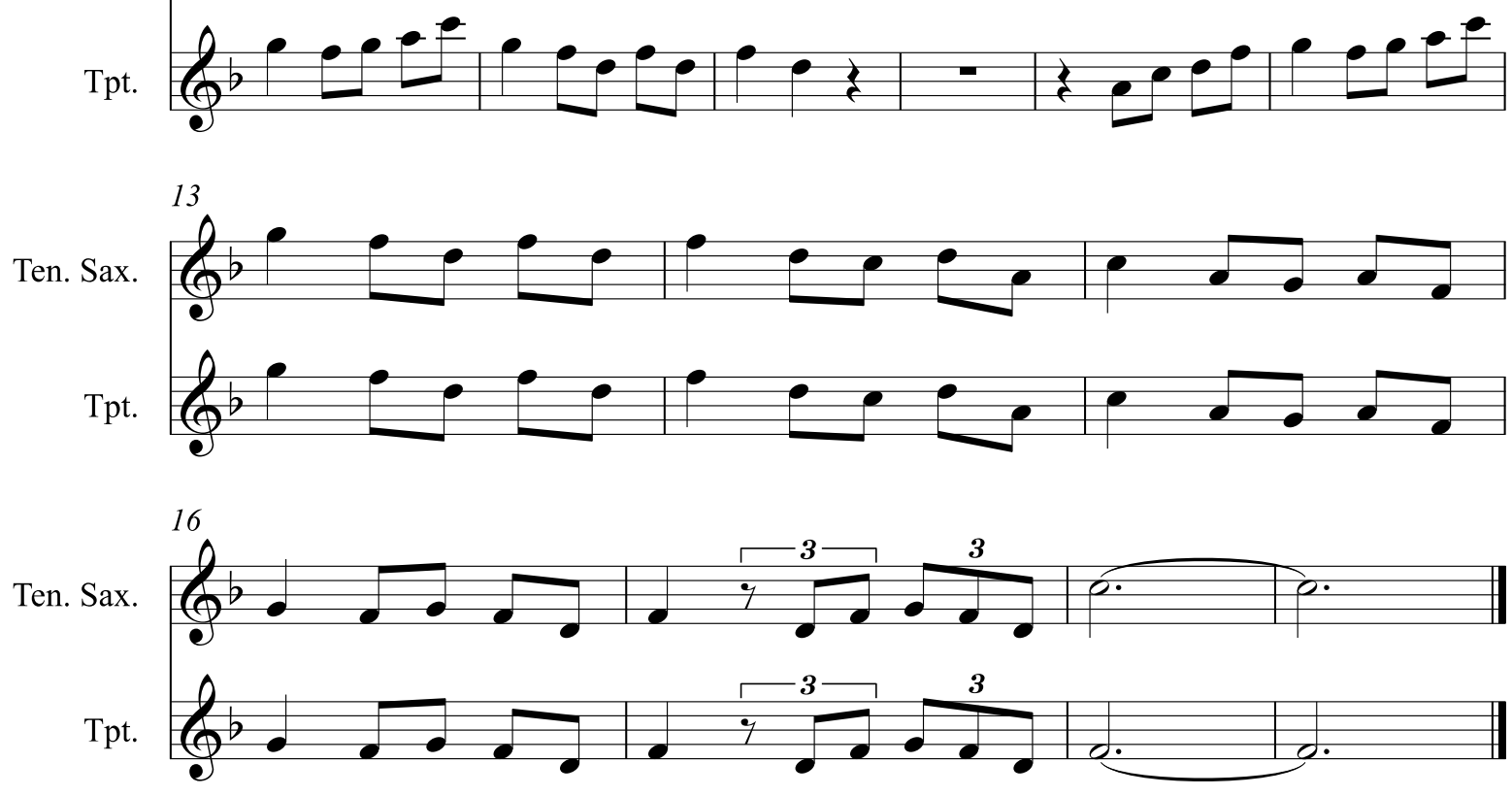
APPENDIX 9

\section{Cha Cha}

Mulatu Astatké
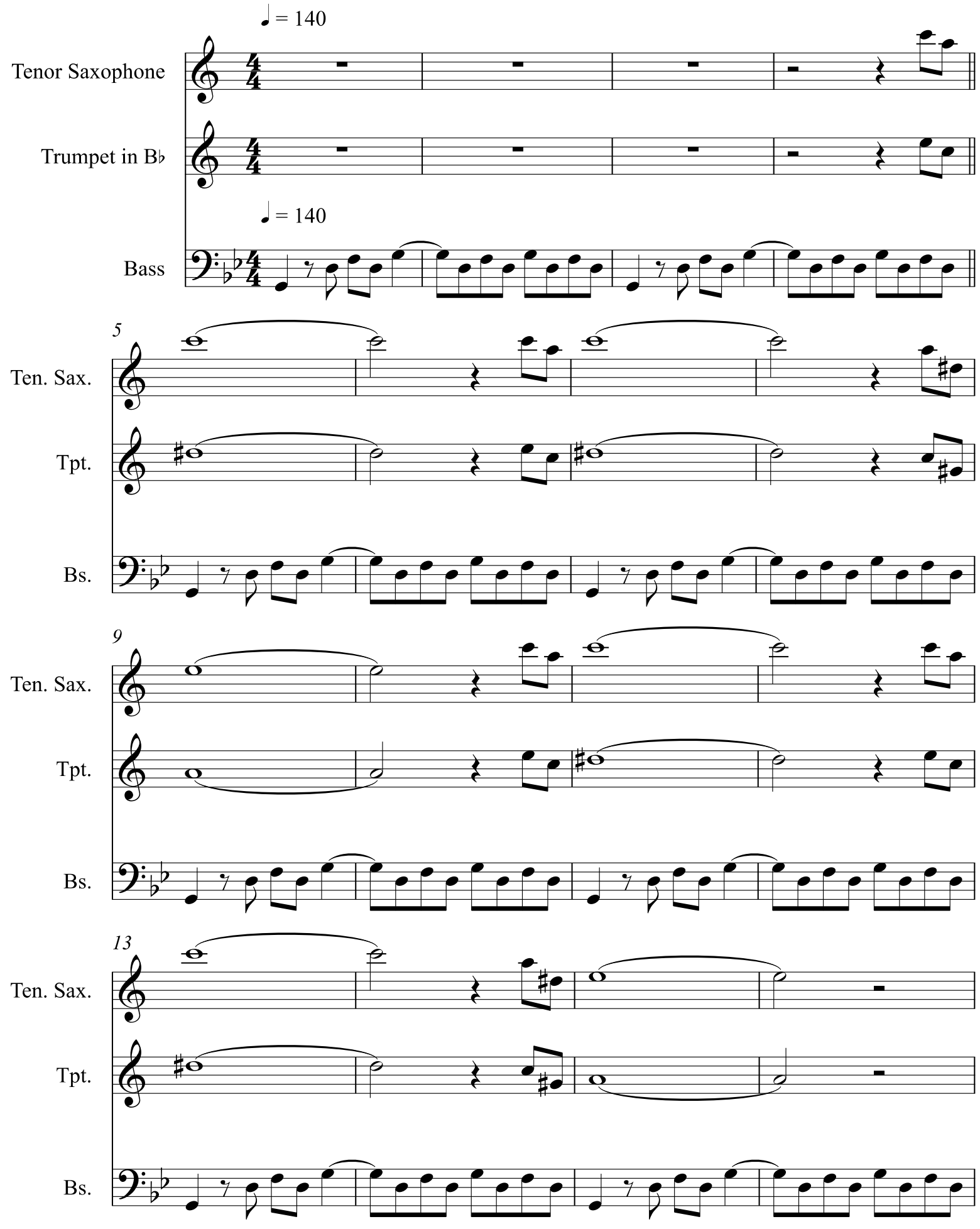

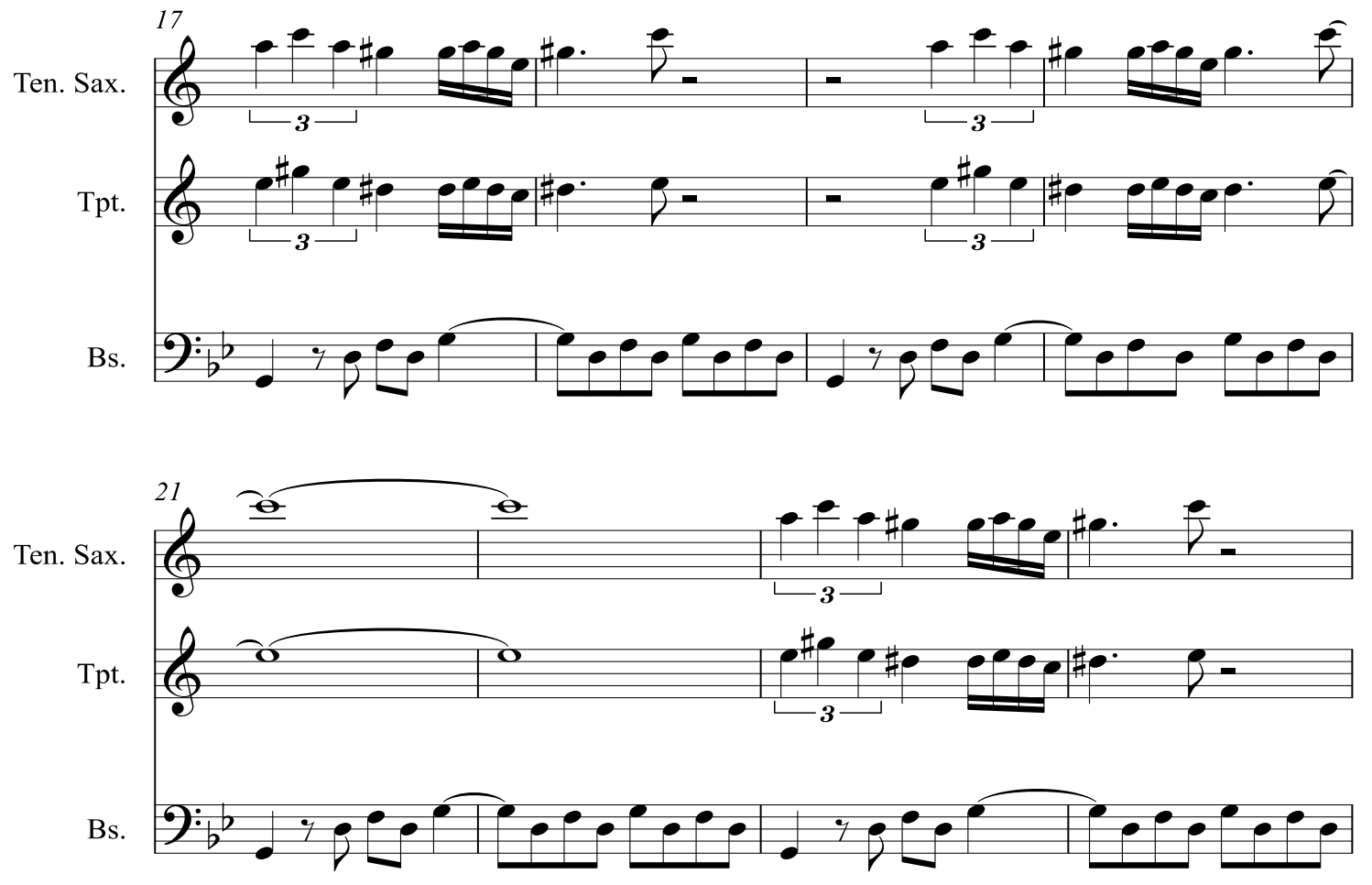

Ten. Sax.

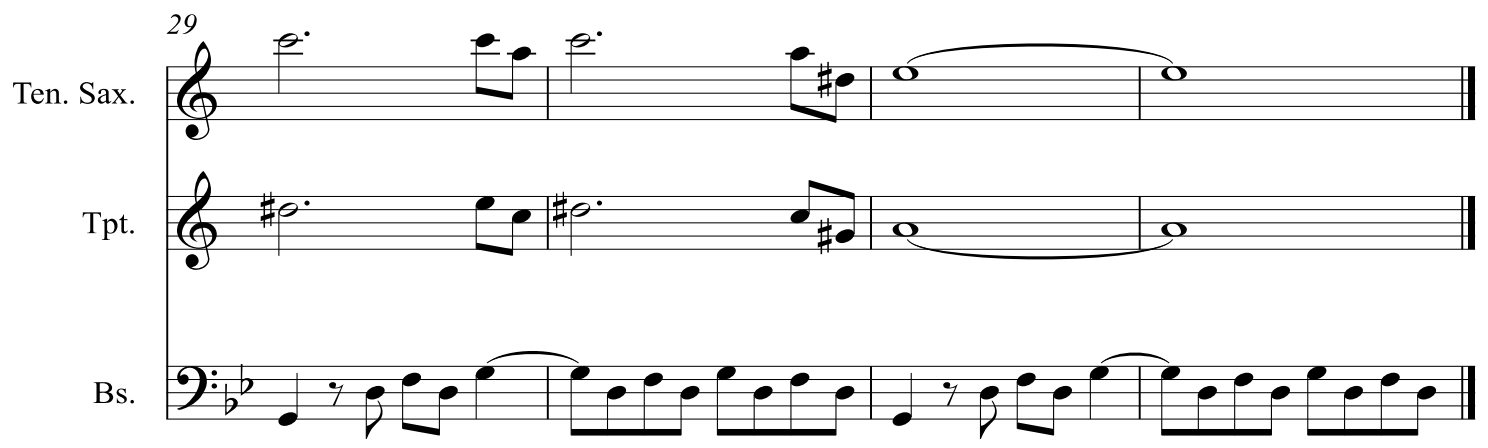




\section{APPENDIX 10}

\section{Chik Chikka}

Mulatu Astatke

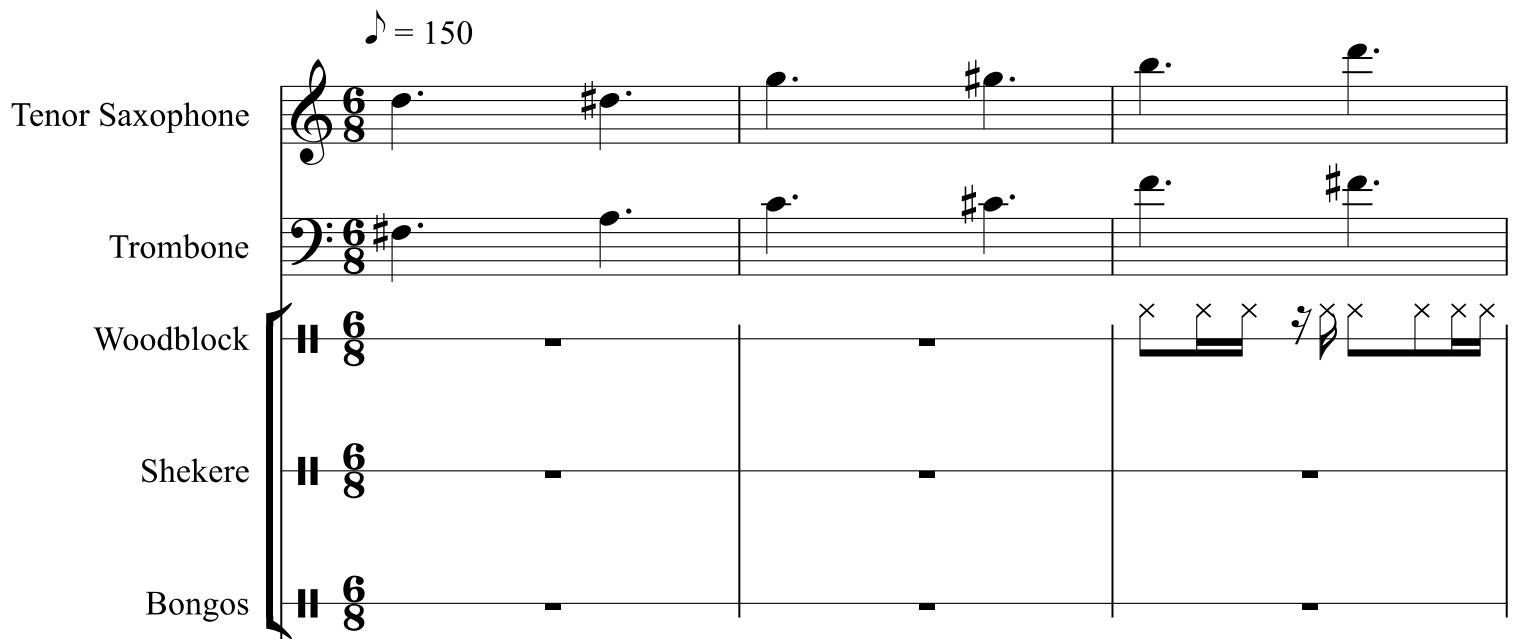

Electric Guitar

Ten. Sax

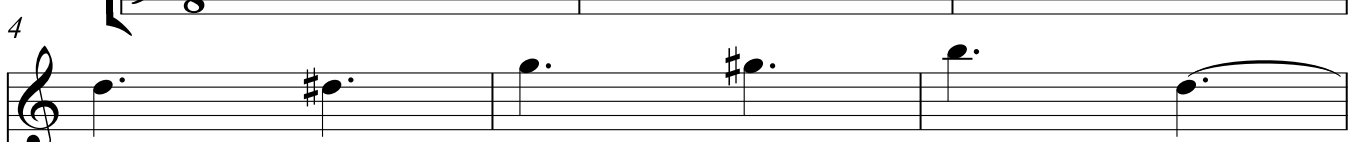

Tbn.
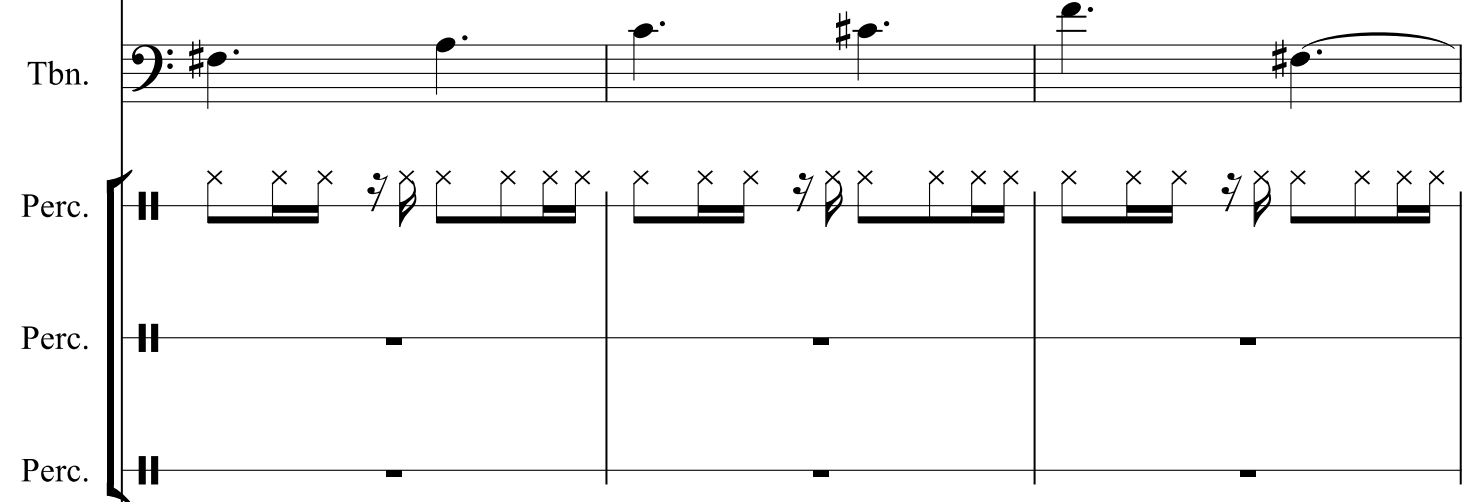

E. Gtr.

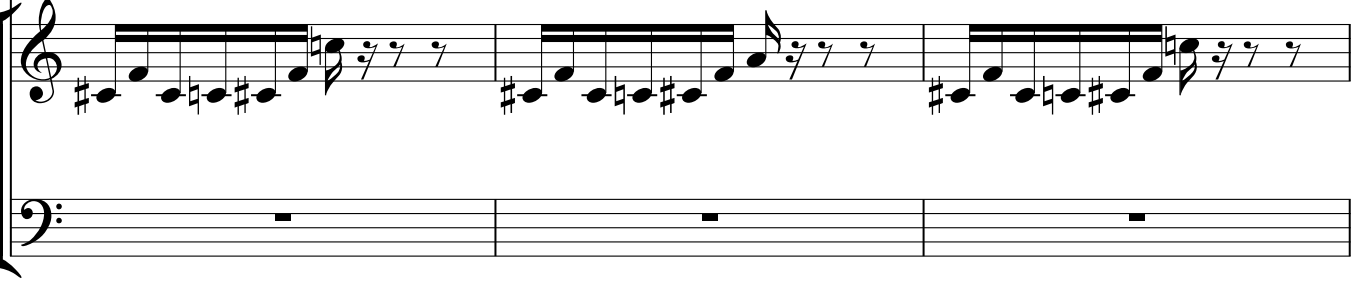


2

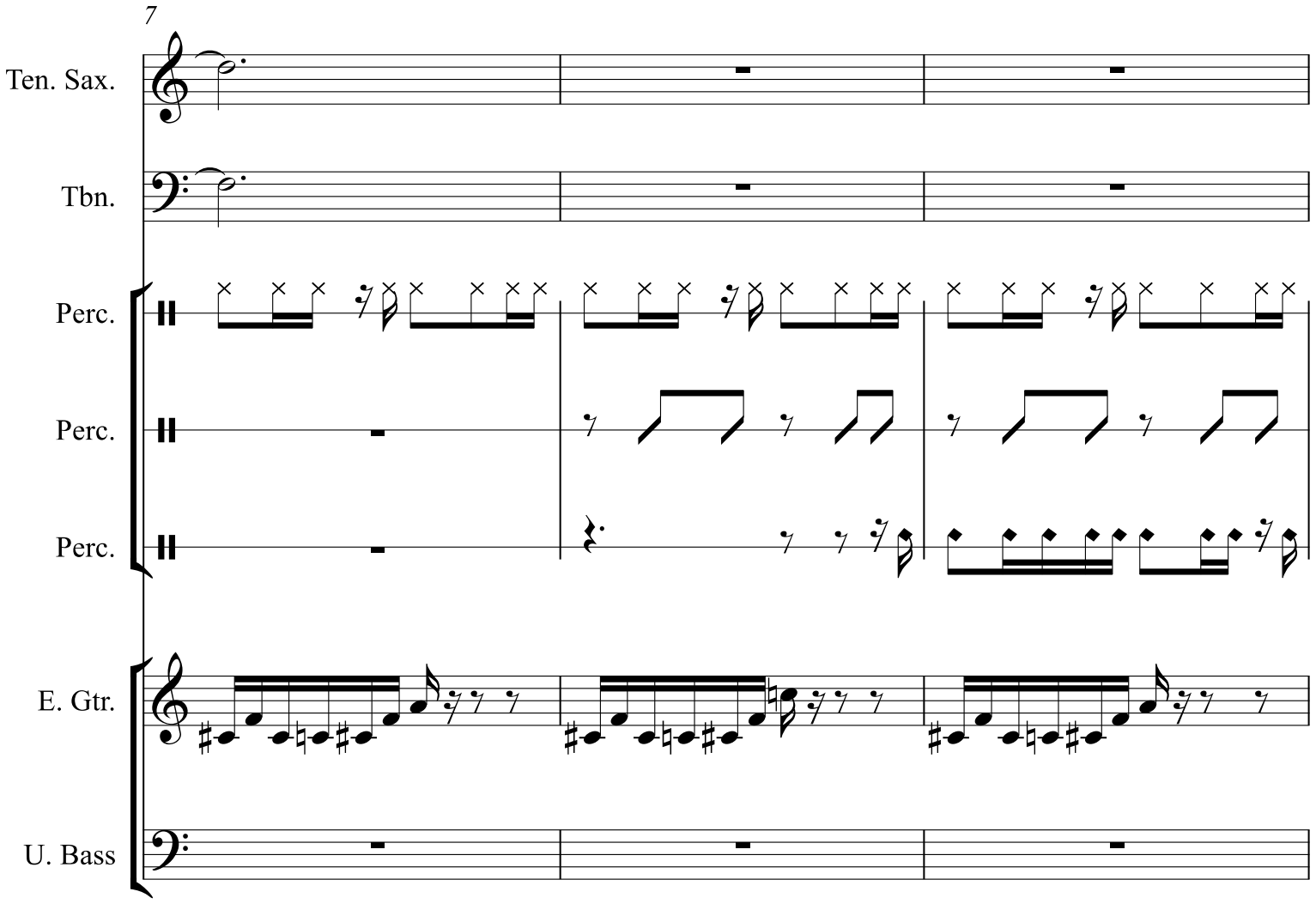

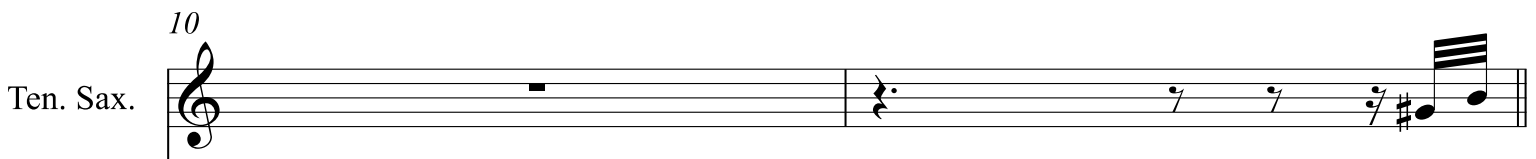
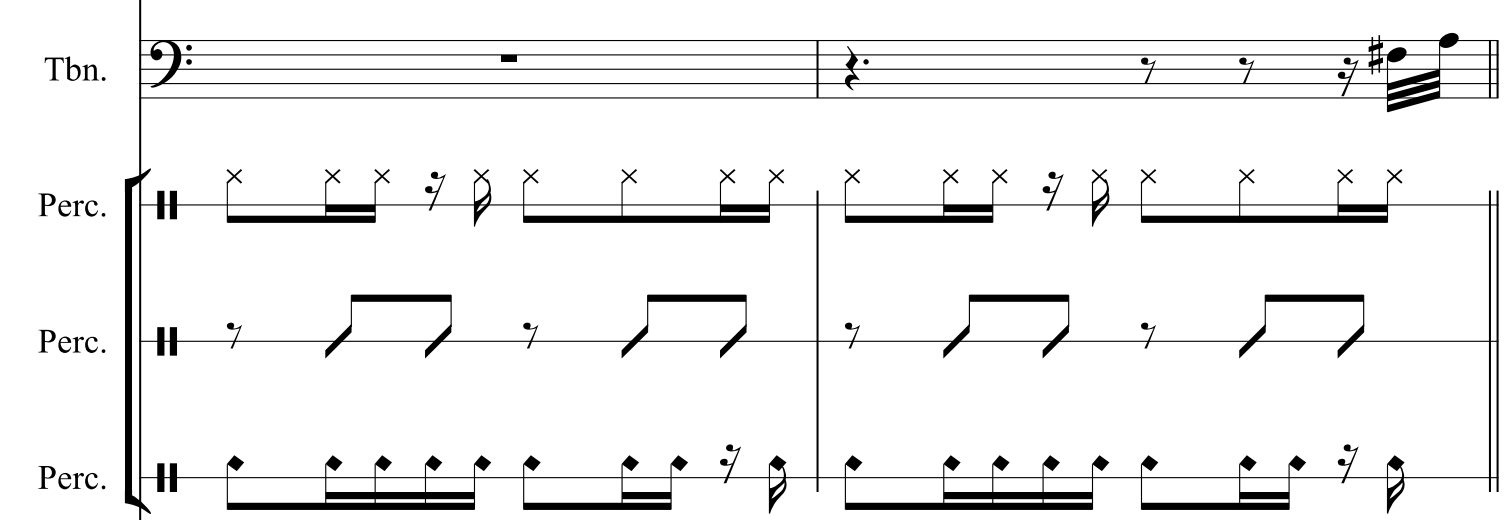

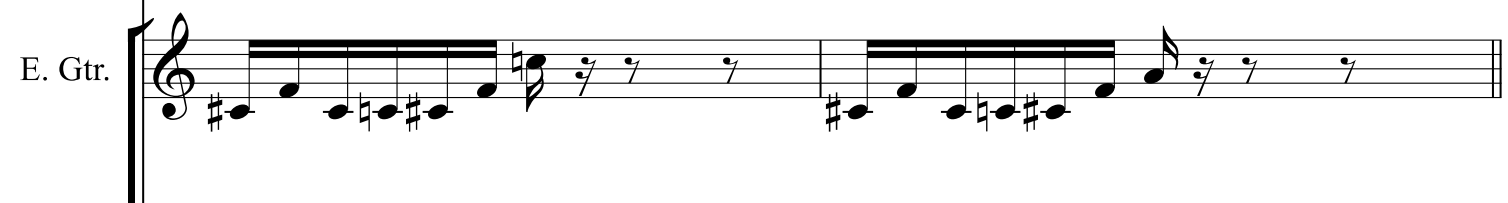

U. Bass 
Ten. Sax.

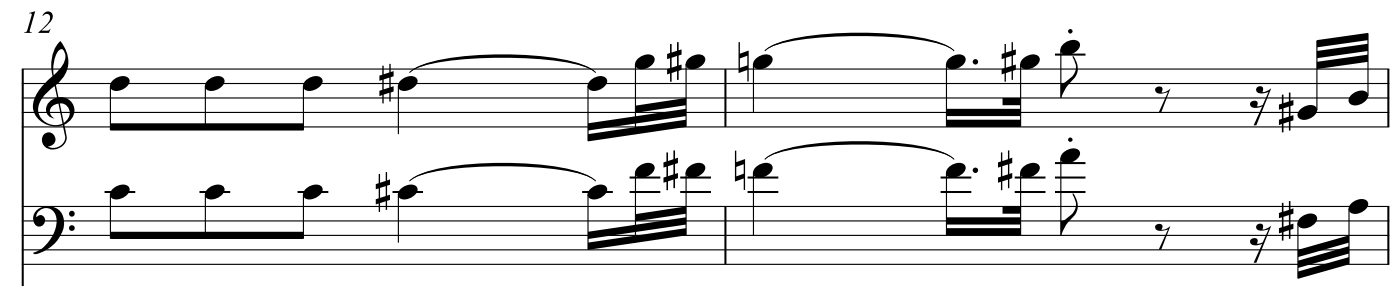

Tbn

Drums and Congas enter

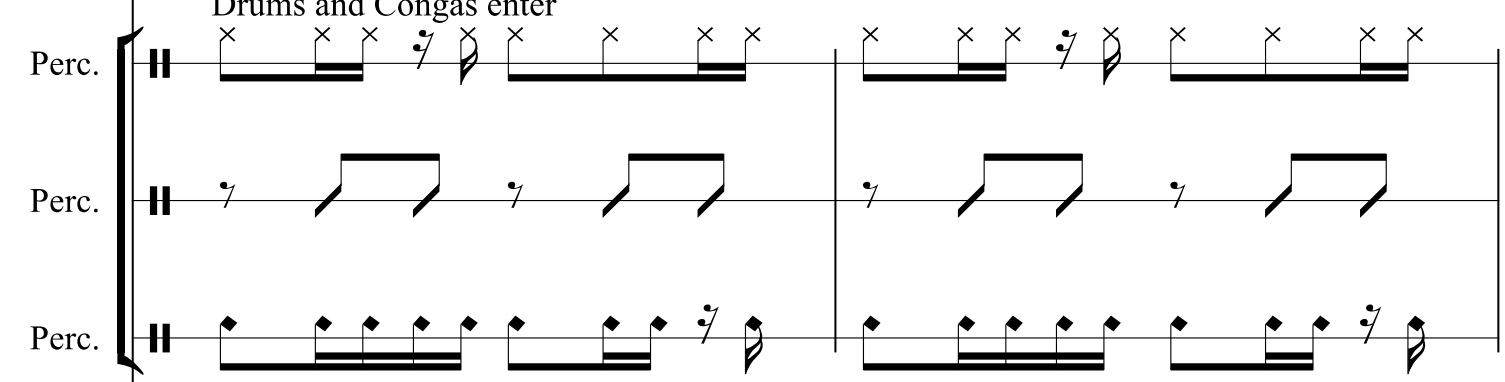

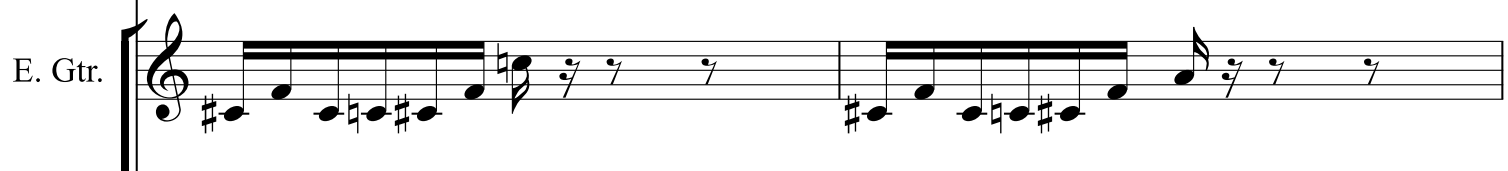

U. Bass

9:

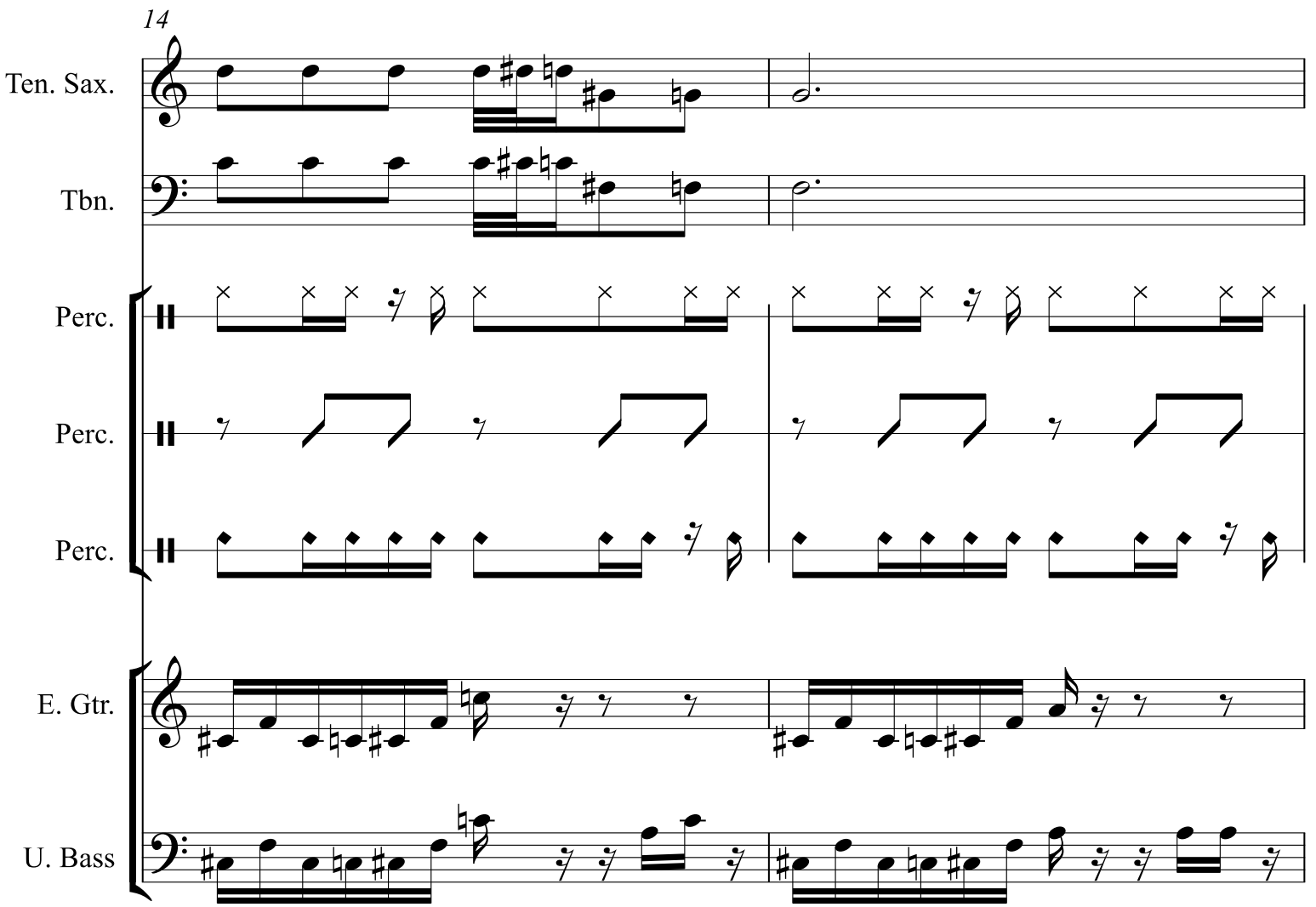


4

Ten. Sax.

Tbn.

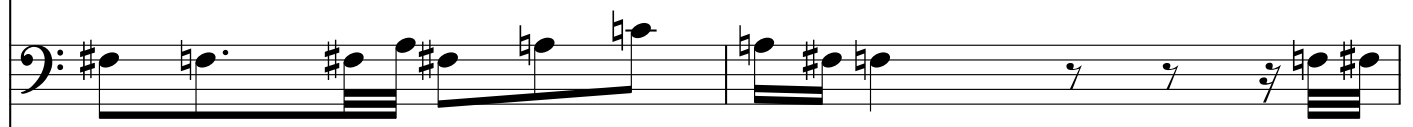

Perc.

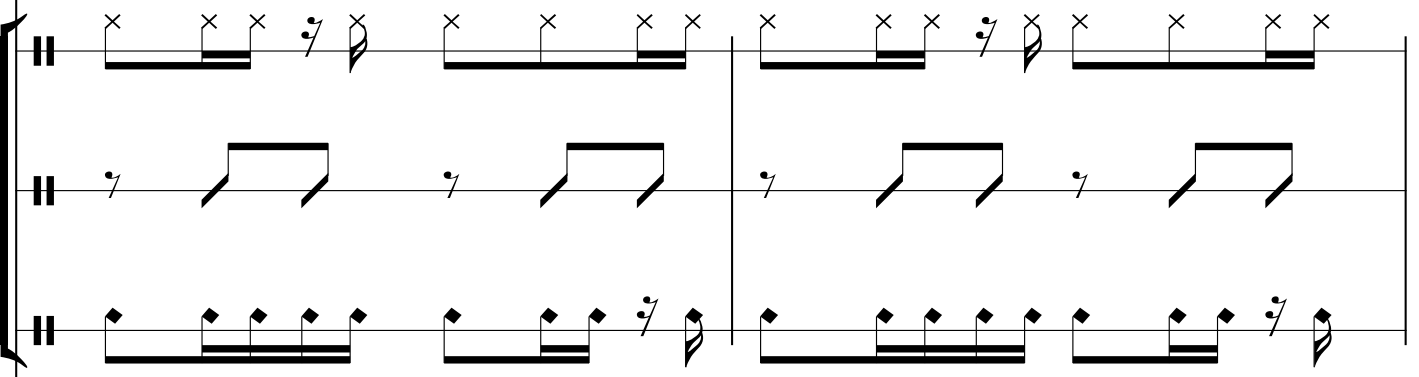

E. Gtr.

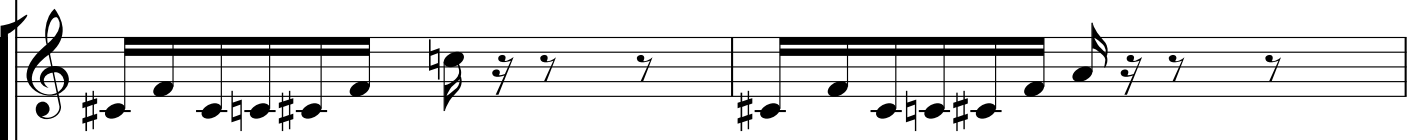

U. Bass
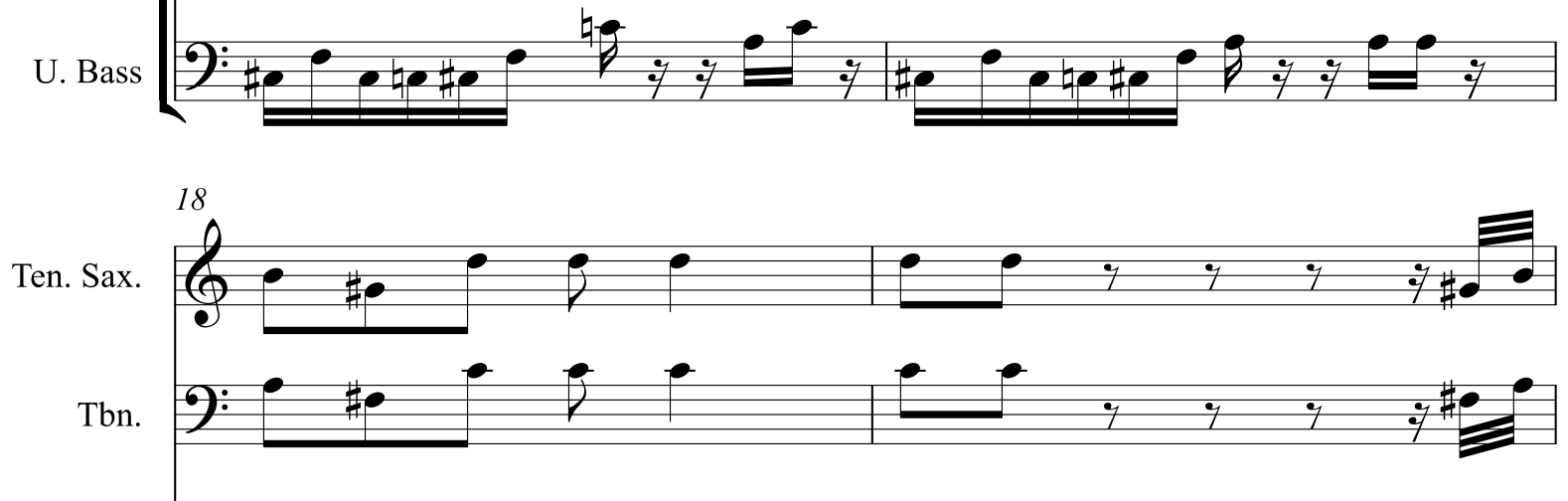

Perc.

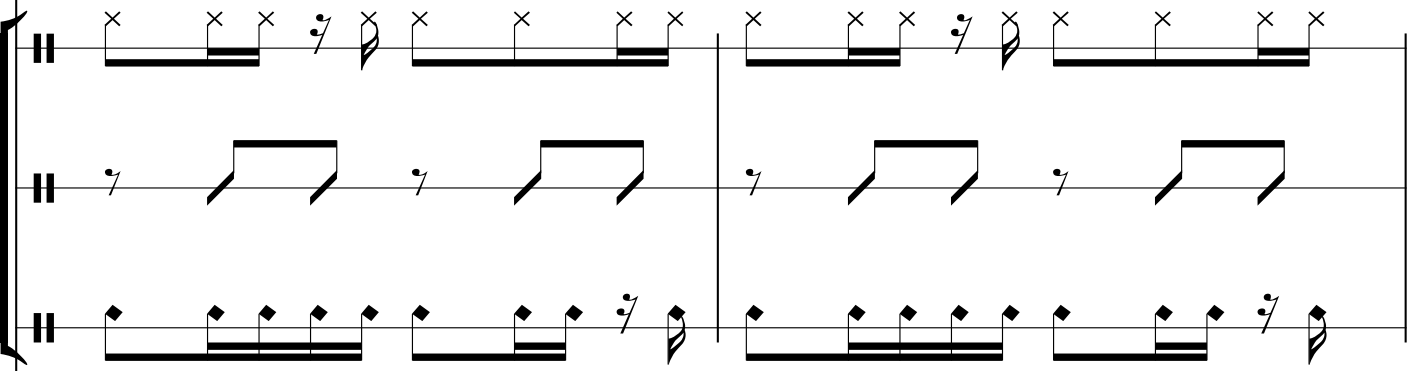

E. Gtr.

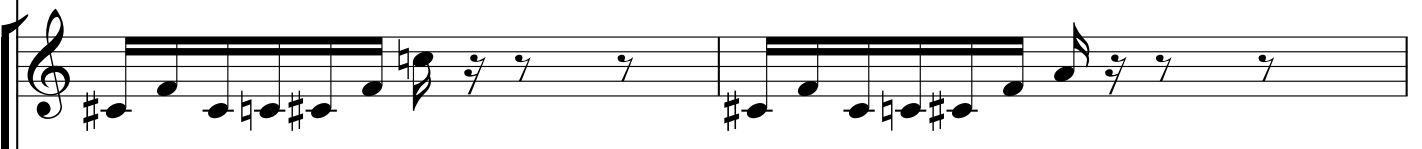

U. Bass

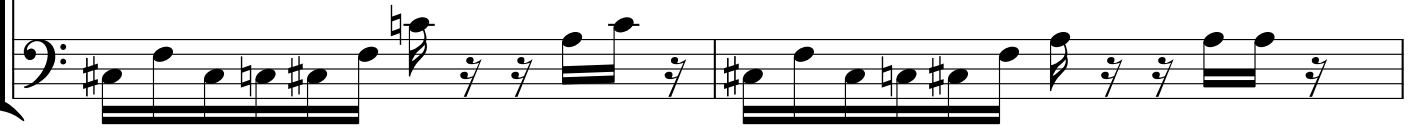



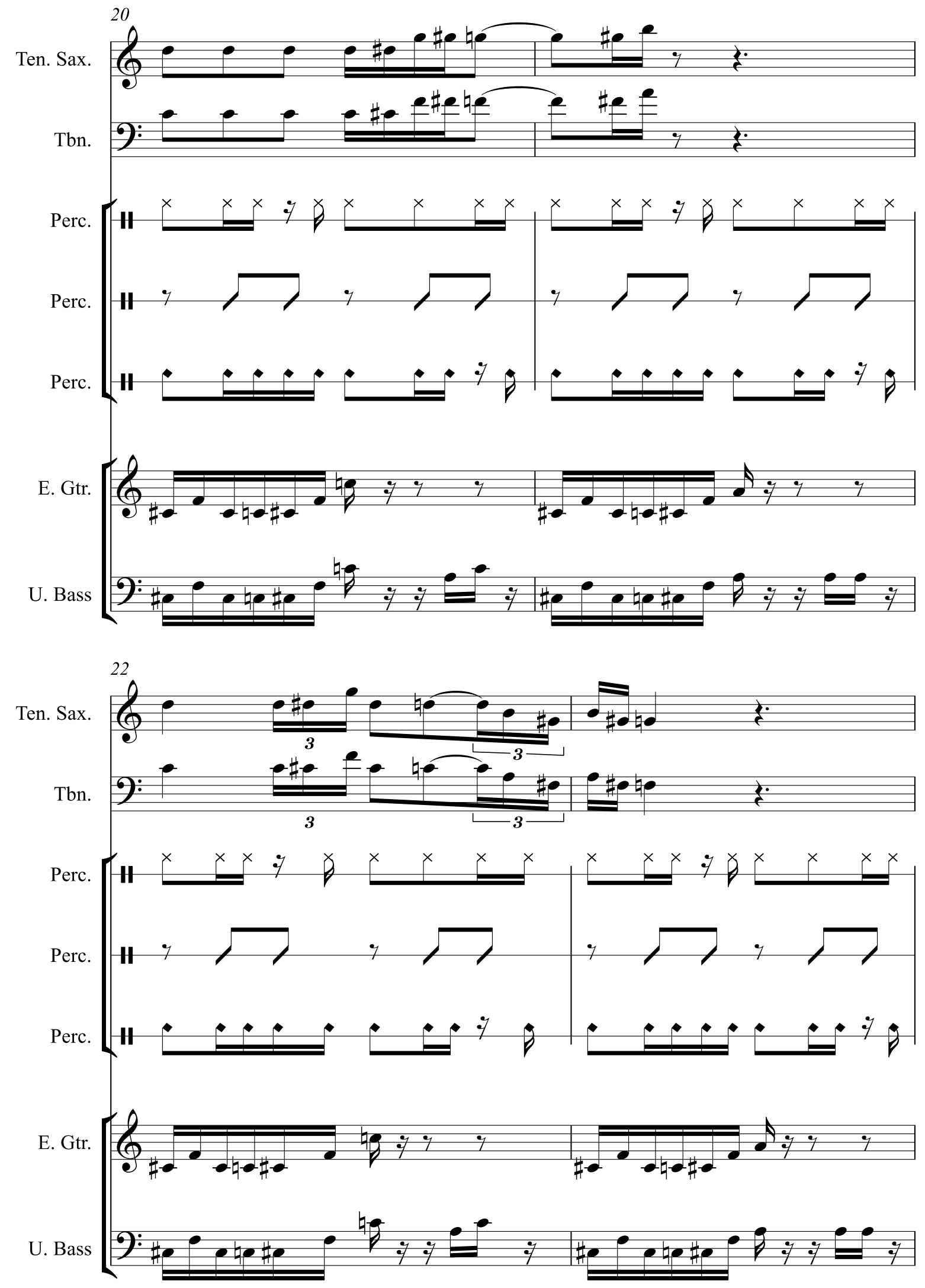
6

Ten. Sax.

$\oint_{0}^{24}$

Tbn.

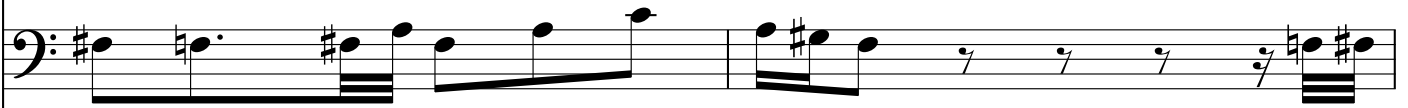

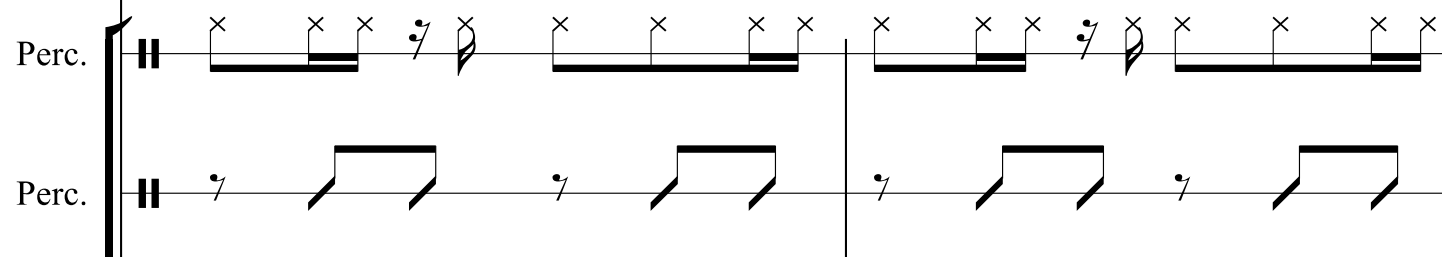

Perc.

$4+\ldots+\ldots,+\ldots+48$

E. Gtr.

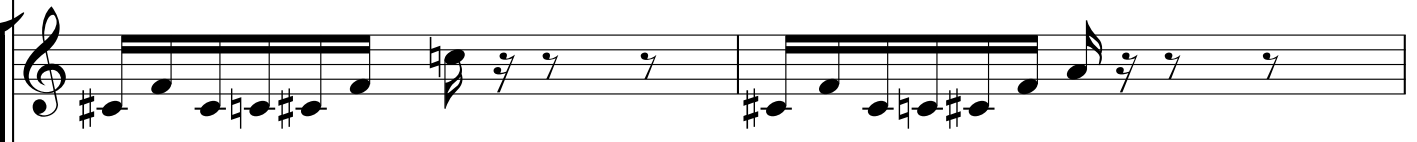

U. Bass

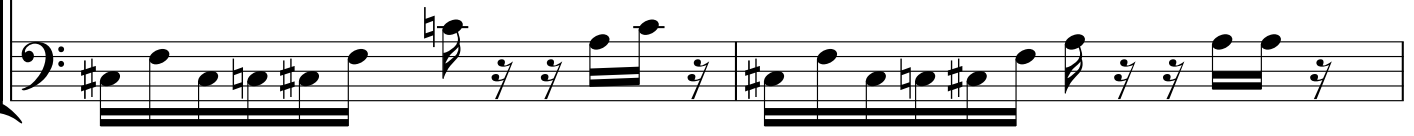

Ten. Sax.

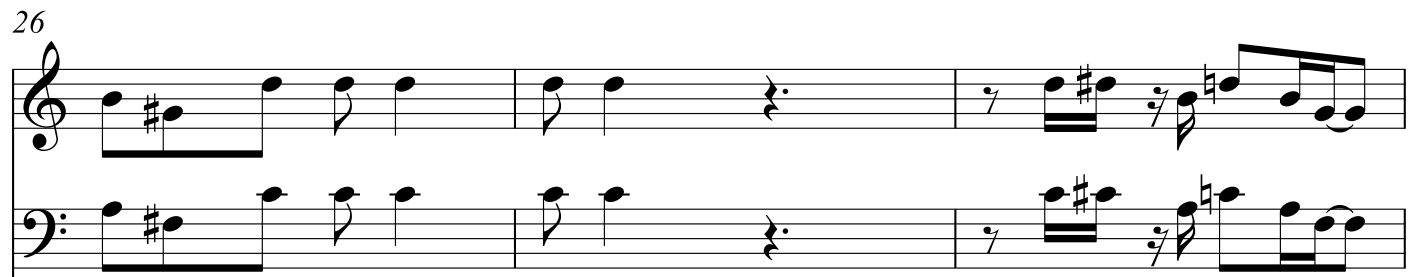

Tbn.

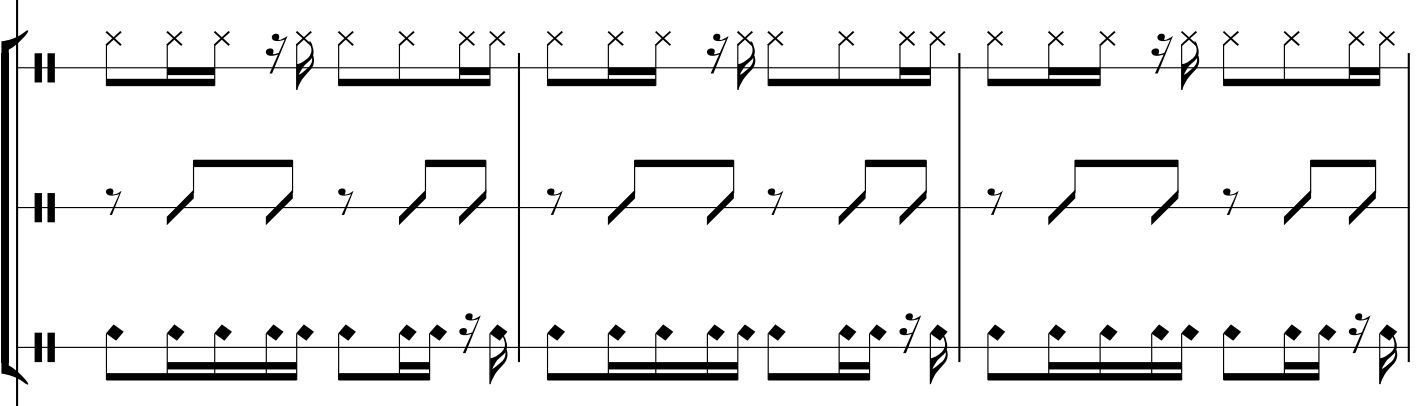

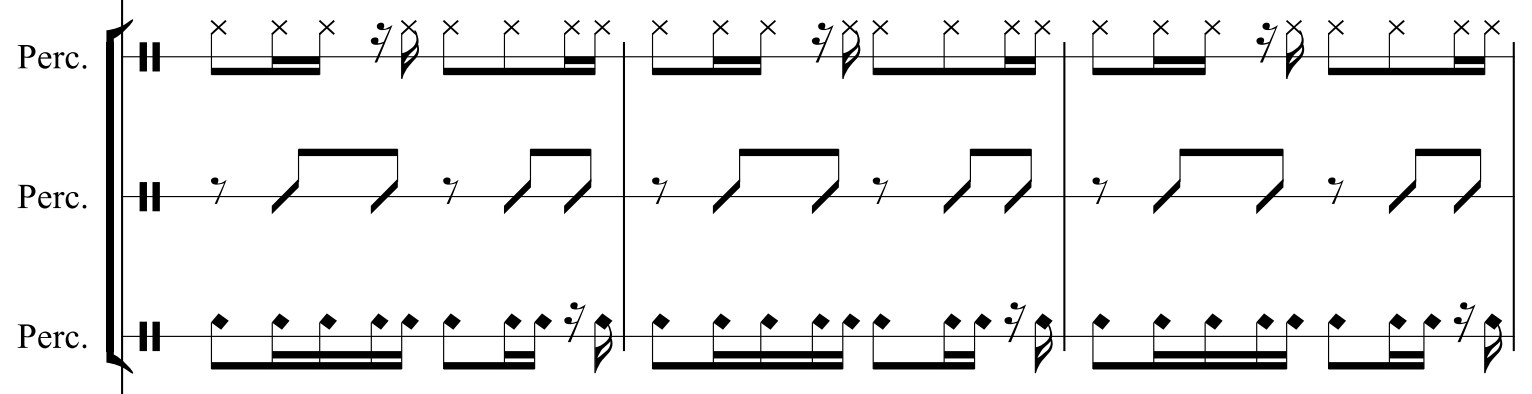

E. Gtr.

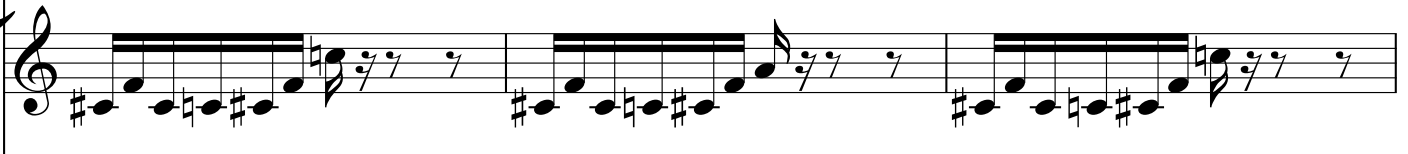

U. Bass

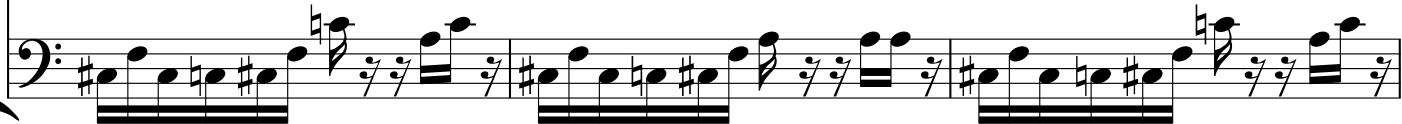


Ten. Sax.

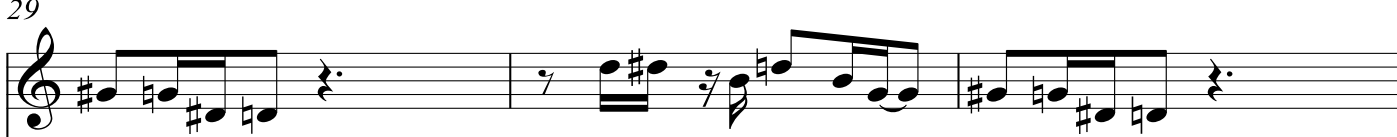

Tbn.

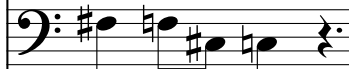

Perc.

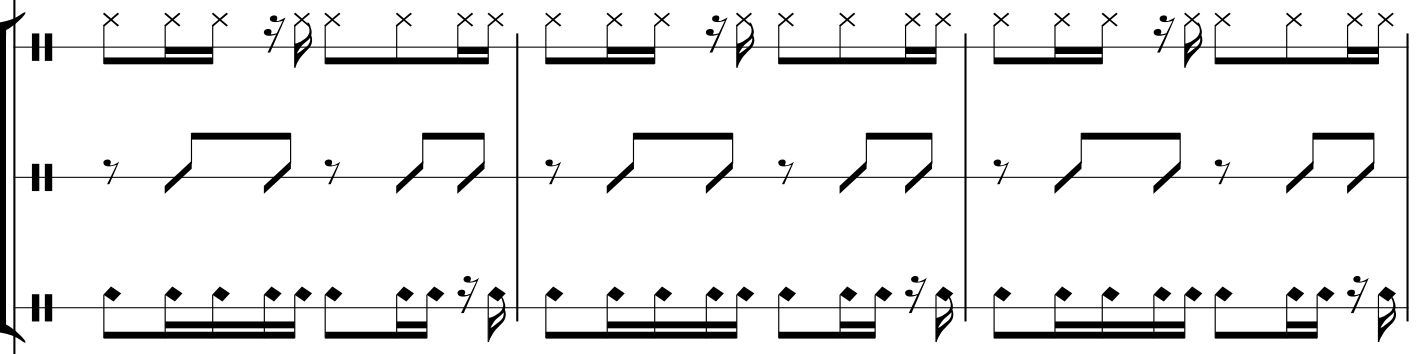

E. Gtr.

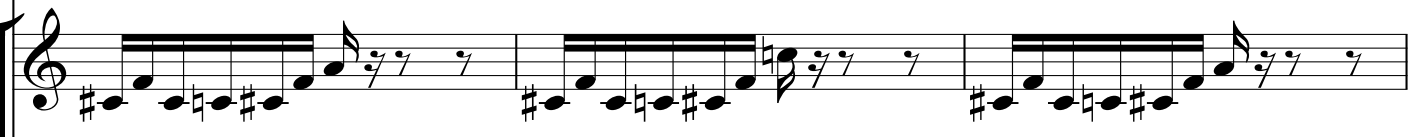

U. Bass

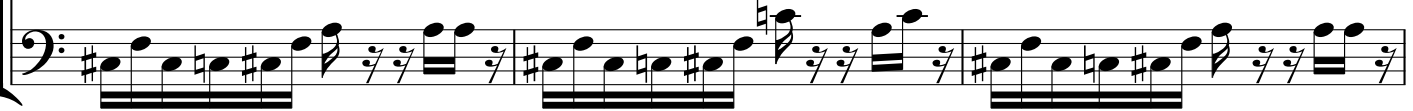

Ten. Sax.

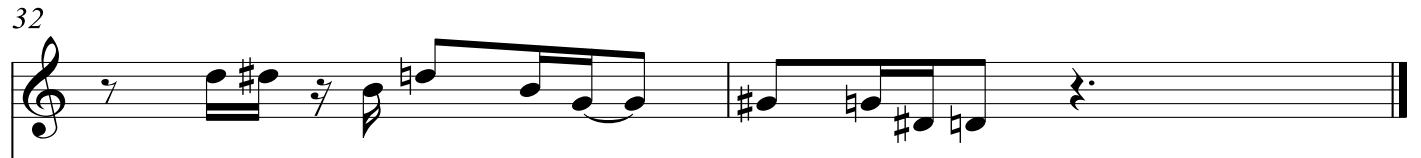

Tbn.

9:

Perc.

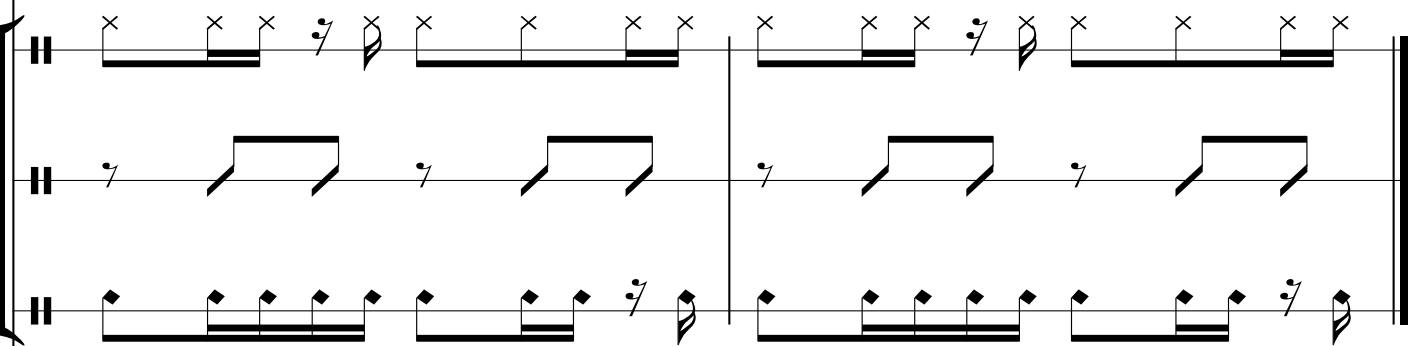

Perc.

Perc.

$$
\text { (a) }
$$


APPENDIX 11

Shellela

Getachew Mekurya
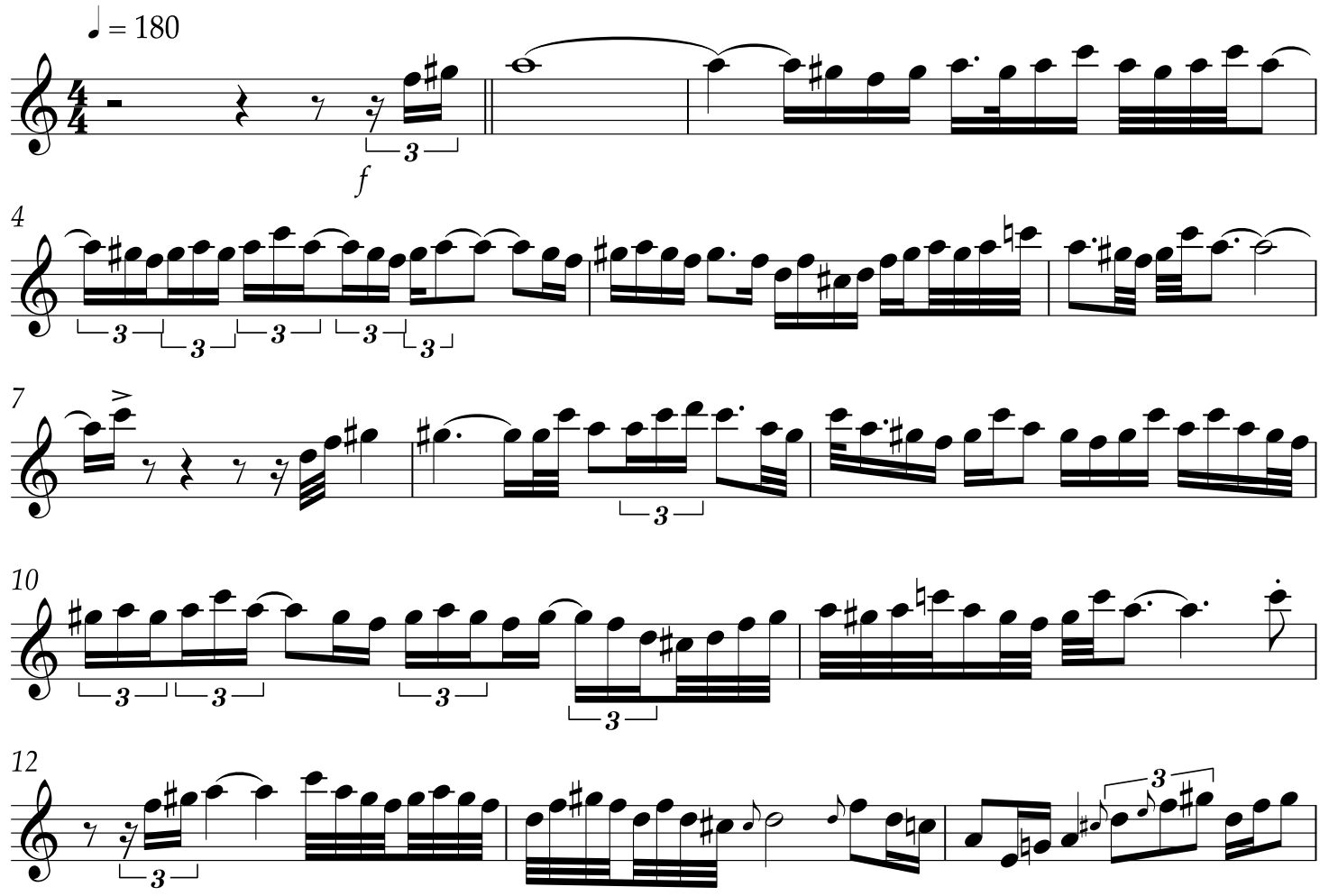

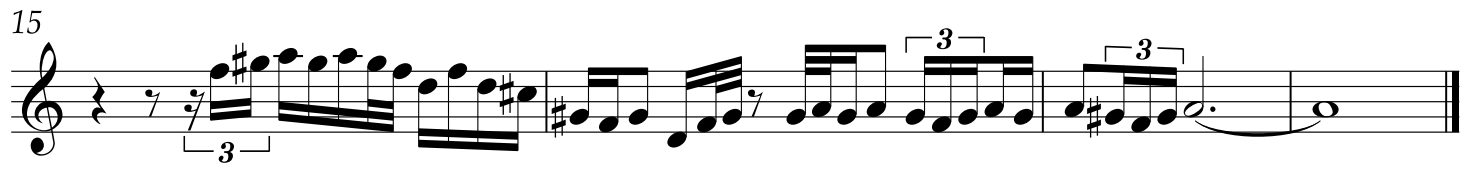


APPENDIX 12

Almaz Yeharewa

Getachew Mekurya

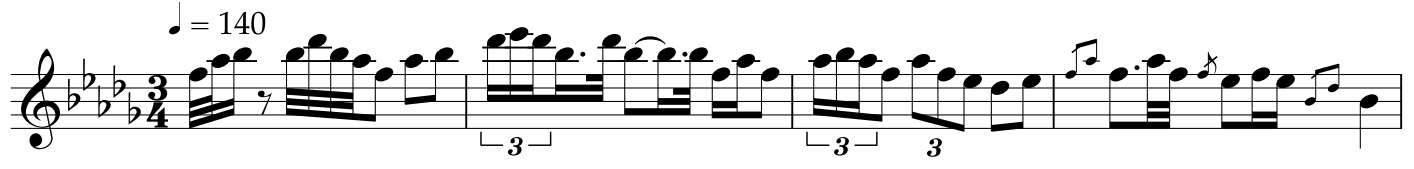

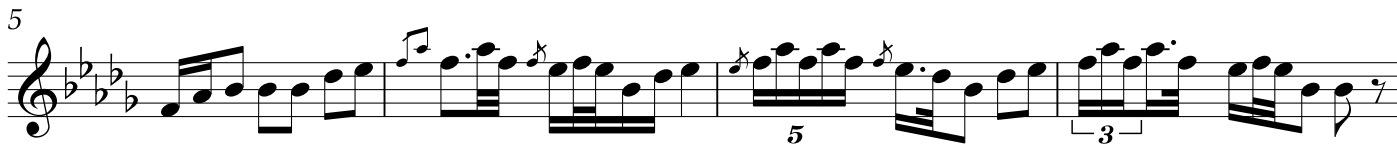

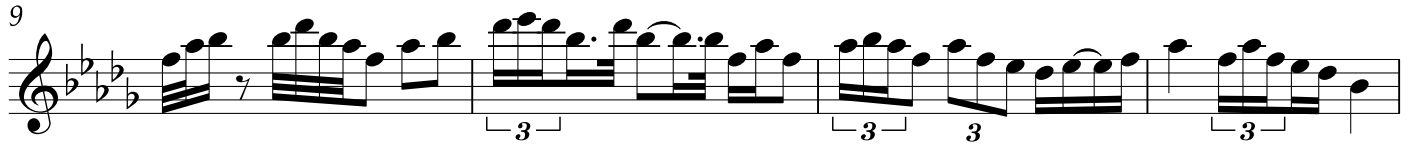

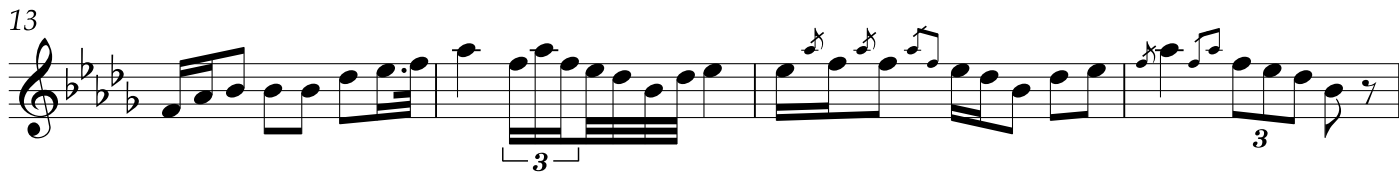

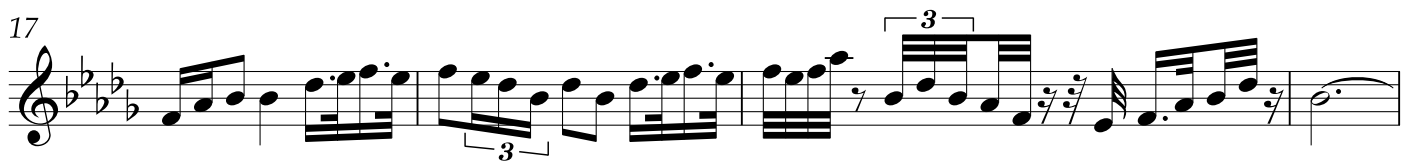

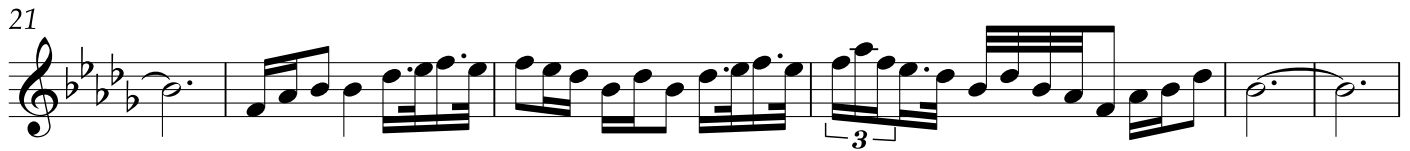

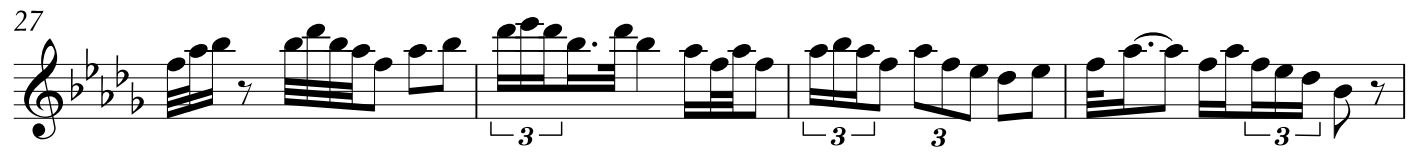




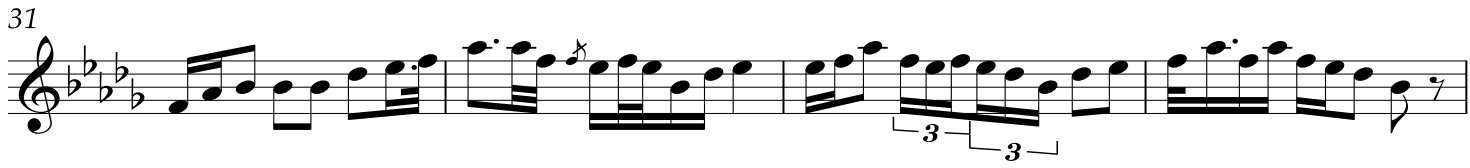

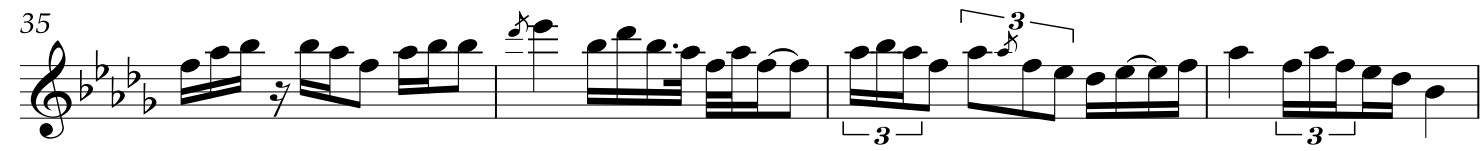

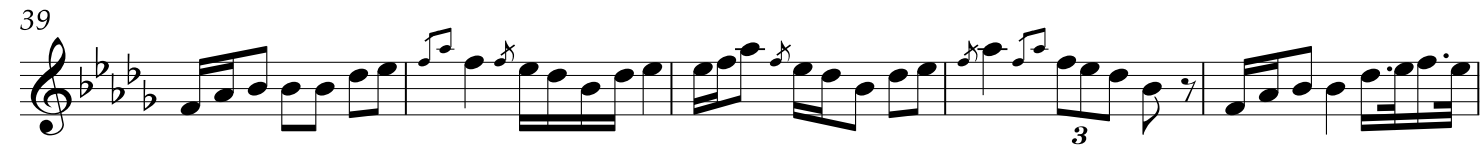

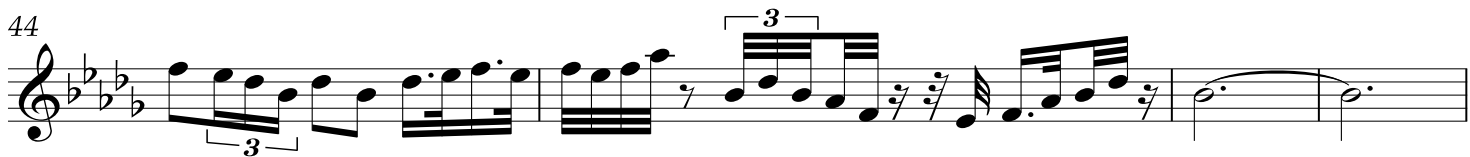

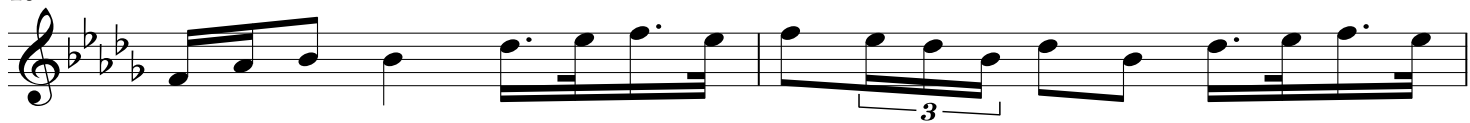

Q 


\section{APPENDIX 13}

\section{Yegenet Muziqa}

Getachew Mekurya
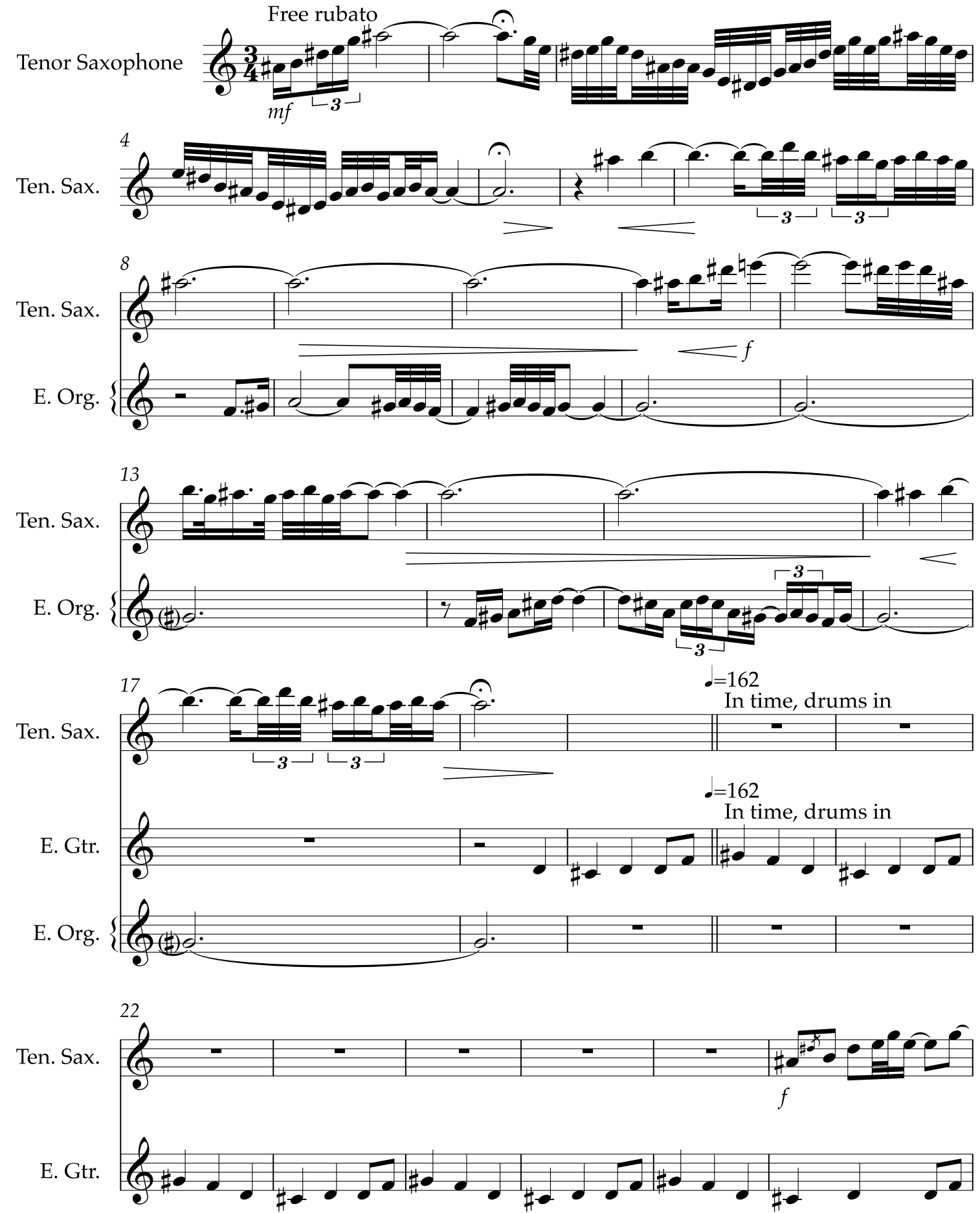
2

Ten. Sax.

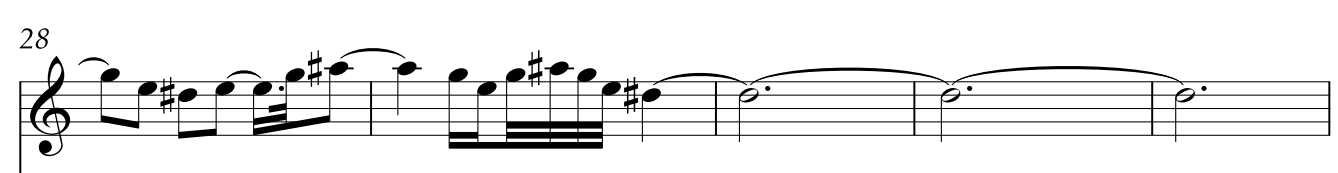

E. Gr.

E. Org.

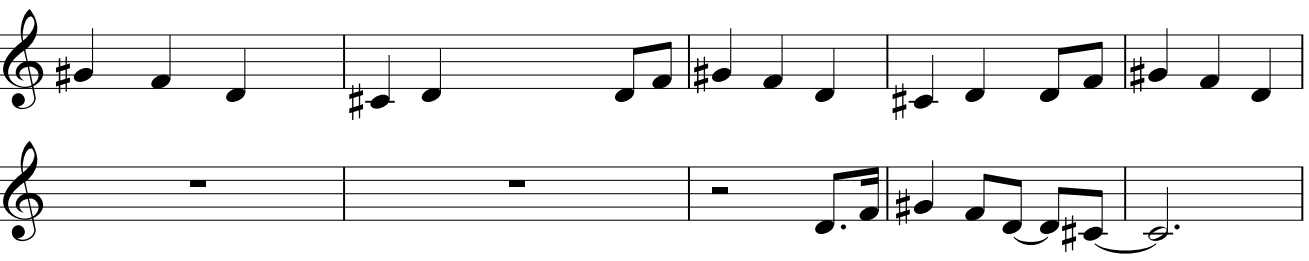

Ten. Sax

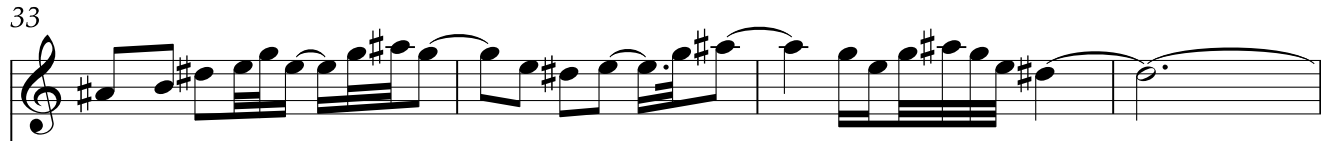

E. Gr.

E. Org.

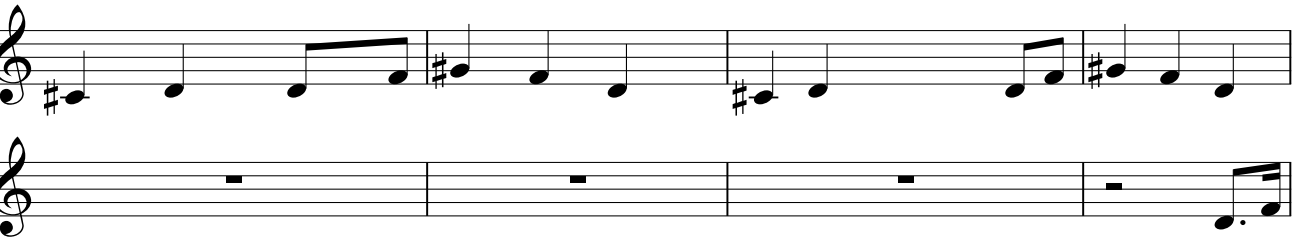

Ten. Sax.

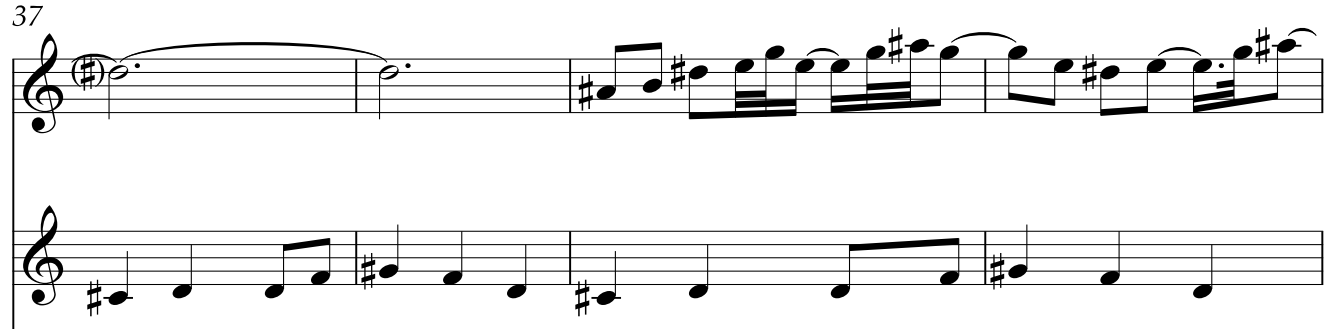

E. Org.

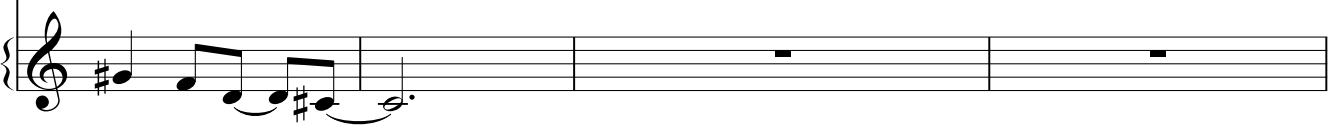

Ten. Sax.

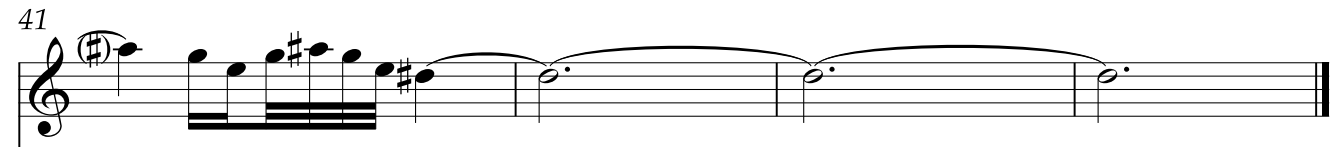

E. Gr.

E. Org. \{
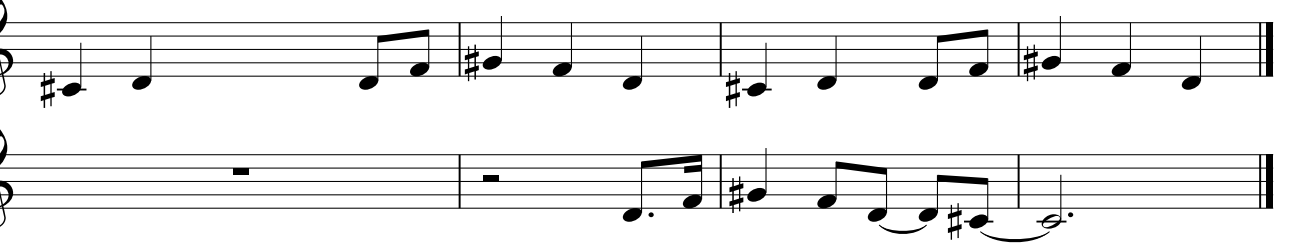

179 


\section{APPENDIX 14}

\section{Ethiopia Hagere}

Ethiopian Trad. arr Getachew Mekurya

$d=142 \quad$ Shuffle

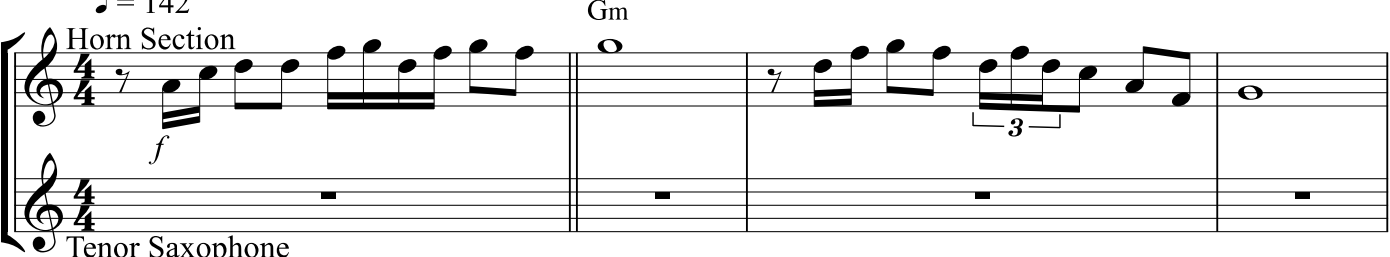

Tenor Saxophone
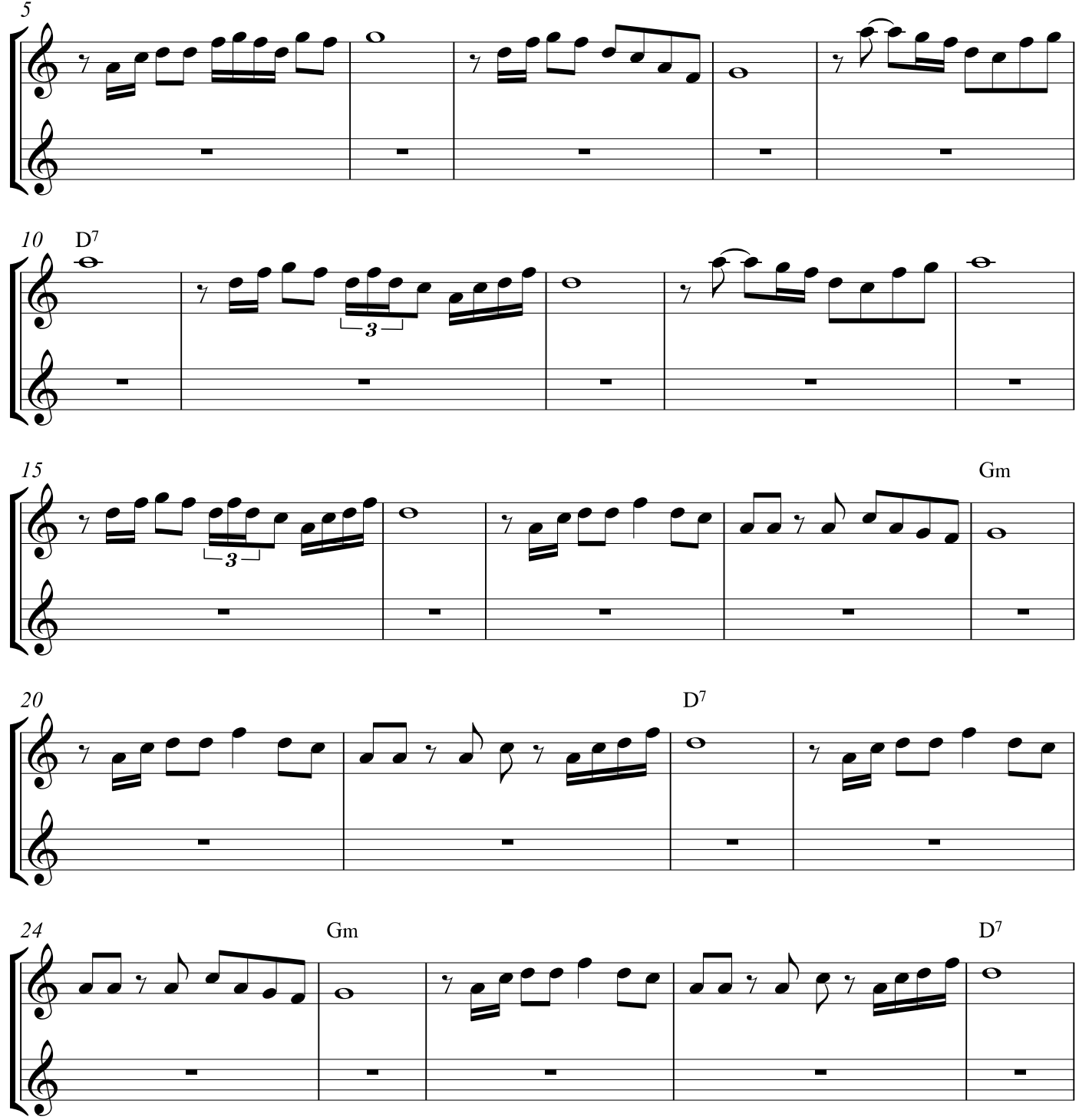


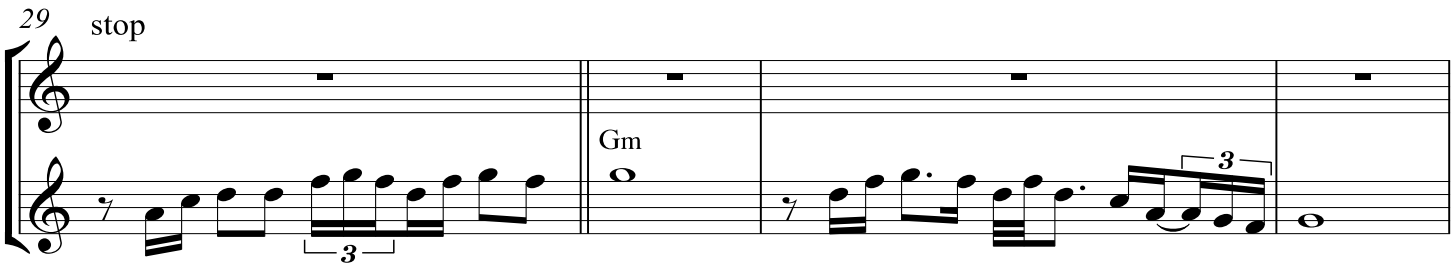

\begin{tabular}{|l|l|l|l|l|}
\hline 3 \\
\hline 0
\end{tabular}

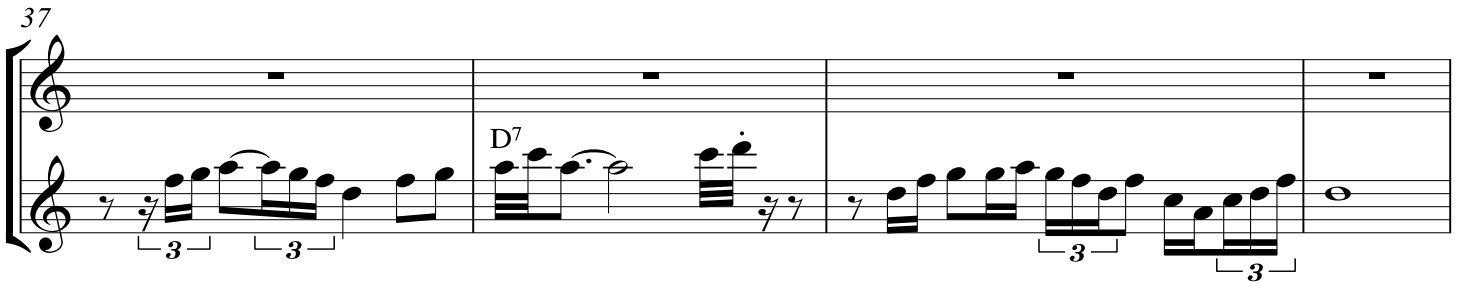

\begin{tabular}{|ll|l|l|l|l|}
\hline \\
\hline
\end{tabular}

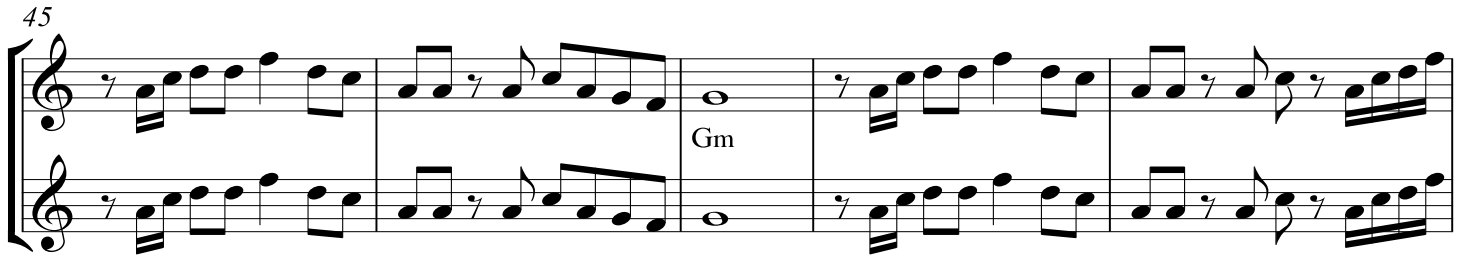

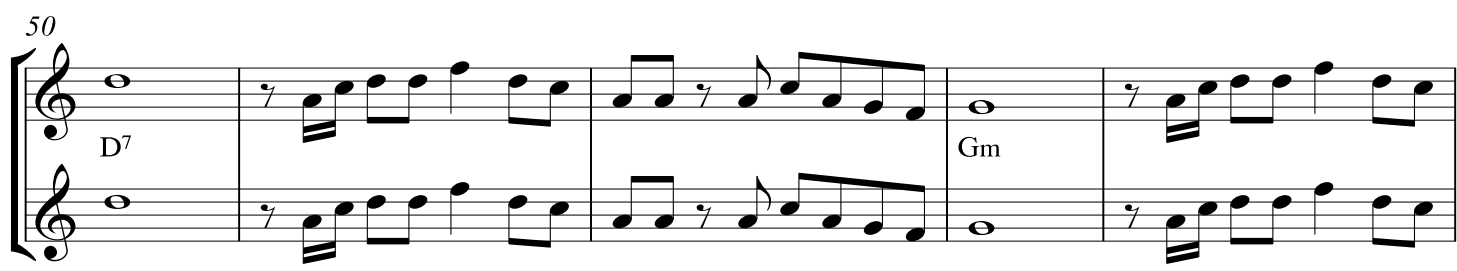

\begin{tabular}{|lll|l|l|l|l|l|l|}
\hline 5 \\
\hline
\end{tabular} 


\section{APPENDIX 15}

\section{Musicawa Silt}

Hailu Mergia and the Walias Band
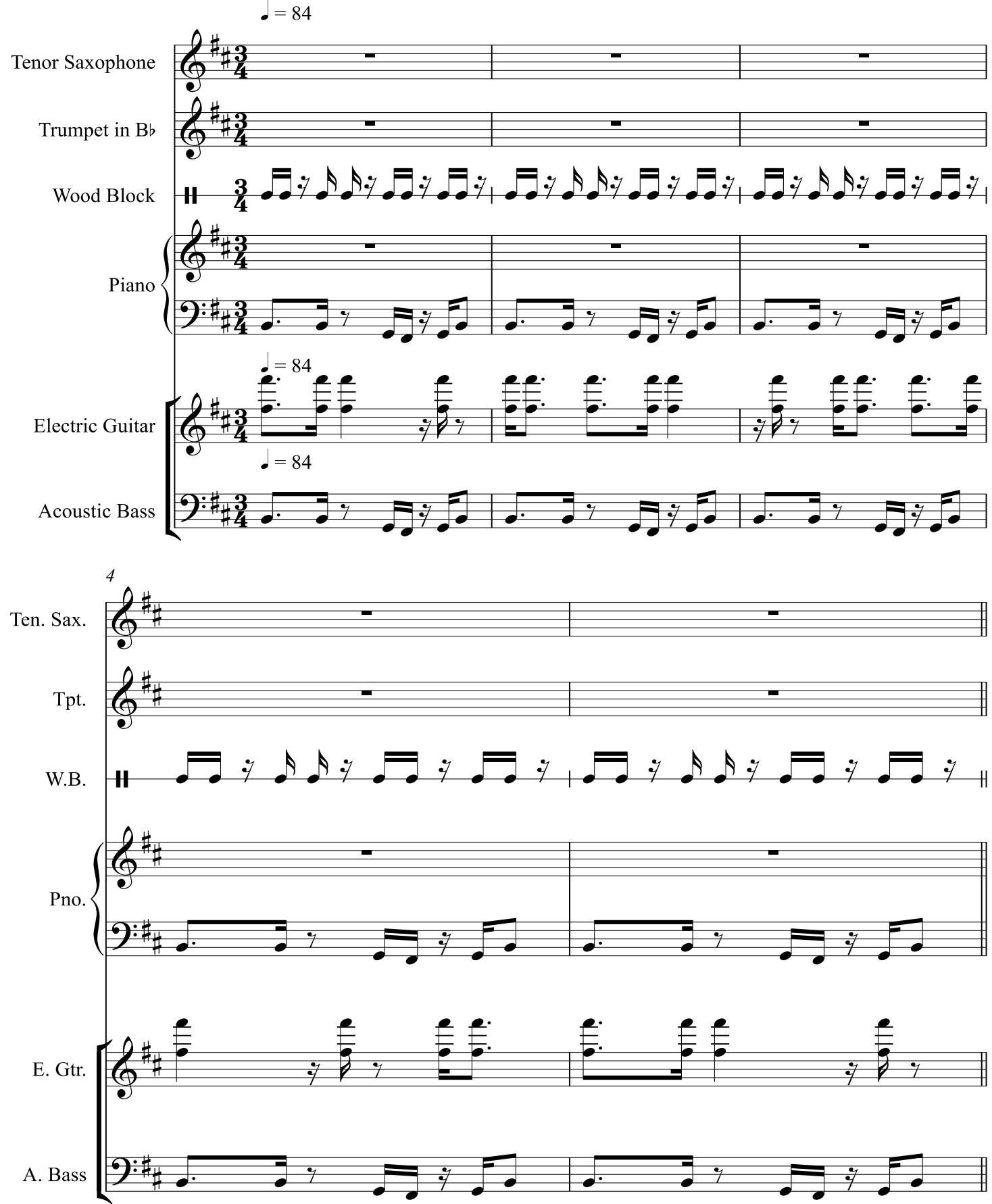

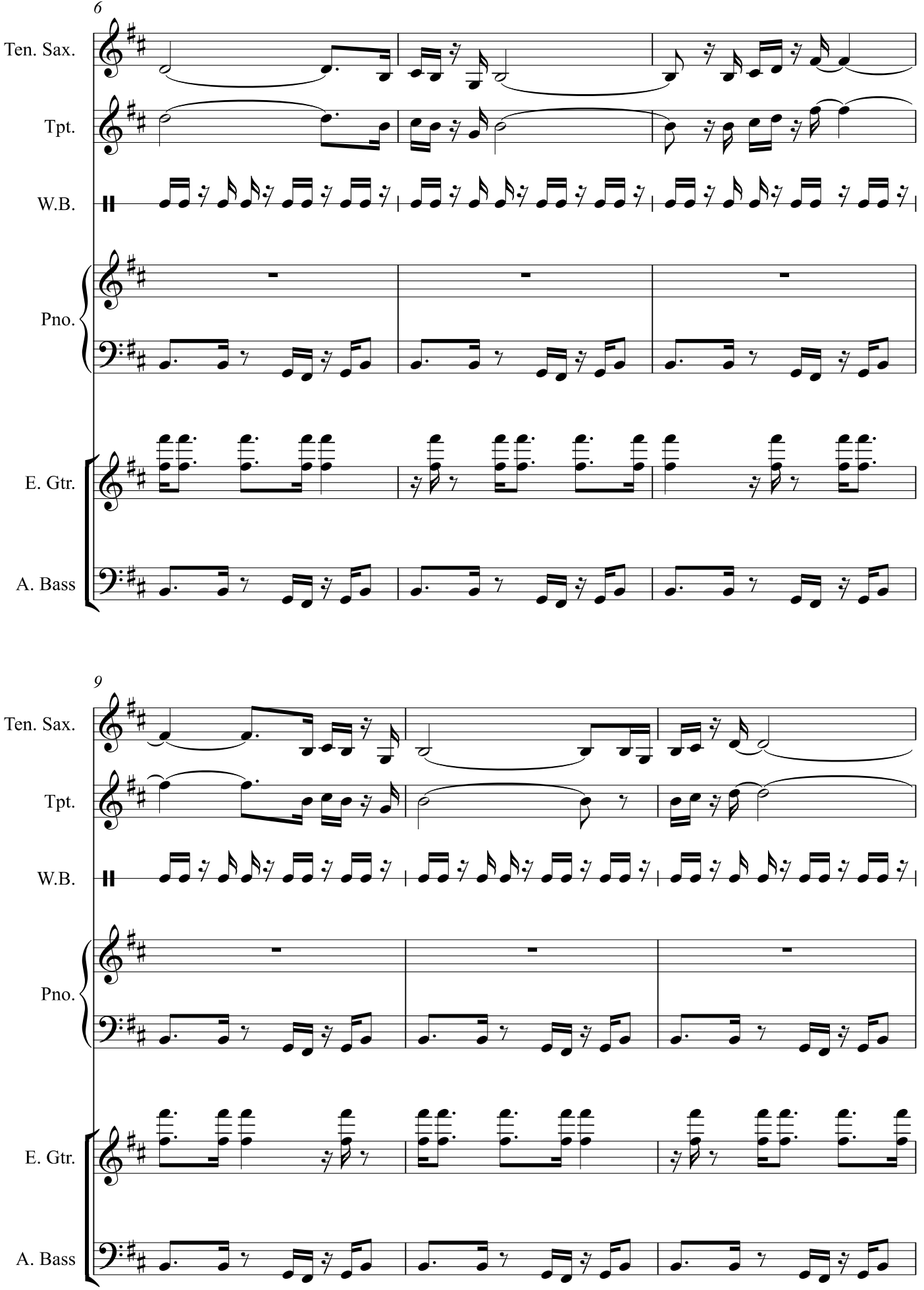

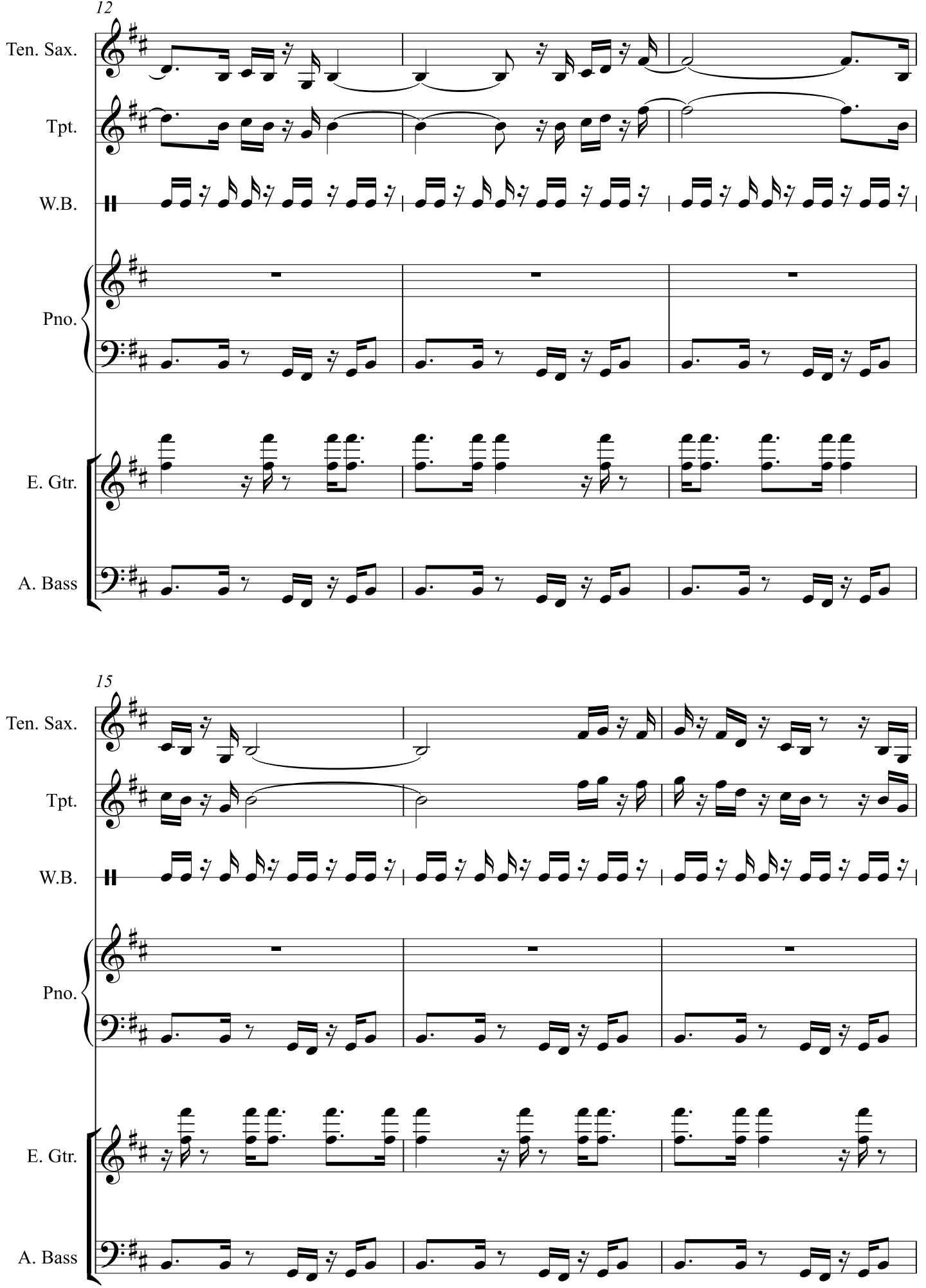

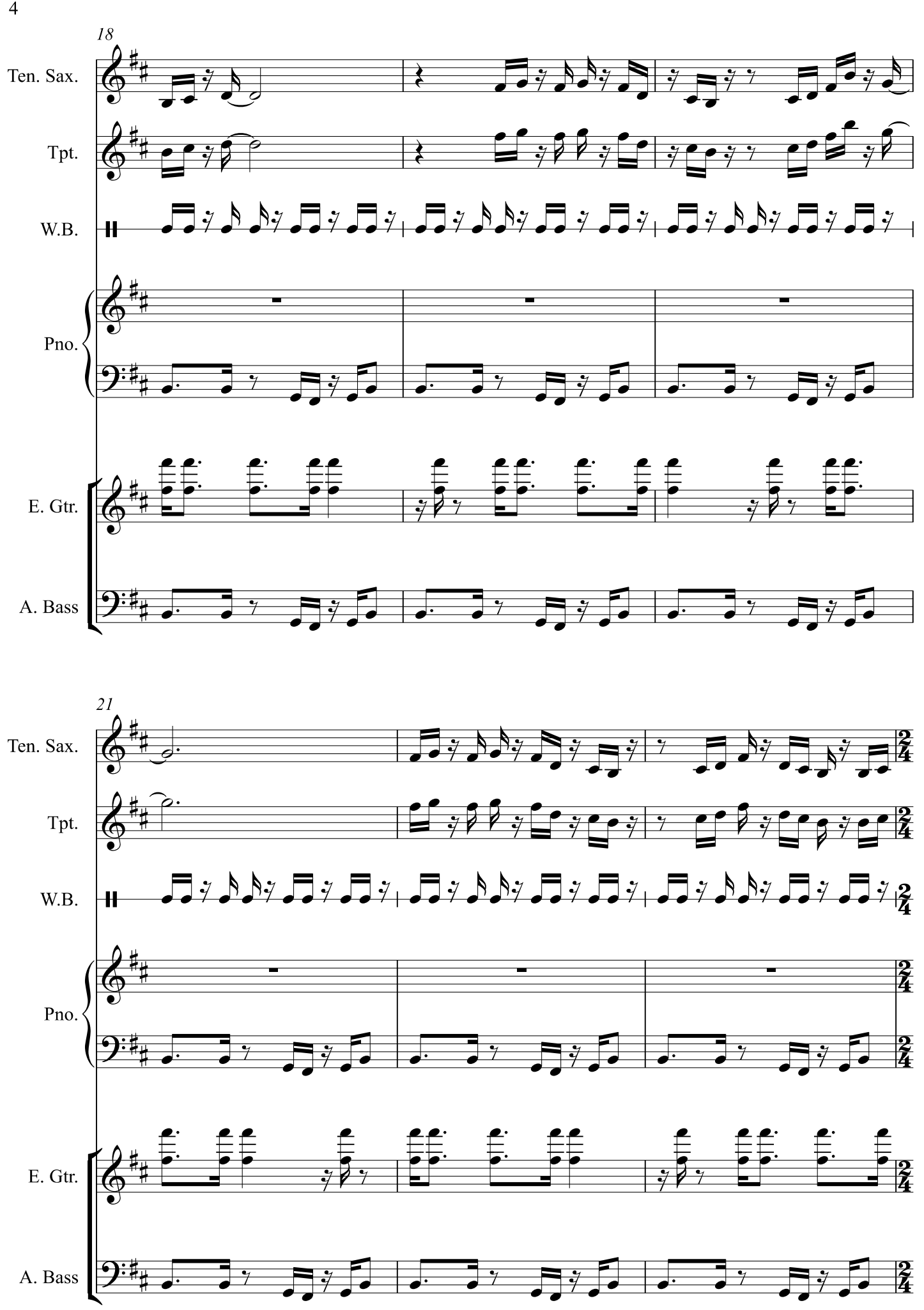


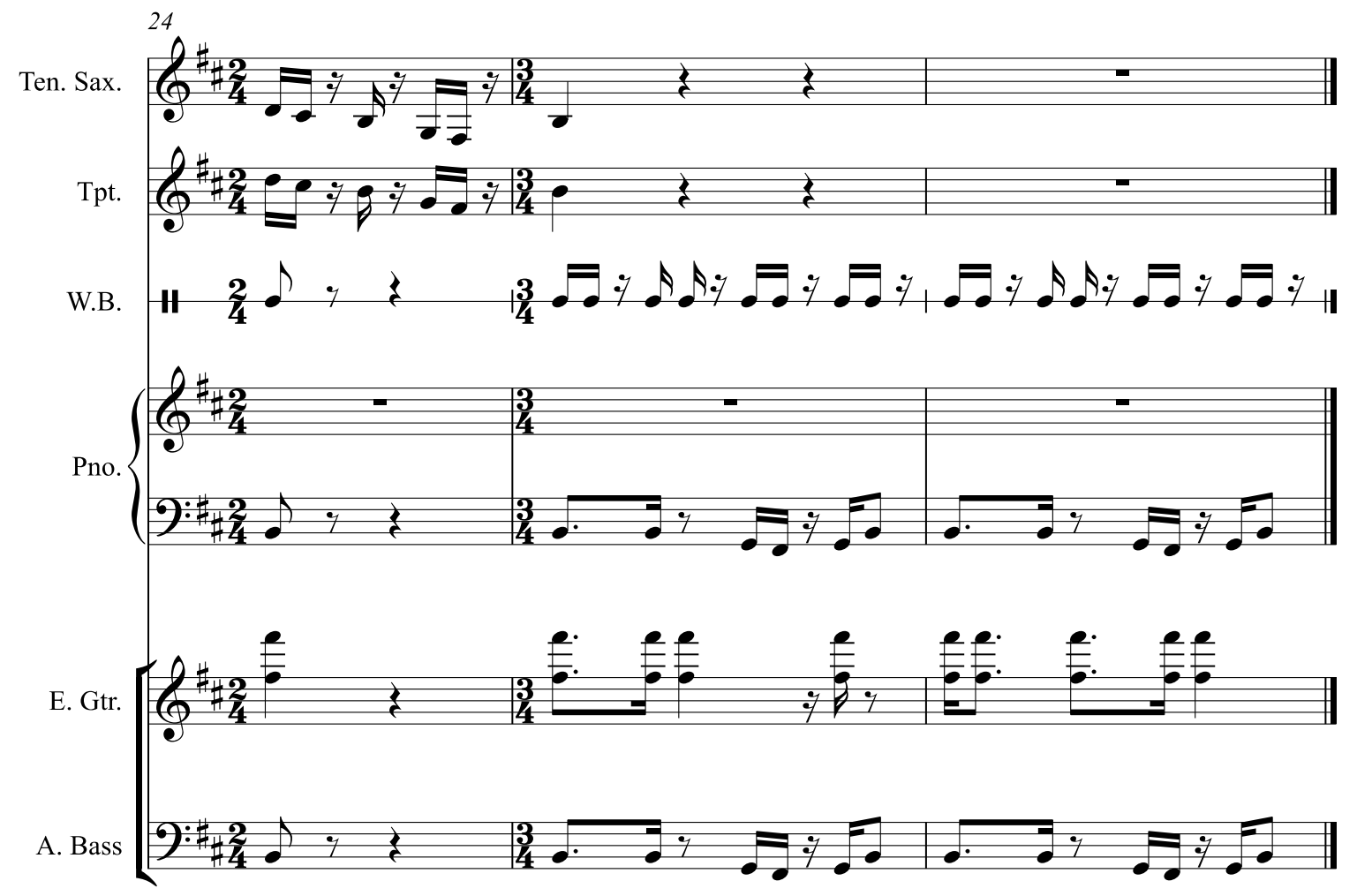




\title{
APPENDIX 16
}

Baritone Saxophone

\author{
Almaz Yeharewa
}

Ethiopian Trad. Performed by Akale Wube

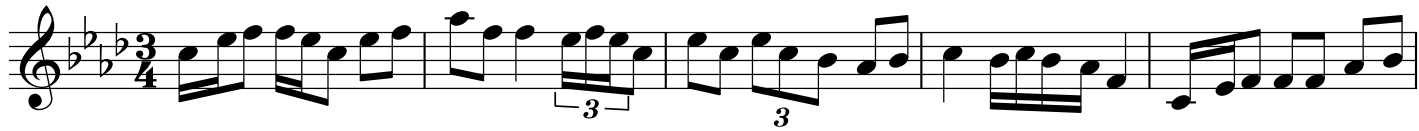
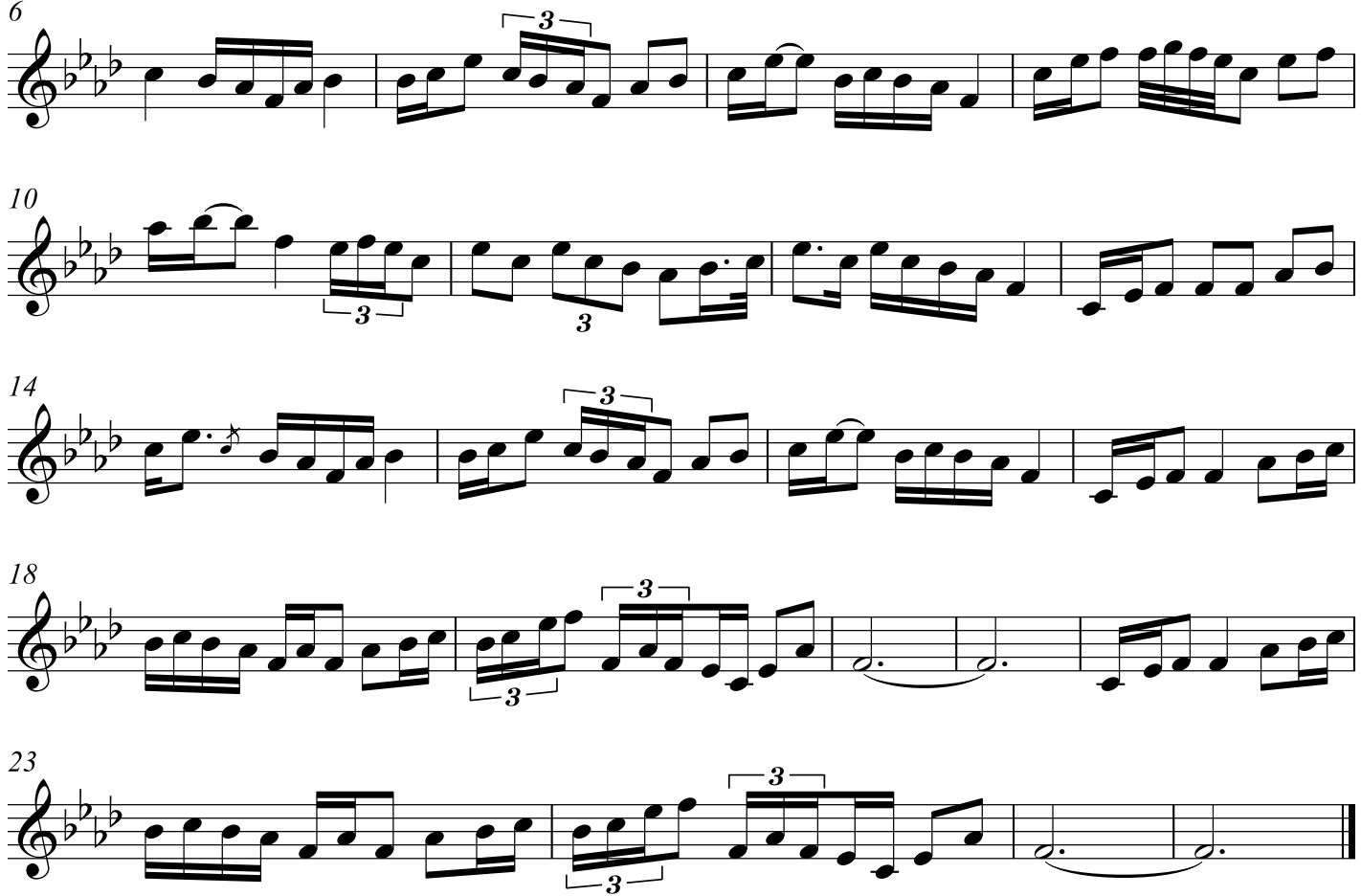


\section{BIBLIOGRAPHY}

Abate, Ezra. “Ethiopian Kiñit (scales): Analysis of the formation and structure of the Ethiopian scale system." In Proceedings of the $16^{\text {ttth }}$ International Conference of Ethiopian Studies, edited by Svein Ege, Harald Aspen, Berhanu Teferra and Shiferaw Bekele, 1213-1224. Trodheim: Department of Social Anthropology, Norwegian University of Science and Technology, 2009.

Adams, Sylvie. “Ambassador of Ethio-Jazz." Evil Monito. Accessed November 12, 2014. http://evilmonito.com/2008/05/01/ambassador-of-ethio-jazz/

Agawu, Kofi. “Representing African Music." Critical Inquiry, Vol. 18, No.2. (Winter, 1992), pp.245-266.

Breihan, Tom. “Damian Marley/Nas: As We Enter.” Pitchfork. 5 February, 2010. Accessed November 12016.

http:/ / pitchfork.com/reviews/tracks/11761-as-we-enter/

Bruce, Keith. "The Rediscovery of the music of Emahoy." The Herald Scotland. December 24, 2013.

Cleret, M and Holland, W. "Mulatu of Ethiopia." Waxpoetics: Hip Hop, Funk and Soul. Fall 2005. 85-94.

Dery, Mark. "Black to the Future: Interviews with Samuel R. Delaney, Greg Tate and Tricia Rose." In Flame Wars: The Discourse of Cyberculture, edited by Mark Dery, 179-222. Durham, NC: Duke University Press, 1994.

Dezfouli, Liza. "Mulatu Astatke and Black Jesus Experience." In Australian Stage. June 10, 2016.

http:/ / www.australianstage.com.au/201606107837/reviews/melbourne/mu lutu-astatke-and-black-jesus-experience.html

Eshete, Amha. "Amha Eshete and contribution of Amha Records to Modern Ethiopian Music." Tadias Magazine, 2012. Accessed 5/6/17.

http:/ / www.tadias.com/05/25/2012/the-legacy-of-amha-eshete-amharecords-contribution-to-modern-ethiopian-music/

Eshun, Kodwo. More Brilliant than the Sun: Adventures in Sonic Fiction. London: Quartet Books Ltd, 1998.

Eyre, Banning. "Francis Falceto - Ethiopia: Empire and Revolution." Afropop Worldwide. 2005. Accessed Jan 19, 2016.

http:/ / www.afropop.org/13068/francis-falceto-ethiopia-empire-andrevolution/ 
Falceto, Francis. Abyssinie Swing: A pictorial history of modern Ethiopian music. Addis Ababa: Shama Books, 2001.

Falceto, Francis. "How Ethiopian music went global." Tadias Magazine. 2012. Accessed November 12, 2014. http:/ / www.tadias.com/05/18/2012/howethiopian-music-went-global-interview-with-francis-falceto/

Feld, Steven. "A Sweet Lullaby for World Music." Public Culture 12.1 (2001): 145-171.

Feld, Steven. "From Schizophonia to Schizmogenesis." Music Grooves: Essays and dialogues. ." Edited by Feld and Charles Keil. Chicago and London: University of Chicago Press, 1994.

Gilroy, Paul. The Black Atlantic: Modernity and Double Consciousness. London: Havard University Press, 1993.

Goodman, Steve. Sonic Warfare: Sound, Affect and the Ecology of Fear. Cambridge: The MIT Press, 2010.

Grant, Steven. “Brian Eno against interpretation.” Trouser Press Magazine, 1982. Accessed June 72017.

http:/ / www.synthtopia.com/ content/2009/09/17/brian-enos-thoughts-onambient-music/

Guebrou, Emahoy Tsegue-Maryam. Music for Piano. Edited by Evgeny Oslon. Jerusalem Season of Culture: Jerusalem, 2013.

Harris, Craig. “Amha Eshete Biography.” Allmusic.com. Accessed Jan 19, 2016. http://www.allmusic.com/artist/amha-eshete-mn0003022788

Howat, Roy. 1994. "Debussy and the Orient." In Recovering the Orient: artists, scholars, appropriations. Edited by Gerstle, Andrew and Milner, Anthony, 4581. Chur: Harwood Academic Publishers.

Howat, Roy. The Art of French Piano Music: Debussy, Ravel, Fauré, Chabrier. New Haven: Yale University Press, 2009.

Johnson, Lucien. "Gig Preview-Mulatu Astatke with the Black Jesus Experience." 2016. Accessed 1/5/17. http://offthetracks.co.nz/guest-postgig-preview-mulatu-astatke-with-the-black-jesus-experience-by-lucienjohnson/

Jones, Leroi (Amiri Baraka). Blues People. New York: William Morrow \& Company, 1963. 
Jurek, Thom. “Tsegue-Maryam Guebrou." Allmusic.com. Accessed Jan 19, 2016. http:/ / www.allmusic.com/album/ethiopiques-vol-21-ethiopia-songmw0000352649

Kebede, Ashenafi. “The Music of Ethiopia: Its development and cultural setting." Ph.D. diss., ProQuest, UMI Dissertations Publishing, 1971.

Kebede, Ashenafi. "Zemenawi Muzika: Modern Trends in Traditional Secular Music of Ethiopia." The Black Perspective in Music 4, no.3 (1976): 289-301.

Kimberlin, Cynthia Tse. "Masinqo and the nature of Qeñet". Ph. D. Dissertation, University of California, 1976.

Lachin, Maurice and Weliachew, Dimitry. L'Ethiopie et son destin. Paris: Gallimard, 1935.

Lockspeiser, Edward. "Debussy's concept of the dream." Proceedings of the Royal Musical Association, 89th Session, 1962-63: 49-61.

May, Chris. "Getachew Mekurya: Negus of Ethiopian Sax." All About Jazz. 2007. Accessed February 16, 2016. http:/ / www.allaboutjazz.com/getatchewmekurya-negus-of-ethiopian-sax-by-chris-may.php

McKenna, Kristine. “Eno: Voyages in time and perception.” Musician (1982). Accessed June 62017.

Mekonnen, Danny A. "Ethio-groove on the World Stage: Music, Mobility, Mediation." Callaloo 33, no. 1 (Winter 2010): 299-313.

Messiaen, Olivier. Music and Color: Conversations with Claude Samuel. Portland: Amadeus Press, 1994.

Momeni, Ali. “African Polyrhythmics and Steve Reich's Drumming: Separate but related worlds." May 2001. Accessed 14 June 2017.

http://alimomeni.net/files/documents/momeni_Reich-African-

Polythythms.pdf

Mueller, Richard. "Javanese influence on Debussy's Fantaisie and beyond." $19^{\text {th }}$ Century Music. Vol 10, No. 2, Autumn, (1986): 157-186.

"Mulatu Astatke". Redbull Music Academy. 2007. Accessed November 12, 2014. http://www.redbullmusicacademy.com/lectures/mulatu-astatke-ethiopian-knight?template=RBMA_Lecture \%2Ftranscript.

"Mulatu Astatke - Het Depot". Rebel Base. 2009. Accessed 31 January 2015. http:/ / www.rebelbase.be/interviews/detail/mulatu-astatke---het-depot102009. 
Natvig, Richard. "Oromos, Slaves, and the Zar Spirits: A Contribution to the History of the Zar Cult" The International Journal of African Historical Studies Vol. 20, No. 4 (1987): 669-689.

Obling, Karen. "Ethiopiques at volume 27: Interview with Francis Falceto". Addis Rumble. Accessed November 12, 2014.

http:/ / addisrumble.com/?p=1999.

Parker, Sylvia. “Debussy's Gamelan”. Symposium, Journal of the College Music Society. Vol.52, 2012.

https://symposium.music.org/index.php?option=com_k2\&view=item\&id=2 2:claude-debussys-gamelan\&Itemid $=124$

Pennycook, Alastair. "Borrowing Others' Words: Text, Ownership, Memory, and Plagiarism." TESOL Quarterly 30.2 (1996): 201-30.

Powne, Michael. Ethiopian Music. London: Oxford University Press, 1968.

Reich, Steve. "Thoughts on Percussion and Rhythm." In The Cambridge Companion to Percussion, edited by Russell Hartenberger. Cambridge: Cambridge University Press, 2016. 173-183.

Said, Edward. Orientalism. London: Routledge and Kegan Paul Ltd, 1978.

Shelemay, Kay Kaufman. A Song of Longing: An Ethiopian Journey. Illionois: University of Illinois Press, 1994.

Sherwood, Harriet. "Rhythm divine: the Ethiopian nun whose music enraptured the Holy Land." The Guardian, August 18, 2013.

Simundža, Mirjana. "Messiaen's Rhythmical Organisation and Classical Indian Theory of Rhythm (II)." International Review of the Aesthetics and Sociology of Music, Vol. 19, No. 1 (1988): 53-73.

Sinker, Mark. "Loving the Alien: In Advance of the Landing." The Wire 96, Feb 1992.

Sorrell, Neil. "Issues of Pastiche and Illusions of Authenticity in GamelanInspired Composition." Indonesia and the Malay World Vol.35, Iss. 101, 2007: 3148.

Spiller, Henry. "Lou Harrison's Music for Western Instruments and Gamelan: Even More Western than it Sounds." Asian Music Vol.40, No.1, 2009: 31-52

Stokes, Martin, ed. Ethnicity, Identity and Music: The Musical Construction of Place. Oxford/Providence: Berg Publishers Limited, 1994. 
Stokes, Martin. "Music and the Global Order." In Annual Review of Anthropology 33, (2004): 47-72.

Sun Ra, ed. John Sinclair. Sun Ra: Interviews and Essays. London: Headpress, 2010.

Sutton, R. Anderson. 2010. "Gamelan Encounters with Western Music in Indonesia: Hybridity/Hybridism." Journal of Popular Music Studies 22(2): 180197.

Tafla, Bairu. Ethiopia and Austria: A History of their Relations. Weisbaden: Harrassowitz Verlag, 1994.

Tate, Greg. Everything But the Burden: What White People are taking from Black Culture. New York: Brooklyn Books, 2003.

Tate, Greg. "Yo! Hermeneutics!: Henry Louis Gates, Houston Baker, David Toop", in Flyboy in the Buttermilk: Essays on Contemporary America, edited by Greg Tate, New York, 1992; repr. in Yo! - Hermeneutics!, ed. Diedrich Diederichsen, Berlin: ID-Verlag, 1993, 165-176.

Taylor, Timothy D. Global Pop: World Music, world markets. New York: Routledge, 1997.

Teffera, Timkehet. "Control, Influence and Violence through Music: The Role of Political Songs during the Ethiopian Revolution (1974-1991)." Paper presented at the annual conference of the German Committee of the International Council of Traditional Music, Hamburg, 13-14 February, 2009. Accessed February 4, 2015.

https://www.academia.edu/7161240/Timkehet_Teffera_2010_._Control_Infl uence_and_Violence_through_Music_The_Role_of_Political_Songs_during_t he_Ethiopian_Revolution_1974-1991_.

Teffera, Timkehet. "Music, Making Music and Dancing: Ethno-Musicological Observations in Meqelle, Tigray." Guandu Music Journal (2005): 126-149

Teffera, Timkehet. "Western Wind Instruments and the Development of Ethiopian Popular Music". In Studia Instrumentorum Musicae Popularis III (New Series), edited by Gisa Jähnichen. Munster: Monsenstein \& Vannerdat, Münster, 2013, 349-376.

Thomas, A. “Ethio Jazzman: Mulatu Astatke." Chaser, Vol 2, no 39, 2006. 4648.

Tigabu, Tibebeselassie. 2012. "The King of Sax Shining on the World Stage." Ethiopian Reporter. Accessed November 12, 2014. 
http:/ / fleurmach.com/2013/04/06/getatchew-mekurya-antchihoye/\#more-7853.

Tillet, Salamishah. "Strange Sampling: Nina Simone and her Hip-Hop Children." In American Quarterly, Vol. 66, No. 1 (2014): 119-137.

Tiruneh, Andargachew. The Ethiopian Revolution, 1974-87: A transformation from an aristocratic to a totalitarian autocracy. London: Cambridge University Press, 1997.

Troughton, Richie. "Mulatu Astatke on the strange world of Mulatu Astatke." The Quietus. Accessed 12 November 2014.

http:/ / thequietus.com/articles/12299-mulatu-astatke-interview-field-day.

Veal, Michael. "Return to the Shrine: Fela Kuti's Legacy Inspires an AfroFunk Revival." Glendora Review 3, no. 3 (2004): 29-38.

Weisser, Stéphanie and Francis Falceto. "Investigating qeñet in Amhara secular music: an acoustic and historical study". Paper presented at the International Conference of Ethiopian Studies 18, Dire Dawa, October 28 November 2, 2012.

Zegeye, Abebe. Mulatu Astatke: The Making of Ethio Jazz. South Africa: University of South Africa, 2009.

Zenebe, Bekele. Music in the Horn: A Primary Analytical Approach to the Study of Ethiopian Music. Stockholm: Forfatters Bokmaskin, 1987. 


\section{SELECTED DisCOGRAPHY/FILMOGRAPHY}

Astatke, Mulatu. Ethiopiques vol. 4: Ethio Jazz \& Musique Instrumentale, 19691974. CD. Paris: Buda Musique, 1998.

Astatke, Mulatu. Mulatu Steps Ahead. CD. UK: Strut Records, 2010.

Astatke, Mulatu. Sketches of Ethiopia. CD. Jazz Village, 2013.

Astatke, Mulatu and his Ethiopian Quintet. Afro-Latin Soul. LP. New York: Worthy Records, 1966.

Astatke, Mulatu and the Heliocentrics. Inspiration Information 3. CD. Strut: Germany, 2009.

Cronenberg, David, dir. The Naked Lunch. CA: Twentieth Century Fox, 1991, film.

Guebrou, Emahoy Tsegue-Maryam. Ethiopiques vol.21: Ethiopia Song. CD. Paris: Buda Musique, 2006.

Jarmusch, Jim, dir. Broken Flowers. United States: Focus Features, 2005. Mekurya, Getachew, The Ex and Friends. Moa Anbesssa. CD. Amsterdam: Terp Records 2006.

Mekurya, Getachew, The Ex and Friends. Y'Anbessaw Tezeta. CD. Amsterdam: Terp Records 2012.

Mekurya, Getachew. Ethiopiques vol. 14: Negus of Ethiopian Sax. CD. Addis Ababa: Buda Musique, 1972/2003.

Nas \& Marley, Damian. Distant Relatives (CD). Los Angeles: Universal Republic, 2010.

Ra, Sun. The Nubians of Plutonia. CD. Chicago: Saturn, 1966.

Simon, Paul. Graceland (CD). New York: Warner Bros, 1986.

Werqu, Asnaqetch. Ethiopiques vol. 16: The lady with the krar. Paris: Buda Musique 2003.

Woima Collective. Tezeta (CD). Netherlands: Kindred Spirits, 2010.

Wubante, Belnayesh and Asfaw, Assegedetch. Ereye Demamu. Vinyl 7". Addis Ababa: Phillips Ethiopia, 1974. 